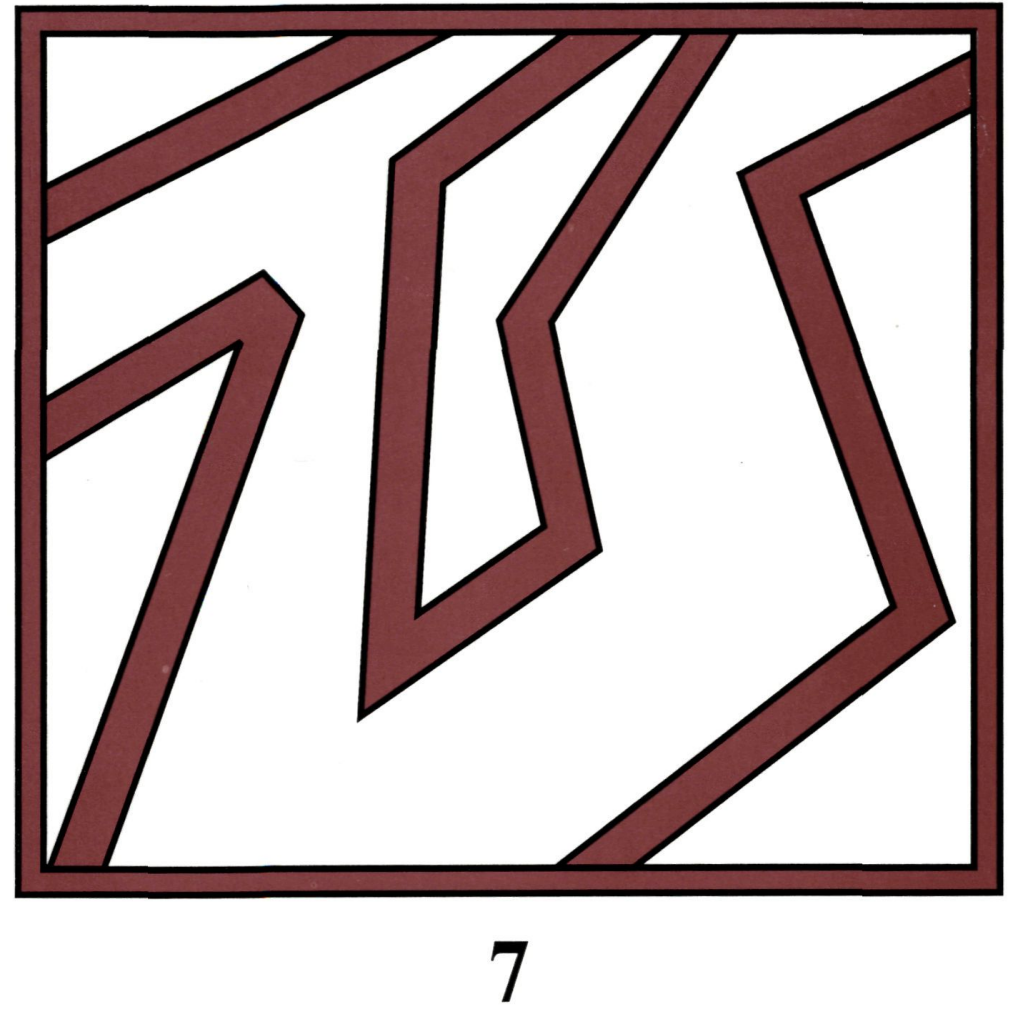

CUADERNOS DE TRABAJO SOCIAL 

3 


\section{ALTERNATIVAS}

\section{CUADERNOS}

DE

TRABAJO SOCIAL 
ALTERNATIVAS. CUADERNOS DE TRABAJO SOCIAL.

N."7. Octubre 1999.

CONSEJO EDITORIAL:

Directora de la revista: M." Teresa Mira Perceval

Directora técnica: $\quad$ M. $^{2}$ Asunción Martínez Román

Secretaria: Hortensia Redero Bellido

Vocales: $\quad$ M." Dolores Díez García

Yolanda Domenech López

M. ${ }^{a}$ José Frau Llinares

Elena Roselló Nadal

EDICIÓN Y ADMINISTRACIÓN:

Escuela Universitaria de Trabajo Social. Universidad de Alicante.

03690 San Vicente del Raspeig. Alicante. España.

Telf: 9659037 70. Fax: 965903572 . E-mail (Escuela): eu.trabajosocial@ua.es

Depósito Legal: M. 37.152-1992.

I.S.S.N.: $\quad 1133-0473$.

Inpresión:

ROMGRAFIC, S.L

Martínez de Velasco, 17.03013 Alicante. España.

Encuadernación:

LIMENCOP, S.L. (Centro Especial de Empleo)

Zarandieta, 7. Tel. 9652571 12. 03010 Alicante. España.

Precio del ejemplar: 2.500 ptas.

Reservados todos los derechos

Suscripciones y venta:

Librería Compás-Universidad, S.L.

Centro de Servicios Universitarios. Universidad de Alicante.

03690 San Vicente del Raspeig. Alicante. España. Apdo. de correos n. 203.

Telf:: 9659093 90. Fax: 9659093 91. E-mail: compasun@ fedecali.es

PRÓXIMA SECCIÓN MONOGRÁFICA:

La atención social de menores en los Servicios Sociales europeos

Plazo para la presentación de artículos: 30 de mayo del 2000. 


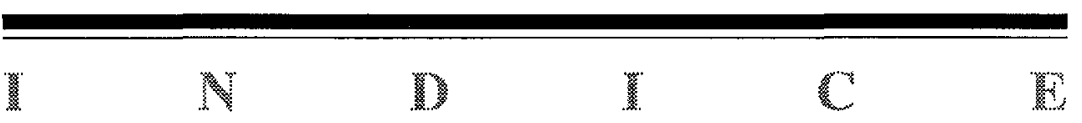



M. ${ }^{a}$ Asunción Martínez Román. Directora técnica del Consejo Editorial de la Revista «Alternativas. Cuadernos de Trabajo Social».

Editorial

\section{Integración sociolaboral.}

Idoia Martín Aranaga. Profesora de la E.U. de Trabajo Social. Departamento de Sociología, Área de Trabajo Social y Servicios Sociales. Universidad del País Vasco.

Las Políticas de Inserción en la Unión Europea: una comparación Francia - Reino Unido - España.

Joaquín García Roca. Profesor de la E.U. de Trabajo Social. Departamento de Trabajo Social y Servicios Sociales. Universidad de Valencia.

Tercer sector e inserción social.

Carlos Arias. Centro Especial de Empleo Limencop, S.L.

Empresa de inserción. Centro Especial de Empleo Limencop, S.L.

Herminia Torreblanca y M. ${ }^{a}$ Francisca Albert. Trabajadoras Sociales del Departamento de Empleo de la Asociación de Padres y Amigos de Niños y Adolescentes Hipoacúsicos (A.P.A.N.A.H.)

Integración socio-laboral de personas con deficiencia auditiva. 


\section{Tribuna libre}

Esther Villegas Castrillo. Profesora de la E.U. de Trabajo Social. Departamento de Trabajo Social y Servicios Sociales. Universidad de Alicante.

Autoconciencia personal y creatividad femenina. Un proceso abierto.

Víctor M. Giménez Bertomeu. Trabajador Social. Coordinador del Centro Social Comunitario "Gastón Castelló". Servicios Sociales Municipales del Ayuntamiento de Alicante.

Polivalencia versus especialización. Aproximación a un modelo saludable de intervención primaria.

José Ramón Bueno Abad. Catedrático E.U. de Psicología Social. José Vicente Pérez Cosín. Profesor Asociado del Departamento de Trabajo Social y Servicios Sociales. E.U. de Trabajo Social. Universitat de València.

Acogimiento familiar. Estudio de las interacciones ante las visitas familiares.

\section{Documentos}

Dictamen del Comité Económico y Social de la Unión Europea sobre la «Aplicación de las directrices para el empleo en 1999».

Ley 39/1999, de 5 de noviembre, para promover la conciliación de la vida familiar y laboral de las personas trabajadoras.

IV. Libros

M. a Asunción Martínez Román. Catedrática de Trabajo Social y Servicios Sociales. Universidad de Alicante.

Título: «Hacia una economía plural. Un trabajo, una actividad, una renta para todos». Miraguano-Promocions. 
Madrid, 1999. Autores: Aznar, G., Caillé, A., Laville, J.L., Robin, J. y Sue, R.

Titulo: «Trabajar para vivir. Una propuesta innovadora de inserción sociolaboral». Miraguano-Promocions. Madrid, 1999. Autores: Frago, E., Jover, D., López, V.M., Márquez, F. y Mora, G.

Título: «Trabajo Social. Orientaciones y prácticas formativas». Editorial Gules. Valencia, 1999. Autores: Gómez Moya, J., Julve Negro, M. y Pérez. Cosín, J.V. Prólogo de Cristina de Robertis.

Título: "Los inmigrantes irregulares en España. La vida por un sueño». Universidad de Deusto-Serie Derechos Humanos, vol. 4. Bilbao, 1999. Autores: Ruiz, Olabuénaga, J.L., Ruiz. Vieytez, E.J. y Vicente Torrado, T.L.

Isabel Pla Julián. Departamento de Economía Aplicada. Universidad de Valencia.

Título: «Crítica y futuro del Estado del Bienestar. Reflexiones desde la izquierda». Tirant lo Blanch. Valencia, 1999. Coordinadores: Fernández García, T. y Garcés Ferrer, J.

\section{Noticias}

«II Curso de Especialista en Dificultad y Conflicto Social: Técnicas de Intervención». Universidad Pontificia de Comillas - Fundación Universidad-Empresa. Madrid. Enero-diciembre 2000.

Federación Internacional de Trabajadores Sociales (IFSW) Conferencias de Trabajo Social 2000-2001: «Promoting equitable societies in the global economy: Social work in the 21 st century», Montreal (Canadá), del 29 de julio al 2 de agosto del 2000; «Managing conflicts in Social Work. Dealig with contradictions», Viena (Austria) y Bratislava (Eslovaquia), del 7 al 30 de agosto del 2000.

Conclusiones del Congreso Internacional «Una sociedad. para todas las edades». Alicante, 5-7 mayo 1999. 
Números publicados

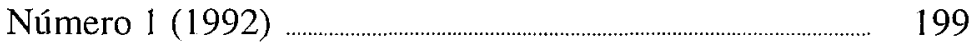

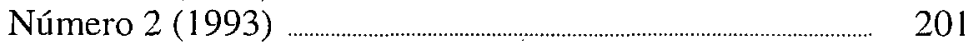

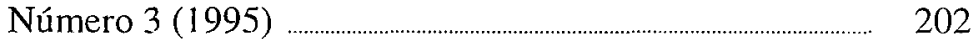

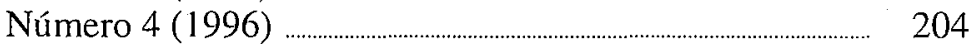

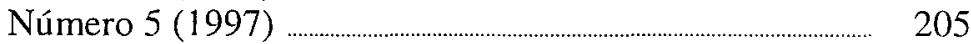

Número 6 (1998) ............................................................................... 207

Pautas generales para la presentación de artículos ……................ 211 


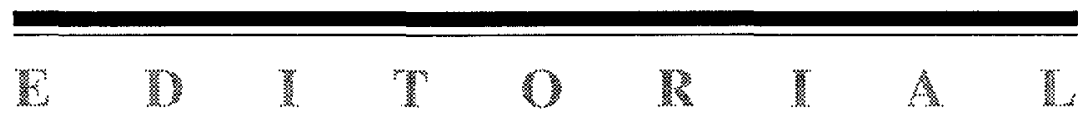





\section{M. ${ }^{a}$ ASUNCIÓN MARTÍNEZ ROMÁN.}

Directora técnica del Consejo Editorial de la Revista «Alternativas. Cuadernos de Trabajo Social».

El Programa de Naciones Unidas para el Desarrollo viene proponiendo desde los 90 situar al ser humano en el centro del proceso de desarrollo, destacando que el crecimiento económico no es un fin sino un medio. Un «desarrollo humano» significa que toda persona debe tener la posibilidad de ampliar plenamente su capacidad humana y aprovecharla al máximo en todas las esferas (económica, social, cultural y política), protegiendo las opciones de las generaciones futuras (desarrollo sostenido) y asignando prioridad a la reducción de la pobreza, promoción de empleo productivo, promoción de la integración social y regeneración del medio ambiente!.

Como opciones fundamentales se señalan: vivir una vida larga, sana y creativa, tener educación (conocimientos y capacidad de comunicación) y disfrutar de un nivel de vida decente. Además, son necesarias otras opciones como libertad política, garantía de otros derechos humanos, respeto por sí mismo, así como recibir el respeto de los demás². Esto significa que todas las personas pueden desarrollar sus potencialidades si disponen de las correspondientes oportunidades para ello, incluyendo apoyos especiales (discriminación positiva) cuando existan limitaciones personales o sociales que así lo aconsejen.

Sin embargo, la realidad es bien distinta, no hay igualdad de oportunidades y hay personas que encuentran numerosos obstáculos o privaciones para su desarrollo, careciendo de unas oportunidades reales para vivir una vida «valiosa y valorada», no tanto por sus propias limitaciones personales cuanto por las limitaciones sociales. Esta situación es injusta porque todas las personas tienen muchas aptitudes que podrían desarrollar con los apoyos adecuados.

1 PNUD, Informe sobre Desarrollo Humano,1994, Fondo de Cultura Económica, México, 1995.

2 PNUD. Informe sobre el Desarrollo Humuno. 1997. Madrid, Mundi Prensa, 1997. 
En muchos casos, los obstáculos al desarrollo humano son estructurales, como el problema del desempleo que ha alcanzado una gran envergadura a escala mundial desde los 80 . La OIT estima que, en 1996, un $30 \%$ de la población activa mundial estaba en desempleo o sub-empleada y que el número de los trabajadores pobres (insuficientemente remunerados) aumentaba sin cesar ${ }^{3}$. Engelhard señala tres consecuencias de esta situación mundial: a) las personas son valoradas socialmente en función de su capacidad de ser productivas y de su poder de consumo y ahorro, por lo que las personas que no pueden acceder a un empleo pasan a estar en riesgo o en situación de exclusión social; b) la competitividad y la eficacia tecno-económica son los criterios financieros dominantes, buscándose la máxima ganancia a pesar de los costes sociales; c) el debilitamiento de lo político, como resultado de la primacía de lo económico sobre lo social y de lo financiero sobre lo económico ${ }^{4}$.

Ya no hay duda de que el desempleo y el trabajo precario excluyen, considerándose que el trabajo es, actualmente, el medio principal de situarse en la estructura social que condiciona la participación en las redes sociales y en los sistemas de protección social ${ }^{5}$. El trabajo comporta una dimensión económica y una dimensión social, es el medio concreto sobre el que se construyen los derechos y los deberes sociales y, en definitiva, es el medio de integración social de las personas en edad activa. La cuestión central es que, en esta situación generalizada de desempleo, aumenta la vulnerabilidad de la población general y, en consecuencia, aumenta la fragilidad de las personas que ya eran antes vulnerables.

Y no hay desarrollo humano sin integración social. Para que sea posible la integración social de todas las personas hace falta que el conjunto social facilite la integración y que las personas quieran integrarse. Es decir, un contexto social que mantenga la cohesión sin discriminar ni excluir a nadie, que promueva la participación de todos sus miembros facilitando a todos un espacio y un status. Además, es necesario que las personas sean capaces de integrarse para lo que hay que seguir un proceso de aprendizaje con el fin de saber convivir en común, respetando la dignidad de cada cual, sin violencia y con solidaridad, adquiriendo habilidades para participar en la vida social, cultural, económica y política. En el contexto de un desarrollo humano sosteni-

3 OIT. El empleo en el mundo 1996-97: las políticas nacionales a la hora de la mundialización. Organización Internacional del Trabajo, Ginebra, 1997.

4 Engelhard, P. L'Homme Mondial. Les sociétés humaines peuvent-elles survivre. Arléa, Paris, 1996, págs. 36-41.

$5 \quad$ Castel, R. Les métamorphoses de la question sociale. Fayard, París, 1995, pág. 415. 
ble esto significa más justicia, más igualdad, más bienestar material y más libertad democrática ${ }^{6}$.

Sin embargo, el contexto socioeconómico de los últimos veinte años ha propiciado una sociedad excluyente y un creciente número de personas excluidas o en situación de precariedad y vulnerabilidad, siendo una de las causas la inadecuación de las políticas activas del mercado de trabajo y las políticas de colocación y formación. A finales de 1995, el Ministerio de Trabajo reconocía que la política de empleo en nuestro país, como en el resto de la Unión Europea, tenía como destinatario el empresario, ofreciéndole incentivos para que contratara, olvidando tanto al colectivo de parados, que necesitaba medios para mejorar su ocupabilidad, como la importancia de incidir en el territorio. Entonces se crean nuevas medidas para atender individualizadamente a cada desempleado, estudiar las necesidades de empleo de la zona y formar a los desempleados ${ }^{7}$. Las primeras iniciativas de inserción socio-laboral ponen de manifiesto que no hay «paro» sino «parados» y que la capacitación profesional de los demandantes de empleo, especialmente de aquellos con mayores obstáculos para su inserción, es todo un proceso que precisa el diseño de un plan de acción individualizado, adecuando los medios existentes a cada situación".

En consecuencia, es evidente que la falta de apoyo público a los desempleados con mayores dificultades es un factor añadido a su mayor vulnerabilidad y explica sus mayores posibilidades de permanecer en situación de desempleo de larga duración. Las necesidades especiales por razón de edad, género, discapacidad (incluyendo las derivadas de enfermedades crónicas), pertenencia a una minoría étnica o cultural, migración, etc., precisan actuaciones especiales a las que las políticas publicas están tardando en dar respuesta.

Un ejemplo, las personas analfabetas y con déficits sociales son uno de los colectivos con mayor riesgo de desempleo de larga duración y mayor dificultad de acceso al primer empleo y, sin embargo, fueron calificadas de «problemas sociales» por el INEM y, por lo tanto, fuera de sus competencias. Por su parte, los Servicios Sociales locales se han visto impotentes para colaborar en la inserción socio-laboral de estos colectivos o se han inhibido, en unos casos intentando sin éxito encon-

" NACIONES UNIDAS. Cumbre Mundial sobre Desarrollo Social. Declaración y Programa de Acción de Copenhague. Nueva York, Naciones Unidas, 1996.

7 Comparecencia del Sr. Secretario General de Empleo y Relaciones Laborales (Peña Pinto) para informar sobre «El empleo: objetivo prioritario de la política económica, análisis y resultados durante el período 1994-95 y perspectiva de futuro». Comisión de Trabajo y Seguridad Social del Senado, 12 diciembre de 1995. Diario de Sesiones del Senado, V Legislatura, Comisiones, $n^{\circ} 256$, págs. 2-6.

* Cáritas es una de las enticlades sociales pioneras. 
trar la forma de que estas personas se beneficiaran del mucho dinero invertido en estos años en formación ocupacional (gracias al FSE) y, en otros, decidiendo simplemente que este asunto no era de su competencia sino de las políticas de empleo. Y, desde Educación, no se ha tenido en cuenta adecuadamente la transición de la etapa escolar a la vida laboral, con resultados muy graves para los alumnos con necesidades educativas especiales.

Para paliar esta situación de abandono de las políticas públicas se han desarrollado experiencias de inserción socio-laboral por iniciativa de entidades no lucrativas, siguiendo orientaciones europeas. Las experiencias que han logrado éxito se han basado en programas específicos de aprendizaje en alternancia (formación-empleo) y con un plan de inserción socio-laboral individualizado, sin olvidar que los déficits socio-culturales y otras situaciones de discapacidad hacen que, con frecuencia, estas personas hayan perdido su autoestima y carezcan de capacidad de movilización para unirse y reclamar sus derechos. Pero todo este trabajo de orientación-capacitación para el empleo debe estar integrado en estrategias de desarrollo del territorio, en un plan de desarrollo local. Esto permite, por una parte, que se promueva la inserción laboral de los colectivos con dificultades desde una perspectiva global, como una cuestión de derecho al empleo de todos los ciudadanos y no pequeñas estrategias aisladas ${ }^{9} \mathrm{y}$, por otra parte, que se propicie la generación de empleo y se adecue la formación socio-ocupacional al perfil de los empleos, aumentando las posibilidades de inserción laboral.

Estas personas precisan medidas de discriminación positiva como recursos-puente que les ayuden a compensar esa desigualdad de partida para después acceder, en la medida de lo posible, a los recursos normalizados. Resulta clave para el éxito el acompañamiento de estas personas en su itinerario de inserción socio-laboral, cumpliendo funciones tanto de índole asistencial, como funciones de promoción, desde la formación hasta la inserción laboral y en todo este proceso tiene un importante lugar el Trabajador Social. La diferencia esencial es que estamos hablando de formación ocupacional como un medio (no un fin), enmarcada en una intervención integral.

Sin embargo, las experiencias coinciden en encontrar un obstáculo final en la última fase del proceso de inserción: la falta de una regulación legal que compense obstáculos insalvables debidos al contexto global económico. Es decir, los esfuerzos de estas interesantes experiencias quedan frustrados al final del proceso debido a que la legislación laboral actual no reconoce la existencia de estos intentos de inser-

"Sin menoscabo del gran esfuerzo de muchas Entidades que defienden únicamente los derechos de un colectivo específico, en el contexto actual parece más aconsejable utilizar otras estrategias que mas allá de ocupar a las personas promuevan, además, su integración social. 
ción y muchos se quedan en lo que se ha calificado de empleo subsidiado o de segunda categoría, por lo tanto sin valor social. Las iniciativas empresariales para promover la inserción sociolaboral que han logrado sobrevivir, han buscado salvar estos obstâculos por distintas vías, dentro de la normativa vigente, al mismo tiempo que han promovido una regulación legal específica que reconozca sus especiales dificultades y les preste apoyo, proyecto legal que no acaba de ver el final.

Y favorecer la integración sociolaboral de las personas que están en situación de desventaja no es sólo responsabilidad de la Administración pública, es responsabilidad de toda la sociedad. La Universidad también tiene responsabilidad, por ejemplo, puede orientar la formación de los futuros profesionales cuyas actuaciones pueden contribuir a un desarrollo humano o, por el contrario, convertirse en obstáculos. Más concretamente, las disciplinas sociales y económicas (Derecho, Trabajo Social, Economía, etc.) deberían replantearse su rol ante una nueva realidad que muestra claramente su interdependencia ${ }^{10}$.

Sintiêndonos corresponsables, este número siete de la «Revista Alternativas. Cuadernos de Trabajo Social» ha querido acercar la actualidad en este ámbito. En la sección monográfica, I. Martín Arinaga realiza un análisis de las políticas de inserción laboral en la Unión Europea que consta de dos partes. En la primera, se describen los antecedentes próximos de la reciente política comunitaria en materia de empleo y las orientaciones que actualmente se deben incorporar como líneas maestras de los respectivos Planes Nacionales de Empleo. La segunda parte es un análisis comparativo de las políticas de inserción de Francia, Reino Unido y España.

J. García Roca, tras analizar el carácter estructural de la exclusión social y sus consecuencias en las personas excluidas, especialmente en los jóvenes, se pregunta por el papel que puede desempeñar el Tercer Sector en la promoción de la inserción y la transformación de las instituciones excluyentes, considerando que le compete un rol de la mayor urgencia: convertir la exclusión en una cuestión de interés general. Analiza las fortalezas y debilidades del tercer sector, en especial en relación al escenario económico en el que se puede apostar por una actividad económica que tenga finalidades sociales y de mejora de las condiciones de vida. En este sentido, se proponen posibles estrategias de mediación de las organizaciones del tercer sector para promover la inserción sociolaboral. 
C. Arias, H. Torreblanca y M. ${ }^{a}$ F. Albert han querido darnos a conocer sus respectivas experiencias en el campo de la inserción sociolaboral de personas con discapacidades. El Centro Especial de Empleo Limencop. S.L. lo hemos visto consolidarse día a día en la Universidad de Alicante con gran profesionalidad, siendo una muestra de su buen trabajo la encuadernación de esta Revista. Por otra parte, desde la Asociación A.P.A.N.A.H., se describe el Proyecto «Dinami» de promoción de la integración socio-laboral de personas con discapacidad auditiva con los «Servicios de Asesoramiento para el Acceso al Empleo de Personas Sordas» y el papel específico que pueden realizar los Trabajadores Sociales y otros profesionales de la inserción laboral.

En la sección Tribuna Libre se abordan temas relativos a la creatividad femenina, la intervención primaria en Servicios Sociales y la evaluación de las visitas familiares en situaciones de acogimiento familiar, en los que se realizan propuestas prácticas relacionadas con las actividades profesionales de los Trabajadores Sociales. Como Documentos se incluyen, de la Unión Europea, el Dictamen del Comité Económico y Social sobre la «Aplicación de las directrices para el empleo en 1999» que ofrece una selección de «buenas prácticas» y, de España, la recientemente aprobada Ley 39/1999, de 5 de noviembre, para promover la conciliación de la vida familiar y laboral de las personas trabajadoras, que incorpora a la legislación española directrices internacionales para promover la igualdad de oportunidades entre hombres y mujeres en el ámbito laboral. Finalmente, recensiones de libros y noticias de interés que han sido comunicadas a la Revista.

El Consejo Editorial agradece a todos los autores sus interesantes aportaciones e invita a colaborar en el próximo número ocho de la «Revista Alternativas. Cuadernos de Trabajo Social» con el tema monográfico: Atención social a los menores desde los Servicios Sociales Europeos. 
I. INTEGRACIÓN

SOCIO-LABORAL 



\title{
LAS POLÍTICAS DE INSERCIÓN EN LA UNIÓN EUROPEA: UNA COMPARACIÓN FRANCIA-REINO UNIDO-ESPAÑA
}

\author{
IDOIA MARTÍN ARANAGA
}

Profesora en la Escuela Universitaria de Trabajo Social de la Universidad del País Vasco, Departamento de Sociología, Área de Trabajo Social y Servicios Sociales.

\section{INTRODUCCIÓN.}

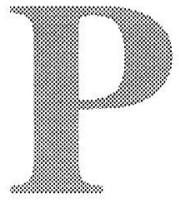

ese a los avances en la integración europea, no se puede hablar de una política comunitaria de empleo hasta la reforma del Tratado de la Unión Europea, aprobada en el Consejo Europeo de Amsterdam en junio de 1997. La política social europea ha existido desde los inicios de la Comunidad, pero no incluía los temas referentes al empleo, a no ser como un resultado que se esperaba de la correcta aplicación de las otras políticas comunes (Bustamante, 1999). Por tanto, Amsterdam marca el final de un proceso y el inicio de otro, el de Luxemburgo, que desarrolla una estrategia europea por el empleo. Así, en este artículo, se pretende llevar a cabo un recorrido a través de los hitos recientes más significativos en materia de incorporación del empleo como objetivo prioritario en el entramado comunitario, que culmina con la identificación de los cuatro pilares y las consiguientes directrices para el empleo, que cada Estado miembro debe tener en cuenta en la elaboración de su "Plan Nacional de Empleo". Para, a continuación, realizar un análisis comparativo de los "Planes Nacionales de Empleo" de tres países de la Unión Europea (Francia, Reino Unido y España), en lo que respecta a sus actuaciones en materia de inserción.

\section{LA POLÍTICA DE EMPLEO EN LA UNIÓN EUROPEA: HACIA UNA ESTRATEGIA COORDINADA EN MATERIA DE EMPLEO A NIVEL COMUNITARIO.}

En materia de empleo, los gobiernos de los Estados miembros han cooperado desde 1958 -el Tratado constitutivo de la Comunidad Europea se firma en Roma en 1957-, y el papel de la Comisión Europea consistía en promover dicha cooperación, realizar el seguimiento de 
las tendencias de empleo y efectuar un trabajo analítico, sin que el Tratado ofreciese una base legal sólida para una acción supranacional (Bustamante, 1999). No obstante, la firma del Acta Única Europea en 1986 va a dar un nuevo impulso a la política social comunitaria, y es por esta razón que situamos el inicio de nuestro recorrido por el entramado comunitario en ese momento histórico.

\subsection{Del Acta Única Europea al Tratado de la Unión Europea.}

El Acta Única Europea, firmada en 1986 y por la que se modifica el Tratado de Roma o Tratado constitutivo de la CEE, confirma el objetivo de completar el mercado único europeo en 1992 (Proyecto del 92), lo que desembocará en el Tratado de la Unión Europea firmado en Maastricht en febrero de 1992.

El Tratado constitutivo de la Comunidad Europea se ve enriquecido con la aportación que hace el Acta Única Europea de nuevos artículos que dan un nuevo impulso a la política social, y en especial de aquellos que insisten en la necesidad de la "cohesión económica y social" de los doce Estados miembros (Scadplus, 1999). Así, mediante los artículos $130 \mathrm{~A}$ a $130 \mathrm{E}$, el Acta Única introduce una finalidad adicional: "promover un desarrollo armonioso del conjunto de la Comunidad (...) y en concreto desarrollar y proseguir una acción encaminada a reforzar la cohesión económica y social" (art. 130 A). Para lograrlo, se precisa una mejor coordinación y racionalización de los fondos estructurales existentes: el Fondo Europeo de Orientación y Garantía Agraria (FEOGA, sección "orientación), el Fondo Social Europeo y el Fondo Europeo de Desarrollo Regional. De hecho, esta voluntad de movilizar los recursos y acciones de los distintos organismos de la Comunidad tiene por fin "reducir las diferencias entre las diversas regiones y el retraso de las regiones menos favorecidas" (art. $130 \mathrm{~A})$.

En la línea de esta disposición, en junio de 1988 se reforman ampliamente los fondos estructurales y en diciembre de 1989 se aprueba la "Carta comunitaria de los derechos sociales fundamentales de los trabajadores", suscrita por todos los Estados miembros a excepción del Reino Unido', país que la adoptará en 1998 tras la elección de Tony Blair. Esta Carta establece los grandes principios sobre los que se

Desde finales de los años setenta, se ha podido apreciar una clara división entre los países continentales y el gobierno británico acerca del desarrollo de un sistema europeo de regulación del mercado de trabajo y de las relaciones laborales. Como apunta M. Rhodes (1997), esto no se explica sólo por las diferencias entre las tradiciones legales anglosajona y romanogermánica, sino también por las diferentes nociones de soberanía nacional y las distintas filosofías de la organización económica. 
basa el modelo europeo de derecho laboral y, de manera más general, el lugar que ocupa el trabajo en la sociedad, pero carece de vinculabilidad jurídica, en el sentido de que no puede ser alegada en los tribunales de justicia (ni comunitarios ni nacionales) como base exclusiva para cualquier tipo de pretensión (Alarcón, 1997). Contiene los siguientes apartados (Comisión de las Comunidades Europeas, 1990): libre circulación; empleo y retribución; mejora de las condiciones de vida y trabajo; protección social; libertad de asociación y negociación colectiva; formación profesional; igualdad de trato entre hombres y mujeres; información, consulta y participación de los trabajadores, protección de la salud y de la seguridad en el medio de trabajo; protección de los niños y de los adolescentes; personas de edad avanzada y personas con discapacidad. Además, en el capítulo sobre "empleo y retribución" se recogen tres derechos básicos: la libertad de elección y de ejercicio de una profesión, el de obtener un empleo justamente remunerado y el de disponer de servicios públicos de colocación gratuitos.

Con el desarrollo del proceso de integración europea se irá afianzando la necesidad de la cohesión económica y social y se irán estableciendo una serie de derechos básicos que conforman la política social comunitaria (Cachón y Palacio, 1999). El Tratado de la Unión Europea (firmado en Maastricht el 7 de febrero de 1992) resalta la importancia de la política social en el proceso de construcción europea, incluyendo entre sus objetivos básicos "promover el progreso económico y social y un alto nivel de empleo" (art. 2) y dedicando un anexo (Protocolo $n^{\circ}$ 14) al "Acuerdo sobre la política social celebrado entre los Estados miembros de la Comunidad Europea a excepción del Reino Unido de Gran Bretaña e Irlanda del Norte" (Unión Europea, 1997a). De esta manera, en el art. 1 del citado Acuerdo se mencionan como objetivos de la Comunidad y de los Estados miembros "el fomento del empleo, la mejora de las condiciones de vida y trabajo, una protección social adecuada, el diálogo social, el desarrollo de los recursos humanos para conseguir un nivel de empleo elevado y duradero y la lucha contra las exclusiones". A continuación del Protocolo ${ }^{\circ}$ 14, se aprueba -esta vez por todos los Estados miembros- un Protocolo $\mathrm{n}^{\circ} 15$, que insiste nuevamente "sobre la cohesión económica y social", cuyo contenido fundamental consiste en la creación de un nuevo "Fondo de Cohesión" destinado a ayudar a los Estados miembros que tengan un producto nacional bruto per cápita inferior al $90 \%$ de la media comunitaria y, por otra parte, en la decisión de flexibilizar las normas de aplicación de los fondos estructurales existentes (Alarcón, 1997).

Sin embargo, y como señala C. Abenza (1996; citado en L. Cachón y J. I. Palacio, 1999, p. 278), en el Tratado de la Unión Europea se 
aprecia cierto desequilibrio entre una política económica y monetaria bien definida y la ausencia de una política social y de empleo, desequilibrio que se verá acentuado en posteriores debates y actuaciones de las instituciones europeas. Según M. Rhodes (1997), ello puede deberse a que la gran mayoría de las medidas que aparecen bajo el epígrafe de "política social" europea han estado más ligadas al concepto de "hacer mercado" (por medio de incentivos a la libertad de movimientos) que al concepto de "modificar mercado" (es decir, rompiendo el monopolio del mercado en términos de distribución del poder, rentabilidades y recursos). Por tanto, a nivel europeo no ha fructificado un proyecto de "integración positiva" (construcción de instituciones del Estado del Bienestar) que contrarreste al de "integración negativa" (la eliminación de barreras para el comercio y la libertad de movimientos, por ejemplo) que ha caracterizado el proceso de convergencia. Lo que no significa que las iniciativas reguladoras europeas hayan sido desarrolladas en vano. Significa simplemente que han de ser consideradas como políticas supranacionales de tipo secundario y débilmente institucionalizadas que complementan, y en ocasiones refuerzan, los derechos y obligaciones que se hallan mejor consolidados a nivel nacional y donde se desarrolla la principal pugna por mantenerlos.

\subsection{El Libro Blanco sobre Crecimiento, Competitividad y Empleo.}

Publicado en diciembre de 1993, el Libro Blanco sobre Crecimiento, Competitividad y Empleo, también conocido como el Libro Blanco de J. Delors, fue concebido en plena fase de recesión económica ${ }^{2}$. Precisamente, uno de los grandes méritos del Libro Blanco ha consistido en situar el empleo en el centro de las prioridades de la Unión Europea $^{3}$, al reconocer el carácter estructural del desempleo en la Comunidad. Entre sus mensajes, se pueden recoger tres (Baglio, 1995): a) el crecimiento económico, incluso sostenido, no parece ser capaz por sí sólo de producir un número suficiente de nuevos empleos para reabsorber el paro; b) progreso económico y progreso social deben ir a la

2 Es preciso recordar que en el espacio de 3 años (1991-93), la Unión Europea había perdido más de 5,5 millones de empleos, es decir, más del $60 \%$ del conjunto de empleos creados durante la fase precedente de expansión económica (1986-1990) (Baglio, 1995).

3 El contenido del Libro Blanco comienza señalando el problema del desempleo como el desequilibrio más grave del proyecto europeo y su principal reto en el futuro, trazando el objetivo de crear 15 millones de puestos de trabajo hasta final del siglo para reducir la tasil de paro a la mitad. Un objetivo subrayado por la magnitud de la tasa de paro que alcanzaba en ese momento el $11 \%$ en la UE -claramente superior al $6.7 \%$ de Estados Unidos y al $2,5 \%$ de Japón- y que manifestaba una tendencia creciente (Gabinete Técnico Confederal de CC.OO., 1994). 
par; el empleo no puede ser considerado como factor residual del crecimiento, sino que debe situarse en el corazón mismo del desarrollo económico; y c) es indispensable tratar los problemas del empleo según una lógica de sistema y no a partir de un enfoque sectorial. En concreto, el Libro Blanco señala seis prioridades que deben tener las acciones al servicio del empleo (Comisión de las Comunidades Europeas, 1993): garantizar que el crecimiento económico se plasme en la creación de nuevos puestos de trabajo; aumentar la flexibilidad interna y externa; reducir el coste relativo del trabajo de baja cualificación; anticipar y acelerar la creación de empleo en las nuevas actividades y en las PYMEs; aumentar la inversión comunitaria en recursos humanos; e intensificar los esfuerzos para integrar o reintegrar a aquellos que se encuentran en una situación de desventaja en el mercado laboral. Y todo ello en un marco de concertación social en cada uno de los Estados miembros (Cachón y Palacio, 1999).

Siguiendo las orientaciones del Libro Blanco, el Consejo Europeo de Essen de diciembre de 1994 invitó a los Ministros de Asuntos Sociales y de Trabajo y al ECOFIN, así como a la Comisión, a que realizaran un atento seguimiento de la evolución del empleo, examinaran las políticas correspondientes de los Estados miembros e informaran anualmente al Consejo Europeo sobre los progresos realizados en el mercado de trabajo. Asimismo, el Consejo Europeo estableció cinco sectores de actuación prioritarios en el mercado de trabajo (Comisión Europea, 1995): refuerzo de las inversiones en formación profesional; aumento de la intensidad en empleo del crecimiento; reducción de los costes laborales indirectos; mejora de la efectividad de las políticas referidas al mercado de trabajo y, por último, medidas en favor de los grupos que sufren un riesgo de exclusión del mercado de trabajo. Sin embargo, ni los sucesivos Consejos Europeos ni la iniciativa "Acción para el empleo en Europa: un Pacto de confianza", presentada en junio de 1996 por el entonces Presidente Santer, con el triple objetivo de movilizar a todos los actores interesados en una verdadera estrategia para el empleo, hacer del empleo una cuestión de interés común a nivel europeo e inscribir la lucha contra el paro en una visión de la sociedad a medio y largo plazo (Scadplus, 1999), lograrán establecer una estrategia coordinada a nivel comunitario en materia de empleo. Habrá que esperar para ello hasta la aprobación de la reforma del Tratado de la Unión Europea en Amsterdam (junio de 1997) y la celebración de la Cumbre Extraordinaria sobre el empleo en Luxemburgo (noviembre de 1997). 


\subsection{Los Consejos Europeos: Amsterdam, Luxemburgo, Cardiffy Viena.}

En el Consejo Europeo de Amsterdam (16-17 de junio de 1997), los Jefes de Estado y de Gobierno de los Estados miembros de la Unión Europea se reafirmaron en la importancia concedida al fomento del empleo y a la reducción del nivel de desempleo en la Unión (Scadplus, 1999). Consideraron también la necesidad de adoptar un enfoque positivo y coherente en materia de creación de empleo que incluya un marco macroeconómico estable, la realización del mercado único, políticas activas en materia de empleo y la modernización de los mercados de trabajo.

Además, en el Consejo Europeo de Amsterdam se concluyó la Conferencia Intergubernamental, con un acuerdo sobre el proyecto de Tratado de Amsterdam ${ }^{4}$, que convierte al fomento del empleo en una "cuestión de interés común" de los Estados miembros y en uno de los objetivos de la Comunidad. Esto supone un nuevo punto de partida de las políticas de empleo, ya que si bien la responsabilidad principal de la decisión y la aplicación de las políticas de empleo continúa en manos de los Estados miembros, el nuevo Tratado insiste en la necesidad de una actuación conjunta y coordinada a escala comunitaria (Cachón y Palacio, 1999). El nuevo Título sobre el empleo, incluido en el Tratado justo después del Título VI, precisa estos objetivos y los medios para alcanzarlos (Unión Europea, 1997b):

- la consideración del empleo en la definición y la aplicación de las políticas y acciones comunitarias;

- la creación, a nivel comunitario, de mecanismos de coordinación que incluyan:

- un informe anual conjunto del Consejo y de la Comisión sobre el empleo, a partir del cual el Consejo Europeo adoptará sus conclusiones (a imagen del seguimiento de la estrategia de Essen);

- la aprobación por el Consejo, por mayoría cualificada y a propuesta de la Comisión, de líneas directrices para el empleo, que deben ser compatibles con las grandes orientaciones de la política económica;

- un mecanismo de vigilancia de aplicación de las líneas directrices que tenga algunas semejanzas con el previsto para las políticas económicas;

- la creación del Comité de Empleo, encargado de fomentar la coordinación de las políticas de empleo realizadas por los Esta-

4 El Tratado de Amsterdam fue aprobado el 2 de octubre de 1997 y entró en vigor el 1 de mayo de 1999 
dos miembros y de formular dictámenes en la materia.

- la posibilidad de que el Consejo adopte por mayoría cualificada medidas incentivadoras, en particular en forma de proyectos piloto.

Así, el 1 de octubre de 1997, la Comisión presenta la propuesta de "directrices" para las políticas de empleo de los Estados miembros en 1998. Estas directrices se centran en cuatro líneas de actuación principales (Comisión Europea, 1997): el espíritu empresarial, la empleabilidad o capacidad de inserción profesional, la adaptabilidad y la igualdad de oportunidades. La Comisión propone asimismo que se fijen objetivos ambiciosos, es decir, un aumento del índice de empleo desde el $60,4 \%$ al $65 \%$ y una reducción del índice de desempleo hasta llegar al $7 \%$ en 5 años.

Estas directrices, que se basan a su vez en el "Informe conjunto sobre el empleo"s, se presentaron al Consejo Europeo extraordinario que se celebró en Luxemburgo los días 20 y 21 de noviembre de 1997. El acuerdo que se alcanzó en la Cumbre asume en gran medida las propuestas de la Comisión; en particular (Scadplus, 1999):

- ofrecer una nueva oportunidad a todos los desempleados jóvenes antes de que lleven seis meses en paro y a todos los desempleados adultos antes de que lleven doce meses en paro; estos objetivos deberán alcanzarse en un plazo de cinco años, que podrá ser mayor en los Estados miembros con un índice de desempleo especialmente alto;

- aumentar en al menos el $20 \%$ el número de desempleados a los que se ofrece formación.

De esta manera, el 15 de diciembre de 1997, el Consejo de Empleo y Asuntos Sociales aprobó formalmente estas directrices en una Resolución (Directrices para el empleo en 1998) que los Estados miembros incluyeron en sus "Planes Nacionales de Acción para el Empleo" (PNAE).

Los compromisos adoptados en materia de política de empleo en la Cumbre de Luxemburgo y que se encuentran recogidos en las "Directrices para 1998", antes mencionadas, no son -como lo han sido otros documentos comunitarios anteriores- simples orientaciones para los Estados miembros (Cachón y Palacio, 1999). Cada Estado miembro debe tener en cuenta los objetivos marcados por las Directrices en el "Plan Nacional de Empleo" que debe presentar a la Comisión. Ade-

5 Tereer Informe conjunto sobre el empleo (1997) para el Consejo Europeo extraordinario sobre el empleo de Luxemburgo (20/21 de noviembre de 1997) (adoptado el 17 de noviembre de 1997 por el Consejo de Empleo y Asuntos Sociales y el Consejo de Asuntos Económicos y Financieros). 
más, el Consejo revisa cada año el cumplimiento de las Directrices por parte de cada uno de los Estados miembros, y puede formular "recomendaciones" que pueden ser consideradas como críticas políticas y sanciones morales del Consejo al Estado miembro. En este sentido, puede decirse que la Cumbre Extraordinaria sobre Empleo, celebrada en Luxemburgo en noviembre de 1997, ha supuesto el nacimiento de la nueva política de empleo de la Unión Europea, anticipando, de esta manera, la puesta en marcha del nuevo título sobre empleo del Tratado de Amsterdam (Consejo Económico y Social, 1999).

Más adelante, el Consejo Europeo de Cardiff ( 15 y 16 de junio de 1998) realizó un examen de los Planes de Acción Nacional de cada Estado miembro (Comisión Europea, 1998c, 1998d) y, si bien reconoció el esfuerzo general realizado por todos los Estados de la Unión, sus conclusiones no pueden considerarse excesivamente entusiastas en relación a los resultados que se pueden esperar de esta política. En Cardiff se decidió que los Consejos de Asuntos Sociales y de Economía y Finanzas debían continuar trabajando conjuntamente durante el segundo semestre de 1998 para desarrollar la evaluación de los Planes de Acción de los Estados miembros, y para establecer las Directrices para el Empleo de 1999, que deberían ser adoptadas en el Consejo Europeo de Viena de diciembre (Consejo Económico y Social, 1999).

Así, con la finalidad de preparar la Cumbre de Viena, en el mes de octubre la Comisión presentó la Comunicación con las propuestas de líneas directrices para las políticas de empleo de los Estados miembros para 1999 (Comisión Europea, 1998e), como dispone el nuevo Tratado de Amsterdam. También se presentó el "Informe sobre la tasa de empleo en 1998" (Comisión Europea, 1998f) -cuyo objeto es presentar un breve análisis de la evolución del empleo en la Unión en los últimos años y extraer conclusiones sobre las contribuciones que cada uno de los Estados miembros podría realizar para lograr un aumento significativo de la tasa media de empleo-, y el Informe conjunto Comisión/Estados miembros que evalúa lo ocurrido en 1998.

$\mathrm{El}$ análisis conjunto de los Planes de los diferentes Estados miembros, reflejado en el "Informe Conjunto sobre el Empleo 1998" (Comisión Europea, 1999a), muestra que a lo largo de 1998 se han producido algunos avances en lo que respecta a la nueva estrategia. El debate sobre la política de empleo ha ganado en transparencia y su dimensión política se ha afirmado en muchos Estados miembros y a nivel de la Unión Europea. Por otro lado, ha mejorado la coordinación de la política de empleo en los Estados miembros y se han establecido nuevas estructuras interministeriales, a veces incluso a nivel regional. Además, tanto los interlocutores sociales como las autoridades locales y regionales han participado y contribuido en la formulación y segui- 
miento de los PNAE, lo que ha dado lugar a nuevas iniciativas conjuntas.

Sin embargo, también se han apreciado algunas dificultades y lagunas del proceso, como la complejidad que conlleva el gran número de participantes, tanto en la Unión Europea como en los países implicados, las dificultades de coordinación entre los mismos, la carencia de indicadores comunes apropiados para el seguimiento y la evaluación, la brevedad de los plazos para la preparación de los Planes Naciones de Empleo o la dificultad para traducir políticas de empleo a presupuestos.

Precisamente, con el objeto de mejorar la estrategia europea para el empleo así como su aplicación más eficaz, en el Consejo Europeo de Viena ( 11 y 12 de diciembre de 1998) se adoptaron las Directrices para el empleo en 1999 (Consejo de la Unión Europea, 1999), que modifican las aprobadas en Luxemburgo a partir de los cuatro pilares que componen su estructura básica. Algunas modificaciones de las Directrices para 1999 son (Consejo Económico y Social, 1999):

- mayor énfasis en las medidas activas;

- mejora de las condiciones de aprendizaje a lo largo de toda la vida, principalmente para las personas mayores;

- apertura del mercado de trabajo a todos los colectivos, en particular los discapacitados y las minorías étnicas;

- conciliación de la vida laboral con la vida profesional, optimización del Sistema de Seguridad Social para los jóvenes y mejora de la participación de las mujeres en el mercado de trabajo.

También durante 1998 se presentaron trabajos que reflejan la necesidad de reformar algunos sectores y propiciar su desarrollo con el objeto de crear empleo. Es el caso, por ejemplo, del "Informe sobre las oportunidades de empleo en la sociedad de la información", y la "Comunicación de la Comisión Europea relativa a la modernización de los servicios públicos de empleo" (Comisión Europea, 1998g).

Para terminar, señalar que a lo largo de 1999 gran parte de las discusiones en materia de política europea de empleo se están centrando en lo que se conoce como "Pacto Europeo para el Empleo". Su filosofía consiste en avanzar en la coordinación de las políticas fiscales y salariales de los Estados miembros, al ritmo de la política monetaria común. En concreto, se proponen medidas que puedan asegurar un crecimiento fuerte y no inflacionista, profundizar en la aplicación de las directrices europeas para el empleo y acelerar la realización de las reformas económicas necesarias para asegurar la competitividad. En lo que respecta a su contenido, las propuestas hacen referencia a cuestiones tales como salarios mínimos europeos, armonización fiscal, pro- 
tección mínima europea en caso de despido, creación de indicadores comparables de paro, política salarial, medidas concretas para colectivos especiales, reformas estructurales, políticas macroeconómicas, innovación, etc. (Consejo Económico y Social, 1999).

\section{LAS POLÍTICAS DE INSERCIÓN EN LOS PLANES NACIO- NALES DE ACCIÓN PARA EL EMPLEO: UNA COMPARACIÓN FRANCIA-REINO UNIDO-ESPAÑA.}

Si las políticas de empleo se definen como un conjunto de intervenciones públicas cuyo objeto consiste, por una parte, en atenuar los efectos sociales ligados a la degradación de la coyuntura económica (medidas pasivas, como por ejemplo, las prestaciones por desempleo) y, por otra, en mejorar el funcionamiento del mercado de trabajo (medidas activas, de ayuda a las empresas o de formación de los parados), en los años 80 , y frente a el aumento de un desempleo masivo y a la aparición del desempleo de exclusión, el aspecto activo de las políticas de empleo se ha desarrollado considerablemente, a través de las políticas denominadas de inserción (Wuhl, 1996). En este apartado, se van a analizar las actuaciones más significativas llevadas a cabo en materia de inserción en tres países de la Unión Europea (Francia-Reino UnidoEspaña), tal y como aparecen recogidas en sus "Planes Nacionales de Empleo" de 1998 y 1999.

\subsection{La creación de actividades y de empleos para jóvenes y la lucha contra las exclusiones en Francia.}

En 1997, la tasa de paro de los jóvenes en la Unión Europea era casi del $20 \%$, siendo este problema particularmente grave en Francia donde esta tasa superaba el $24 \%$. Parecía, por tanto, existir una clara desventaja para este colectivo en lo que respecta a su inserción en el mercado de trabajo. Además, los que lograban insertarse lo hacían mediante contratos temporales, a menudo de corta duración, viviendo situaciones particularmente precarias.

Por otro lado, el Gobierno francés era consciente en ese momento de que la economía francesa presentaba una relativa pobreza en actividades de servicio, aún cuando existían necesidades que quedaban sin satisfacer y otras estaban emergiendo.

Precisamente, para hacer frente a este doble problema (penuria de servicios y paro de los jóvenes) el Gobierno francés decide poner en marcha el programa "Nuevos Servicios, Empleos para Jóvenes" (Nouveaux Services, Emplois Jeunes), con la aprobación de la "Ley de 
16 de octubre de 1997, relativa al desarrollo de actividades para el empleo de los jóvenes" (Van Lerbergue, 1999).

El programa "Nuevos Servicios, Empleos para Jóvenes" nace con la finalidad de favorecer la creación de empleos en actividades nuevas, que respondan a necesidades emergentes todavía no satisfechas por el mercado, principalmente en actividades culturales, educativas, deportivas, de medio ambiente y de proximidad (Comisión Europea, 1999c). Sus objetivos responderían a la línea directriz 10 (promover la creación de empleo a nivel local) para 1998, que marca la nueva política de empleo de la Unión Europea.

Por tanto, se trata de un programa de desarrollo local que pretende la creación de actividades consideradas de "utilidad social", previendo para ello una subvención ${ }^{6}$ que el Estado concede a los organismos ${ }^{7}$ que las crean. Esta ayuda del Estado es otorgada mensualmente, durante un período de 5 años, lo que permite (Comisión Europea, 1999c):

- un verdadero lanzamiento de la actividad, y su estructuración, así como la emergencia de una verdadera demanda;

- una experiencia profesional real para los jóvenes así contratados.

Entre los nuevos servicios que han sido creados con la puesta en marcha de este programa, pueden citarse (Van Lerbergue, 1999):

- En primer plano, aparecen los servicios que contribuyen al reforzamiento de la cohesión social y al desarrollo de la solidaridad $(15,5 \%)$ : este sector ha sido objeto de numerosas iniciativas tendentes a mejorar la atención de las personas mayores, prevenir situaciones de exclusión o rupturas familiares y profesionales, favorecer el derecho y acompañamiento socio-educativo de las personas más desfavorecidas, desarrollar una ayuda multiforme en la vida de las personas discapacitadas;

- Sector igualmente caracterizado por la importancia y la diversidad de los servicios es el sector del medio ambiente (15,5\%), el cual ha permitido responder a la aspiración de una mejor calidad de vida en una sociedad de consumo. Se pueden mencionar aquí actividades tales como el tratamiento de los desechos, la protec-

" Para alcanzar el objetivo de creación de empleos para los jôvenes, esta subvención es concedida para cada empleo creado en el seno de esta actividad, y ocupado por un joven (con edad comprendida entre 18-25 años cualquiera que sea su situación, o entre 26-29 años si carece de empleo o no se beneficia de un subsidio de paro (Van Lerbergue, 1999). Esta subvención representa actualmente la cantidad de $93.843 \mathrm{~F}$ ( 14.214 euros) por año, lo que equivale al $80 \%$ del salario mínimo (Comisión Europea, 1999c).

7 Los organismos elegibles son esencialmente las asociaciones, las colectividades locales y los establecimientos públicos. 
ción del medio ambiente, la prevención de la contaminación, las economías de energía y la protección del patrimonio.

- El desarrollo de servicios en el sector de la cultura (10,9\%) es particularmente significativo. Concierne principalmente el desarrollo y el acceso a las nuevas tecnologías de la información y la comunicación, el acceso a la lectura o a otras prácticas culturales en los barrios desfavorecidos o en el medio rural y, en relación con el sector del turismo $(4,8 \%)$ y del medio ambiente, la valorización y la promoción del patrimonio.

- La creación de servicios para el desarrollo del deporte $(9,9 \%)$ en numerosas disciplinas y abriéndolos a nuevos públicos, a menudo con una dimensión de animación y de prevención en los barrios desfavorecidos, ha sido objeto de numerosas iniciativas de asociaciones y de clubes deportivos así como de colectividades locales.

- En el sector de la vivienda y de la vida en los barrios desfavorecidos $(8,9 \%)$, los servicios han respondido a necesidades en materia de mediación social, de mejora de las relaciones entre los usuarios y las instituciones y servicios administrativos, pero igualmente de apoyo al desarrollo de la vida asociativa.

- El desarrollo de servicios en el campo de las actividades extraescolares, del tiempo del menor y del tiempo libre $(8,5 \%)$ ha sido realizado por asociaciones de educación popular y por las colectividades locales, completando la acción del Ministerio de Educación Nacional.

- En el seno mismo del Ministerio de Educación Nacional, el apoyo aportado a los alumnos por los ayuda-educadores (aideéducateurs) ha contribuido a la mejora de la vida escolar en los establecimientos y al desarrollo de las actividades de animación. Ha permitido asimismo facilitar el acceso de los alumnos a las nuevas tecnologías de la información y comunicación, desarrollar las actividades de documentación y reforzar el apoyo a los alumnos en situación de fracaso escolar.

En cuanto a los resultados obtenidos hasta el momento, hay que señalar que el objetivo incluido en el PNAE de 1998 (Comisión Europea, 1998a), de crear 150.000 empleos mediante este programa, ha sido superado notablemente puesto que a finales de 1998 se habían creado 160.000 empleos (Comisión Europea, 1999c). El desarrollo de estas actividades ha permitido a los jóvenes -de los cuales más del $70 \%$ estaban desempleados- encontrar un empleo. Por otro lado, los empleos ocupados han sido casi en su totalidad a tiempo completo y el $79 \%$ con contrato temporal, remunerados generalmente ligeramente 
por encima del salario mínimo (sobre todo en las asociaciones donde los jóvenes presentan mayor cualificación). Sólo las asociaciones utilizan de manera significativa los contratos de duración indefinida (Comisión Europea, 1999a). Asimismo, durante 1999 se prevé la creación de 100.000 empleos suplementarios gracias a este programa.

Sin embargo, a pesar de los buenos resultados alcanzados, también se mencionan algunas críticas que comentamos a continuación. Así, la creación de empleos para jóvenes a través de esta medida no parece haber invertido la tendencia hacia la exclusión de los no diplomados, provocada ya antes por la carencia de empleos, obligando así a los más desaventajados escolarmente a recurrir a medidas antiguas y temporales (contrato empleo-solidaridad, contrato de adaptación, contrato de cualificación) (Pariat y Allouche-Benayoun, 1998).

En cualquier caso, la acción gubernamental con respecto a este programa se prosigue actualmente en tres direcciones (Van Lerbergue, 1999):

- continuar con el apoyo a la emergencia de nuevos servicios;

- favorecer una verdadera profesionalización de las actividades y de los jóvenes que las ejercen,

- ayudar a los organismos subvencionados a encontrar las vías para que su actividad perdure más allá de los 5 años que dura la ayuda del Estado.

Pero, además del programa "Nouveaux services-emplois jeunes" -el cual está considerado el programa "estrella"- en el Plan Nacional de Acción para 1999, Francia ha elegido conjugar una política de tratamiento del paro de larga duración y de la exclusión, construida hace ya un tiempo pero reforzada significativamente con el programa y la Ley contra las exclusiones ( $L O \mathrm{OI} \mathrm{n}^{\circ} 98-657$ du 29 juillet 1998 d'orientation relative à la lutte contre les exclusions /J.O. num. 175 du 31 juillet 1998), con una política de prevención, a partir del programa "nuevo comienzo" (nouveau départ) (Comisión Europea, 1999c).

Así, en 1999, se van a promover soluciones duraderas de inserción profesional y social para las personas adultas en situación de exclusión social, cuya intención es romper con la precariedad de las soluciones excesivamente provisorias, privilegiando el empleo antes que las medidas de asistencia, y tratando igualmente de aportar una respuesta global a los problemas sociales, de salud, vivienda, etc. Es por ello que el "programa de prevención y de lucha contra las exclusiones" (programme de prévention et de lutte contre les exclusions), presentado por el Gobierno francés en marzo de 1998, y la "Ley contra las exclusiones", aprobada en julio de ese mismo año, presentan como primer principio la afirmación del derecho al empleo y la voluntad de traducirlo a la 
realidad (Comisión Europea, 1999c). Según el Artículo 1 de la citada Ley: "La lucha contra las exclusiones es un imperativo nacional fundado en el respeto de la igual dignidad de todos los seres humanos y una prioridad del conjunto de las políticas públicas de la nación. La presente ley tiende a garantizar en el conjunto del territorio el acceso efectivo de todos a los derechos fundamentales en los dominios del empleo, la vivienda, la protección de la salud, la justicia, la educación. la formación, la cultura y la protección de la familia y de la infancia".

\subsection{La "Nueva Política" (New Deal) dirigida a los desempleados en el Reino Unido.}

En la línea de la política de la "tercera vía" propuesta por A. Guiddens (1999), el Gobierno laborista de T. Blair en el Reino Unido se plantea como objetivo reconstruir el Estado del Bienestar en base al trabajo. De hecho, el nuevo Gobierno laborista pretende promover el trabajo a través de las siguientes medidas (VV.AA., 1998):

- ayudando a las personas desempleadas a pasar del bienestar al trabajo a través de las "Nuevas Políticas" (New Deals) y "Zonas de Empleo" (Employment Zones);

- desarrollando servicios flexibles y personalizados para que los desempleados encuentren trabajo;

- removiendo las barreras para que puedan acceder al trabajo los que pueden y quieren trabajar;

- haciendo que el trabajo merezca la pena, reformando el sistema fiscal y de pensiones, incluyendo un "Crédito para las Familias Trabajadoras" (Working Families Tax Credit), reformando los "Seguros Nacionales" (National Insurance) y el impuesto sobre la renta, e introduciendo un salario mínimo nacional; y

- asegurando que las responsabilidades y los derechos se encuentran justamente equilibrados.

La finalidad de su programa integral de bienestar para trabajar (Welfare to Work), inspirado en la experiencia estadounidense en relación a los programas de asistencia social (McGregor, 1999), es romper el molde del viejo sistema pasivo de subsidios, centrándose para ello en cinco aspectos de la "Nueva Política" (New Deal) dirigida a: jóvenes desempleados, familias monoparentales, discapacitados o enfermos crónicos y parejas de los parados. Junto a estos programas nacionales, se han puesto en marcha igualmente ayudas para áreas con altas tasas de desempleo de larga duración, a través de las nuevas "Zonas de Empleo" (Employment Zones). 
De entre las nuevas políticas activas introducidas en el Reino Unido, la más importante es la "Nueva Política para los Jóvenes" (New Deal for Young People), experimentada primero en doce "zonas piloto" en enero de 1998, antes de extender su aplicación a nivel nacional en abril de 1998 (Comisión Europea, 1999a). La "Nueva Política para Jóvenes" constituye el elemento principal de la estrategia puesta en marcha en este país para luchar contra el paro juvenil. Se propone, de esta manera, ayudar a los jóvenes parados, de edades comprendidas entre los 18 y los 24 años, a encontrar empleos y a conservarlos (VV.AA., 1998). Sus objetivos coinciden entonces con los de la línea directriz 1 (combatir el desempleo juvenil). Además, el programa está financiado por el impuesto especial cargado sobre los "beneficios excesivos" de las industrias privatizadas del agua, electricidad y gas, que ha recaudado unos 650.000 millones de pesetas (Gurruchaga, 1999).

Si bien la "Nueva Política para Jóvenes" contiene elementos ya presentes en medidas aplicadas anteriormente en el Reino Unido, esta medida es innovadora por varias razones; en particular (Comisión Europea, 1999a):

- por su importancia (el gasto previsto asciende a la cantidad de 3.160 millones de $£$ para el período 1997-2002) y su carácter global: está dirigido a todos los jóvenes en edades comprendidas entre 18-24 años que perciben el subsidio de demandantes de empleo (Jobseekers' Allowance - JSA) ${ }^{8}$ desde hace como mínimo 6 meses. Además, varios colectivos pueden beneficiarse del New Deal antes de alcanzar los 6 meses en paro";

- presenta elementos característicos de un "itinerario de inserción": todos los participantes realizan un programa inicial denominado "Acceso" (Gateway), de una duración máxima de cuatro meses, que consiste en sesiones intensivas de orientación y asesoramiento. Este programa pretende ayudar al mayor número posible de participantes a encontrar empleos no subvencionados en el mercado ordinario de trabajo, y preparar al resto sobre las diferentes posibilidades propuestas por la fase principal del New Deal;

- al finalizar el programa Gateway, los jóvenes que no hayan encontrado empleo no subvencionado tienen, en función de la evaluación de sus competencias y necesidades, la posibilidad de ele-

* En octubre de 1996, el JSA reemplazó los sistemas anteriores de subsidio de desempleo y de complementos de recursos (Comisión Europea, 1999a).

- Los colectivos que pueden beneficiarse antes del New Ded incluyen a las personas discapacitadas, los ex-reclusos, las personas a cargo de las autoridades locales y aquellas que tienen dificultades para leer y cscribir (Comisión Europea, 1999a). 
gir entre cinco opciones ${ }^{10}$.

1. un empleo subvencionado durante seis meses en el mercado ordinario de trabajo, por el cual el empleador recibirá un subsidio por puesto de trabajo de hasta $60 £$ a la semana;

2. seis meses de trabajo en el Equipo de Trabajo de Medio Ambiente (Environmental Taskforce) (programa de creación de empleos en el sector del medio ambiente);

3. seis meses de trabajo en una organización del sector voluntario;

4. para los que no posean cualificaciones de nivel 2 NVQ (cualificaciones profesionales nacionales), una educación o formación a tiempo completo de una duración máxima de doce meses sin pérdida del subsidio;

5. el acceso a una actividad no asalariada (subvencionada durante seis meses);

- el New Deal incluye un elemento importante de "activación", en la medida en que los jóvenes que rehusan participar en alguna de las opciones propuestas se exponen a sanciones financieras como, por ejemplo, la pérdida del subsidio de demandante de empleo $(J S A)$.

En lo que respecta a los resultados, y según las estadísticas oficiales, 35.000 empresas se han sumado al New Deal for Young People, al que han acudido 266.300 jóvenes, de los cuales alrededor de 100.000 han encontrado una ocupación gracias a este programa, que cumple un año de existencia (Gurruchaga, 1999).

Pero además de la "Nueva Política para jóvenes", el Gobierno británico ha puesto en marcha otras medidas como la "Nueva Política para desempleados mayores de 25 años" (New Deal for people Aged $25+)^{11}$ en junio de 1998, la "Nueva Política para familias monoparentales" (New Deal for Lone Parents) ${ }^{12}$ en octubre de 1998, así como

10 En sus inicios, el programa preveía cuatro opciones (Comisión Europea, 1998b); la quinta (empleo no asalariado) fue añadida en julio de 1998 (Comisión Europea, 1999a).

" La "Nueva Política para desempleados mayores de 25 años" (New Deal for people Aged $25+$ ) está dirigida a los desempleados de ese tramo de edad, que se encuentran en situación de desempleo desde hace 2 años como mínimo, y ofrece (Comisión Europea, 1998b, 1999d):

- un empleo durante seis meses por el cual el empleador recibe un subsidio de $75 £$ a la semana;

- la posibilidad de que cerca de 10.000 personas, que carecen de las competencias básicas, puedan estudiar a tiempo completo durante un período máximo de un año, percibiendo una indemnización.

12 Este programa pretende mejorar las perspectivas de empleo y la capacidad de inserción profesional de las familias monoparentales que perciben el ingreso mínimo de inserción (Comisión Europea, 1999d). 
la "Nueva Política para Discapacitados" (New Deal for Disabled People) ${ }^{13}$, la "Nueva Política para las parejas de los desempleados" (New Deal for Partners) ", la "Nueva Política para las Escuelas" (New Deal for Schools) y la "Nueva Política para las Comunidades" (New Deal for Communities) (Comisión Europea, 1999d).

\subsection{Las medidas en favor de la estabilidad en el empleo en España.}

España no sólo es el país de la Unión Europea que presenta la tasa más elevada de desempleo ${ }^{15}$, sino también la tasa más alta de empleo temporal, esta última más o menos estable desde 1992 (Comisión Europea, 1999a). En 1997, estas tasas alcanzaron el 20,3\% y 33,2\% (Comisión Europea, 1999b), aproximadamente el doble y más del triple de la media europea, respectivamente, habiendo sufrido una cierta reducción en el último período hasta llegar en el segundo trimestre del año en curso al 15,6\% y 32,7\% (Alegre, 1999).

En nuestro país, la creciente utilización de la contratación temporal vino propiciada por la reforma del mercado de trabajo de 1984, que generalizó el uso de los llamados "contratos temporales de fomento del empleo" (contratos temporales no causales). La reforma de 1984 se inscribía abiertamente en la tendencia flexibilizadora del momento, moviéndose en torno a tres ejes o directrices fundamentales: la ampliación del ámbito de la contratación temporal "normal"; la flexibilización al máximo de la contratación temporal "coyuntural"; y la "normalización" del juego de otras modalidades de contratación (Durán et al., 1987; citado en L. Cachón y J. I. Palacio, 1999, p. 285). Más adelante, dos reformas posteriores, la de $1992^{16}$, ligada a los recortes en el siste-

1.3 Consiste en un programa específicamente destinado a las personas que se benefician de prestaciones de invalidez y que desean encontrar un empleo o continuar trabajando (Comisión Europea, 1999a).

14 Se trata de un programa dirigido a las parejas de los desempleados que se encuentran también en situación de desempleo. Las parejas con edades comprendidas en el tramo de edad 18-24 están incluidas en la "Nueva Política para los Jóvenes"; sin embargo, las parejas con menores a cargo y las que son mayores de 25 años pueden recurrir a la "Nueva Política para las parejas" (New Deal for Partners) (Comisión Europea, 1999d).

15 En España, el desempleo ha estado caracterizado por los siguientes rasgos (Ródenas y Sánchez, 1998): un alto paro de larga duración, centrado sobre los jóvenes y las mujeres, con mayor incidencia en las personas sin estudios; con grandes diferencias entre Comunidades autónomas; que coexiste con una tasa de actividad inferior al $50 \%$ de la población en edad activa; y que persiste incluso en situaciones de crecimiento del PIB.

16 En 1992, se promulga el RDL 1/1992, después Ley 22/1992, de 30 de julio, de Medidas Urgentes sobre Fomento del Empleo y Protección por Desempleo, con el fin de fomentar la contratación indefinida y eliminar algunos incentivos económicos dirigidos hacia la contratación temporal (Flórez, 1994). 
ma de protección por desempleo, y la reforma de 1994, han tratado de limitar, al menos formalmente, el auge de dicha contratación temporal (García Serrano, Garrido y Toharia, 1999). Pero, y como señalan los autores C. García Serrano et al. (1999), el análisis de la evolución de la temporalidad en España muestra que en 1992 se inicia una nueva etapa caracterizada por una mayor intensidad de uso de los contratos temporales, unida a una creciente rotación de la mano de obra ${ }^{17}$. Para A. Recio (1998), esta generalización de la temporalidad, con la consiguiente precarización del empleo, habría tenido como efecto el debilitar tanto a los sindicatos como a los trabajadores individuales, impidiendo además que una parte de la población pueda disfrutar de los mismos derechos laborales, así como de unas condiciones de trabajo que ofrezcan oportunidades para la formación, la realización personal y la estabilidad vital. De esta manera, han sido las reformas de mayo de 1997 y noviembre de 1998, que tratan de potenciar, respectivamente, la contratación indefinida y el trabajo a tiempo parcial estable (Comisión Europea, 1999b), las que han dado un nuevo impulso a la limitación de la contratación temporal, ante el fracaso evidente de las reformas anteriores.

En abril de 1997, se produce la firma de varios acuerdos interconfederales entre las organizaciones empresariales más representativas a nivel estatal (CEOE y CEPYME), y las igualmente más representativas centrales sindicales (UGT y CC.OO.). Estos acuerdos son tres: el "Acuerdo Interconfederal para la Estabilidad en el Empleo", el "Acuerdo Interconfederal sobre Negociación Colectiva" y el "Acuerdo Interconfederal sobre Cobertura de Vacíos". El primero de estos acuerdos ha sido asumido en gran medida por el Gobierno, promulgándose dos Reales Decretos Leyes, ambos de 16 de mayo (BOE del 17; corrección de errores $\mathrm{BOE}$ de 24 de mayo): el RDL 8/1997, de medidas urgentes para la mejora del mercado de trabajo y el fomento de la contratación indefinida; y el RDL 9/1997, por el que se regulan incentivos en materia de Seguridad Social y de carácter fiscal para el fomento de la contratación indefinida y la estabilidad en el empleo (Albiol, Camps y Goerlich, 1997).

17 La desaparición legal de los "contratos temporales de fomento del empleo" turo como efecto un importante incremento de la rotación laboral de los contratados temporalmente. Ya que al eliminarse la posibilidad que tenían esos contratos de prorrogarse hasta cubrir tres años, la alternativa que se plantea una vez finalizados es convertirlos en indefinidos o el despido. Y la evolución de la temporalidad muestra que la opción mayoritaria ha sido el despido. Por lo que la defensa de la contratación indefinida durante el período 1992-1996 ha venido a convertir los contratos temporales en improrrogables, salvo pasándolos a indefinidos, lo que no parece haber resultado rentable para la mayoría de los empleadores (García Serrano, Garrido y Toharia, 1999). 
La finalidad de estos Acuerdos es desarrollar un modelo de relaciones industriales más estable para aumentar la competitividad de las empresas, mejorar la capacidad de inserción profesional y reducir la rotación de la mano de obra así como la contratación temporal (Comisión Europea, 1999a). En este sentido, se pretende fomentar la estabilidad laboral suprimiendo ciertas modalidades de contratación temporal y diseñando un nuevo contrato indefinido al que puedan acogerse los colectivos de desempleados más desfavorecidos (Ministerio de Trabajo y Asuntos Sociales, 1998), es decir, los jóvenes de 18 a 29 años, los parados de larga duración, los desempleados mayores de 45 años, los minusválidos y los trabajadores con contratos temporales. Quedan, por tanto, excluidos de esta medida los parados jóvenes menores de 18 años y los adultos de 30 a 44 años que no sean parados de larga duración o minusválidos. Además, estos contratos contemplan una indemnización por despido, cuando sea por causas objetivas y se le declare improcedente, de 33 días de salario por año trabajado hasta un máximo de 24 mensualidades, inferior a la establecida para el resto de los contratos indefinidos (de 45 días y el máximo de 48 mensualidades según el art. 56.a de la Ley del Estatuto de los Trabajadores para los despidos improcedentes y los 20 días de indemnización por año de servicio y tope de 12 mensualidades) (Cachón y Palacio, 1999). En su primer año de aplicación, cerca del $70 \%$ de los nuevos contratos indefinidos han recurrido a las nuevas medidas de fomento, en particular a la conversión de contratos temporales existentes en contratos indefinidos, beneficiado especialmente a los jóvenes trabajadores (59\%) (Comisión Europea, 1999a).

Por su parte, el 13 de noviembre de 1998 se firmó el Acuerdo sobre trabajo a tiempo parcial y fomento de su estabilidad, que fue suscrito por el Gobierno y las organizaciones sindicales UGT y CC.OO.. La nueva regulación del trabajo a tiempo parcial a que da lugar el Acuerdo se ha llevado a cabo mediante la aprobación del Real Decreto-Ley 15/1998, de 27 de noviembre, de medidas urgentes para la mejora del mercado de trabajo en relación con el trabajo a tiempo parcial y el fomento de su estabilidad. El Acuerdo fue rechazado y criticado por los empresarios porque, según las organizaciones CEOE y CEPYME, convierte el contrato a tiempo parcial en un instrumento rígido, complejo y de difícil comprensión, lo que puede limitar su utilización en las empresas, en especial en las de menor dimensión. Sin embargo, las organizaciones sindicales UGT y CC.OO., firmantes del Acuerdo, consideran que la nueva regulación legal concede garantías laborales y de protección social a la contratación a tiempo parcial de las que carecía anteriormente y que eran necesarias para mejorar las condiciones del trabajo a tiempo parcial (Consejo Económico y Social, 1999). 
Por todo lo anterior, en España, los Planes de Acción para el Empleo de 1998 y 1999 han incluido entre sus objetivos la potenciación de la estabilidad en el empleo y la reducción de la tasa de temporalidad. De hecho, en el PNAE de 1999, para cuya financiación general se han visto afectados 1.100 .000 millones de pesetas, se han destinado a este apartado 300.000 millones. Así, tanto en la Directriz 4 (reestructurar el sistema de prestaciones y fiscalidad) como en las Directrices 14 (reducción de la carga fiscal sobre el trabajo) y 17 (tipos de contratos más adaptables), se contempla, entre sus actuaciones, la realización de un nuevo programa de bonificaciones a la contratación estable de trabajadores. Pero, además, el PNAE de 1999 ha establecido los siguientes objetivos generales (Comisión Europea, 1999b):

- consolidar la estrategia de actuación basada en el desarrollo de políticas activas de empleo;

- promover la actividad de las pequeñas y medianas empresas (PYMEs), a través de la reforma de la fiscalidad (más favorable a la creación y mantenimiento del empleo), la simplificación administrativa y un mejor acceso a la financiación;

- conciliar la vida profesional y familiar para favorecer la mayor participación de la mujer en el mercado de trabajo.

Y como acciones innovadoras a desarrollar en 1999 en el marco del citado PNAE, conviene destacar las siguientes:

- facilitar, mediante una nueva ley, la conciliación de la vida familiar y la vida profesional de los trabajadores;

- preparación de una Ley de Inserción Socio-Laboral, con el fin de establecer un marco apropiado que favorezca y fomente la inserción laboral de personas en situación de exclusión social o de marginalidad;

- reducción de trámites para la creación de PYMEs;

- dentro de la intensificación de la actuación en políticas activas, se pretenden abordar las siguientes iniciativas: la puesta en marcha del Programa "Talleres de Empleo"18; el Programa piloto de-

1* El programa de Talleres de Empleo y las bases reguladoras de la concesión de subvenciones públicas a dicho programa han quedado establecidas por el Real Decreto 282/1999, de 22 de febrero, y por la Orden de 9 de marzo de 1999, que desarrolla dicho Real Decreto. El programa de Talleres de Empleo está dirigido preferentemente a los parados de larga duración mayores de 25 años con especiales dificultades de inserción laboral, y su finalidad es proporcionar formación y práctica laboral mediante la realización de obras y servicios de utilidad pública o interés social. Tiene una duración entre 6 y 12 meses. Cada Taller se organiza por una entidad promotora que es habitualmente una Corporación Local o una entidad sin ánimo de lucro. Los recursos públicos financian los costes de formación y contratación de los desempleados (Comisión Europea, 1999b). 
nominado "Compromiso Voluntario de Actividad"19, dirigido a los beneficiarios de las prestaciones por desempleo; y la puesta en marcha de un Programa de tutoría individualizada en favor de los desempleados que presentan dificultades de inserción;

- promoción de las políticas de desarrollo local desde una doble perspectiva: reforma del programa de "Iniciativas Locales de Empleo" y puesta en práctica de un Plan de Choque en 100 municipios afectados por altos índices de desempleo ${ }^{20}$. En ambos casos se priorizarán las experiencias que incidan en actividades de servicios cuya demanda se constata insuficientemente satisfecha.

\section{CONCLUSIONES.}

El análisis de la política de empleo a escala europea ha mostrado los pasos -ciertamente lentos- que se han ido dando en la definición de dicha política, y que ha sido a partir del Consejo Europeo Extraordinario sobre el empleo, celebrado en Luxemburgo en noviembre de 1997, cuando se ha podido apreciar una nueva estrategia en materia de empleo a nivel comunitario. Partiendo de la reforma del Tratado de la Unión Europea aprobada en Amsterdam en junio de 1997, la mencionada cumbre del empleo ha fijado por primera vez un conjunto de medidas para el fomento del empleo, que constituyen sin lugar a dudas una incipiente política de empleo a nivel de la Unión Europea, con un carácter marcadamente activo (Cachón y Palacio, 1999).

Pero, las políticas de empleo siguen siendo competencia de los Estados miembros y, aunque los objetivos marcados por las "Directrices para el empleo", aprobadas cada año por el Consejo de Empleo y Asuntos Sociales, deben ser tenidas en cuenta por cada Estado miembro en la elaboración de sus respectivos "Planes Nacionales de Acción para el Empleo", que han de presentar a la Comisión, lo cierto es que se apre-

(1) Consiste en la firma de un Convenio entre el Servicio Público de Empleo y el perceptor de prestaciones por desempleo, en el que ambas partes asumen la obligación de desarrollar un programa intensivo de actuaciones dirigidas a la mejora de la empleabilidad, organización de la búsqueda activa y acceso al empleo. Para los Servicios Públicos de Empleo supone un compromiso de oferta de un conjunto completo y suficiente de acciones de formación, orientación y empleo (Comisión Europea, 1999b).

20 Este Plan de Choque consiste en la realización de planes de inserción experimentales dirigidos a colectivos específicos y diseñados de acuerdo a sus necesidades previamente detectadas. Ha sido elaborado en colaboración con la Federación de Municipios y Provincias, y será ejecutado en colaboración con éstos. Se contará además con la participación de otras entidades colaboradoras, principalmente interlocutores sociales y tercer sector (Comisión Europea, 1999b). 
cian diferencias entre los países de la Unión Europea en cuanto a las actuaciones emprendidas y dotación presupuestaria en esta materia. Esto es lo que se ha pretendido mostrar al analizar -sin buscar la exhaustividad-algunas de las actuaciones llevadas a cabo en tres países de la Comunidad (Francia, Reino Unido y España), en lo que respecta a sus políticas de inserción. Tras la comparación de las políticas de inserción de estos tres países, se distinguen tres líneas de actuación:

- Evitar que los mecanismos de protección social frente al desempleo acaben desincentivando la búsqueda y aceptación de empleo. En este sentido, se posiciona el Gobierno laborista del Reino Unido con su "Nueva Política" (New Deal) en la que las ayudas concedidas están condicionadas a que el desempleado esté dispuesto a aceptar un empleo o un curso de formación.

- Para una parte importante de las personas desempledas, especialmente los jóvenes y los parados de larga duración, el coste de la contratación no constituye el principal obstáculo (Romero, 1998). Influyen más en su situación de desempleo la falta de experiencia o de conocimientos adecuados a lo que demanda el mercado. Es por esta razón que iniciativas de contratación impulsadas desde los poderes públicos en torno a los nuevos servicios de proximidad y, en general, a los nuevos yacimientos de empleo, como la llevada a cabo por el Gobierno socialista francés a través del Programa "Nuevos Servicios, Empleos para Jóvenes" (Nouveaux Services, Emplois Jeunes) merecen una especial atención.

- La mayoría de las veces, cuando los parados (especialmente los jóvenes) logran insertarse en el mercado de trabajo lo hacen mediante contratos temporales, a menudo de corta duración, lo que les conduce a situaciones vitales particularmente precarias. Una forma de evitar la excesiva temporalidad del empleo, consiste en la aprobación de medidas que fomenten la estabilidad en el empleo y la contratación indefinida. Es por esta vía que ha optado, en gran medida, el Gobierno español, tras las reformas de 1997 y 1998, que tratan de potenciar, respectivamente, la contratación indefinida y el trabajo a tiempo parcial estable.

En definitiva, se constatan diferentes modelos de actuación en materia de inserción en los tres países objeto de la comparación, fruto de la diversidad de sus contextos socioeconómicos y de regulación de los mercados de trabajo y de las relaciones laborales. Cabría preguntarse, además, si a través de las diferentes medidas analizadas se están ofreciendo empleos de calidad o si, por el contrario, suponen el mantenimiento en la precariedad de los colectivos con dificultades de inserción en el mercado de trabajo. En este sentido, y con respecto al programa "Nueva Política para Jóvenes" en el Reino Unido, por ejemplo, 
existe el peligro de que el salario subsidio, aliado con la coacción de la amenaza de reducción de subsidios, pueda conllevar un aumento del número de trabajos con bajos salarios (McGregor, 1999). Por otro lado, y como ya se ha mencionado anteriormente en relación al programa francés "Nuevos Servicios, Empleos para Jóvenes", la creación de empleos para jóvenes a través de esta medida no ha sido capaz de invertir la tendencia hacia la exclusión de los no diplomados, obligando así a este colectivo a recurrir a medidas antiguas y temporales. Por último, las medidas de fomento de la contratación indefinida, aprobadas recientemente en España, parece que han dado buenos resultados en su primer año de aplicación. No obstante, y como resaltan $\mathrm{M}^{\mathrm{a}} \mathrm{A}$. Davia y V. Hernanz (1999), habrá que esperar a ver la evolución de estos contratos en el futuro puesto que pueden estar generando un fuerte "peso muerto", de manera que no se estén firmando más contratos de los habituales sino que se estén registrando más al amparo de las bonificaciones.

\section{BIBLIOGRAFÍA.}

ALARCÓN, M. R.: "La Carta Social Europea", en L. MORENO (comp.), Unión Europea y Estado del Bienestar, CSIC, Madrid, 1997, pp. 169-218.

ALBIOL, I.; CAMPS, L. M. y GOERLICH, J. M ${ }^{\text {a: }}$ La reforma laboral de 1997, Tirant lo Blanch, Valencia, 1997.

ALEGRE, Ma T.: "El paro cae el 10\% en Álava y Guipúzcoa, mientras Vizcaya soporta más del 18\%", Diario El Correo, viernes 13 de agosto de 1999 , p. 29.

BAGLIO, A.: Politiques de l'emploi en Europe, Ponencia presentada en la Conferencia Internacional sobre "Redes de Colaboración para el empleo", celebrada en Bilbao los días 15-16 de noviembre de 1995.

BUSTAMANTE, J. I.: "El empleo: objetivo prioritario tras el Tratado de Amsterdam", en VV.AA., Políticas de Empleo en la Unión Europea: Presente y Futuro, Federación de Cajas de Ahorros Vasco-Navarras, VitoriaGasteiz, 1999, pp. 39-46.

CACHÓN, L. y PALACIO, J. I.: "Política de empleo en España desde el ingreso en la Unión Europea", en F. MIGUÉLEZ y C. PRIETO (dir. y coord.), Las relaciones de empleo en España, Siglo XXI, Madrid, 1999, pp. 273304.

COMISIÓN DE LAS COMUNIDADES EUROPEAS: Carta comunitaria de los derechos sociales fundamentales de los trabajadores, Oficina de $\mathrm{Pu}-$ blicaciones Oficiales de las Comunidades Europeas, Luxemburgo, 1999. 
COMISIÓN DE LAS COMUNIDADES EUROPEAS: "Crecimiento, competitividad y empleo. Retos y pistas para entrar en el siglo XXI. Libro Blanco", COM (93) 700 final, Bruselas, 5 de diciembre de 1993.

COMISIÓN EUROPEA: "Comunicación de la Comisión al Consejo: seguimiento del Consejo Europeo de Essen sobre el empleo", COM (95) 74 final.

COMISIÓN EUROPEA: "Comunicación de la Comisión, de I de octubre de 1997: propuestas de orientaciones para las políticas de empleo de los Estados miembros en 1998", COM (97) 497 final.

COMISIÓN EUROPEA: Plan National d'Action pour l'Emploi France, 1998 (a).

COMISIÓN EUROPEA: United Kingdom Employment Action Plan, March 1998 (b).

COMISIÓN EUROPEA: Des lignes directrices à l'action concrète: évaluation. préliminaire des PAN. Rapport d'appui, Bruxelles, 1998 (c).

COMISIÓN EUROPEA: "Comunicación de la Comisión de las directrices a la acción: los Planes Nacionales de Acción para el Empleo", COM (1998) 316 final, 13 de mayo de 1998 (d).

COMISIÓN EUROPEA: “Comunicación de la Comisión relativa a las propuestas de directrices para las políticas de empleo de los Estados miembros en 1999", COM (1998) 574 final, 14 de octubre de 1998 (e).

COMISIÓN EUROPEA: "Informe de la Comisión sobre la tasa de empleo en 1998. Evolución del empleo en los Estados miembros", COM (1998) 572 final, 14 de octubre de 1998 (f).

COMISIÓN EUROPEA: "Comunicación de la Comisión Europea relativa a la modernización de los servicios públicos de empleo para apoyar la estrategia europea de empleo", COM (1998) 641 final, 13 de noviembre de $1998(\mathrm{~g})$.

COMISIÓN EUROPEA (1999a): Politiques de l'emploi dans l'UE et dans les États membres. Rapport conjoint 1998, Office des publications officielles des Communautés européennes, Luxembourg.

COMISIÓN EUROPEA: Plan de Acción para el Empleo del Reino de España 1999, 21 de mayo de 1999 (b).

COMISIÓN EUROPEA: Plan National d'Action pour l'Emploi pour 1999 et Bilan du Plan 1998 France. 1999 (c).

COMISIÓN EUROPEA: Plan d'Action du Royaume-Uni sur l'emploi 1999 (d).

CONSEJO ECONÓMICO Y SOCIAL: Memoria sobre la situación socioeconómica y laboral de España en 1998, CES, Madrid, 1999. 
CONSEJO DE LA UNIÓN EUROPEA: "Résolution du Conseil sur les lignes directrices pour l'emploi en 1999", DO, num. C 69/2, 12 mars 1999.

DAVIA, M"A. y HERNANZ, V.: "Políticas de empleo para jóvenes", en VV.AA., Politicas de Empleo en la Unión Europea: Presente y Futuro, Federación de Cajas de Ahorros Vasco-Navarras, Vitoria-Gasteiz, 1999, pp. 301-315.

FLÓREZ, I.: La contratación laboral como medida de política de empleo en España, CES, Madrid, 1994.

GABINETE TÉCNICO CONFEDERAL DE CC.OO.: "Libro Blanco sobre el Empleo en Europa. El precio de la competitividad", Noticias Obreras $n^{\circ}$ 1.129/1-10-94/15-10-94.

GARCÍA SERRANO, C.; GARRIDO, L. y TOHARIA, L.: "Empleo y paro en España: algunas cuestiones candentes", en F. MIGUÉLEZ y C. PRIETO (dir. y coord.), Las relaciones de empleo en España, Siglo XXI, Madrid, 1999, pp. 23-50.

GIDDENS, A.: La tercera vía. La renovación de la socialdemocracia, Taurus, Madrid, 1999.

GURRUCHAGA, I.: "Blair canta victoria", Diario El Correo, domingo 27 de junio de 1999, p. 58.

McGREGOR, A.: "Políticas de Empleo en el Reino Unido", en VV.AA., Políticas de Empleo en la Unión Europea: Presente y Futuro, Federación de Cajas de Ahorros Vasco-Navarras, Vitoria-Gasteiz, 1999, pp 135-146.

MINISTERIO DE TRABAJO Y ASUNTOS SOCIALES: Plan de Acción para el Empleo del Reino de España, 1998.

PARIAT, M. y ALLOUCHE-BENAYOUN, J.: Guide de l'insertion. professionnelle et sociale, Dunod, París, 1998.

RECIO, A.: "La política laboral: acuerdo y conflicto en un contexto de reforma continua", en R. GOMÀ y J. SUBIRATS (coords.), Políticas públicas en España. Contenidos, redes de actores y niveles de gobierno, Ariel, Barcelona, 1998, pp. 113-132.

RHODES, M. (1997): “El futuro de la dimensión social europea”, en L. MORENO (comp.), Unión Europea y Estado del Bienestar, CSIC, Madrid, pp. $143-167$.

RÓDENAS, F. y SÁNCHEZ, S.: "Política social y empleo", en C. ALEMÁN BRACHO y J. GARCÉS FERRER (coords.), Política Social, McGrawHill, Madrid, 1998, pp. 233-269.

ROMERO, J.: "Prólogo" del libro Un nuevo contrato para el bienestar. La propuesta laborista, Fundación Tolerancia y Solidaridad, NAU llibres, Valencia, 1998, pp. 3-17. 
SCADPLUS: Política de la Unión. Empleo y Asuntos Sociales, 28 de abril de 1999.

UNIÓN EUROPEA: "Tratado de la Unión Europea", Diario Oficial C 340 de 10.11.1997 (a), pp. 145-172.

UNIÓN EUROPEA: Tratado de Amsterdam, Oficina de Publicaciones Oficiales de las Comunidades Europeas, Luxemburgo, 1997 (b).

VAN LERBERGUE, R.-M.: Los nuevos empleos para los jóvenes, Conferencia presentada en el Congreso Internacional "El futuro del trabajo", organizado por el Club de Roma/Unesco, y celebrado en Bilbao los días 9 al 12 de marzo de 1999.

VV.AA.: Un nuevo contrato para el bienestar. La propuesta laborista, Fundación Tolerancia y Solidaridad, NAU llibres, Valencia, 1998.

WUHL, S.: "Politiques de l'emploi et politiques d'insertion: quelques perspectives", en S. PAUGAM (dir.), L'exclusion. L'état des savoirs, La Découverte, París, 1996. 


\section{TERCER SECTOR E INSERCIÓN SOCIAL}

\section{JOAQUÍN GARCÍA ROCA}

Profesor de la E.U. de Trabajo Social. Departamento de Trabajo Social y Servicios Sociales. Universidad de Valencia.

\section{INTRODUCCIÓN}

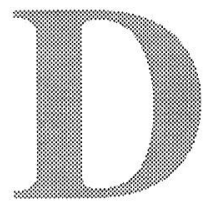

espués de un tiempo en el que el escenario de la margina-lidad estaba ocupado por ciertas figuras tradicionales (mendigos y vagabundos, transeúntes e indigentes...) hemos asistido en las últimas décadas a un cambio de personajes y también de decorado. En la nueva escena, los personajes tradicionales asumen papeles secundarios, y se produce un cambio profundo en el reparto: han aparecido en escena los parados de larga duración, los jóvenes sin empleo, las personas golpeadas por la drogodependencia, las familias monoparentales, las mujeres con responsabilidades familiares, la violencia doméstica, la inadaptación juvenil, la inmigración económica..., todos ellos crecen en las fronteras de un nicho de bienestar y privilegio como islas habitadas por todos aquéllos que no han podido pagar el precio de la integración social: han quedado fuera del trabajo regular, de la vivienda decente, de la cohesión social, de la convivencia estable y de las instituciones de socializacion. Permanecen fuera de las grandes corrientes por donde circulan los dinamismos de la sociedad, se reproducen entre ellos, viven de prestaciones y pasan de todos los esfuerzos bien intencionados de quienes quieren moralizarles y normalizarles; los excluidos, jóvenes o adultos, viven su humillación aislándose o buscando refugio en el alcohol, la droga y la autodestrucción.

¿Qué tienen de común todas estas figuras y estos espacios que han ido cristalizando en una intensa geografía social que va desde ciertos subgrupos que habitan en barrios desheredados hasta los alumnos de escolaridad fracasada con deficiencias múltiples, inadaptados sociales, familias mal socializadas y personas "inempleables"?

\section{EL NUEVO ESTATUTO DE LA EXCLUSIÓN.}

En primer lugar, comparten el estatuto de la complejidad que rompe cualquier aproximación sustentada en causalidades simples e invalida 
cualquier aproximación en sede a problema-causa-remedio. En su lugar, se domicilian en la interrelación de todos sus componentes: sin vivienda no hay trabajo, sin trabajo no hay vivienda y sin trabajo ni vivienda no hay participación. Se realiza como multiproblema ya que a las dificultades económicas se le añaden las sociales, las étnicas y las culturales. La desorientación, que sentimos a pie de obra, es la interrelación de muchas desventajas juntas que se retroalimentan mutuamente: la renta, el paro, la baja cualificación, la vivienda inadecuada, la mala salud, la ruptura familiar, la insignificancia y la desafiliación.

En segundo lugar, la exclusión no está donde están los excluidos, sino que anda por otra parte, entre tramas y marañas; nos permite constatar la existencia de una población sobrante que no está donde quisiera estar; «nadie puede, a priori, ser considerado responsable de su exclusión; es un sufrimiento y una injusticia tal que ninguna de sus víctimas podría desearla para sí»' Debe, en consecuencia, distanciarse de cualquier consideración que la confunda con la culpabilidad de quien la sufre. Hay que afirmar inequívocamente esta dimensión porque hay muchos empeñados en culpabilizar la exclusión y convertirla en un acto de voluntad; con frecuencia se escucha que son personas que se lo merecen, que se lo han ganado, que están ahí porque quieren. Resultan radicalmente falsos los intentos de identificar exclusión y culpabilidad, como si cada uno estuviera allí donde ha elegido estar. No se les puede culpabilizar por la situación de no-trabajo que ellos no han elegido, como quiere el actual clima neoliberal. La paradoja de la inserción consiste en ocuparse de validos invalidados por la coyuntura. De este modo la exclusión se emparenta con la víctima y se hermana con la injusticia. Cuando se olvida este aspecto, se impone una aproximación administrativa a la exclusión que la convierte en un fenómeno totalmente natural, de este modo quedan acreditados para controlarla, manipularla y privarle del carácter de violencia. Queda de este modo a disposición de medidas legales y policiales. Son pocos los que relacionan el paro, la pobreza, la marginalización o la exclusión con la injusticia. Lo que es grave. «El sufrimiento sufrido por los excluidos es una desdicha que no provoca necesariamente una reacción política; a lo sumo puede suscitar compasión, piedad, caridad; ni siquiera convoca necesariamente a la indignación, a la cólera o a la protesta colectiva. El sufrimiento sólo suscita movimientos de solidaridad y de protesta cuando se asocie el sufrimiento del otro con la convicción de que este sufrimiento es injusto.» ${ }^{2}$

CEE. Dictamen sobre la pobreza del Comité Económico y Social, sesión 268 del 12 de junio 1989. en Diario oficial de las Comunidades Europeas, 28 agosto 1989.

2 DEJOURS, $\mathrm{CH}$. Souffrance en France. La banalisation de l'injustice sociale. Seuil, París, 1998, p.17-18. 
En tercer lugar, al remitir el problema de la exclusión fuera de sí mismo, no se quiere convertir en una variable del sistema, o un capítulo del destino social, como se pretende desde algunas cátedras e incluso púlpitos, sino que el mundo de la exclusión incorpora al sujeto con una extraña complicidad entre estructura y acción. La exclusión es, en la actual realización de la marginalidad, el punto final de unas posibilidades humanas, la expropiación del ser humano y la interrupción de sus relaciones interhumanas. Estamos ante un proceso que pone en cuestión al sujeto, pero no lo elimina. Es necesario pasar del trayecto al proyecto y afirmar que son ellos también los responsables de su propio fracaso o de su propio éxito, son ellos mismos los protagonistas de su propio aprendizaje. ${ }^{3}$ Interesa subrayar este aspecto para afrontar la actual geopolítica de la impotencia que se basa en anular las capacidades de las personas y sus acciones colectivas en función de unos poderes superiores que les convierten en meros satélites.

En la actualidad somos reos de la ilusión económica que ha invadido todos los rincones de la vida, y ha sometido la forma de amar y de desear, de esperar y desesperar a la dictadura del mercado. Esta prepotencia de lo económico genera la idea de que las víctimas no pueden hacer otra cosa que mostrar las contradicciones del sistema. Ni unos ni otros creen en la formación de actores sociales autónomos, capaces de ejercer una influencia sobre las decisiones políticas, sólo queda la impotencia o la llamada a la indiferencia. ${ }^{4}$

\section{LAS TRES RUPTURAS}

La experiencia contemporánea de la exclusión ha de ponerse en relación con tres auténticos seísmos, que originan circuitos excluyentes como ondas expansivas sobre el resto de la sociedad. ${ }^{5}$ Se trata de un virus mutante que combina en su interior diferentes elementos de muy distinto origen; alguno de carácter estructural o sistémico, otros de tipo relacional o contextual y los terceros que se domicilian en el sujeto, en su capacidad de amar y de esperar, de desear y de soñar. Existen, pues, tres constelaciones de la exclusión: el orillamiento de una organización, la desafiliación de unas relaciones sociales y la desmotivación personal. La exclusión es la radicalización de la pobreza; es la pobreza allí donde ésta se convierte en desgarro personal, en desafiliación co-

3 HERNÁNDEZ ARISTU, LÓPEZ, A.: Formación profesional dual: una intervención reflexiva. Nau Llibres. Valencia, 1998, p. 107.

4 TOURAINE, A.: Comment sortir du liberalisme? Fayard, París, 1999, p. 8-9.

s GARCÍA ROCA, J.: Contra la exclusión. Responsabilidad pública e iniciativa social. Santander, 1995. 
lectiva, en ruptura cultural.

\subsection{Organización excluyente y las fracturas sociales}

La condición de excluido está vinculada, en primera instancia, a la existencia de una organización que orilla y expulsa a personas y grupos. La exclusión se ha instalado en el corazón mismo de la sociedad hasta invertir su orientación inclusiva. ${ }^{6}$ Mientras el sueño de la inclusión era que el crecimiento económico y el bienestar social incorporaría cada vez a más sectores sociales como si viajaran en la misma dirección pero con distinta velocidad, la realidad de la exclusión puede compararse al viaje colectivo de un tren en el que los vagones que transportaban a los mas vulnerables fueron desenganchados.

La existencia de la exclusión expresa y se alimenta de los conflictos sociales, que son las grandes fracturas de carácter estructural, instaladas en la organización social. Cabe señalar aquellas fracturas que tienen mayor importancia en la configuración actual de la exclusión; en primer lugar, el conflicto capital-trabajo inicia una fase en que la productividad del capital crece sin trabajo y lo que es bueno para el capital no lo es para el trabajo (cada mañana se anuncian a la vez las ganancias para las empresas y las reducciones del personal), su población problema son los jóvenes que deambulan buscando un lugar en la sociedad, el parado de larga duración o el joven con una media de 38 meses para encontrar el primer empleo, los trabajadores poco cualificados y los jóvenes con poca experiencia profesional ${ }^{7}$. En segundo lugar, el conflicto Norte-Sur agranda la brecha entre países y cuya población problema es la emigración que llega a nuestras casas como una «pesadilla errante», como desesperación por un lado y de cerrazón por otro. Mientras Brahim, uno de los pocos sobrevivientes del naufragio de una patera el 16 de septiembre de 1998, en nombre de todas las pateras del mundo decía «nadie puede poner fronteras a nuestra hambre» ${ }^{8}$. El conflicto varon-mujer como expresión del dominio de la tribu, que tiene su población problema en la mujer violada y violentada,

6 FOUCAULD J.B. y PIVETEAU, D.: Une société en quête de sens, Odile Jacob, 1995, p. 144- 145.

7 En España el $40 \%$ de las jóvenes y el $36 \%$ de los jóvenes están desempleados, el $39 \%$ y el $30 \%$ en Italia y el $32 \%$ y el $22 \%$, respectivamente, en Francia.

s En este fin de inilenio, el $15 \%$ de la población mundial posee el $79 \%$ de la riqueza; la pobreza absoluta castiga a 1.300 millones de personas a vivir con menos de un dolar por día (lo que cuesta un pasaje de autobús). La fortuna de los tres hombres más ricos del planeta (Bill Gates, el sultán de Brunei y Waren E. Buffet) supera el Producto Interior Bruto (PIB) de los 48 países más pobres, o lo que es lo mismo, que sólo 225 personas acumulan los mismos bienes que 2.6000 millones de sus semejantes. 
en la prostitución forzada, así como la explotación laboral de las mujeres en condiciones de verdadera esclavitud. ${ }^{y}$ Finalmente se anuncia el conflicto entre capital financiero y producción que tiene su población problema en los pueblos declarados improductivos, en especial aquellos territorios como Africa subsahariana que no existen para la globalización económica, y los grupos «económicamente inútiles».

\subsection{Contextos inhabilitantes y la desvinculación}

¿Qué tienen en común las exclusiones actuales? Las exclusiones actuales, de cualquier índole, afectan a las relaciones, al modo de ser y estar en el mundo. Tienen sus vinculaciones sociales rotas y fragilizados los nexos relaciones. La exclusión alude, de este modo, a la presencia masiva y desafiante de la desafiliación, a la ruptura de los contextos y de las relaciones. Especial importancia tiene la fragilización de las redes sociales en todas sus modalidades: redes familiares, vecinales, amistosas que protegían al individuo y le concedían protección, seguridad y libertad. La existencia de unos contextos disgregados, fragmentados, atomizados inhabilitan para el ejercicio de las solidaridades de proximidad. Hay personas que se han visto descolgadas de sus redes naturales como mecanismos de protección general, y se convierten cada vez más en individuos sin apoyos. Es el grado máximo de desafiliación familiar y de ruptura de sus vínculos naturales y de sus redes sociales.

Nos encontramos ante redes que no dan protección " y cuya población problema son las jóvenes madres solteras, que tienen que asumir responsabilidades como madre, con sus necesidades de adolescentes y de cónyuge abandonado, que une al abandono el coraje de sacar sus hijos adelante. Redes que no dan seguridad, cuya población problema son aquellos barrios o zonas de vulnerabilidad, caracterizados por la desafiliación y la ruptura de los vínculos sociales. Redes que no dan libertad sino desanclaje de personas que deambulan como supernumerarios, sin territorio y sin pertenencia, o el nuevo fenómeno de los niños y niñas forzosamente desaparecidos.

\subsection{Subjetividad frágil e insignificancia personal}

¿Qué tienen en común todos los procesos de exclusión? Lo más

9 La participación de las mujeres en las instancias de toma de decisiones no rebasa el $4 \%$, de cada 100 analfabetos en el planeta 66 son mujeres.

(1) El múmero de hogares en España donde todos los miembros activos se encuentran en paro ascendía a finales de 1996 a 973.060, lo que equivale a un 11\% de todas las familias activas. El numero de familias desprotegidas que no cuenta con ningún preceptor de prestaciones por desempleo es 472.000 , equivalente al $5 \%$ del total de familias. 
visible de la exclusión es que causa la muerte, resulta mortal. Los excluidos de hoy, como los pobres de ayer y los indigentes de anteayer, son los que mueren antes de tiempo (casi 200 millones de personas no llegarán a vivir 60 años), los que dejaron de esperar (vivir es una pesada carga). La exclusión en esta tercera dimensión se hermana con la destrucción de los dinamismos vitales que en última instancia significa muerte en sus distintas manifestaciones: la muerte física, la muerte psíquica, la muerte legal y la muerte social. Muerte física, cuya población problema son los jóvenes que murieron prematuramente y a destiempo, en ciertos lugares no hay tiempo para elaborar el luto"; la muerte psíquica, cuya población problema son los afectados por las patologías de la subjetividad: la falta de confianza en sí mismo, la inseguridad e incapacidad de lucha, la crisis de identidad personal. Muerte legal, cuya población problema son aquellos colectivos que no han conquistado todavía su reconocimiento legal: los inmigrantes y los adolescentes con problemas con la justicia. Muerte social, que equivale a insignificancia, a no contar socialmente; ser excluido significa no contar para nada, no ser considerado útil a la sociedad, ser descartado de la participación y, sobre todo, sentirse insignificante.

\subsection{Conclusiones}

¿Qué consecuencias prácticas tiene el reconocimiento de esta triple dimensión de la exclusión? A la luz de las explicaciones anteriores, abordar la exclusión de los/as jóvenes significa atender a un tiempo propio, a un estatuto original y a unos procesos concretos.

La lucha contra la exclusión vive hoy el dilema de los tres relojes que Dahrendorf identificó en la reconstrucción de la sociedad possovietica: seis meses pueden ser suficientes para elaborar una reforma constitucional, seis años pueden no bastar para actuar una reforma económica, mientras que la formación y difusión de valores, comportamientos y estilos de vida de una sociedad civil moderna pueden necesitar generaciones enteras. ${ }^{12}$ La lucha contra la exclusión sólo tendrá éxito si acertamos con los tres relojes, si ninguno de ellos se atrasa y ninguna hora se menosprecia: el tiempo largo para revertir la organización a través de la lucha política y económica, el tiempo intermedio para crear nuevas redes sociales o amortiguar la ruptura del tejido social y el tiempo corto para las estrategias de acompañamiento que re-

1) No hay motivos para morir hoy por haber utilizado una jeringuilla de otra persona, pero miles y miles de jóvenes siguen muriendo; no hay motivo para que mi barrio tenga una media de vida de 40 años.

12 DAHRENDORF, R.: Reflections on the revolution in Europe. Clatto and Windus, London 1990 . 
hagan las identidades.

En segundo lugar, si ła exclusión nace y se reproduce en el interior de auténticas tramas estructurales, que no sólo crean la exclusión sino que agarrotan a los excluidos, remiten fuera del excluido la razón de su exclusión. Entenderla es perseguir sus tramas, su maraña, enfrentarse a la distribución del poder económico, político y social. No hay solución si no se mueve también la sociedad. Hay una mala representación de las estrategias contra la exclusión que las sitúan en el excluido. Invertimos en sus habilidades, en sus capacidades pero sin mover nada. En la lucha contra la exclusión no sólo se deben mover los excluidos sino todos, incluidos los sistemas educativos y las empresas.

Luchar contra la exclusión es entrar en el mundo de una realidad conflictiva y conflictuada. No se puede trabajar en la exclusión sin provocar conflictos. Sin una voluntad de soportar conflictos, perder amistades, despertar sospechas municipales, perder dinero, el trabajo por la marginación es fácilmente cooptado. Sólo los que puedan estar en el conflicto sin romperse, están llamados a esta apuesta. En la actualidad posmoderna y neoliberal pareciera que mencionar conflictos casi se ha convertido en cosa de mal gusto y poco estético.

\section{APELACIONES AL TERCER SECTOR}

La inserción debe afrontar una organización que orilla y expulsa, unos contextos desagregados e inhabilitantes y unos sujetos desmotivados y apáticos. Si la exclusión se instala en la estructura misma de lo social, desgarra los contextos de proximidad y golpea los dinamismos vitales debe atemperarse cualquier discurso que lo afronte de manera parcial; más bien se necesita golpear a la vez y simultáneamente en todos los frentes de la exclusión con estrategias transversales y movilizadoras de diferentes actores, recursos públicos y privados y administraciones centrales y locales. Sólo la integralidad permite albergar alguna esperanza en la lucha contra la exclusión, ya que las medidas parciales, fragmentadas e incoherentes la retroalimentan y la refuerzan. Actores políticos, económicos, sociales y culturales han de insertarse en una solución integrada; nadie por sí mismo puede ganar la batalla y todos por el contrario son necesarios.

¿Qué papel pueden desempeñar los nuevos actores sociales que se identifican como tercer sector? ¿Cuál es su aportación?

\subsection{El Tercer sector en el escenario del Estado}

Se necesitan medidas de índole política para remover una organiza- 
ción social, que se sostiene sobre una determinada distribución del poder político, económico y cultural. No resulta indiferente al tercer sector la orientación de las políticas generales; cualquier regresión en el nivel de protección aumenta el darwinismo contra los excluidos; cuando en mi barrio se ha cerrado un taller o se ha reducido un subsidio, ha aumentado el desgarro de los excluidos y nunca he podido confirmar que fuera bueno para ellos como proclaman los que les atribuyen el poder de pasivizarles o desmotivarles.

EI Tercer sector tiene en el escenario del Estado una agenda llena y bien repleta. No puede esconder su vocación política, en la medida que tiene voluntad de transformar las organizaciones excluyentes y desarrollar sus competencias en el ámbito político.

\subsubsection{Interlocutor de las políticas públicas}

Si el problema de la exclusión no está en los excluidos, apelar al Tercer sector significa activar tanto la capacidad de presión como de negociación, convertirse en interlocutor de las políticas públicas. En la esfera pública, el Tercer sector se propone representar los intereses de los excluidos, con ellos y desde ellos; en la actualidad, no parece que la población excluida encuentre sus canales de representación a través de los sindicatos, ya que están fuera del mundo laboral, ni tampoco tienen garantizado el acceso a los beneficios del Bienestar, ya que tienen rotos los canales de la información, que les dejan en la antesala del estado de bienestar.

Para ser interlocutor le falta articulación, coordinación y capacidad de crear lo común y le sobra desconfianza hacía el poder político. Para representar al mundo de los excluidos, el tercer sector tiene que convertirse en "partner" de las políticas públicas, con capacidad de crear sinergia con sindicatos, empresas, grupos comunitarios.

La urgencia mayor del Tercer sector ante la realidad de la exclusión consiste en convertirla en una cuestión de interés general, contra la opinión liberal que la reduce a un asunto privado del que la sufre. Construir una sociedad sin marginalidades es un bien común que debe socializarse. Lo cual tiene consecuencias importantes; el Tercer sector es un servicio público que rompeta separación entre lo estatal y lo privado; es el espacio público en el interior de la sociedad civil, una expresión de lo público, que se diferencia de lo estatal y de lo privado; interesa acentuar este aspecto en un momento en el que el Tercer sector se está potenciando como un capítulo de las privatizaciones, cuando realmente es una resistencia a las políticas privatizadoras. En consecuencia, pueden considerarse como un modo de redistribución de los presupuestos públicos, en lugar de alinearse con los que pretenden 
reducirlos. "Sus actividades deben organizarse como medio de redistribución, bajo la égida del estado o de los municipios". ${ }^{13}$

Asimismo, el Tercer sector amplía el ámbito tradicional de lo político, que se identificaba con los partidos y la gestión del poder; la transformación no sólo está servida por la política como gestión del poder sino también por lo pre-político que a veces lo disuelve y lo metapolítico que con frecuencia lo relativiza. Y, sobre todo, trae una nueva representación de las organizaciones públicas más cercana a los ciudadanos y con mayor capacidad de aprendizaje. Cuando los ciudadanos se "apoderen" del Estado, éste será vivido por los ciudadanos como un asunto propio. Por esta razón, el Tercer sector se considera un actor, que profundiza la democracia y la participación ciudadana, complementando a los sindicatos, a los partidos, a los movimientos sociales más tradicionales.

\subsubsection{Un nuevo contrato social}

En su último libro, Ulrich Beck se pregunta “¿Cuánta pobreza podrá soportar la democracia?" ¿Cuánta exclusión, nos preguntamos nosotros, podrá soportar una sociedad cohesionada? Beck sugiere la necesidad de un pacto social contra la exclusión ${ }^{14}$ que contemple algo parecido a un sistema de previsión social de carácter transnacional que incorpore garantías básicas, redes sociales de autoprevision y autoorganización, y un compromiso mayor con la justicia social y económica a escala mundial. No cabe duda que estos asuntos resultarán decisivos para la suerte de los excluidos: la garantía de las rentas mínimas, el reparto del trabajo, la distinción entre trabajo y protección, la consolidación de los sistemas de protección.

La tarea principal del Tercer sector consiste en promover un nuevo contrato social, que, además de estas medidas, reconozca el derecho de inserción como una deuda social, que ocupa una posición intermedia entre el derecho (es accesible a todos) y el contrato (vinculado a una contrapartida a través de su compromiso personal). No es un mero derecho como exigencia ni una ayuda social paternalista, sino que se abre a la implicación recíproca del individuo y de la sociedad a través de estrategias contractuales.

El tercer sector permite inaugurar una nueva concepción del derecho: no son créditos que se pueden exigir sino derechos-proyectos que requieren la implicación de todos los que intervienen. El estado actual de la exclusión requiere la emergencia de nuevos actores que conside- 
ren a los individuos como miembros de una sociedad en la cual han de tener un puesto. El contrato de inserción vincula al excluido a su participación en un proyecto. La lucha contra la exclusión invita a explorar un tercer tipo de derechos que articulan ayuda económica, participación social e implicación personal. Este compromiso personal va desde la formación hasta la participación en actividades de interés general, desde los esfuerzos personales de rehabilitación hasta la promoción de organizaciones sociales. Es un derecho bastante paradójico puesto que está basado en una especie de derecho individualizado y a la vez condicionado. ${ }^{15}$ La condicionalidad, cuando se trata de ofrecer oportunidades de inserción, se practica con frecuencia como una penalidad y un castigo -se te ofrece una ayuda económica a condición de que cumplas unos deberes o te empeñes en unos compromisos-cuando realmente es la emergencia de un nuevo derecho.

\subsubsection{Politicas culturales}

A los actores sociales corresponde revertir las actuales puertas de entrada a una sociedad excluyente: la seguridad económica como salario de por vida, la participación como consumo de mercancías, la protección como competencia exclusiva del Estado y la identidad personal como individualismo posesivo y competitivo. Se precisan actores culturales, que sean capaces de desarmar a los integrados, de proponerles alternativas contagiosas a sus modos de vivir y de acaparar; al final la historia será la batalla sobre la felicidad: quién ofrece más felicidad, quién enseña a competir y en consecuencia a excluir, o quién vive solidariamente. Es una cuestión que afecta a la persona y cuando se trata de "transformación de personas no se puede controlar causal y técnicamente por medio del derecho y el dinero". ${ }^{16}$

El Tercer sector es también una realidad cultural, capaz de remover los factores de inclusión: el trabajo, como única entrada a la renta económica, a la identidad social, a las expectativas sociales, el consumo como marca de prestigio y posición social que consiente que 250 personas dispongan de lo mismo que la mitad de la población mundial, la protección que se delega al Estado con olvido de las instituciones intermedias, y la identidad personal construida desde la autoafirmación excluyente en lugar de la cooperación. 


\subsection{El Tercer sector en el escenario económico}

Al suscitar, sostener y animar iniciativas socio-económicas, el Tercer sector se convierte en un ámbito necesario para las estrategias de inserción. Se trata de colocar la utilidad social en el centro de lo económico. Lo cual tiene consecuencias importantes sobre ciertos jóvenes que están condenados a la inactividad y a deambular desorientados por las periferias del bienestar.

La actividad económica del Tercer sector contribuye decididamente a la integración social en la medida que en el origen de la exclusión está el desempleo que obstruye la puerta de entrada a los beneficios sociales (renta económica, posición social, protección...), el aislamiento que rompe los vínculos sociales y la crisis de sentido con la consiguiente inadaptación y anomia.

¿Qué papel desempeña la economía social para las medidas de inserción? ¿De qué forma contribuye a combatir la desocupación, romper el aislamiento y combatir la inadaptación?

\subsubsection{Nuevas formas laborales}

La relación con el trabajo constituye un elemento sustantivo en el origen de la exclusión, ya que en muchos casos empieza siendo un problema laboral y en la medida que el trabajo es la puerta de entrada a la organización social, se convierte en un problema de insignificancia social y crisis de identidad personal.

Si el trabajo se identifica únicamente con su forma salarial se estrecha la puerta de entrada a la integración y se dificulta la situación de los desempleados cuando se identifica estar integrado con ser asalariado. El surgimiento de la sociedad salarial ha impulsado una seria reducción de las modalidades del trabajo, de forma que tener trabajo ha acabado significando tener un salario, un contrato de por vida, vacaciones inteligentes y una organización de la que depende su seguridad. ${ }^{17}$

La aportación más significativa del Tercer sector a las medidas de inserción consiste en ampliar las formas de trabajo y las modalidades de la ocupación más allá de la forma salarial; el tercer sector reintroduce la problemática de las formas de trabajo y amplia el concepto mismo de ocupación a través de otras formas como el trabajo colectivo, la actividad ocupacional, los servicios de autoayuda, la producción no monetarizada... El trabajo no se crea sólo mediante la salarización y la

17 CASTEL, R.: Les métamorphoses de la question sociale. Une chronique du salariat. Fayard, París, 1995 
mercantilización, este prejuicio será una fuente constante de marginalidad.

La economía de mercado y la sociedad salarial no bastan para asegurar la ocupación, conviene complementarla con otras actividades que obedecen a otras reglas para satisfacer necesidades colectivas. El último informe al Club de Roma sobre el dilema del empleo trata de superar este equívoco que ha tenido graves consecuencias para las políticas de integración. La mentalidad de la revolución industrial ha tenido graves consecuencias al no valorar en términos económicos las aportaciones no monetarizadas ni las contribuciones no remuneradas. Hoy asistimos a la necesidad de revalorizar las actividades productivas no remuneradas por distintas razones; en primer lugar, por razones estrictamente económicas, ya que el valor económico no puede ligarse solamente al trabajo y a las actividades productivas medidas con un criterio monetario, sino también a los servicios que son intrínsecos al sistema de producción: el estado de salud, la autoestima, la confianza... En segundo lugar, por razones sociales "sólo cuando empecemos a valorar por igual las aportaciones no remuneradas y las remuneradas podemos reconocer plenamente la participación del trabajo de la mujer y su papel en nuestra economía". Y en tercer lugar por razones políticas; los elevados costes de los servicios pro-bienestar diseñados exclusivamente desde los gastos institucionales hacen cada vez menos viable el sistema de bienestar. Se necesita incorporar el sistema no monetarizado para salvarnos de la ineficacia del sistema monetarizado; de este modo resulta productivo la incorporación de la atención domiciliaria a los tratamientos hospitalarios, o la movilización de los abuelos y las abuelas para realizar los cuidados de los pequeños. ${ }^{18}$

\subsubsection{Nuevas vinculaciones sociales}

El Tercer sector se propone inscribir la solidaridad en el corazón de la economía; la actividad económica puede y debe ejercerse en función de finalidades sociales y mejora de las condiciones de vida. Hay grupos que se organizan como economía solidaria porque entienden que el mundo económico no puede abandonarse a las leyes de las ganancias y del beneficio privado, ni tampoco estamos condenados a corregir los efectos perversos mediante los mecanismos de protección activados por el Estado de bienestar sino que intentan incidir en la lógica misma de lo económico. Ni las empresas tiene el monopolio en la creación de empleo ni el Estado tiene el monopolio del interés público. ${ }^{19}$

1s GIARINI, LIEDTKE: El dilema del empleo. El futuro del trabajo. Galaxia Gutem. Barcelona, 1998 , pp. 134 y 161.

19) LAVILLE, J.L. L'Économie solidaire. Desclée de Brouwer, París, 1998, p.141. 
La economía ha sido uno de los elementos básicos en la creación del individualismo posesivo en cuanto que ha consagrado la competitividad y el beneficio individual. La economía solidaria se basa sobre la confianza personal en lugar de los intereses, sobre la colaboración en lugar de la competencia. Sin renunciar a la lógica económica, combina eficiencia y contribución a la integración, profesionales y voluntarios, principios económicos y principios sociales de cuyas sinergias mutuas recibe su acreditación.

En lugar de una economía exclusivamente selectiva que refuerza la diferencia entre privilegiados y excluidos, el tercer sector apuesta por una economía social que, a pequeña escala, inaugure otra lógica del intercambio.

\subsubsection{Integración autoregulada}

En la exclusión quedan afectados los dinamismos vitales que frecuentemente se traducen en procesos de inadaptación social y en síntomas de desestructuración personal. Aunque no es bueno ni razonable identificar las actividades económicas de utilidad social con la intervención en las personas excluidas, es evidente que resulta un laboratorio para la reconstrucción de la identidad personal y de la autoestima.

Frente a la esfera heterónoma, que representa el mercado tradicional y la esfera económica tradicional, el tercer sector ensaya la autoimplicación como una forma apropiada para dinamizar los procesos de inserción. Los excluidos pasan de objetos de atención a sujetos y protagonistas de su propio destino; pasan de socios a ciudadanos activos. De este modo se afianza su autoestima y se recrean sus dinamismos vitales, siempre que se puedan establecer otros fines y criterios no medibles únicamente en términos económicos ni a través de la lógica monetaria. Pasar de la heteronomía a la autoregulación está en el centro de todo proceso insertivo.

La ventaja comparativa del Tercer sector está en combinar el trabajo profesional con la intervención familiar, hermanar asalariados con voluntarios, pero sobre todo poner en manos de los excluidos la decisión acerca de sus propios destinos.

\subsection{El Tercer sector en el escenario de los mundos vitales}

Los proyectos de inserción incorporan un momento, que afecta a la resocialización, a la reconstrucción de la identidad y a los dinamismos vitales. ¿Qué puede aportar el Tercer sector a la reconstrucción de la identidad personal y relacional? 


\subsubsection{Creación de vínculos sociales}

Las estrategias más acreditadas en el campo de la exclusión son las prácticas reticulares, que se enfrentan a la desafiliación y a la ruptura de las redes sociales. La lucha contra la exclusión se impone como tarea activar entornos, reconstruir el medio ambiente interhumano, recrear las redes de dependencia afectivas y el entorno comunicativo.

Para reconstruir las redes sociales, el Tercer sector aporta la gestión de la inclusión desde lo local, desde las potencialidades locales y desde el desarrollo de actividades autogestionadas; sólo la movilización de los recursos locales para tratar «in situ» un problema de exclusión, resulta pertinente. Y, en segundo lugar, sugiere la reconstrucción de los enclaves afectivos y simbólicos para la resocialización y recreación de las motivaciones; para ello son esenciales los recursos educativos y culturales, y la creación de espacios de sociabilidad que hagan soportable la cotidianeidad, ayuden a abrirse a la singularidad y refuercen la autoestima, ya que no siempre el tipo de trabajo contribuye a la autoestima. ${ }^{20}$

Las organizaciones del Tercer sector son instituciones de mediación que facilitan también las pasarelas para activar los factores de inserción, y superar el aislamiento social y la guetización de los excluidos.

\subsubsection{Acompañamiento}

El territorio del asociacionismo es un espacio inmantado por el encuentro de personas y la comunicación entre ellas. Los procesos de inserción que potencian el Tercer sector en los mundos vitales se sostienen sobre la reconstrucción de los valores desde la proximidad en el interior de los problemas cotidianos: el excluido, como cualquier ser vivo, necesita de oxígeno, agua, alimento; pero como ser humano necesita de reconocimiento, que es un derecho y un deber de la vida cotidiana. Y, finalmente, alude al uso delicado de la fuerza en el interior del conflicto social; no sitúa más allá del conflicto, ya que éste es parte de la realidad, sino que obliga a estar atentos a que no rompa al excluido. Los excluidos piden instituciones «tiernas» frente a instituciones desgarradoras, frías, distantes.

En los procesos de inserción es necesario activar una ecología del espíritu, que promueva procesos de identidad personal y colectiva en el interior de la trama de significaciones. Sobre todo los jóvenes precisan de esferas personales interesadas por la afirmación de la identidad 
personal en el interior de una comunidad humana. Necesitan una identidad abierta, que se deja asaltar por el grito de los últimos y de los que están peor situados, aunque sea una identidad fracturada por la diferencia y tensionada por la desigualdad.

\subsubsection{Relación de ayuda}

El Tercer sector no puede ser el remedio a los desgarros de la exclusión, en sus manos sólo está promover medidas y acompañar personas que permita hacerse cargo de sí mismo, apoderarse de sus propias competencias.

No tiene el poder de construir una alternativa al mercado total, pero tiene la fuerza para rechazar su lógica y racionalidad cuando impregna a toda la sociedad. En el campo de la exclusión, la solidaridad es más promoción de proyectos que oposición política.

Un gran número de jóvenes se encuentran arrastrados por relaciones que no son capaces de entender, dominar o ignorar por sus propios medios o capacidades. Los excluidos no están en muchos casos en condiciones para ayudarse a sí mismos, necesitan ser ayudados. ¿Qué relación de ayuda resulta necesaria y positiva? Las personas y grupos excluidos han creado un nuevo concepto de ayuda que es inseparable de la participación, función tutorial y relaciones afectivas.

La ayuda acreditada es inseparable de la participación. Las prácticas de inserción no son ni un subsidio asistencial ni una prestación de Seguridad Social. Hay un compromiso recíproco del individuo y de la colectividad, teniendo en cuenta las necesidades, aspiraciones y posibilidades de los beneficiarios. Capacita a los excluidos para su propia autoorientación y autoregulación, y crea en ellos la capacidad y la actitud activa hacia la toma de decisiones sobre su propio futuro.

La relación de ayuda en el ámbito de la exclusión es inseparable de la función tutorial, que entraña una relación individualizada con la persona excluida, con sus actitudes, aptitudes, conocimientos e intereses. La acción tutorial debe atender a las peculiares características de cada persona excluida. Implica de manera coordinada a las distintas personas e instituciones educativas, sanitarias, culturales y laborales. Cuando se tienen en cuenta las necesidades, aspiraciones y posibilidades del individuo, se inaugura una nueva relación de ayuda individualizada, casi tutorial. Ya no es posible una gestión homogénea, burocrática ni tecnocrática que nos enmarca a los excluidos en categorías juridicoadministrativas. Se trata de un itinerario adaptado a las necesidades de la persona que depende de la situación de cada uno. Es un itinerario individualizado ya que no existe la exclusión sino los excluidos. Lo cual exige un cambio de residencia mental que afecta no sólo a la orien- 
tación general de las políticas sociales sino a la propia intervención y al estilo mismo de la acción social. El compromiso del Tercer sector consiste en entrar en el mundo de la exclusión por la puerta de la amistad; lo cual trae consigo algo importante, la amistad. No hay auténtica relación de ayuda en el ámbito de la exclusión si no está unida a la amistad. Sólo la amistad introduce en la constelación de la exclusión que no sólo invoca los mecanismos económicos y abstractos sino la celebración de la dignidad que requiere actividades basadas en el don y en la reciprocidad. ${ }^{21}$ 


\title{
EMPRESA DE INSERCION
}

\author{
CARLOS ARIAS
}

Centro Especial de Empleo LIMENCOP, S.L. Alicante.

\section{INTRODUCCIÓN}

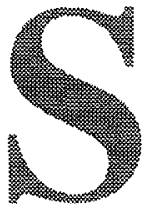

omos un centro especial de empleo, es decir, una empresa que está obligada a que al menos el $70 \%$ de sus trabajadores sean discapacitados psíquicos, físicos o sensoriales. En la actualidad somos 30 trabajadores, de los cuales cuatro somos discapacitados físicos, dos sensoriales y veintiuno psíquicos.

Nuestra estructura es la de una empresa de servicios con una administración y gestión centralizada y con cuatro secciones diferentes:

- Limpieza industrial.

- Encuadernación artesanal.

- Reprografía.

- Cocina industrial.

Nuestra empresa presta sus servicios de limpieza industrial a la Universidad de Alicante y a comunidades de vecinos. En la actualidad nos encargamos de la limpieza de tres edificios del campus de San Vicente y de tres comunidades de vecinos. El taller de encuadernación también está ubicado en el campus de San Vicente y presta sus servicios tanto a la Universidad como a otros clientes que nos los solicitan. La sección de reprografía presta sus servicios a la Universidad Miguel Hernández y lo hace desde sus instalaciones en el campus ilicitano. La cocina industrial está ubicada y presta sus servicios en el centro ocupacional Terramar. Por último, el departamento de administración tiene sus oficinas en Alicante.

La Escuela de Trabajo Social se encuentra en el mismo inmueble que el taller de encuadernación y es uno de los edificios que tenemos asignado en la limpieza. Llevamos dos años compartiendo el mismo espacio. Después de este tiempo de convivencia, nos invitan a contar nuestra experiencia en su revista. Aceptamos porque nuestra experiencia es importante para todos nosotros (para muchos es nuestro primer trabajo) y creemos que también lo puede ser para la Escuela, que tiene en nosotros un ejemplo práctico de lo que es un fin para los presentes y futuros trabajadores sociales: la integración. 


\section{NUESTRA HISTORIA}

Somos conscientes de que no utilizamos la pluma con la misma soltura que el plumero, pero, como la experiencia es un grado, vamos a desempolvar una historia, la nuestra. Esta vez queremos ser protagonistas, por eso el centro del relato será nuestra propia historia. Habrá también opiniones y reflexiones, tanto sobre el aspecto económico como sobre el aspecto social. De hecho, es la integración de estos dos elementos entre sí lo que consideraremos propiamente el fundamento de la integración y no otras acciones o campañas tácticas o puntuales, por muy buenas que nos parezcan.

\subsection{Los principios}

Al igual que los dos primeros años de vida son fundamentales para el desarrollo posterior, y que personas e instituciones bucean en sus orígenes para entender mejor su presente y encauzar su futuro, echaremos una mirada sobre nuestros comienzos concediéndoles mucha importancia. Valoraremos los principios tanto desde el punto de vista cronológico -de comienzo- como desde el punto de vista estructural -de fundamento-.

Nuestro principio y principal fundamento es la Asociación ProDeficientes Psíquicos de Alicante (APSA). APSA es una asociación de padres y familiares de deficientes psíquicos que se unieron en 1961 para encontrar soluciones a los distintos problemas con los que se encontraban sus hijos y ante la falta de respuestas desde los poderes públicos a esos problemas.

Hace ya más de veinte años que APSA inició las primeras acciones en orden a la integración socio-laboral:

- En 1984 convocó el primer Simposio Internacional para la Integracion Socio-laboral de los Deficientes Psíquicos, con lo que se ofreció un foro para el debate de técnicos y expertos, nacionales y del resto de Europa. También estaban personas de la Administración que podían influir en un cambio en la legislación, sin el cual todo quedaría en teorías irrealizables.

- En 1987 promocionó una sociedad mercantil, Terramar S.A., que puso en marcha el primer centro especial de empleo.

- En 1990 promocionó una segunda sociedad mercantil, Avimar S.L., que puso en funcionamiento el segundo centro especial de empleo.

Todas estas acciones de APSA en orden a la integración socio-laboral supusieron un cambio en la mentalidad y en la forma de trabajar: 
en la mentalidad, porque se reconocen en la persona con discapacidad psíquica aptitudes para el empleo; y en cuanto a la forma de trabajar, porque el desarrollo de estas aptitudes para el empleo pasa a ser una parte importante de la formación.

El mercado laboral se convierte, al igual que en la mayoría de los procesos de formación, en el horizonte que configura los distintos planos o etapas que debemos atravesar. Lo cual supone para nuestro colectivo un más amplio futuro -hasta ahora ciertamente estrecho-, al tiempo que un reto para los profesionales que trabajan en el sector, de los que en parte depende el desarrollo de las posibilidades que se abren delante de nosotros.

En una de esas acciones para el desarrollo socio-laboral, APSA firmó en 1995 un convenio marco de colaboración con la Universidad de Alicante. De este convenio marco partió una iniciativa de formación, dentro de la Universidad, para discapacitados psíquicos, que contaba con el apoyo de la Diputación Provincial de Alicante.

Esta iniciativa pretendía formar para el empleo a un grupo de personas con discapacidad psíquica. El convenio contemplaba que, en el caso de lograr el objetivo de esta formación, se generaría empleo en la propia Universidad. APSA crearía una nueva sociedad mercantil y la Universidad ofrecería el trabajo.

Este convenio no fue fruto de la casualidad, sino de la intencionalidad integradora y de la experiencia de APSA, para la cual el desarrollo integral de las personas con discapacidad psíquica es su razón de ser. Sin este interés, en el sentido más amplio de la palabra, es muy difícil acometer una tarea de esta complejidad.

Pero una iniciativa de este tipo no se puede desarrollar plenamente si no se incide también en el ámbito económico. Plantear una acción de esta índole, si no está considerado en su justa medida el plano económico, como en la creación de cualquier otra sociedad mercantil, es, probablemente, plantear un fracaso. Y cuando se habla del factor económico se habla, en primer lugar, de viabilidad y financiación y, en segundo lugar, de creación de riqueza y rentabilidad. Pero estos términos no tienen que ser entendidos, como tantas otras veces, en contra del factor humano ni en contra de un sector más desfavorecido, sino más bien todo lo contrario: estamos hablando de una actividad puramente humana (la económica) y de la apertura y desarrollo de posibilidades para una población vulnerable, castigada por los fracasos, un colectivo necesitado de confianza.

Tan necesaria es la confianza en nosotros mismos como que los demás confíen en nosotros. Que se nos dé, al menos, esa primera oportunidad en la que podamos demostrar nuestras posibilidades. Plantear 
esa confianza en el ámbito de lo personal, cuando estamos hablando de un colectivo integrado fundamentalmente por deficientes psíquicos, sería probablemente plantear otro fracaso y esta vez en doble sentido: para nosotros mismos y para aquellas personas que habían depositado su confianza en nosotros.

Por eso, para hablar de confianza, al contrario que tantas otras veces, tendremos que hablar de empresa, de organización empresarial. Será la empresa la que coordine, respalde, garantice y ordene los distintos aspectos que nos encontremos, ya sean de carácter económico, financiero, tecnológico, de recursos humanos...

Buscar -o mejor, encontrar-como partner a la Universidad ha sido un acierto. Por un lado, en ella nos encontramos con una institución que es, en general, culturalmente abierta y socialmente sensible, sobre todo si se trata de un proyecto de formación para el empleo, ya que la formación es una de sus tareas fundamentales y el empleo una de sus permanentes preocupaciones. Por otro lado, una institución como la Universidad genera por sí misma una gran actividad económica. Esta actividad económica la convierte en un cliente potencial y su especial sensibilidad, en un cliente ideal.

Así es como en los comienzos nos encontramos con un conjunto de elementos que, en principio, eran positivos. El buen término de esta incipiente empresa dependía del desarrollo de todas esas potencialidades. A partir de este momento comienza nuestra tarea. En la exposición de la misma vamos a hablar de la formación, de nuestros clientes, del desarrollo de la organización empresarial, de los aspectos tecnológicos, de los recursos humanos, del control de calidad...

\subsection{Periodo formativo}

Con la firma del convenio entre APSA -que aportaba el personal y el apoyo técnico-, la Universidad - que cedía su espacio, aportaba maquinaria y tutelaba el proyecto- y la Diputación -que lo financiaba-, se inició nuestro periodo formativo. El proyecto lo coordinaba una psicóloga de APSA y estábamos divididos en dos grupos de cinco personas cada uno: cuatro personas en formación y un formador por cada grupo. La finalidad de uno de los grupos era la formación para la limpieza industrial y la del otro la formación para la encuadernación artesanal.

En este tiempo, las personas en formación estaban integradas en el centro ocupacional de APSA y simultaneaban la formación en el centro ocupacional y en la Universidad. Los que estaban en formación en este tiempo dependían del centro ocupacional, aspecto que tenía su importancia. Por una parte, suponía una seguridad adicional y ausen- 
cia de rupturas en un momento prematuro, y por otra, la formación laboral pasaba a ser algo externo, más directamente evaluable.

El grupo de encuadernación se instaló en las dependencias de la Biblioteca de Letras de la Universidad. Con los libros que aportaba la Universidad los alumnos fueron desarrollando todas sus habilidades de cara a la posible creación de una empresa. Aunque es verdad que al comienzo de la formación esto no era nada más que un horizonte, era el eje fundamental sobre el que giraban todos los esfuerzos. El aprendizaje, desarrollo y dominio de las técnicas de encuadernación artesanal, así como la generación y el desarrollo de las aptitudes básicas para el trabajo fueron el pivote básico de un trabajo de año y medio. El grupo de limpieza comenzó en el edificio de la Escuela de Óptica con el mismo enfoque que el grupo de encuadernación, pero con distinta misión y con distintas herramientas.

Los hilos conductores del proyecto los podríamos resumir en tres:

1. El técnico, cómo desarrollar y dominar la técnica concreta del trabajo específico.

2. El humano, ordenar el conjunto de comportamientos hábitos y relaciones de los trabajadores.

3. El externo, conocimiento y adecuación al medio en el que nos desenvolvíamos.

El conocimiento y desarrollo de la técnica concreta del trabajo ocupaba prácticamente la totalidad de las jornadas. Procesos de aprendizaje y repetición hasta conseguir el dominio de la técnica. La adaptación del conjunto de comportamientos, hábitos y relaciones al mundo laboral es otra de las tareas esenciales, sin la cual todo lo anterior es más que susceptible de convertirse en una tarea irrealizable. El apoyo familiar resultó de vital importancia para la consecución de este objetivo. El conocimiento del medio en el que nos movíamos y la adaptación al mismo era otra parte de la tarea formativa. La Universidad era un nuevo mundo que nosotros queríamos conquistar.

Es cierto que nos embarcamos hacía ese nuevo mundo a causa de nuestra discapacidad, pero si queríamos conquistarlo sería a base de nuestras múltiples capacidades, nuestros empeños e ilusiones. Nuestra ruta, en este tiempo, tenía como norte la exigencia y como puntos fuertes el trabajo, la responsabilidad y la autonomía. No era un juego. En este tiempo éramos ya una empresa. Queríamos "conquistar" la Universidad y la conquistamos, pero no por la discapacidad o por caridad mal entendida. Habíamos hecho un buen trabajo, nos habíamos ganado la contratación. Con nuestro propio esfuerzo y el apoyo ajeno lo habíamos conseguido. 
Para nosotros ésta fue la historia, pero también se podría contar la otra historia, la de las personas que nos vieron llegar, la de las que nos fuimos encontrando en este trayecto, la de las personas que dudaron de nosotros, la de las que creyeron en nosotros, la de las que nos contrataron... Mirando atrás, esperamos que nuestro periodo formativo haya sido también formativo para otros, para los que quieren crecer aceptando las diferencias, para los que creen en la igualdad de oportunidades..., para muchos, para todos.

\subsection{Creación de la empresa}

Una vez acabado el periodo formativo, como la Universidad pensaba que éramos aptos para la tarea en la que nos habíamos formado, APSA creó una nueva sociedad mercantil desde la cual prestaríamos nuestros servicios de encuadernación y limpieza (acordados previamente mediante un nuevo convenio).

Estando en los preparativos de la nueva empresa, nace la Universidad de Elche, que nos ofrece la posibilidad de prestar el servicio de reprografía. El ofrecimiento es aceptado y la nueva empresa, que estaba aún por nacer, sufre sus primeros cambios y pasa a ser una empresa de servicios con tres secciones: limpieza industrial, encuadernación artesanal y reprografía. La sociedad mercantil nace como un centro especial de empleo y con el nombre de LIMENCOP, S.L. (limpieza, encuadernación y copistería).

Antes de empezar ya se estaban tomando decisiones que iban a decidir, o al menos condicionar en gran medida, el futuro de la empresa. En este caso la decisión viene tomada para dar mejor servicio, dada la ampliación del mercado, y con la intención de optimizar nuestros recursos, todavía escasos. A partir de este momento las decisiones son de carácter empresarial. Nuestro tiempo de formación ya se ha acabado, ahora empieza nuestra historia como empresa.

Aunque todas las secciones de nuestra empresa comparten raíz y tronco, nos pararemos de manera particular por cada una de ellas.

\subsection{Limpieza industrial}

En virtud del nuevo convenio firmado entre la Universidad y APSA, nuestra sección de limpieza se haría cargo de dos nuevos edificios ubicados dentro de la Universidad. Un día antes de entrar en vigor el nuevo convenio, una riada inhabilitó uno de los dos edificios que teníamos asignados. En menos de un mes, por unas obras inesperadas, hubo traslado general en el otro. Hablábamos de normalización y la tuvimos, de una manera imprevista, pero natural. Tuvimos que comenzar buscando 
y negociando salidas para dar respuesta a una situación que no era querida por nadie.

Si se trataba de una empresa, no podíamos pretender que todo estuviera garantizado por adelantado. Es verdad que éramos un centro especial de empleo y que, por serlo, se nos ayudaba y hasta se nos protegía; pero también empezábamos a ser una empresa que estaba en el mercado y que muchas circunstancias, sobre todo las imprevistas, nos afectaban. Pretender otra cosa, por muy especial que fuera el empleo, sería vivir fuera de la realidad, cosa que no deseábamos, pues de hecho éramos de los pocos centros especiales de empleo que vivíamos inmersos en una realidad especialmente rica y dinámica, como es la de la Universidad. Queremos vivir dentro de esa realidad, que es también parte de nuestra riqueza y dinamismo.

$\mathrm{Si}$ algunas circunstancias fuesen personalmente infranqueables, teníamos una empresa que se encargaría de dar las soluciones oportunas. Si además de objetivos de empresa hablamos, al mismo tiempo y de manera integrada, de objetivos sociales de inserción, estamos hablando de nuestra razón de ser.

Otras de las primeras decisiones no dependieron tanto de las circunstancias como de nosotros mismos, pero también llevaban el camino de la integración. No podemos querer inserción y pedir constantemente excepciones, no debemos pretender dar servicio a través de nuestra empresa y resultar un estorbo y no queremos subrayar constantemente lo que nos diferencia, sino, por el contrario, lo que nos hace iguales. Cuestiones como el horario y los transportes fueron resueltos con la más absoluta normalidad. Nuestra única diferencia, la referida al horario (entramos a las siete en lugar de las seis), es debida a la falta de transporte público a una hora más temprana.

Este segundo comienzo, esta vez como empresa, ha estado cargado de elecciones que probablemente han ido marcando un rumbo y descartando otros muchos posibles. Unas veces obligados por las circunstancias, otras de una manera libre y decidida, hemos sido, en gran parte, como una empresa "normal". Estas primeras decisiones tuvieron también sus consecuencias positivas: tras quedarnos sin los edificios asignados, nos fuimos a uno recién estrenado y realmente adecuado para nosotros, el de Ciencias Sociales. Como nuestros servicios agradaron, logramos que se añadiese en el convenio. Fue nuestro primer logro. Conseguimos una ampliación gracias a la calidad de nuestro trabajo.

Pero afortunadamente no eran todo decisiones imprevistas y dificultades. Había en el apartado de limpieza una continuidad con el recorrido anterior. Al final de la etapa de formación habíamos ido aumentando el tiempo de trabajo y las responsabilidades para que el salto 
del tiempo de formación al del trabajo no fuese excesivamente grande.

En el periodo formativo éramos un total de cinco personas, incluyendo al formador. En la sección de limpieza empezamos cuatro trabajadores más un encargado. Tres de los trabajadores éramos los mismos que acabamos la formación, el cuarto sustituía a un compañero al que una grave enfermedad le impidió, a pesar de su gran esfuerzo, continuar en el proyecto. El trabajo era parecido al de la anterior etapa, si bien aumentaba nuestra responsabilidad. El encargado coordinaba la sección, se encargaba de aquellas tareas que por algún motivo no podíamos asumir el resto y garantizaba a la Universidad el buen funcionamiento del servicio de limpieza.

Desde entonces, la sección no ha dejado de crecer. En estos casi dos años el número de metros cuadrados que limpiamos en la Universidad se ha duplicado y hemos asumido el servicio de limpieza de tres comunidades de vecinos que nos lo han solicitado. Para nosotros es motivo de satisfacción el hecho de que hayan requerido nuestros servicios. Es una buena manera de reconocer de verdad nuestro trabajo, por no decir la mejor.

En esta sección, desde el principio hasta ahora, ha habido un grupo de compañeros en formación, que están acompañados por un formador. Es nuestro principal vivero y gracias a ellos nos podemos seguir planteando nuevos retos.

El crecimiento del número de empleos es uno de nuestros objetivos como empresa, pero también lo es la calidad del empleo. Al tratarse de una empresa de limpieza, en la que mucha parte del trabajo es manual o puede hacerse manualmente, podíamos caer en la tentación de pensar que la maquinaria nos podría alejar de nuestro objetivo. Pero en realidad lo que nosotros queremos es que aumente la calidad de los servicios que ofrecemos y que, al mismo tiempo, aumente la calidad de nuestros puestos de trabajo. Para conseguir este objetivo es fundamental disponer e integrar en nuestra empresa la tecnología más avanzada. El aumento cuantitativo y cualitativo del empleo son dos aspectos que con frecuencia entran en tensión, una tensión, por otra parte, necesaria para conseguir el equilibro.

Si queremos ser y crecer como empresa, la calidad tiene que convertirse en nuestra única tarjeta de visita. Referencias a nuestra discapacidad, a nuestro ser distintos, tienen que tender a desaparecer. Decíamos en "los principios" que necesitábamos que se nos diera una oportunidad; ahora se nos contrata por nuestra calidad, se nos renueva por nuestra calidad y se amplían nuestros cometidos por nuestra calidad.

La desconfianza, la no valoración y hasta el rechazo forman parte 
de la realidad. Aceptarlo sumisamente como algo dado o perder el tiempo quejándonos de la maldad y cerrazón ajenas supondría quedarnos donde estábamos. Afrontar esta mentalidad ajena y conseguir, mediante nuestro trabajo, algún cambio, quizás sea lograr un dinamismo distinto, del cual seríamos los auténticos protagonistas. Con estas actitudes plantearíamos las cosas de otra manera y pasaríamos, probablemente por primera vez, de ser los eternos pacientes sociales a ser los auténticos agentes sociales. Agentes y no pacientes de nuestros logros, de nuestra propia historia.

Entre barrido y fregado algunos de los temas por los que nos hemos paseado han quedado sin una mota de polvo, otros siguen abiertos y no deseamos cerrarlos. Quizás esta lectura llegue a ser interactiva.

\subsection{Encuadernación artesanal}

Si los comienzos de la sección de limpieza tuvieron su complicación, los de encuadernación fueron especialmente delicados. En la primera semana nos quedamos sin nuestro espacio, debido a una inesperada renovación del edificio en el que nos encontrábamos ubicados. Otra de las dificultades con las que partíamos en encuadernación es que, al contrario que en limpieza, comenzábamos sin tener la venta de nuestra producción asegurada. La Universidad, por el convenio, se convertía en nuestro principal cliente y nos facilitaba el espacio. Nosotros tendríamos que conseguir el resto de los clientes.

El tener garantizada por adelantado la venta de la producción es un punto fundamental en cualquier empresa. Hace unos años el tema central de la economía de la empresa era la producción y la pregunta clave era cómo producir más al menor coste posible. La comercialización y venta de los productos era una consecuencia. Ahora la preferencia la tiene el mercado; las primeras preguntas se las tenemos que hacer al mercado. El qué, el cuándo, el cuánto y el cómo es lo primordial en la vida empresarial. Sólo después aparece si nosotros podremos satisfacer las necesidades del mercado y, en último término, cómo hacerlo de la mejor manera posible. Hace 25 años entrábamos en una grave crisis económica por el encarecimiento de la energía, que redundó en el encarecimiento de la producción (la conocida crisis del petróleo). Recientemente hemos vivido una reactivación de la economía motivada fundamentalmente por el abaratamiento del precio del dinero, que ha supuesto un aumento del poder adquisitivo. Ha habido grandes cambios y las empresas que se querían mantener en un mercado cambiante han tenido que renovarse en mentalidad, tamaño y estructura.

Todas estas cosas puede que no tengan nada que ver con montar una pequeña empresa de encuadernación artesanal. Podemos ver y oír 
que en el entorno de los discapacitados psíquicos se encuaderna artesanalmente desde siempre, que según los expertos es una tarea especialmente adecuada para nuestra capacitación laboral, que hay gente que vive de eso... Todas estas frases y otras muchas que nos dejamos en el tintero son, al menos en parte, verdad. Sin embargo, si queremos ser y formar una empresa siguiendo el criterio elegido de normalización, deberemos integrar estas cuestiones en un marco empresarial y seguir el orden indicado de preguntar primero al mercado. Empeñarse en vender al mercado lo que nuestra empresa produce, en vez de producir, en la medida de nuestras posibilidades, lo que el mercado solicita es, cuando menos, una necedad, y, en cualquier caso, añadir una dificultad a las muchas existentes.

El hecho objetivo es que no podíamos producir, porque nos habíamos quedado, literalmente (nunca mejor dicho, porque estábamos en una biblioteca), sin espacio y no teníamos toda la producción vendida. El tiempo corría en nuestra contra. Ante esta situación extrema entramos en crisis antes de empezar. Es posible que fuera auténtica mala suerte, pero también es posible que los planteamientos iniciales no estuvieran suficientemente maduros y que esta situación haya servido para corregir y dar solidez a dichos planteamientos, para conocer mejor el mercado y para buscar respuestas más serias.

Se ha sabido reaccionar y se han ido buscando soluciones. La experiencia no ha sido cómoda para nadie, pero ha sido nuestra experiencia y ha resultado altamente positiva. También debemos reconocer que la encuadernación artesanal no tiene las mismas posibilidades en el mercado que la limpieza industrial, y que como empresa que somos estaremos sujetos de una u otra manera a las leyes del mercado. Otras pretensiones se encarga la realidad de pulverizarlas.

Ahora, después de dos años, la sección está saneada y con grandes posibilidades de cara al futuro. La calidad de nuestros productos y nuestra capacidad para integrar nuevas tecnologías puede marcar la diferencia. Ahora todo depende de nuestro trabajo; volvemos a ser protagonistas de nuestra propia historia.

Como hemos abierto una sección de reprografía en la que el número de publicaciones se ha multiplicado, hemos adaptado nuestro taller para dar también servicio de encuadernación industrial. Esta nueva área del taller mejora las expectativas económicas del mismo y abre grandes posibilidades por las sinergias con la sección de reprografía.

\subsection{Reprografía}

Parece ser que nuestra tarea no era lo suficientemente complicada y nos encontramos de repente metidos también en otra aventura total- 
mente diferente. Sería para poner a prueba nuestra capacidad de dar diferentes respuestas al mismo tiempo en distintas situaciones. Si habíamos decidido ser una empresa de servicios ésta era una buena prueba. En el mismo periodo que comenzábamos como empresa nace la Universidad de Elche y nos ofrece hacernos cargo de la sección de reprografía, propuesta que es aceptada.

En los apartados anteriores de limpieza y encuadernación comenzamos con el período formativo y después de un largo recorrido llegamos a nuestro puesto de trabajo. Si aceptábamos el reto de reprografía, el planteamiento debía ser obligatoriamente distinto. También en este caso las dificultades superaron las previsiones. Conviene insistir que relatamos las dificultades sin ningún ánimo de victimismo ni nada parecido, ni siquiera las queremos agrandar. Simplemente las narramos porque son parte de nuestra historia, y un poco con el orgullo de haberlas afrontado con la mayor normalidad.

En un principio nos encontramos con que las peticiones de equipamiento y de servicio por parte de la Universidad excedían claramente de nuestras posibilidades. El coste de las máquinas superaba los 20 millones de pesetas, nuestro capital social era de quinientas mil y nuestra experiencia en el sector nula (para todos los seleccionados era su primer trabajo).

Una vez salvados los escollos con la colaboración de todos y con una gran confianza en nuestras posibilidades, nos encontramos con dificultades de tipo jurídico para la firma del convenio, lo cual retrasó enormemente el inicio de la prestación del servicio. El hecho de comenzar con tanto retraso hacía el servicio aún más necesario, con lo cual nada más firmar el convenio comenzamos a operar (veinticuatro horas más tarde para ser exactos).

Era todo un reto: la exigencia era muy grande, el trabajo era mucho y nuestra experiencia y organización insuficientes. La exigencia, a la que dimos mucha importancia en el tiempo de formación, ahora nos venía dada de la mano del cliente. Satisfacer sus necesidades se convirtió en nuestro objetivo, pero no era nada fácil. Si queríamos prestarles un buen servicio, debíamos estar a su altura, tanto en los tiempos, como en las tecnologías y en la calidad del servicio. La Universidad estaba aún despegando y la velocidad de su crecimiento era vertiginosa. Encontramos la lógica colaboración entre los proveedores. Nuestros clientes nos facilitaron la adaptación suficiente y fuimos adquiriendo la experiencia necesaria. Además, recibimos el apoyo de un formador, que primero nos fue ayudando a adaptarnos al puesto de trabajo y después fue preparando a los que serían nuestros futuros compañeros. 
Al finalizar el curso, el servicio de gestión y control de calidad evaluó, a través de una encuesta, el grado de satisfacción de los usuarios en lo concerniente a los servicios que presta a la Universidad y nuestra calificación fue satisfactoria. Todo un logro que nos llenó de alegría; lo habíamos conseguido. Se repetía la misma historia: todo dependía de la calidad de nuestro trabajo.

Al comienzo del segundo curso se nos ofreció la posibilidad de añadir al servicio de fotocopias el de publicación de apuntes. Aceptamos este segundo reto, ya que llevaba consigo el contar con maquinaria digital. Gracias a este reto la calidad de nuestro servicio ha aumentado sensiblemente y el servicio de publicaciones ha generado tanto trabajo como el de copias y ha facilitado que podamos dar un amplio servicio de impresión. Es verdad que hemos tenido que hacer un gran esfuerzo para adaptarnos en poco tiempo a una nueva forma de trabajar, pero ha merecido la pena, ya que nos hemos ido capacitando para dar un servicio con mayor valor añadido.

El inicio de este tercer año se presenta otra vez con nuevos retos: empezamos a dar servicio a través de la red de la propia Universidad, a lo largo del curso podemos recibir trabajos desde todos los puntos de la Universidad, nuestro servicio de publicaciones ha adquirido una dimensión importante, comenzaremos a editar CDs. Nuestro equipamiento material ha mejorado en calidad y en cantidad y contamos con la experiencia acumulada.

El ritmo de desarrollo de la nueva Universidad ha sido explosivo y su exigencia de calidad no ha sido menor. El acompañar a la Universidad en ese ritmo de crecimiento ha sido una tarea ardua, de la que esperamos cosechar abundantes frutos.

\subsection{Cocina industrial}

A mediados del curso pasado pusimos en marcha otra sección de la empresa: cocina industrial. Esta sección tiene su origen en un curso de formación de cocina que tuvo lugar en las dependencias del centro ocupacional Terramar. Con su creación se persiguen, en un principio, dos objetivos: prestar el servicio de comidas al centro ocupacional e iniciar otra rama laboral, lo cual amplía las posibles salidas laborales. Nace esta sección teniendo su producción asegurada.

La experiencia de este primer curso ha sido satisfactoria: hemos pretendido dar un servicio de calidad y el grado de aceptación del cliente ha sido grande. Hemos realizado puntualmente servicios de catering. Vamos acumulando la suficiente experiencia para afrontar en un futuro, probablemente no muy lejano, nuevos proyectos. Los planteamientos y la mentalidad con la que abordaremos los posibles proyectos no 
es distinta que para el resto de la empresa.

\subsection{Administración}

En los comienzos de nuestra empresa estábamos tan volcados en la acción que tuvimos que delegar en la administración de APSA nuestra gestión administrativa. En estos dos años el crecimiento ha sido tan grande que hemos creado dentro de LIMENCOP la sección de administración. Podemos considerar la administración como otra sección de la empresa. Gracias a ello, cada sección puede estar volcada en su trabajo habitual, mientras desde el departamento de administración se organiza y coordina todo el trabajo administrativo de las distintas secciones.

Los planteamientos y exigencias para esta sección recién nacida son los mismos que para el resto de la empresa. Pretendemos crear una estructura administrativa ágil, eficaz, transparente y dotada con la tecnología más avanzada del mercado. Un buen soporte administrativo es imprescindible para una buena gestión.

\section{CONSIDERACIONES FINALES}

Hemos relatado experiencias reviviendo una historia especialmente intensa. Somos conscientes de que se nos han quedado muchas cosas en el tintero. Hemos dejado brotar espontáneamente aquello que dejó más huella. No hay más intención en el relato que la de compartir una experiencia. Análisis más rigurosos para los distintos campos que citamos se los dejamos a los expertos de las distintas disciplinas.

Las constantes consideraciones sobre la discapacidad han ido abandonando su lugar central del principio para dejar paso a consideraciones sobre el trabajo y, en todo caso, sobre las adaptaciones necesarias para poder llevar a cabo ese trabajo. Esto sucede tanto en el relato como en la realidad.

Puede llamar la atención que, siendo un artículo escrito para una revista de la Escuela de Trabajo Social, los agentes sociales brillen por su ausencia. La razón es clara: estamos plenamente convencidos de la necesidad de diferentes intervenciones, como, por ejemplo, apoyo y refuerzo personal y familiar, intervenciones puntuales, adaptaciones al puesto de trabajo, etc.; pero lo estamos igualmente de que cualquier intervención social tiene que ser realizada fuera de la estructura empresarial. Cuando hablamos de proyectos empresariales serán los empresarios y los técnicos los que lideren estos procesos de expansión y crecimiento. Respecto a los agentes sociales, es preferible que acom- 
pañen, sin interferir en el diseño y desarrollo de la estructura empresarial, de lo contrario es probable que creemos estructuras empresariales realmente obsoletas, anacrónicas y, sobre todo, poco competitivas. Aunque los procesos personales nos puedan interesar de manera especial, consideramos que entran dentro del entorno personal privado y que no es una tarea nuestra como empresa. Sería tratar de ser agentes sociales sin serlo.

Uno de los temas que se han quedado en la recámara es el de la retribución. Se trata de un punto a negociar por la empresa y los representantes sindicales. Nuestro objetivo básico es el funcionamiento normalizado de la empresa en todos sus aspectos; en este sentido, entendemos que la tendencia será converger con los salarios base de cada sector, según convenios concretos, y ligar una parte de la retribución a objetivos alcanzados, de cara a incentivar, de una manera normalizada, a los trabajadores. 


\section{INTEGRACIÓN SOCIO-LABORAL DE PERSONAS CON DEFICIENCIA AUDITIVA}

\section{HERMINIA TORREBLANCA CAPDEVILA $M^{a}$ FRANCISCA ALBERT CANTÓ}

Trabajadoras Sociales del Departamento de Empleo de la Asociación de Padres y Amigos de Niños y Adolescentes Hipoacúsicos (A.P.A.N.A.H.).

\section{RESUMEN}

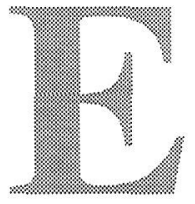

1 artículo que vamos a desarrollar a continuación quiere difundir la labor que estamos realizando dos trabajadoras sociales en el departamento de empleo de la Asociación de Padres y Amigos de Niños y Adolescentes Hipoacúsicos (A.P.A.N.A.H.), a través de los Planes de Empleo de la Federación Española de Asociaciones de Padres y Amigos de los Sordos (FIAPAS).

El presente artículo pretende explicar cuál es la situación actual del desempleo de los jóvenes sordos, de la legislación vigente respecto a discapacitados, el proceso de inserción laboral que atraviesan los jóvenes demandantes de empleo y de las funciones específicas que desarrollan los profesionales como intermediarios laborales.

Planteando un enfoque teórico-práctico fruto del trabajo que se viene realizando desde enero de 1998 hasta la fecha actual a través del Proyecto DINAMI para la integración socio-laboral para personas con deficiencia auditiva.

\section{PALABRAS CLAVE}

Discapacidad auditiva, proceso de integración socio-laboral, habilidades laborales, fomento de empleo, técnico de inserción laboral, formación profesional, búsqueda de empleo, empleo ordinario, tejido empresarial, HORIZON. 


\section{INTRODUCCIÓN.}

El trabajo desde el punto de visto antropológico, aparece como la realización personal del hombre; desde el punto de vista socioeconómico como eje y núcleo de toda actividad productiva personal y social, y desde el punto de vista psicológico, como realización y aplicación práctica de la capacidad humana, que facilita confianza y seguridad de la persona en sí misma.

En una sociedad como la nuestra, la persona no se realiza del todo si no es mediante el trabajo; por ello, el derecho de la persona discapacitada al trabajo es el derecho a realizarse como persona. De modo, que el acceso y mantenimiento en un puesto de trabajo es fundamental en la vida de las personas con discapacidad auditiva, ya que el tipo de empleo, el salario y las oportunidades laborales definen el estilo de vida de la persona y afectan directamente al modo de cómo nos percibimos cada uno y al modo de cómo nos percibe y valora la comunidad en que vivimos.

El facilitar a la persona con deficiencia auditiva la obtención de un trabajo remunerado en el medio ordinario supone, además de cobrar, una valoración social positiva tanto por parte de la propia familia como de la comunidad en que vive, un mayor grado de libertad e independencia personal, una afirmación de su autoestima al sentirse útil a la sociedad y la posibilidad de establecer relaciones y amistades con personas sin discapacidad y una experiencia de gozar de los mismos derechos que los demás en el seno de la comunidad y de formar parte integrante de la misma.

\section{FUNDAMENTACIÓN TEÓRICA}

Las personas sordas quieren y pueden trabajar, exactamente igual como las normooyentes. Es obvio que no todos los trabajos resultan adecuados a su circunstancia, pero también lo es que ninguna persona es útil para cualquier tipo de trabajo. La cuestión radica en adecuar el puesto laboral a las facultades y capacidades de cada uno. Igual que un licenciado en filología no es normal que esté en condiciones de trabajar en el departamento de investigación de un laboratorio farmacéutico, tampoco lo es que una persona sorda desempeñe una tarea de atención telefónica. Pero eso no significa que ni el filólogo no tenga un mercado laboral donde aplicar sus conocimientos, ni que la persona sorda no disponga de un amplio catálogo de opciones profesionales donde su discapacidad carezca de importancia.

Estos hechos, que expuestos así parecen tan evidentes, no son, por 
desgracia, percibidos con igual claridad por nuestra sociedad, de ahí la necesidad de un esfuerzo intenso y continuado de información y sensibilización que desvele ante la sociedad en general, y ante el empresario en particular, el potencial profesional todavía inutilizado que encierran las personas sordas. Potencialidades que pueden mejorarse con una formación adecuadamente orientada a su futuro laboral, por ello, debemos impedir que la educación vaya por un lado y la demanda laboral para las personas afectadas de sordera vaya por otro, es esencial que la oferta educativa para los jóvenes sordos responda a las expectativas laborales que en cada momento permiten el mercado de trabajo y el desarrollo de la técnica.

Para concluir, nos queda resaltar que el fomento del empleo de las personas no es sólo una exigencia de justicia para quienes padecen esa discapacidad. Es también una necesidad para que la sociedad pueda aprovechar el capital creativo de un amplio conjunto de sus miembros, que puede, quiere y sabe trabajar.

La realidad de nuestro colectivo de jóvenes con deficiencia auditiva presenta carencias formativas y de cualificación, que, unido a las dificultades propias de acceso a la información, nos demandan una atención dirigida a la orientación y formación profesional compatible con su discapacidad y ajustada a la realidad de la oferta laboral que posibilite a estos jóvenes su acceso a un trabajo.

Debido a la falta de contacto con el mundo laboral, los jóvenes sordos requieren una formación teórico-práctica que les facilite la adquisición de habilidades sociales, habilidades laborales y técnicas de búsqueda de empleo para permitirles enfrentarse al mundo laboral sin dificultades.

Teniendo en cuenta la existencia de barreras a la contratación de personas sordas, motivada en muchas ocasiones por el desconocimiento del empresariado en general acerca de las capacidades y aptitudes de los trabajadores sordos, y también a que la Administración no ha dotado de mecanismos suficientes para la integración en el mercado laboral ordinario; es de vital importancia formar un equipo de trabajo, el cual, a través de la intermediación laboral entre la empresa y el joven sordo, capacite al joven con deficiencia auditiva para desarrollar las funciones en el puesto de trabajo de una empresa ordinaria.

Por todo ello, FIAPAS (Federación Española de Asociaciones de Padres y Amigos de los Sordos) desarrolla en la actualidad el proyecto DINAMI, dentro de la iniciativa comunitaria HORIZON, y cofinanciado por el Fondo Social Europeo, el IMSERSO y la FUNDACIÓN ONCE.

La finalidad del Proyecto DINAMI es la integración socio-laboral de personas con discapacidad auditiva, mediante los Servicios de Ase- 
soramiento para el Acceso al Empleo de Personas Sordas (SAES), coordinados, dirigidos y supervisados por los técnicos de inserción labo$\mathrm{ral}$

La cobertura nacional del proyecto es de diez provincias, entre las cuales se encuentra Alicante, representada por A.P.A.N.A.H. (Asociación de Padres y Amigos de Niños y Adolescentes Hipoacúsicos), con sede en Elda, formado por un equipo multidisciplinar compuesto por: dos padres voluntarios responsables del proyecto, un técnico en inserción laboral, y una trabajadora social que desarrollan el proyecto desde enero de 1998 hasta diciembre de 1999.

En definitiva, se pretende salvar barreras en las estructuras y políticas de empleo, para derivar en la aplicación efectiva de las medidas ya existentes y en la adopción de otras nuevas que posibiliten: la accesibilidad del joven sordo al mercado de trabajo, la cualificación del trabajador sordo y, como consecuencia de todo ello, poder aportar información que determine la renovación de convenios formativos, adaptaciones curriculares puntuales y diseño de nuevos perfiles profesionales.

\section{III.FUNDAMENTACIÓN LEGISLATIVA}

Tras una larga etapa pasada, los gobiernos han tomado en consideración la necesidades de las personas con discapacidad para lograr su integración en al ámbito del trabajo y, con ello, alcanzar el status de personas con derechos y deberes sociales en plenitud de ejercicio, medidas favorecedoras del empleo en el medio laboral ordinario.

El Título VII de la Ley de Integración Social de Minusválidos (LISMI), al abordar la inserción laboral de los discapacitados, fundamenta toda la estrategia en los siguientes principios:

1) Normalización e Integración: art. 37.

2) No discriminación: art. 38.2.

3) Equiparación de oportunidades: art. 38.4.

En estos momentos la normativa estatal, dentro de las políticas activas de empleo, tiene establecidos importantes instrumentos facilitadores del empleo e integración social de las personas con discapacidad. Se puede sistematizar de una forma sencilla siguiendo el criterio de la naturaleza jurídica de la relación laboral que se pretende ofertar por parte del empresario a la persona con discapacidad:

R/D 1/99 8 de enero BOE 8 enero 99.

1. Contrato para el fomento de la contratación indefinida:

- Subvención de 650.000 ptas. por cada contrato celebrado. 
- Bonificación de las cuotas empresariales de la Seguridad Social, del $70 \%$ o $90 \%$ según la edad.

- Deducción de 800.000 ptas. sobre el Impuesto de Sociedades.

- Subvención para la adaptación al puesto de trabajo hasta 150.000 ptas.

- Subvenciones para la formación profesional de los trabajadores.

2. Contrato para la formación (Ley 63/1997 de 26 de diciembre).

- Reducción del 50\% de la cuota empresarial de la Seguridad Social.

- Sin límite de edad para personas con minusvalía.

- El trabajador con minusvalía no se computa para determinar el número máximo de estos contratos que las empresas pueden realizar en función de su plantilla.

3. Contrato en prácticas (Ley 63/1997 de 26 de diciembre).

-Reducción del $50 \%$ de la cuota empresarial de la Seguridad Social por contingencias comunes.

4. Contrato temporal de fomento de empleo.

- Sólo se puede realizar este tipo de contrato a personas con minusvalía.

- Reducción del 75\% de la Seguridad Social por contingencias comunes o el $100 \%$ si es el primer trabajador contratado desde enero de 1994.

- Posibilidad de acogerse a los beneficios del contrato indefinido en el momento de su transformación en fijo (incluso los posteriores al 17 de mayo de 1997).

5. Fomento de empleo por cuenta propia.

- Subvención parcial de intereses de los préstamos de cualquier entidad de crédito (concertados con el Ministerio de Trabajo y Asuntos Sociales), con un máximo de 500.000 pesetas.

- Subvención para inversión de capital fijo: de hasta 400.000 pesetas.

- Subvención de Asistencia Técnica del 50\% al 100\% del coste de los estudios de viabilidad, auditoría y asesoramiento.

- Subvención de rentas de subsistencia de hasta 500.000 pesetas para garantizar unos ingresos mínimos durante el inicio de la actividad.

6. Medidas de obligado cumplimiento.

6.1. Sistema de cuotas: La Ley establece que las empresas públicas (incluidas las Administraciones Públicas) o privadas, que empleen un número de trabajadores fijos, cuya plantilla exceda de 50 , están obligados a contratar un número de trabajadores con discapacidad no inferior al $2 \%$ de la misma. 
La Ley 13/1995 de Contratos de las Administraciones Públicas introdujo la preferencia en la adjudicación de los contratos en aquellas empresas públicas o privadas que acrediten tener en su plantilla un número de trabajadores con discapacidad no inferior al $2 \%$, siempre que dichas proposiciones igualen en sus términos a las más ventajosas desde el punto de vista de los criterios objetivos que sirvan de base para su adjudicación.

6.2. Empleo Selectivo: Los trabajadores en situación de incapacidad permanente, tienen preferencia absoluta para su readmisión en la empresa en la que venían trabajando, una vez terminado el correspondiente proceso de recuperación.

Las empresas tendrán derecho a reducciones del $50 \%$ de la cuota patronal de la Seguridad Social correspondientes a las contingencias comunes, durante el periodo de 2 años.

Es muy importante destacar que en 1998 el Gobierno presentó, el 15 de abril en Bruselas, ante las autoridades de la Unión Europea, el Plan Nacional de Acción para el Empleo del Reino de España, que prevé, en la Directriz número 19, medidas específicas para personas con discapacidad, dentro del marco de las políticas para reforzar la igualdad de oportunidades. A continuación, se destacan las principales medidas contempladas en las recientes directrices para 1999.

7. Pan Nacional de Acción para el Empleo 1999.

Directriz 9:

71. Objetivos: Insertar laboralmente a los trabajadores discapacitados y minorías étnicas mediante actuaciones preventivas que faciliten su integración en el mercado de trabajo.

\subsection{Medidas:}

- Impulsar la Ley de Inserción Socio-Laboral.

- Potenciar la integración de las personas con discapacidad en el mercado de trabajo.

- La mejora de su capacidad de inserción profesional: adecuar la formación escolar a las necesidades y características de los alumnos con discapacidad.

- El apoyo a su contratación e inserción laboral: equipos especializados de intermediación laboral, incentivos, etc.

9. Acuerdo MTAS-CERMI sobre el Plan de Medidas Urgentes para la Promoción del Empleo de las Personas con Discapacidad.

El Comité Español de Representantes de Minusválidos, CERMI, presentó el 3 de diciembre de 1996, coincidiendo con el Día Europeo del Discapacitado, al Ministerio de Trabajo y Asuntos Sociales un Plan de Medidas Urgentes de Fomento de Empleo para Personas con Discapacidad. 
En octubre de 1997, el Consejo de Ministros aprobó el Plan de Empleo para Personas con Discapacidad, rubricándose el mismo con un acuerdo entre el Ministerio de Trabajo y Asuntos Sociales, y el CERMI, fruto de las negociaciones entre ambos, que recoge el Plan de Medidas Urgentes para la Promoción del Empleo de las Personas con Discapacidad.

\section{METODOLOGÍA.}

El itinerario o inserción laboral de los jóvenes sordos es un proceso, y como tal conlleva el paso por una serie de fases consecutivas:

1. Información y orientación:

- Elaboración de un censo de personas sordas en edad de trabajar.

- Creación de la bolsa de trabajo, ampliación continua y captación de demandantes de empleo.

- Informar, asesorar y sensibilizar a todos los destinatarios y participantes del proyecto sobre las capacidades y aptitudes sobre las personas con deficiencia auditiva, con el fin de conseguir la normalización en la concepción de la discapacidad en la sociedad.

- Realizar difusión de los objetivos y contenido del proyecto, de la puesta en marcha y funcionamiento del SAES, en los departamentos de orientación de los centros educativos, empresas, entidades públicas, medios de comunicación, etc.

- Realizar acciones informativas y sesiones de trabajo con las familias de jóvenes sordos, con el objetivo de concienciarles para que fomenten y faciliten su autonomía a través de la inserción laboral.

2. Contacto y diagnóstico:

- Trabajar conjuntamente a través de entrevistas con los jóvenes sordos la elaboración del itinerario individualizado de inserción.

- Determinar el perfil del usuario en lo que respecta a actitudes, cualidades y habilidades orientadas al mundo laboral e informarles sobre sus posibilidades reales, la necesidad de cualificación, de búsqueda activa de empleo, de los hábitos laborales y de las habilidades sociales que requiera el puesto de trabajo.

- Elaborar un diagnóstico en base a indicadores objetivos y operativos de la problemática específica de cada caso y llevar a cabo por parte del técnico en inserción laboral un plan personalizado de trabajo.

3. Formación y profesionalización:

- Impartir por parte de la trabajadora social formación en técnicas 
de búsqueda de empleo, habilidades sociales, y habilidades laborales que faciliten y potencien la correcta adaptación al puesto de trabajo.

- Facilitar la formación profesional "in situ" en la empresa, a través del técnico de inserción laboral con un aprendizaje real de las tareas concretas, estableciendo para ello los apoyos y las adaptaciones necesarias.

- Proporcionar formación sobre la deficiencia auditiva a los profesores, tutores, departamentos de orientación, responsables de recursos humanos, empresas, entidades públicas, privadas, etc.

- Orientar e informar al joven sordo de los cursos de formación profesional, salidas laborales, módulos profesionales, formación reglada, formación continua, etc.

- Formación continua del técnico de inserción laboral, y de la trabajadora social en jornadas, cursos y seminarios relacionados con la inserción laboral de discapacitados.

4. Búsqueda de empleo:

- Favorecer el acceso al empleo público de las personas con discapacidad auditiva, informando a las Administraciones Públicas y reclamando el cumplimiento de las medidas que potencien la contratación de trabajadores minusválidos: cupo de reservas de plazas, adaptaciones en las pruebas de acceso en los puestos de trabajo.

- Contactar con el mayor número de empresas y organizaciones empresariales posibles, con el fin de informar y sensibilizar a la mayor parte del tejido empresarial de la provincia y así conseguir ofertas de empleo para los jóvenes sordos.

- Informar a los empresarios sobre las principales características de la deficiencia auditiva y sobre las aptitudes y posibilidades laborales y de formación de las personas sordas en los distintos puestos de trabajo.

- Informar a los empresarios sobre las ventajas y ayudas económicas a la contratación de personas con discapacidad.

- Realizar un seguimiento por parte del técnico en inserción laboral de la evolución del trabajador en la empresa, para apoyar cualquier dificultad.

- Potenciar convenios de colaboración con la Administración Autónoma, la Diputación y las corporaciones locales para aumentar la contratación de personas con discapacidad auditiva en el sector público.

5. Coordinación:

- Coordinación con otras asociaciones de discapacitados, que lleven a cabo proyectos de inserción laboral. 
- Coordinación con los responsables de los departamentos de orientación de los centros y profesores de apoyo.

- Participación en los diferentes foros de representación de las personas con discapacidad, que se formen en la provincia, para trasladar las demandas del colectivo en temas relacionados con el empleo.

- Coordinación interna con el resto de profesionales y responsables de la asociación.

6. Seguimiento y evaluación:

- Realizar un seguimiento exhaustivo de las actuaciones llevadas a cabo por los profesionales y de la trayectoria en los itinerarios de inserción laboral de los jóvenes sordos.

- Realizar informes por parte de los Profesionales de los contactos realizados con empresas, centros educativos, Administración Pública, contactos con las familias y con los demandantes de empleo, número de inserciones laborales, etc.

- Hacer una evaluación conjunta, a nivel cualitativo y cuantitativo del proceso de inserción laboral de los jóvenes sordos, de los objetivos alcanzados a lo largo del Proyecto y de las dificultades encontradas.

7. Resultados: La valoración general del proyecto a mitad de su desarrollo es francamente positiva, por las expectativas de empleo generadas y que se intentarán cubrir hasta finalizar el año.

\section{A nivel nacional:}

Hasta el momento podemos decir que en el territorio nacional se han conseguido un total de 420 empleos, de los cuales 8 de cada 10 son en empresa ordinaria y sólo dos de empresa protegida. Esto revela la capacidad de las personas sordas para competir con éxito en el mercado de trabajo ordinario, en virtud de sus propios méritos.

La importancia de este hecho es que las personas sordas no están circunscritas en su horizonte profesional al empleo protegido, sino que tienen unas perspectivas mucho más amplias.

En cuanto a los sectores de actividad, los contratos se producen en una gran diversidad de actividades: industria $57 \%$, servicios $38 \%$ y Sector Público 5\%. La diversidad de sectores revela una amplia multiplicidad de opciones para el empleo de personas sordas.

A nivel provincial:

Durante el transcurso del primer año de proyecto se ha realizado una labor intensiva de difusión del proyecto, una toma de contacto con las empresas y con los centros educativos y con los jóvenes 
sordos. Así como una labor de sensibilización e información hacia la población en general de las capacidades y aptitudes de las personas sordas muchas veces desconocidas.

Se considera que es en el último semestre de actividad cuando han comenzado a cosecharse los resultados de siembra previa. Esto hace pensar que se obtendrán al final del periodo unos resultados sumamente satisfactorios, demostrando que hace falta tiempo para que el tejido empresarial asimile la propuesta que se les formula.

Los datos demuestran una vez más la realidad del acceso al empleo ordinario de las personas con discapacidad auditiva, puesto que de 15 empleos conseguidos desde APANAH, tan sólo uno es en empresa protegida.

Se han cuantificado los resultados obtenidos en cuanto al sector de la empresa, sectores de ocupación, ocupaciones, bolsa de empleo, sexo, edad y formación que son los siguientes:

TABLA 1: Empresa

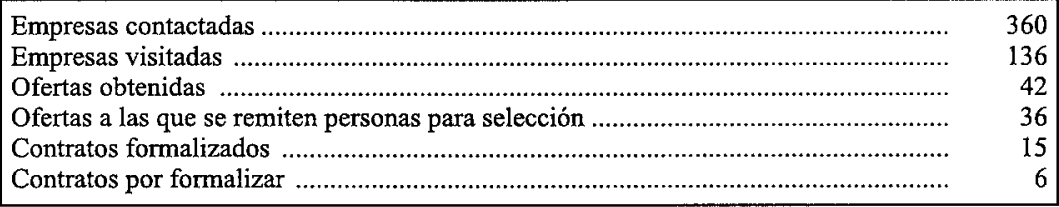

TABLA 2: Sectores de ocupación

\begin{tabular}{|c|c|}
\hline Protegido & 1 \\
\hline Industria $\ldots \ldots \ldots \ldots$ & 5 \\
\hline Servicios & 4 \\
\hline Administración & 5 \\
\hline 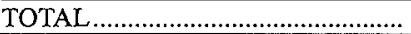 & 15 \\
\hline
\end{tabular}

TABLA 5: Bolsa de empleo

\begin{tabular}{|c|c|}
\hline N. ${ }^{\circ}$ de demandantes de empleo & 30 \\
\hline 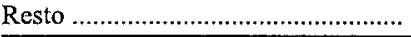 & 33 \\
\hline TOTAL $\ldots \ldots \ldots \ldots \ldots \ldots \ldots \ldots$ & 63 \\
\hline
\end{tabular}

TABLA 7: Edad

\begin{tabular}{|c|c|}
\hline $16-26$ & 42 \\
\hline $26-36$ & 13 \\
\hline $36-46 \ldots$ & 6 \\
\hline $46-56$ & 2 \\
\hline 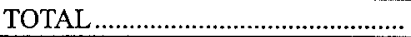 & 63 \\
\hline
\end{tabular}

TABLA 4: Ocupaciones

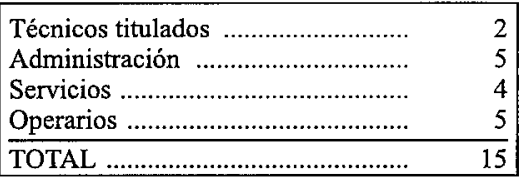

TABLA 6: Sexo

\begin{tabular}{|c|c|}
\hline Hombres & 27 \\
\hline Mujeres & 36 \\
\hline 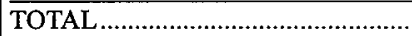 & 63 \\
\hline
\end{tabular}

TABLA 8: Formación

\begin{tabular}{|c|c|}
\hline 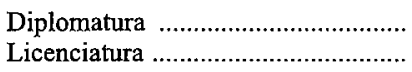 & $\begin{array}{l}3 \\
3\end{array}$ \\
\hline Certificado de Escolaridad ... & 27 \\
\hline 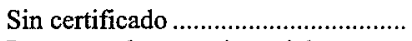 & 4 \\
\hline Programa de garantía social & \\
\hline Estudiantes centros educativos ........ & 16 \\
\hline Estudiantes Universidad & 9 \\
\hline TOTAL. & 63 \\
\hline
\end{tabular}


En conclusión, respecto a la empresa, se ha contactado con 360 , de las cuales se han formalizado en visitas 136, esto demuestra las reticencias en un primer momento para establecer el contacto personal, debido al desconocimiento y a los miedos infundados de la deficiencia auditiva.

En cuanto a contratos formalizados, son 15 los llevados a cabo, de la 42 ofertas obtenidas, no siendo cubiertos muchos de ellos por falta de cualificación, debido a la baja formación profesional, puesto que en la bolsa de empleo de APANAH, de 63 personas inscritas, 27 no poseen el certificado de escolaridad, estas contrataciones se han llevado a cabo, en sectores tan diversos como industria, servicios y Administración, lo que demuestra una vez más que la inserción laboral de personas con discapacidad auditiva, es difícil, pero posible.

\section{CARACTERÍSTICAS DEL PROCESO.}

Uno de los ejes vertebrales sobre los que versará la intervención es el itinerario de inserción, a través del cual se establece un determinado modelo metodológico, capaz de ofrecer una respuesta integradora de los diferentes recursos y servicios.

Sus características esenciales son:

- Singulariza el proceso: Configura una respuesta de carácter individualizado, elaborada "a la medida" del usuario y adaptada a sus características concretas.

- Identifica y selecciona prioridades: Se diseña a partir del diagnóstico inicial, por medio del cual se determinan y clasifican las dificultades de inserción laboral y se gradúan por orden de dificultad.

- Personalizado: Necesita un tratamiento altamente personalizado a partir de entrevistas individuales y un seguimiento a cargo de los profesionales.

- Motivadora: Es un sistema que estimula la motivación y proporciona seguridad al joven sordo. Su implicación es facilitada del origen de las primeras ideas asociadas al diagnóstico y autoanálisis, que realizan los profesionales y los jóvenes sordos.

- Responsabilidad: Es una oferta abierta, pero limitada, de opciones sobre las cuales tiene que escoger y llegar a un compromiso.

- Participación del joven sordo en la gestión de su itinerario: Se establece un marco formal donde situar los compromisos y las relaciones. Los acuerdos que se toman se llevan al término dentro de unos plazos de tiempo y con unos recursos determinados. Hay 
una serie de deberes y derechos que se van desarrollando progresivamente en función del cumplimiento de objetivos y consecución de resultados previstos.

Esta metodología de trabajo permite la situación objetiva de la problemática de la persona, la orientación conjunta con la persona y la búsqueda de recursos formativos o de la inserción directa, tanto por parte de los profesionales como de los jóvenes sordos demandantes de empleo.

\section{FUNCIONES DEL TRABAJADOR SOCIAL. PROFESIONALES DE INSERCIÓN LABORAL.}

- Informar a todos los socios y posibles interesados de la existencia del Servicio de Asesoramiento para el Acceso al Empleo de Jóvenes Sordos en la Asociación.

- Conocer y analizar el perfil de los jóvenes sordos que acudan al S.A.E.S, manteniéndose en contacto permanente con ellos para actualizar sus datos.

- Informar y orientar a los jóvenes sordos sobre las distintas alternativas en cuanto a formación y empleo que existen en la provincia, asesorándoles en función del perfil de cada uno.

- Contactar, informar y sensibilizar a las empresas e instituciones públicas sobre las posibilidades de contratación de personas con deficiencia auditiva, los incentivos fiscales, las capacidades y aptitudes de las personas sordas, etc., con el fin de conseguir la inserción laboral de estos jóvenes en la empresa ordinaria.

- Analizar las tareas a desempeñar en el puesto de trabajo y asesorar sobre las adaptaciones necesarias.

- Dar a conocer a la persona que accede al puesto de trabajo, las características de éste: tareas a desempeñar, horario de trabajo, sueldo real, posibilidad de hacer horas extras, etc.

- Realizar la selección de los candidatos más adecuados al empleo ofertado y presentarlos al empresario.

- Ofertar puestos de trabajo a los jóvenes sordos informándoles sobre todas las características de éstos.

- Realizar el seguimiento de cada inserción laboral conseguida, informando al empresario y compañeros del joven sordo de las características de la deficiencia auditiva.

- Formar a los usuarios del S.A.E.S. en la adquisición de habilidades para la vida laboral y en técnicas de búsqueda activa de empleo, y 
actuar como agente motivador de las mismas.

- Colaborar con las familias de los jóvenes sordos en la integración laboral de éstos.

- Coordinar con los centros educativos, la Dirección Provincial del INEM, otras asociaciones de discapacitados, etc. que lleven a cabo proyectos de inserción laboral.

\section{REFLEXIÓN FINAL.}

La siguiente exposición son palabras textuales extraídas de una reflexión realizada por una persona sorda que expone la problemática a la hora de acceder a un puesto de trabajo adecuado a su discapacidad.

"La deficiencia auditiva es una minusvalía de las más importantes, pero sigue ocupando el primer lugar de abandono, de desconocimiento, de dejadez y de falta de información.

La discapacidad que la persona sorda padece solamente afecta a su canal auditivo, por lo que sus capacidades físicas e intelectuales son exactamente iguales a las del resto de las personas. La única diferencia es la forma de recibir la información del mundo que les rodea, ya que ésta es a través del canal visual, lo que no afecta a la capacidad de la persona para realizar trabajos que no dependan directamente del órgano auditivo. Con la formación necesaria, la persona sorda puede alcanzar la cualificación que le capacite para desarrollar cualquier trabajo.

Nuestro lenguaje muchas veces no es expresivo, ni receptivo, tampoco poseemos un rico vocabulario, no hemos tenido facilidad de comunicación. Recibimos poca información, tenemos dificultad para asimilar toda la información oral que los oyentes se comunican entre sí. Por eso recibimos mejor la información visual o la información escrita.

Una persona sorda se halla muy gravemente limitada en su lenguaje, en el ámbito del pensamiento, confinado en realidad a un mundo pequeño y limitado. Es un peligro que amenaza al desarrollo humano, tanto intelectual como emotivo, cuando no se aprende el lenguaje adecuadamente.

Las personas con deficiencias auditivas se encuentran en su vida cotidiana con las llamadas barreras de comunicación. La incapacidad para dar o recibir información como cualquier persona oyente. 
Podemos decir, que las personas sordas trabajan sin necesidad de personal de apoyo y se convierten así en personas independientes, tienen una excelente capacidad de concentración, así como de atención y de memoria visual, y son capaces de realizar trabajos manuales como los no manuales, pudiendo llegar a desempeñar diferentes tareas, para las tantas y tantas profesiones que existen actualmente en el mercado laboral.

Una persona con deficiencia auditiva responde con energía y se dedica con gran entusiasmo ha realizar cualquier tipo de trabajo para formarse como persona independiente.

Esperanza Castelar Amigot, diplomada en Biblioteconomía y Documentación que actualmente está trabajando en la Biblioteca Virtual de la Universidad de Alicante, como técnico de biblioteca. A través de los Servicios de Empleo de A.P.A.N.A.H.

\section{CONCLUSIONES.}

Las personas sordas responden con eficacia, en muchos casos con brillantez, al desafío del mundo del trabajo. Precisamente porque tienen que superar una barrera social, su empeño, dedicación y voluntad son superiores a quienes no se encuentran con esa dificultad añadida.

Y lo peor de todo no son las limitaciones por razones objetivas, sino las limitaciones subjetivas, es decir, la prevención del empresario a contratar personas sordas debido al profundo desconocimiento que existe al respecto. Las desconfianzas infundadas, los recelos debidos a la pura y simple ignorancia constituyen barreras mucho más difíciles de franquear que la propia estrechez del mundo laboral.

Es éste un trabajo urgente, necesario y útil. Urgente, porque no se puede permitir por más tiempo una situación de manifiesta injusticia para las personas sordas, y de desaprovechamiento de su contribución a la sociedad. Necesario, porque el mundo del trabajo debe abandonar su tradicional prevención hacia las personas sordas, a fuerza de información y de experiencia. Y útil, porque allí donde una persona sorda comienza a trabajar, se está demostrando que siempre supera las expectativas del contratador, y se convierte automáticamente en el mejor agente propagandístico para la contratación de nuevas personas sordas.

A.P.A.N.A.H. se propone este reto y este compromiso; ya que desde nuestra experiencia podemos afirmar que la contratación de personas sordas es un hecho posible y real. A fecha de hoy son 15 las personas que actualmente están trabajando, siendo la inserción laboral de 
personas con deficiencia auditiva una tarea difícil de alcanzar por las barreras existentes por parte del tejido empresarial; es por esto que son muchas las personas que hoy están trabajando para alcanzar tan ambiciosos objetivos, y confiamos en que a finales de 1999, cuando concluyan los actuales programas de fomento de empleo que desarrolla FIAPAS, hayamos sentado las bases para que las empresas reciban a las personas sordas en función de sus propios méritos y desaparezcan los prejuicios trasnochados.

\section{BIBLIOGRAFÍA}

FIGUEREDO DELGADO, $\mathrm{M}^{\mathrm{a}} \mathrm{A}$ :: "Transición de la escuela al trabajo de las personas sordas". MINUSVAL. Ministerio de Trabajo y Asuntos Sociales. IMSERSO, Madrid, nº 115. 1999. Págs. 30-31.

FUNDACIÓN MAPFRE MEDICINA, GRUPO ATED ATAM-FUNDESCO: Metodologías y estrategias para la integración laboral. Editorial MAFRE. Madrid, 1994.

FUNDACIÓN ONCE: Minusvalía e inserción laboral en la Comunidad Valenciana. Escuela Libre Editorial. Madrid, 1996.

GARCÍA DÍAZ, N.: "Transición de la escuela al empleo en el Plan de Acción". MINUSVAL. Ministerio de Trabajo y Asuntos Sociales. IMSERSO. Madrid, nº 115, págs. 16-17.

INSTITUTO PARA LA FORMACIÓN: Minusvalía e inserción laboral. Madrid, 1995.

LIBRO BLANCO DE ECONOMÍA SOCIAL EN LA COMUNIDAD VALENCIANA: Ciriec-España, Valencia, 1997.

MINISTERIO DE TRABAJO Y ASUNTOS SOCIALES: Empleo $y$ Discapacidad. Madrid, 1998.

MORA, G.: "Inserción laboral e itinerarios personalizados". Revista de Serveis Socials. Consellería de Trabajo y Asuntos Sociales, Valencia, 1994, págs. 23-28.

NAVARRO JIMÉNEZ, A.: "En marcha la campaña de Fomento de Empleo". FIAPAS, Madrid, 1998, n 65, págs. 6-22.

RAMÓN RICO, M.F. y GÓMEZ JARABO, G.: Diseño de puestos de trabajo para personas con discapacidad. Ministerio de Trabajo y Asuntos Sociales, Madrid, 1998.

RUEDA, B.: "Intermediación laboral y tránsito al empleo ordinario". MINUSVAL. Ministerio de Trabajo y Asuntos Sociales. IMSERSO, Madrid, nº 115 , págs. 25-27. 

II. TRIBUNA

I.IBRRE 



\section{AUTOCONCIENCIA PERSONAL Y CREATIVIDAD FEMENINA. UN PROCESO ABIERTO}

\section{ESTHER VILLEGAS CASTRILLO}

Profesora de la E.U. de Trabajo Social. Departamento de Trabajo Social y Servicios Sociales. Universidad de Alicante.

Pido perdón a las grandes preguntas por mis respuestas pequeñas. W.Szymborska

\section{CONTEXTO DE REFLEXIÓN}

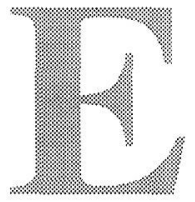

n la introducción de su obra Le deuxième sexe, aparecida en 1949, S. de Beauvoir llamaba la atención sobre la necesidad de tomar conciencia de las nuevas vías abiertas a la emancipación de la mujer, al mismo tiempo que constataba el hecho de que ya en aquella época la literatura femenina estaba animada no sólo por una voluntad de reivindicación y por actitudes polémicas sino también $-\mathrm{y}$, tal vez, sobre todo,- por lo que ella denomina «un effort de lucidité»' ${ }^{1}$, que buscaba desvelar las causas reales de los fenómenos de opresión de la mujer, analizar las contradicciones latentes y sugerir alternativas de acción.

En las décadas inmediatamente posteriores, y prolongando el análisis de algunas de las claves que inspiran la obra de esta autora (insuficiencia de la teoría psicoanalítica e inadecuación de explicaciones que intentan dar razón de la situación de opresión de la mujer, imposibilidad de que ésta viva como sujeto libre mientras siga interpretándose a sí misma según los mitos de la feminidad inventados por el hombre y mantenga su dependencia económica con respecto a él), el llamado Women's Liberation Movement denuncia el carácter patriarcal de la sociedad y desvela los obstáculos que impiden la igualdad efectiva de derechos sexuales y políticos entre mujeres y hombres. El supuesto básico de que ahora se parte es que los condicionamientos socioculturales y las relaciones de poder son la explicación auténtica de las dife- 
rencias entre los dos sexos, no el hecho puramente biológico, como otros autores irán exponiendo posteriormente ${ }^{2}$.

La diversificación de los movimientos feministas a lo largo de las últimas décadas -que prosiguen, de diferentes modos, el esfuerzo por hacer efectivos en la praxis cotidiana los derechos políticos, económi$\cos$ y sociales que teóricamente se reconocen a la mujer y romper los esquemas inspirados en la supuesta desigualdad biológica o «natural» de los sexos- permite constatar una rica pluralidad de planteamientos doctrinales, de orientaciones, de estrategias, de propuestas alternativas, tendentes a sugerir formas nuevas de autorrealización personal de la mujer, de interpretar su posición en la sociedad, en la familia, en la política, en el trabajo y en la cultura. En particular, no puede desconocerse la singular relevancia que han tenido los debates -todavía abiertos-a propósito de la identidad de la mujer y sobre su igualdad y diferencia, saliendo al paso de visiones distorsionadas, de mitos, de idealizaciọnes y de concepciones reduccionistas.

En este contexto de reflexión y de búsqueda, una aproximación lúcida a las aspiraciones -latentes o explícitas- que siguen estando a la base de los diferentes planteamientos sobre la mujer parece ir imponiendo la convicción de que es preciso ensayar una ampliación de horizontes y una búsqueda de nuevas alternativas, en el sentido de que «la nueva andadura del feminismo debería tener un carácter distinto, menos reivindicativo y más creativo, menos teórico y más ejemplar» ${ }^{3}$.

Desde la convicción de que esta propuesta constituye un reto atractivo y fecundo, el presente estudio pretende recordar algunos criterios que han venido inspirando esta nueva orientación y sugerir otros posibles; en cualquier caso, ese nuevo impulso creativo debería encontrar su fuente de inspiración, a mi entender, en la condición misma de persona de la propia mujer, ya se trate de valorar sus reivindicaciones históricas, o de abordar el problema de su igualdad y diferencia, o de someter a crítica determinados planteamientos doctrinales, o de elaborar un proyecto coherente de presencia activa en la sociedad, en la política y en la cultura.

2 Veáse, entre otros, Belsey, C., The subject of Tragedy, Methuen, Londres, 1985. La propia S. de Beauvoir subrayaba con fuerza el hecho de que la mujer es consciente de que el universo en su conjunto es masculino, que son los hombres los que la han modelado y dominado, manteniéndola en dependencia: «enfermée dans sa chair, dans sa demeure, elle se saisit comme passive en face de ces dieux à face humaine qui définissent fins et valeurs» (op.c., II, p.484).

Camps, V., El genio de las mujeres, Espasa Calpe, Madrid, 1990, p.145. Más adelante se precisa que «el discurso ético de nuestro tiempo se enfrenta con miedo a la determinación de la igualdad y sus contenidos... La aportación femenina a tal discurso - el discurso de la dignidad-, aportación singular e innovadora, es sin duda el reto que tiene planteado el feminismo a partir de ahora» (lb., p.163). 
Las experiencias acumuladas en muchos años de lucha por el reconocimiento de sus derechos y de su identidad han hecho posible que la mujer tenga una percepción diferente de su subjetividad e identidad, que posibilita la articulación de un nuevo discurso en el que la reflexión sobre lo humano deja de estar presidida por una identificación - velada o explícita- de lo masculino con lo universal. A partir de esta autoconciencia queda más disponible para proseguir el proceso abierto, para explorar nuevos caminos, para tomar nuevas iniciativas, para afrontar nuevos desafíos. En suma, para desplegar su propia creatividad y constituirse en sujeto activo dentro de los procesos sociales y culturales.

\section{PLANTEAMIENTO INICIAL.}

\section{I. Sensibilidades diferentes, objetivos comunes.}

Cuando se analizan los diversos criterios de aproximación a los movimientos feministas a lo largo del tiempo, y las diferentes valoraciones de que han sido y son objeto, se hace patente algo que es común a cualquier estudio histórico, a saber, que las convicciones, experiencias, actitudes, sentimientos, expectativas y concepciones de la vida de aquel que describe los hechos, desde el presente, condicionan sus percepciones y juicios, de modo que lo que es aprehendido en la historia narrada no son los hechos mismos, en su realidad originaria, sino en cuanto se vinculan, de un modo u otro, con situaciones que afectan al propio interprete. J. Grünfeld, por ejemplo, ha subrayado que, consciente e inconscientemente, quienes hacen historia seleccionan, simplifican o esquematizan los datos, dejando fuera lo que consideran menos importante y subrayando lo que para ellos es más esencial. En este sentido -ya se reconozca o no-cada historiador tiene, por así decirlo, su propia «filosofía de la historia» ${ }^{4}$. Esto explica la íntima relación existente entre el pasado que es objeto de estudio y el presente de quien lo estudia, como ha expuesto, entre otros autores, L. Febvres.

4 Grünfeld, J., «Historical Insight», en Rev. Univ. d'Ottawa, 38 (1968), p. 73,; el autor subraya la tendencia que existe a reducir el caos de los acontecimientos a un determinado orden, ritmo y movimiento con el fin de hacerlos, de algun modo, inteligibles. Al proceder de este modo, el historiador «... should remain conscious, even then, of the element of arbitrariness and subjectivity that necessarily enters into all combinations of fact» (Ib. p.90)

5 Febvre L., Combates por la historia, Ariel, Barcelona, 1971, p. 32: «El hombre no se acuerda del pasado, siempre lo reconstruye... arranca del presente y, a través de él, conoce e interpreta el pasado». Esta misma idea está latente, en el fondo, en la afirmación de Ortega y Gasset de que «el pasado no está allá, en su fecha, sino aquí, en mí. El pasado soy yo, se entiende mi vida» Ortega y Gasset, J., La historia como sistema, O.C., VI, Rev. Occidente, Madrid, 195052, p. 45 . 
Los diversos modos de afrontar el problema de la igualdad y desigualdad, desde ópticas feministas contrapuestas (liberales, militantes de izquierda, radicales), pueden constituir una ilustración esclarecedora de esta interacción entre las realidades históricas -o las ideas que están a su base- y el modo de describirlas y valorarlas en función de una determinada sensibilidad o marco de referencia. Desde una concepción conservadora, por ejemplo, se acepta más fácilmente que las desigualdades son «naturales» (incluyendo como tales la tradición, la costumbre, la fuerza del pasado), mientras que, desde otra perspectiva diferente se entiende que esas desigualdades arraigan en unas determinadas condiciones socio-históricas y culturales que pueden y deben modificarse ${ }^{6}$.

En este contexto de reflexión, parece un hecho indiscutible que la conciencia siempre más explícita y profunda que ha ido adquiriendo la mujer de su condición de persona, de su subjetividad e identidad, constituye un apoyo muy importante para proseguir el avance hacia ese nuevo feminismo creativo que se va configurando como aspiración compartida y proyecto común, más allá de las estrategias y programas específicos de los diferentes movimientos o grupos feministas. Porque la primera y más radical manifestación de este impulso deberá consistir precisamente en la reafirmación de la voluntad de seguir afrontando las resistencias que se oponen al avance hacia su igualdad plena y al reconocimiento de su diferencia en libertad, y que se enmascaran bajo criterios o pautas de comportamiento que, de forma implícita o encubierta, tienden a favorecer actitudes excluyentes o a prolongar sistemas de discriminación (legal, social, económica, política, cultural).

Sin embargo, sea cual sea el horizonte teórico desde el que se reflexione sobre la igualdad, es también cierto que, al insistir en la necesidad de establecer relaciones y compartir criterios que faciliten el logro de objetivos comunes, no puede obviarse el hecho de que entre ellas existen diferencias fundamentales que no pueden considerarse irrelevantes o secundarias. En otras palabras, es inevitable constatar que «hoy ya no es posible, ni en el plano teórico ni en el político, hacer invisible o encubrir la complejidad de las diferencias culturales entre mujeres... Las diferencias en razón de raza, nacionalidad, clase social, posición económica, nivel cultural, sexualidad, tradición, etc., elementos

" Teniendo presente esta idea, N. Bobbio observa que «el movimiento feminista ha sido un movimiento igualitario. La fuerza del movimiento dependió también del hecho de que uno de sus argumentos preferidos siempre ha sido independientemente de la veracidad de los hechos, que las desigualdades entre hombre y mujer aunque teniendo raíces en la naturaleza, han sido el producto de costumbres, leyes, imposiciones, del más fuerte sobre el más débil y son socialmente modificables». Bobbio, N., «Derecha e izquierda. Razones y significados de una distinción política», Taurus, Madrid, 1995, p. 144-46. 
todos ellos que son los ejes que conforman las identidades personales, son diferencias que marcan, separan, dividen y aun enfrentan a las mujeres entre sí. Son diferencias que interactúan y se entrecruzan, que se canalizan conjuntamente de diferentes maneras en diferentes contextos histórico-culturales»?

Más allá de esas diferencias, un objetivo común que puede ser asumido como factor dinamizador de los diversos movimientos feministas consiste precisamente en la interpretación crítica de su propio pasado, desvelando las causas que han estado a la base de la exclusión de la mujer, de su marginación y discriminación, así como la voluntad activa de recuperar los valores positivos, las cualidades específicas, las experiencias enriquecedoras y los modos de comprensión de la existencia individual y social que ha ido acumulando a lo largo del tiempo, con el fin de que, de una forma $u$ otra, sigan siendo operantes en el presente. Desde esta perspectiva, la reivindicación de la diferencia puede y debe ser un enriquecimiento individual y colectivo, no una obsesión estéril por reducir la feminidad a la simple contraposición de lo masculino. Porque, en último análisis, si es cierto que los sexos humanos «sólo en los cuadros descriptivos, de tan poca calidad científica como humana, aparecen jerarquizados ${ }^{8}{ }^{8}$, esto se debe a que la condición de persona iguala la mujer al varón, más allá de cualquier diferencia, en cuanto que ambos pertenecen al phylum hombre, en el que se integran los dos géneros.

\subsection{Autoconciencia personal y compromiso solidario}

La referencia a la persona, cuando se afrontan problemas de fondo relacionados con la mujer -en los que inciden factores conceptuales, histórico-sociales, culturales, educativos-, no es arbitraria ni carente de fundamento. En este sentido, considero muy esclarecedora la observación que hace P.Ricoeur cuando subraya que «si la persona vuelve es porque ella sigue siendo el mejor candidato para sostener los combates jurídicos, políticos, y sociales»", ya que otras nociones alternativas que

7 Santa Cruz, I., «Sobre el concepto de igualdad: algunas observaciones», Isegoria, 6 (1992), p. 149. La autora completa su pensamiento subrayando que poner de relieve críticamente las diferencias entre las mujeres, cuando se reivindica su igualdad, «no destruye la política feminista, sino que la complejiza y la enriquece tanto teórica como prácticamente» (lb., 149).

× Castro, C., «La mujer en una sociedad nueva», Razón y Fe, T. 204 (1981), p. 208.

- Ricoeur, P., Amor y justicia, Caparrós editores, Madrid, 1993, p. 95-103, El mismo E. Mounier reconocía que lo mejor que puede sucederle al personalismo es que -después de haber despertado en el interior de muchos hombres el sentido total de su condición de tales-, desaparezca sin dejar rastro, totalmente confundido en el rumbo cotidiano de los días (texto recogido en Moix, C., El pensamiento de E. Mounier, Estela, Barcelona, 1969, p. 184) 
la han venido desplazando hasta ahora («conciencia», «sujeto», «yo») han perdido su sentido e impulso originarios como consecuencia del impacto de doctrinas como el psicoanálisis, el estructuralismo, las posiciones críticas de la Escuela de Frankfurt y otras orientaciones contemporáneas del pensamiento ${ }^{16}$.

Este retorno no significa, por otra parte, la adhesión acrítica a determinadas formulaciones del «personalismo», o bien a antropologías que nacieron y se desarrollaron estrechamente vinculadas a concepciones filosóficas, religiosas o culturales que hoy están cuestionadas, aunque se puedan encontrar en ellas elementos valiosos y propuestas orientadoras. En cualquier caso, sigue siendo una referencia importante el carácter de fin en sí que la moral kantiana reconoce a la persona -idea que constituye la clave de su sistema de pensamiento-, como lo es también el planteamiento que hace $M$. Scheler en su esfuerzo por llegar a la fundamentación de un personalismo ético.

La apelación a la persona -como sujeto consciente, libre y autónomo-, a pesar de las dificultades existentes para determinar cómo y por qué constituye un valor absoluto ${ }^{11}$, es un hecho constante cuando se abordan cuestiones relacionadas con la ética, la política, el derecho o la antropología cultural, aunque es evidente que esa referencia verbal puede derivar, en muchos casos, en generalizaciones que no tienen una incidencia real en la praxis cotidiana ${ }^{12}$. Piénsese, por ejemplo, en el art. 10.1 de la Constitución Española, o en el documento final de la Conferencia sobre la Seguridad y la Cooperación en Europa (Helsinki, 1975) o en la IV Conferencia Mundial sobre la mujer, en la que se hace referencia a la defensa y promoción de la igualdad de derechos y a la dignidad humana intrínseca de mujeres y hombres (Beijing, 1995).

Una cuestión distinta es que la realización práctica de los derechos vinculados a la persona se logre o no plenamente en un Estado de Derecho. El caso de la mujer, puede ser ilustrativo de esta dificultad, a

11) Ib., p. 99. Esta apuesta por la persona exige, sin duda, una profundización en el lenguaje, en los criterios que inspiran su actuación y sus actitudes, en el compromiso para hacer efectivas en la práctica real sus aspiraciones; pero esto no impide que el concepto mismo recupere la fuerza y el significado profundos vinculados a él.

1 Cf. Cortina, A., Etica mínima. Introducción a la filssofia práctica, Tecnos, Madrid, 1986, p. 251 y ss. La autora explica las razones existentes para esclarecer qué tipo de nexo une necesariamente los conceptos «valor absoluto» - «fin en sí mismo» - «persona», observando que no se trata de un nexo analítico ni una conexión intuitivamente captable. Por otra parte, y teniendo en cuenta que la historia del pensamiento ha acuñado diferentes categorías para destacar la especificidad del ser humano (racionalidad, función simbólica, capacidad de autodeterminación, etc.) se pregunta si esas categorías son suficientes para expresar plenamente lo que implica el dato "persona» y el carácter inviolable que se le atribuye.

12 Moltmann, J., La dignidad humana, Edic. Sigueme, Salamanca, 1983, p., 50 y ss. 
pesar de las intenciones de los legisladores. Tove Stang Dahl, por ejemplo, ha llamado la atención sobre el hecho de que en la medida en que vivimos en una sociedad donde hombres y mujeres tienen trayectorias diferentes en la vida, diferentes condiciones de existencia, con distintas necesidades y oportunidades, «las normas legales necesariamente afectarán de forma diferente a hombres y mujeres» ${ }^{13}$.

En cualquier caso, se plantea aquí, una vez más, la necesidad de tomar conciencia de que la comprensión de los derechos humanos exige no sólo ahondar en su fundamentación teórica sino también entenderlos y explicarlos en su dimensión total, que se concreta últimamente en su incorporación al derecho positivo como condición previa para exigir su realización en la praxis cotidiana ${ }^{14}$. No es inútil recordar que en el Estado social de Derecho el ejercicio del poder político se orienta a promover y desarrollar los valores y exigencias de la comunidad, esto es, a desarrollar y transformar el Estado-sociedad. De ahí que su aspiración sea hacer que prevalezca la llamada «función promocional del derecho», orientada a la realización efectiva del valor de la justicia. En otras palabras, el Derecho, en todas las fases de su proceso (génesis, interpretación, aplicación), deberá adecuarse, en la mayor medida posible, a las aspiraciones y necesidades de los individuos y de los grupos sociales, de modo que los valores que van emergiendo en los procesos de transformación de la sociedad sean realmente su referencia última ${ }^{15}$.

Un modo de entender este empeño es el esfuerzo actual por hacer efectiva la presencia de la mujer en el ámbito de la política y del poder, esto es, en los procesos de toma de decisiones que afectan a la socie$\mathrm{dad}$, venciendo resistencias o actitudes contrarias que no constituyen

1.) Stang Dahl, T., Derecho de la mujer: Una introducción a la jurisprudencia feninista, Vindicación feminista, Madrid, 1987, p. 22; la autora entiende que no puede considerarse una postura unilateral considerar la perspectiva y necesidades de un grupo específico, como son las mujeres, puesto que «aún hoy día es el derecho masculino el que se aplica en la mayoría de las áreas, de modo que para la mayor parte de las opiniones son las necesidades y conflictos de los hombres los que están codificados en el derecho» (lb., p. 22). Prolongando esta reflexión, se insiste en que el derecho es una parte importante de la hegemonía cultural que los hombres poseen en nuestras sociedades y que la actual infrarepresentación de mujeres en importantes instituciones políticas y en las profesiones puede explicarse como una consecuencia natural del antiguo concepto de mujer (lb., p. 23).

14 Peces-Barba Martínez, G. "Sobre el fundamento de los Derechos Humanos», en el vol col. El fundamento de los Derechos Humanos, Ed. Debate, Madrid, 1989, p. 265 y ss.

15 Pasini, D., Problemi di filosofia della politica, Jovene, Napoli, 1977, p. 230-231. El autor explica cómo y por qué la función preminente del derecho se ha ido transformando radicalmente, pasando de una función conservadora-represiva, típica del Estado monocrático, a la función conservadora de garantía, que caracteriza al Estado de derecho, y finalmente a la función innovadora y promocional, que es propia del Estado social. 
sólo una cuestión coyuntural, como ha podido creerse en algunos casos, sino más bien «un problema estructural» que continúa sin resolverse $^{16}$.

Paralelamente, se ha ido imponiendo la convicción de que es preciso ir más allá, en un esfuerzo de autocrítica y discernimiento, para poder determinar no sólo aquello que, en las tendencias feministas dominantes, favorece los intereses de las propias mujeres sino también lo que puede contribuir, además, a combatir las causas que generan cualquier forma de explotación y dominación, sean cuales fueren los sujetos que las padecen, sin ignorar las contradicciones de clase o la complejidad de la realidad, o incluso la posibilidad de ser -de forma consciente o inconsciente- cómplices de las desigualdes e injusticias que se pretenden erradicar.

No es casual que en los últimos años, superando cualquier tentación de ensimismamiento, haya venido tomando forma un feminismo más pragmático y solidario, decidido a hacer causa común con otros colectivos y grupos reivindicativos, ya sea dentro de un determinado país, o bien en contacto con organizaciones y movimientos existentes en pueblos o culturas diferentes. Ni es tampoco casual que el sexismo, o sometimiento de las mujeres a los varones sobre la base de una supuesta superioridad masculina intrínseca, sea percibido en su estrecha relación con el racismo -opresión estructurada de una raza por otra basado en una supuesta inferioridad biológica- y con el clasismo que, en último análisis, considera a la persona como un instrumento o fuerza de trabajo, como una mercancía comercializable, un dato más para calcular el coste de la producción ${ }^{17}$.

En este contexto, adquiere relevancia indudable la contribución que ha hecho el movimiento feminista, especialmente en Latinoamérica, para la recuperación del valor simbólico del cuerpo de la mujer, que ha sido y sigue siendo objeto de explotación, o fuerza de trabajo, o instrumento de placer, o recurso para la manipulación y el control de la población. Ivone Gebara ha resaltado el hecho de que «hablar de cuerpo no significa solamente hablar del cuerpo individual de cada persona.

16 Martínez Ten, C. - Paramio, L., «Nuevo contrato entre hombres y mujeres», Leviatán, 69 (1997), p. 98-99.; los autores completan esta idea subrayando que « hay barreras que impiden o dificultan la entrada y participación de mujeres en el poder. A estas barreras el feminismo las ha denominado el techo de cristal, y estudiando su composición se advierte que están constituidas por diferentes elementos, como la supremacía masculina en los mecanismos de cooptación, la sobrecarga que supone la política junto a las responsabilidades familiares y el trabajo asalariado, la falta de socialización de las mujeres para el poder y la toma de decisiones, o la ausencia de modelos en este sentido» (lb.,p. 99).

17 Copeland, Sh., «Interacción de racismo, sexismo y clasismo en la explotación de las mujeres», Concilium, 214 (1987), p., 365. 
Significa también tocar en el cuerpo social, en el cuerpo cultural de los negros, indígenas, asiáticos y otros grupos étnicos que manifiestan su propia originalidad a partir de su cuerpo ${ }^{18}$. En suma, la entrada del cuerpo en el pensamiento filosófico significa la salida del universalismo abstracto que era, en realidad, el universalismo masculino y occidental.

Las breves consideraciones que anteceden ponen de manifiesto que la voluntad de la mujer de ser reconocida como persona es inseparable de su decisión de colaborar a que el «otro»-cualquier «otro»- sea también persona. Creatividad, en suma, es también solidaridad.

\section{ALGUNOS MARCOS DE REFERENCIA.}

\subsection{Ampliar el margen de lo posible.}

Además de este planteamiento militante y comprometido a que hemos hecho referencia-aunque estrechamente vinculado a él-, se abren en muchos campos posibilidades nuevas de actuación que amplían el horizonte de la creatividad femenina.

Entendida en sentido amplio, esa creatividad constituye una noción abarcadora y trasciende al género. En el ámbito individual, por ejemplo, se relaciona con las actitudes, pensamientos y vivencias de la persona, en el sentido de que impulsa a dilatar el margen del presente, a buscar nuevos sistemas de referencia, a ampliar los vínculos con la realidad externa y con los demás. Y en relación con el mundo social y cultural, la actitud creativa se concreta, entre otras cosas, en la presencia activa dentro de los procesos que tienen lugar en él, sin hacer abstracción de los condicionamientos que están a la base de éstos ni de las múltiples distorsiones que los centros de poder aspiran a introducir en la dinámica de la evolución social y, en suma, en la capacidad de innovar, de someter a crítica lo establecido, de reformar las mentalidades amorfas y de ir más allá de cualquier intento de planificación totalitaria del futuro.

Siendo la creatividad una actitud genuinamente ética, se comprende que hay siempre en ella una apelación implícita a lo que se ha llamado moral como actitud ${ }^{19}$, expresión que hace referencia a la capacidad de ir más allá de los marcos vigentes de comportamiento, teniendo

Is Gebara, I., «Presencia de lo femenino en el pensamiento cristiano latinoamericano», en el vol. col. Cambios social y pensamiento cristiano en América latina, Ed. Trotta, Madrid, 1993. p. 209.

15 López Aranguren, J.L., Etica de la Felicidad y otros ensayos, Tecnos, Madrid, 1988, p.111. 
presente que en una sociedad monolítica existe siempre la tendencia a una moral estática, o bien a imponer un determinado código moral. Una actitud moral creativa se inspirará, en suma, en la idea de que es posible abrir esa sociedad a nuevas alternativas a través de la ruptura con lo establecido y de la voluntad de invención de lo que está todavía por establecer.

Limitándonos aquí a un ámbito concreto relacionado con la creatividad de la mujer, parece indudable que sus posibilidades en relación con el desarrollo de la actividad intelectual y su presencia en las instituciones académicas, en especial en las que se imparten las enseñanzas de los saberes propios de las ciencias humanas y sociales han estado limitadas no sólo por la dificultad de acceso a la docencia, controlada tradicionalmente por el poder masculino, sino también por los contenidos mismos que se imparten y que, de una forma u otra, marginan aspectos y valores íntimamente vinculados a su condición femenina. Por ejemplo, se han venido presentando como «naturales» realidades o conceptos relacionados con la mujer y que, en realidad, son construcciones histórico-sociales que propician o enmascaran la dominación ejercida sobre ella y constituyen, en suma, la negación de su condición de persona ${ }^{20}$. Esta constatación está a la base de la decisión de hacer frente a determinadas orientaciones de los diferentes saberes académicos elaborados en las centurias anteriores exlusivamente por varones y que se inspiraban en presupuestos considerados inamovibles.

La posibilidad de ruptura con estos esquemas rígidos de pensamiento constituye el transfondo de los planteamientos críticos de diversos pensadores contemporáneos, compartidos y alentados por mujeres que han venido profundizando en el análisis de los procesos de comunicación, en el lenguaje, en los condicionamientos del conocimiento y en la complejidad del discurso científico. Las aportaciones de autoras como M.M. Gergen, S. Harding o D.F. Schnitman, entre otras muchas, son esclarecedoras y estimulantes. ${ }^{21}$

20 Stolcke, V., «¿Qué revolución feminista en la enseñanza: «Estudios de la mujer» o «integración curriculars??, Papers, nl 30, 1988, p.39-40. La autora manifiesta que de la combinación de sus vivencias personales y del esfuerzo de ir más allá de ellas ha resultado su interés por lo que denomina «procesos de naturalización de desigualdad social», en las que ve una vinculación fundamental entre esta última y la desigualdad social y racial. Su conclusión es que siempre que, por razones sociopolíticas que pueden variar históricamente, se naturalizan ideológicamente las relaciones sociales, una consecuencia es el control y la dominación ejercida sobre las mujeres (Ib., p.40).

21 Gergen, M.M.(ed.), Feminist Thought and the Structure of Knowledge, New York University Press, London-N.York, 1988; Harding, S., The Science, Cornell University Press, Ithaca, 1986; Schnitman, D.F. (ed.), Question in Feminism Nuevos Paradigmas, Cultura y Subjetividud, Paidos, Barcelona, 1984. 
Es importante, a mi juicio, tomar conciencia de que este esfuerzo se enmarca en las tendencias epistemológicas y metodológicas que han venido imponiéndose en las ciencias humanas y sociales, en cuanto que -partiendo de supuestos diferentes-convergen en la incitación a la búsqueda, a la reflexión crítica, a la ruptura con criterios dogmáticos y verdades absolutas, al cuestionamiento de posiciones reduccionistas y de códigos impuestos.

Las posiciones mantenidas por K. Popper o E. Bloch, entre otros, en las cuales se habla de complementariedad, búsqueda, Asueño diurno@, universo abierto o conciencia anticipadora del futuro, son suficientemente indicativas del sentido de esta nueva orientación. Desde otro ángulo de reflexión, E. Morin ha subrayado la importancia que tiene poder disponer de un pensamiento capaz de concebir y comprender la complejidad intrínseca que se halla, según el, en el mismo corazón de la ciencia: «una teoría no es una llegada, es la posibilidad de una partida; no es una solución, es la posibilidad de tratar un problema» $)^{22}$.

La experiencia y la cultura femeninas, en cuanto abiertas al futuro y portadoras de elementos valiosos para activar procesos de cambio, encuentran un estímulo importante en esta «conciencia de lo posible» que lleva consigo la capacidad de hallar alternativas diferentes, de abrir perspectivas nuevas. Y esto, tanto si se trata del ámbito de las opciones personales de cada mujer, como de su esfuerzo por hacer efectivas las aspiraciones a la igualdad de su género, o de su empeño solidario para mantenerse abierta al interés común humano. Esto explica su resistencia a aceptar acríticamente saberes presuntamente absolutos, o conceptos unitarios de racionalidad que exigen una adhesión absoluta. En este sentido, se explica la apelación que hace V. Camps a lo que denomina «actitud irónica» y desmitificadora, que describe como «aquella que sabe separar lo que debe ser apetecido a toda costa de lo que sólo merece ocupar un lugar secundario. Una mirada que discierne en el pasado y en el presente lo que hay que conservar para el futuro» ${ }^{23}$.

\subsection{Nuevas estructuras mentales}

La atención que viene prestando la mujer al análisis de los diferentes modos unilaterales de entender la racionalidad, y que están a la base de la posición subordinada en que se ha encontrado respecto al hombre, haciendo muy difícil el acceso a la conciencia de sí misma y

22 Morin, E., Ciencia con consciencia, Anthropos, Barcelona, 1984, p. 38

2.3 Camps, V., El genio de las mujeres, Op.cit., p.163 
al desarrollo de su subjetividad ${ }^{24}$, coincide también con el esfuerzo contemporáneo por recuperar la fuerza emancipadora de la razón, al mismo tiempo que se intentan desvelar las causas que han posibilitado sus deformaciones a lo largo de la modernidad, ya se trate de la razón instrumental, de las corrientes neopositivistas, de determinados planteamientos historicistas o de la conversión del racionalismo científico en ideología.

Es significativa, por ejemplo, la referencia que hace Habermas a la necesidad de conseguir que el pensamiento filosófico y la construcción teórica de las ciencias sociales contribuyan a «hacer accesibles las dimensiones ocultas de la razón y ello, precisamente, a través del poder explorativo de la propia razón ${ }^{25}$. Se trataría, según él, de poner en movimiento la interrelación de lo cognoscitivo-instrumental con lo moral-práctico y lo estético-expresivo que constituye un conjunto paralizado en la alienación de la vida cotidiana. El mismo autor ha subrayado la necesidad de que la conciencia trascendental llegue a concretizarse en la práctica del mundo de la vida, esto es, a «cobrar carne y sangre en materializaciones históricas ${ }^{26}$.

En cualquier caso, al analizar el proceso de modernización se han ido desvelando las insuficiencias de su pretensión inicial de hacer que prevaleciera en la comprensión de todos los aspectos de nuestro comportamiento un determinado modo de entender la racionalidad humana ${ }^{27}$. Las mujeres, en particular, descubren cómo la oposición que ha venido estableciéndose con el hombre está en estrecha correspondencia con otra previa que se daba por supuesta entre razón y naturaleza y que, de una forma u otra, conducía a hacer que quedara excluida de participar activamente en una sociedad que, en último análisis, está sometida al dominio del hombre ${ }^{28}$. Recientemente, y tras recordar los motivos que hacen posible y necesario que el feminismo se inscriba

24 Una aportación importante es la obra de Nye, A., Words of power: a Feminist Reading of History of Logic, Routledge, Londres, 1990.

25 Habermas, J., Ensayos Políticos, Ed. Península, Barcelona, 1988, p.108.

26 Id., Pensamiento postmetafïsico, Taurus, Madrid, 1990, p. 17; el autor hace referencia a diversos intentos contemporáneos de «devolver a sus contextos esa razón abstractamente endiosada y de situarla en los ámbitos de operación que le son propios» (lb; p. 17).

27 Los educadores más clarividentes, por ejemplo, han subrayado que la formación inspirada en criterios racionalistas abstractos, que, como lamentaba Rousseau, no ve en el niño más que un adulto futuro, atentaba gravemente contra los mecanismos normales que configuran la personalidad, tal como existen en las diversas sociedades y culturas. En suma, el niño es víctima de una representación negativa de la infancia y del desarrollo de la personalidad. Una profundización en el análisis de las consecuencias de planteamientos de esta naturaleza puede verse en Mendel, G., La descolonización del niño, Ariel, Barcelona, 1974.

2N Touraine, A., «Modernité et spécificités culturelles», R.I.Sc.S., n1 118 (1998), p., 501. 
decididamente en el modo de pensar que inaugura la Ilustración, E. Beltrán Pedreira ha subrayado el hecho de que la existencia de diferentes posiciones feministas no impide que todas ellas compartan una misma actitud crítica frente a la «razón patriarcal», aunque esa crítica no implica, en modo alguno, ponerse del lado del irracionalismo sino únicamente cuestionar manifestaciones unidimensionales de la razón y posiciones esencialistas inspiradas en ellas, buscando una nueva reafirmación del valor de lo individual. ${ }^{29}$

Esta búsqueda de alternativas encuentra un estímulo importante dentro de los movimientos contemporáneos que se agrupan bajo el concepto de postmodernidad. Aún reconociendo la equivocidad de este término y los diversos modos de interpretarlo, es posible descubrir en él, de forma explícita o implícita, una sensibilidad nueva respecto a las microteorías o discursos fragmentarios - sin que ello signifique relativismo arbitrario o dispersión anárquica que haga imposible la comunicación e interrelación de saberes--, en contraposición a los grandes sistemas y a las concepciones dogmáticas. V. Camps ha observado que «las mujeres tienden a encontrarse cómodas y a manejarse bien en ese modelo ${ }^{30}$, en cuanto que el acento se pone ahora en las diferencias y se evita reducir a la persona a puras generalizaciones de intereses.

Más en particular, y desde la perspectiva en que se sitúa nuestra reflexión, pienso que tiene un gran valor de ejemplaridad el plantemiento crítico que hace $\mathrm{M}$. Gatens al analizar determinados criterios básicos en que se ha inspirado la filosofía occidental. De acuerdo con su planteamiento, ni el rechazo total de esa filosofía, propuesto por algunos grupos feministas radicales, ni una comprensión artificial de la complementariedad varón-mujer pueden aportar nada positivo. Un afrontamiento lúcido del problema debería consistir, según ella, en desvelar cuáles han sido las dicotomías de ese pensamiento filosófico que han estado presentes desde sus mismos orígenes y las consecuencias que se han derivado de ellas ${ }^{31}$. La actitud más fecunda no es, en suma, ni el rechazo de la filosofía ni la descalificación del propio femi-

24 Beltrán Pedreira, E., «Público y privado. (Sobre feministas y liberales: argumentos en un debate acerca de los límites de lo político)», Doxa, 15-16 (1994), p. 390-91.

3) Camps, V., El genio de las mujeres..., op.cit., p.161. Un análisis amplio de las relaciones entre modernidad y postmodernidad, con referencias explícitas a la incidencia que han tenido en el feminismo las diversas posiciones que han venido manteniéndose, puede verse en Von Beyme, K., Terria política del siglo XX. De la modernidad a la postmodernidad, Alianza Universidad, Madrid, 1994, p. 242 y ss.

31 Gatens, M., Feminism And Philosophy, Polity Press, Cambridge, 1993, p. 92.: «The claim here is not that dichotomous thought is bad or oppressive per se, but rather that it can covertly promote social and political values by presenting a conceptual division as if it were a factual or natural division». 
nismo, sino la decisión de contribuir a hacer posible la transformación de ambos, of reciendo medios para conceptualizar y vivir otras formas diferentes de pensamiento que tendrán su expresión en la política y en la ética.

Más en particular, se trataría de ofrecer una concepción integrada que reconozca la conexión entre ser y conocer, entre política y ética, entre cuerpos y mentes, evitando el recurso a un ejercicio teórico puramente abstracto. En este sentido, la autora entiende que la utilización feminista de la teoría psicoanalítica y la «deconstrucción» han abierto un camino que ofrece medios para integrar razón y emoción, mente y cuerpo, naturaleza y cultura, sin asumir la dicotomía que estructura estas distinciones ${ }^{32}$.

Efectivamente, el psicoanálisis, entendido e interpretado con un criterio abierto y no dogmático, ha sido una ayuda importante para la comprensión de la condición de la mujer. Entre otras cosas, ha llamado la atención sobre la necesidad de distinguir entre el análisis descriptivo que hace Freud de la situación femenina y entre sexo y género, de tal manera que puedan asumirse determinados puntos de vista del psicoanálisis sobre lo que J. Van Herik llama «el poder transgeneracional de los procesos inconscientes para reproducir la asimetría de los géneros ${ }^{33}{ }^{3 .}$. Desde esta perspectiva, se reconoce la existencia en el propio Freud de sugerencias importantes para eliminar esa asimetría, en sus raíces inconscientes, y para encontrar las estrategias que permitan un cambio profundo de la cultura patriarcal dominante.

Una estudiosa española de la obra de Freud, Norma Ferro, ha llamado la atención sobre el hecho de que «parecería que en el psicoanálisis, al hablar de la mujer, hay una dependencia del dogma freudiano que impide la evolución y la rectificación. Y, sin embargo, Freud nunca dudó en modificar sus propias teorías cuando la mayor comprensión de los procesos psíquicos lo hacía necesario ${ }^{34}$. Advierte, sin embargo, que sería insuficiente atenerse únicamente a la teoría psicoanalítica sin tener en cuenta las aportaciones de otras ciencias sociales, no dudando en someter a crítica, entre otras cosas, la falta de atención del psicoanálisis al rol de subordinación en la mujer, independientemente de sus procesos intrapsíquicos, a la vez que pone de manifiesto la ne-

32 Ib., p.99: «the disjunctive relations internal to the reason/passion, mind/body and nature/ culture dichotomies must be eroded»

3 Van Herick, J., "Crítica feminista del psicoanálisis clásico», Concilium, n. 176 (1982), p. 4l4; la autora hace referencia a algunas obras significativas en que, de una forma u otra se expresa esta aspiración común.

34 Forro, N., El instinto maternal o la necesidad de un mito, Siglo XXI Ed., Madrid, 1991, p.XI. 
cesidad de analizar el funcionamiento de la cultura y de los procesos de cambio.

Esta constatación no impide reconocer que Freud no sólo aportó un método terapeútico, un estudio del inconsciente de la personalidad y del desarrollo humano, sino también una serie de afirmaciones sobre la propia sociedad y sus instituciones, de tal manera que el individuo y sus pulsiones tienen estrecha relación con el grupo social que le hace internalizar o interiorizar los valores (super-yo). Por tanto, las necesidades básicas del ser humano, en cuanto organismo biológico, no pueden considerarse al margen de la realidad social ${ }^{35}$. Esto explica que determinados movimientos feministas hayan decidido utilizar las teorías de Freud no como psicólogo (de la mujer) sino como teórico de la cultura (de géneros asimétricos). Por otra parte, esta concepción ha sido defendida por una determinada corriente de intérpretes según los cuales el psicoanálisis constituye un tipo de disciplina humanística que no pretende explicar la conducta conforme a leyes generales rigurosas, sino que tiende únicamente a desvelar las motivaciones que están a la base de la conducta de los individuos y de las orientaciones culturales $^{36}$.

Como prolongación de esta labor de discernimiento crítico, dentro del movimiento feminista se ha prestado también, lógicamente, una atención relevante al análisis que diversos autores, como $\mathrm{H}$. Marcuse -profundizando o corrigiendo la doctrina de Freud-, han venido ha-

35 Bocock, R., Freud and Modern Society, Nelson, London, 1976. En diversos capítulos de esta obra, el autor muestra cómo a partir de Freud es imposible una clara distinción entre individuo y sociedad y, por tanto, entre psicoanálisis y sociología. En este sentido, entiende que la escuela de Frankfurt ha acertado al hablar del psicoanálisis como una teoría social del hombre vinculándolo tanto con la sociología de inspiración marxista como con la de Weber. Una profundización en las relaciones entre psicoanálisis y sociedad se encuentra en el vol. de Castilia del Pino, C., Psicounálisis y marxismo, Alianza editorial, Madrid, 1971, p. 109 y ss; Roazen, P., Freud. Su pensamiento político y social, Martínez Roca, Barcelona, 1970.

3n Ricoeur, P., Freud: una interpretación de la cultura, Siglo XXI, México, 1970. Es importante también tener presente la observación que hace G. W. Allport a propósito del psicoanálisis en el sentido de que el criterio freudiano sobre los motivos de la conducta humana puede ser un modelo aceptable únicamente para determinadas conductas no normales. Su punto de vista personal, que denomina "autonomía funcional de los motivos», sostiene que éstos pueden ser independientes de sus orígenes (y generalmente lo son en las personas sanas); tienen por función animar y guiar la vida hacia «objetivos que armonizan con la estructura actual, las aspiraciones actuales y las condiciones actuales" (Allport, G. W. Qué es la personalidad, Edic. Siglo XX, Buenos Aires, 1976, p. 66). El autor reconoce en las tendencias contemporáneas de neofreudismo dos notables adelantos: una aceptación más amplia de las contribuciones de la cultura a la enunciación de un yo más activo, intencional y de mayor alcance que aquel que había sido concebido por Freud, acosado por el ello, el super-yo y la realidad externa. 
ciendo a propósito de las condiciones de existencia en la sociedad contemporánea ${ }^{37}$. En particular, se tiene presente la dificultad de hacer efectiva en esa sociedad la complementariedad entre espíritu y cuerpo, razón e imaginación, necesidades intelectuales y tendencias instintivas, idea que está a la base de Eros y civilización ${ }^{38}$.

El punto de partida es la constatación de que el aparato psíquico es el resultado de la tensión dinámica entre estructuras inconscientes y conscientes, entre procesos primarios y secundarios, entre «instintos de vida» (Eros) e «instintos de muerte» (Thanatos). La historia del ser humano, ya sea en un plano ontogenético (crecimiento del individuo desde la primera infancia hasta su existencia consciente en sociedad), ya sea en un plano filogenético (desde los estadios primitivos hasta las instituciones más evolucionadas de la convivencia civil), está caracterizada por la represión constante de los instintos primarios; esto es, el principio del placer queda sacrificado en favor del principio de realidad. En la medida en que tienden hacia una meta destructiva -la satisfacción considerada como fin en sí misma-, los instintos primarios deben ser inhibidos, desviados de su meta natural para que puedan resultar productivos. De esta represión nace la llamada «civilización»; y el paso al estado de seguridad y estabilidad que es propio de ella acontece a través de la pérdida de la primacía del principio del placer y la sublimación represiva de la libido. Esas fuerzas, las fuerzas reprimidas, continúan ejerciendo una secreta presión en las zonas inconscientes de la $P$ siche y están en el origen del «malestar de la cultura» denunciado por Freud ${ }^{39}$.

En este contexto de reflexión -y teniendo presentes las dificultades que continúa encontrando la mujer para hacer efectivas sus aspiraciones en la sociedad- ha ido imponiéndose la evidencia de que un medio insustituible para ir más allá de los condicionamientos que bloquean su autonomía y creatividad es su intervención en el ámbito educativo y en sus contenidos, en cuanto que puede hacer posible otra forma de inserción de la persona en su propia cultura, esto es, en el

$\therefore$ Landes, J.B., «Marcuse's feminist dimension», Telos, n 141 (1979), p., 158-165. Amplias referencias a Marcuse y a sus aportaciones básicas pueden verse en la escritora Puleo, A.H., Dialéctica de la sexualidad. Género y sexo en la filosofia contemporánea, Cátedra, Madrid, 1992.

is Marcuse, H. Eros y civilización, Seix Barral, Barcelona, 1968.

3. Freud, S., El malestar de la cultura, Alianza Editorial, Madrid, 1995. Este «malestar» surge de que la cultura impone al hombre trabas a la satisfacción del instinto (prohibición del incesto, censura de la sexualidad infantil, canalización rígida de la sexualidad en las estrechas vías de la legitimidad y la monogamia, obligatoriedad del imperativo de la procreacción, etc.). La cultura sólo es otro nombre del super-yo que lleva a cabo la tarea primordial de la prohibición de los impulsos que son incompatibles con el orden social. 
conjunto de ideas, valores, actitudes y objetivos que rigen su vida individual, social e histórica.

Es evidente que el ambiente social no es la única clave para la comprensión del sujeto humano -hombre o mujer-, ni la única medida para establecer su desarrollo. Pero es innegable su influencia en el proceso de aculturación de la persona, fundamentalmente a través de los dinamismos educativos. En efecto, una parte importante de la participación en la propia cultura es, como ha subrayado G.W. Allport ${ }^{40}$, la ejecución de un determinado rol: el educando no sólo recibe de la sociedad informaciones, valoraciones o apoyos, sino que adquiere conciencia de su deber de integrarse en ella y colaborar con los demás. Esos roles son también aprendidos, en cuanto se transmite a los escolares una determinada imagen de lo que deben ser como hijos, como compañeros, como miembros de un grupo o como pertenecientes a un determinado sexo.

Ahora bien, el modelo cultural vigente en una sociedad no tiene por qué ser asumido acríticamente por el sujeto; es cierto que cada persona percibe a su modo esa pluralidad de roles; pero, desde su propia madurez y convicción, puede y debe decidir su aceptación, o bien su rechazo, juntamente con las pautas y los criterios vinculados a ellos, en caso de ser percibidos como una mera imposición externa. En suma, su asimilación e incorporación en la propia estructura de la personalidad sólo puede realizarse a través de una labor previa de discernimiento que presupone, lógicamente, el acceso a un nivel básico de autoconciencia.

Cuando se pregunta, pues, por el significado de la cultura, no se trata únicamente de ofrecer un horizonte de adaptación a las pautas sociales vigentes en una sociedad. La cultura puede ser también disidencia y tener una función de desadaptación, en cuanto que entraña el rechazo de determinadas pretensiones que están a la base de una concepción puramente pragmatista y de la obsesión -subyacente a ella-de mantener, a cualquier precio, la continuidad y estabilidad de un siste$\mathrm{ma}^{41}$. Esto explica, entre otras cosas, por qué, yendo más allá de los planteamientos tradicionales, J. Duvignaud ha querido poner de mani-

40 Allport, G.W, Pattern and growth in personality, Holt, N.York, 1961; una reflexión más amplia sobre los planteamientos de este autor puede verse en Ronco, A., «Personalità $e$ educazione secondo G.W. Allport», Orientamenti Pedagogici, vol. XVI, (1969), p. 786 y ss.

41 Ricoeur,P. «La Parole est mon royaume», Esprit, 23 (1955), p. 194: Je dirai paradoxalement que toute culture introduit non seulement un délai dans l'adaptation, mai encore un facteur de désadaptation, de désenchantement, de désensorcellement technique... Cette fonction de désadaption par rapport à l'immédiateté, qui me parait être le grand problème du loisir (et en général de la jouissance des biens que nous consommons), met en déroute toute philosophie étroitement pragmatiste de la culture (lb., p, 195). 
fiesto que no es aceptable una consideración puramente negativa de la anomia; al contrario, constituye en muchos casos una actitud vital subversiva, en cuanto que implica adelantarse a la experiencia vivida, lo cual es una incitación a transformar la relación protectora que existe entre el modelo fijado por una cultura o tradición y las posibilidades que tiene un individuo; en otras palabras, equivale a «ir de lo simplemente admitido a lo extraño, de lo convenido a una diferencia percibida a través de una relación simbólica» ${ }^{42}$, esto es, a dar a las personas la posibilidad de buscar algo distinto a lo ya dado o a lo ya vivido.

Desde el plano del conocimiento, y como reacción contra la prevalencia de modos unilaterales de concebir la racionalidad, una de las formas en que se manifiesta esta disconformidad es la búsqueda contemporánea de un equilibrio dinámico entre el pensamiento y la sensibilidad, entre el razonamiento lógico y la intuición, entre el conocimiento abstracto y la percepción profunda de la realidad. Si es cierto que el intelectualismo separa la vida sensible de la vida espiritual en su totalidad y relega o margina ámbitos importantes de la existencia, como si la realidad se redujera a hechos únicamente cognoscibles por la razón, lo es también que, como contrapunto a este movimiento, se ha venido afirmando en la cultura una reacción vital y espontánea que empuja al hombre a ir más allá de la pura inteligencia abstracta y de visiones unilaterales de la racionalidad que se inspiran, por ejempo, en el criterio de las ciencias físicas.

Esta reorientación explica que, a lo largo de las últimas décadas, el análisis de los acontecimientos que han tenido lugar en el ámbito de la psicología (por ejemplo, el descubrimiento de las riquezas del pensamiento simbólico), o del psicoanálisis (la revelación del mundo de los arquetipos), o de la filosofía (retorno a lo concreto más allá de las abstracciones, mayor sensibilidad a la experiencia inmediata y a las nuevas formas de percepción de lo real), hayan ido poniendo de manifiesto que la visión del mundo que imponía un cierto realismo intelectualista no puede considerarse ya aceptable, en cuanto que se ha hecho posible una comunión más amplia de nuestro ser profundo con las cosas vivas. Como reacción vital y espontánea, la cultura incita ahora a ver lo que la inteligencia abstracta y el pensamiento técnico no valoraban.

Esta nueva mirada sobre la realidad descubre aspectos inaccesibles al puro conocimiento racional. Detrás de la forma, detrás del conocimiento que explica, existe una posibilidad de participación que sólo

42 Duvignaud, J., «Herejía y subversión. Ensayos sobre la anomia», Icaria, Barcelona, 1990, p., 35. Desde estos supuestos, parece evidente que «la misma anomia ha cambiado de sentido con nuestra sociedad y nuestra civilización. Estamos condenados a innovar o a reventar» (Ib., p.36). 
hacen posible la intuición; la sensibilidad y la imaginación. Todavía en su estudio sobre la Contracultura, Roszak lamentaba que en Occidente nos hayamos acostumbrado a destruir la visión receptiva de la realidad a cambio de una mirada escrutadora y particularista; de este modo, nuestra cultura «ha perdido completamente los ojos para ver el mundo de otra manera ${ }^{43}$. Se trata, en último análisis, de una percepción profunda de la relatividad de los discursos y proyectos teóricos, de la necesidad de apertura a una realidad que es inagotable y que exige, por tanto, mantenerse abiertos a nuevos interrogantes y a nuevas búsquedas.

En la configuración de este modo de pensar ha tenido $-\mathrm{y}$ sigue teniendo- una relevancia singular la experiencia artística, en cuanto que activa en la persona la conciencia de posibilidades no realizadas y alienta en ella -en expresión de $\mathrm{O}$. Paz- la esperanza de recuperar «la mitad perdida» de su humanidad ${ }^{44}$.

Esta misma idea es subrayada, entre otros muchos, por E. Fischer cuando observa que necesitamos el arte para volver a crear la percepción de la vida, de la realidad, perdida en los procesos automáticos de nuestra existencia, o cuando considera alentador y estimulante cualquier esfuerzo que se realice para llevar a los seres humanos a una mayor participación emocional e intelectual, o cuando advierte que, por mucho que cambien las funciones del arte, nunca perderá la de recordar al hombre que sus posibilidades no están ni estarán agotadas $^{45}$.

La cultura femenina encuentra en esta perspectiva, a mi juicio, un estímulo importante para hacer frente a planteamientos inspirados en la razón positivista, en los criterios tecnocráticos, en la planificación y el control, o en la obsesión por la eficacia, que desconocen o marginan dimensiones de la persona cuya recuperación es necesaria para hacer posible un cambio cualitativo en las relaciones interhumanas. En este sentido, no se trata sólo de contribuir a transformar las estructuras económicas o políticas, sino también, e inseparablemente, de ayudar a que se modifiquen las estructuras mentales. Tal vez sea esta una de las claves de la nueva percepción que tiene la mujer de sí misma y que, de

4: Roszak, Th. El nacimiento de una contracultura, Kairós, Barcelona, 1970, p. 266.

44 Paz, O., La búsqueda del comienz,o», Ed. Fundamentos, Madrid, 1974, p. 80. Según el autor, «todas las empresas del arte moderno se dirigen a restablecer el diálogo con esa mitad. El auge de la poesía popular, el recurso al sueño y al delirio, el empleo de la analogía como llave del universo, las tentativas por recobrar el lenguaje original, la vuelta a los mitos, el descenso a la noche, el amor por las artes de los primitivos, todo es búsqueda del hombre perdido».

45 Fischer, E., «EI caos y la forma», en el vol. E. Fischer y el hombre sin atributos, Ed. Ayuso, Madrid, 1970, p. 95.; Id., «La libertad del arte», Convivium, n132, (1970), p. 24. 
forma latente o explícita, alienta su presencia activa en la sociedad y en la cultura, en su aspiración a conseguir que -como persona individual y como género- pueda llegar a «vivre au féminin» ${ }^{46}$.

\section{IV.UN PROCESO ABIERTO}

Las consideraciones que se han hecho en este estudio a propósito de la creatividad femenina son, a pesar de su aparente dispersión, un intento por encontrar algunas referencias básicas orientadoras y de reflexionar sobre determinados modos concretos en que esa creatividad puede encontrar su expresión real.

- La conciencia de ser persona -y la voluntad de ser reconocida como tal- ha alentado a lo largo del tiempo sus reivindicaciones de igualdad y libertad, sean cuales fueren los diferentes planteamientos o estrategias que se han seguido. En ella ha encontrado también el camino hacia la solidaridad activa con el «otro»-más allá de consideraciones de género, de raza o de cultura-, colaborando en el empeño de hacer que los valores que se proclaman teóricamente se hagan realidad en la práctica contidiana, en las costumbres, en las instituciones, en la legislación.

- Es cierto que la persona es razón, pero es también voluntad, instinto, intuición, sentimiento, amor, percepción de valores. Esta autocomprensión justifica el esfuerzo contemporáneo de la mujer por contribuir a recuperar el valor auténtico de la racionalidad y sus posibilidades de emancipación, pero también, la decisión de combatir sus deformaciones, ya sea la racionalidad instrumental que elimina el espacio para las dimensiones de sentido, o el pensamiento tecnocrático que reduce la realidad a lo ya existente y a su justificación, o el intelectualismo abstracto que desconoce o margina las realidades concretas de la vida.

- Expresión del impulso creativo de la mujer es también esa nueva sensibilidad -aunque no es exclusiva suya- que la hace preferir los interrogantes a las certezas, la exploración al hallazgo, el planteamiento correcto de los problemas a la obsesión por encontrar respuestas, la toma de conciencia de la complejidad y de la incertidumbre propia de los saberes a la simplificación de los planteamientos o a la incapacidad de abrirse a alternativas inéditas.

En este contexto de reflexión, la creatividad femenina se revela como un impulso permanente que amplía los horizontes mentales y existenciales, abre caminos, reactiva energías, quiebra fatalismos, genera ac- 
titudes solidarias y alienta prácticas liberadoras. Los obstáculos, limitaciones y resistencias que continúa encontrando la mujer en su vida cotidiana y en los ámbitos en que ésta se inscribe son, en cualquier caso, una invitaciôn a tomar conciencia de que esa creatividad -en el trabajo, en la familia, en la cultura, en la política, en los procesos sociales- es una tarea inacabada, sigue siendo un proceso abierto. 



\title{
POLIVALENCIA VERSUS ESPECIALIZACIÓN. APROXIMACIONES A UN MODELO SALUDABLE DE INTERVENCIÓN PRIMARIA
}

\author{
VÍCTOR M. GIMÉNEZ BERTOMEU \\ Trabajador Social. Coordinador del Centro Social Comunitario "Gastón Castelló". Servicios \\ Sociales Municipales del Ayuntamiento de Alicante.
}

\section{CONCEPTOS CLAVE}

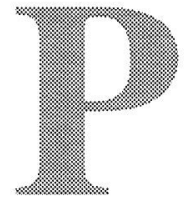

olivalencia, especialización, especificidad, intervención primaria, modelo de intervención por niveles, organización de los Servicios Sociales Generales.

\section{INTRODUCCIÓN}

Hemos oído con frecuencia a políticos, directivos y profesionales hablar de las magnificencias y ventajas de contar o ser profesionales polivalentes, que tanto valen "para un roto como para un descosido", como si de zurcir calcetines se tratara en los Servicios Sociales. Detrás de dicha concepción de lo polivalente, se esconde, en el caso del nivel político o de la alta dirección, una mal entendida polivalencia que entre líneas apunta a la economía en el número de trabajadores/as sociales y a un profundo desconocimiento del auténtico enfoque generalista que nos caracteriza como profesionales. Entre los profesionales "autocalificados" como polivalentes, traduce una peligrosa mimesis con los Servicios Sociales de Atención Primaria, que sí son polivalentes, o la ocultación de carencias en la formación y en el ejercicio.

El presente artículo pretende aportar una serie de apuntes para la reflexión acerca del ejercicio profesional de los/as trabajadores/as sociales en la organización actual de los Servicios Sociales de Atención Primaria. Con base en dos polos aparentemente opuestos, pero complementarios, la especialización y la polivalencia, se introduce un nivel intermedio de actuación, la intervención específica, que es atribuido a la Atención Primaria. 
Se apuesta por un modelo de trabajo en Atención Primaria que se fundamenta en la división del trabajo en dos niveles de intervención, el Primer Nivel (de carácter primario y más polivalente) y el Segundo Nivel (de carácter secundario y específico), y en su atribución a profesionales diferentes. Dicho sistema de intervención se ha implantado progresivamente en los Servicios Sociales Municipales de Alicante desde 1995.

\section{DEFINICIONES Y CARACTERÍSTICAS}

\subsection{La polivalencia}

En primer lugar, se hace necesario delimitar el concepto de "polivalencia" e identificar algunas de sus características.

El Diccionario de la Lengua Española de la R.A.E.' define la polivalencia como "calidad de polivalente", es decir, que posee varios valores, y la equipara al término "plurivalente".

E. Ander-Egg, en su Diccionario del Trabajo Social, ${ }^{2}$ define lo polivalente como un adjetivo compuesto de las partículas polys "muchos" y valens "que vale", que significa que puede ser capaz de diversas cosas; que puede servir para varios usos.

Por último, Maria Sitjà, en Terminologia dels Assistens Socials ${ }^{3}$, utiliza el término "polivalente" para referirse a:

- Trabajo Social polivalente: "Trabajo social orientado a atender toda clase de problemas sociales".

- Asistente Social polivalente: “Asistente social que tiene la facultad de intervenir profesionalmente en todos los niveles del trabajo social y atender distintas clases de problemas sociales".

- Servicio Social polivalente: "Servicio social dirigido a realizar trabajo social polivalente".

De este modo, hemos encontrado fundamentalmente dos usos del término, que ya recogió Maria Sitjà:

- Con referencia a una modalidad de ejercicio profesional de los/as trabajadores/as sociales, identificándolos/as con profesionales

REAL ACADEMIA ESPAÑOLA: Diccionario de la Lengua Española (21 ${ }^{a}$ edición). Editorial Espasa Calpe. Madrid, 1997.

2 ANDER-EGG, E.: Diccionario del Trabajo Social. Publicaciones de la Caja de Ahorros de Alicante y Murcia. Alicante, 1981.

SITJÀ, M.: Terminologia dels Assistents Socials. Col.legi Oficial de Diplomats en Treball Social i Assistents Socials de Catalunya. Barcelona, 1988. 
polivalentes, es decir, profesionales multifuncionales que desarrollan sus competencias en servicios polivalentes. En esta última acepción, los/as trabajadores/as sociales polivalentes actúan como avanzadilla en el desarrollo de los Servicios Sociales Generales ${ }^{4}$, realizando un estudio y diagnóstico social para el desarrollo de servicios específicos y programaciones territoriales adecuados a las características de la zona.

- Con referencia a una modalidad de Servicios Sociales, los Servicios Sociales Generales, identificándolos como servicios polivalentes, es decir, servicios con la capacidad de dar respuesta a una multiplicidad de necesidades sociales. Esta acepción atribuye a los SS.SS. Generales el carácter de "primera instancia de actuación y de contacto de la población con el sistema de Servicios Sociales, de base territorial, que desarrolla funciones de información, orientación y canalización de los usuarios hacia los servicios y recursos existentes", en palabras de Josep Arenas".

Asimismo, observamos una serie de características comunes al término "polivalencia" o "polivalente" en su uso en el ámbito de la acción social:

- Implica multifuncionalidad (funciones propias y funciones bisagra).

- Atribuye un carácter primario a la intervención y al tipo de servicios.

- Supone generalidad y amplitud en el objeto de intervención.

- Significa especialización en la atención a un objeto múltiple.

\subsection{La especialización}

El Diccionario de la Lengua Española de la R.A.E. ${ }^{6}$ define la especialización como la acción o efecto de especializarse, es decir, "cultivar con especialidad una rama determinada de una ciencia o de un arte". En este sentido, señala como "especialidad" "la rama de una ciencia, arte o actividad, cuyo objeto es una parte limitada de las mismas, sobre la cual poseen saberes o habilidades muy precisos quienes la cultivan".

${ }^{4}$ Este papel de vanguardia es recogido ya en las primeras reflexiones acerca de la organización y desarrollo de los Servicios Sociales Comunitarios. A este respecto vid. COLOMER, M. et al. Los Centros Municipales de Servicios Sociales. Documento policopiado. 1983.

5 Vid. ARENAS, J. "Seminario sobre el Contenido y Funciones de los Centros de Servicios Sociales". Revista de Servicios Sociales y Política Social n³. Consejo General de Colegios Oficiales de D.T.S. y AA.SS. Madrid, 1985. p. 22.

r REAl aCADEMia española. Op. cit. 
Por último, Maria Sitjà, en Terminologia dels Assistens Socials ${ }^{7}$, utiliza el término "especializado" para referirse a:

- Atención Especializada o Secundaria: “Atención social dirigida a la población con desventajas personales o problemas de dependencia, orientada al tratamiento, la rehabilitación y la reinserción, a la cual el usuario suele tener acceso a través de los servicios sociales de atención primaria"

- Servicio Social Especializado: "Servicio social dedicado a prestar atención especializada"

Sitjà incluye también el término "específico" con referencia al "servicio social específico", entendido como un "servicio social de apoyo a la atención primaria destinado a un sector de población y abierto a todas las personas de una zona determinada".

De este modo, como ocurría con la polivalencia, encontramos fundamentalmente dos usos del término, que también recogió Maria Sitjà:

- Con referencia a una modalidad de ejercicio profesional de los/ as trabajadores/as sociales, identificándolos/as con profesionales especializados, es decir, profesionales especialistas que desarrollan sus competencias en servicios específicos o especializados.

- Con referencia a una modalidad de Servicios Sociales, los Servicios Sociales Especializados, identificándolos como servicios especializados, es decir, servicios especialistas en dar respuesta a un sector de población o a una necesidad o grupo de necesidades. Esta acepción atribuye a los SS.SS. Especializados el carácter de segunda instancia de actuación y de contacto de la población con el sistema de Servicios Sociales, por agotamiento de las posibilidades de intervención primaria o por la idoneidad de la actuación desde un nivel especialista que desarrolle funciones de atención y rehabilitación social con medios técnicos complejos".

Podemos, por tanto, destacar una serie de características comunes al término "especialización" en su uso en el ámbito de la acción social:

- Implica funciones de alta complejidad técnica.

- Atribuye un carácter secundario a la intervención y al tipo de servicios.

- Supone limitación en el objeto de intervención.

- Significa especialización en la atención a un objeto específico. 


\subsection{La intervención primaria.}

La Intervención Primaria se lleva a cabo desde los denominados Servicios Sociales Generales, Comunitarios o de Atención Primaria. Éstos han recibido un tratamiento abundante en los trabajos profesionales e institucionales, por lo que no nos detendremos en desarrollar sus características y su contenido. En su lugar, es de interés para encuadrar el análisis que realiza este trabajo identificar brevemente las características generales que definen la Intervención Primaria":

a) Prestación técnica, que implica un nivel de cualificación profesional para su realización.

b) Básica, por cuanto es la prestación principal en la que se apoyan los SS.SS. Generales y se desarrolla desde el primer nivel de atención al ciudadano.

c) Descentralizada, al prestarse en el contexto territorial más próxi-mo al ciudadano.

d) Dinámica, pues se desarrolla en un contexto cambiante y con el que interactúa.

e) Territorializada, al dirigirse a un ámbito geográfico de actuación determinado.

f) De carácter público, fundamentalmente.

Con variaciones en las denominaciones de las diferentes Comunidades Autónomas, la Intervención Primaria desde el Sistema Público de Servicios Sociales incluye las siguientes prestaciones básicas en respuesta a las necesidades propias del Sistema:

\begin{tabular}{|l|l|}
\hline NECESIDADES & \multicolumn{1}{|c|}{ PRESTACIONES } \\
\hline ACCESIBILIDAD & 1. Información, Orientación, Valoración y Movilización de Recursos. \\
\hline CONVIVENCIA & $\begin{array}{l}\text { 2. Apoyo a la Unidad Convivencial y Ayılda a Domicilio. } \\
\text { 3. Alojamiento alternativo. }\end{array}$ \\
\hline INTEGRACIÓN & 4. Inserción Social. \\
\hline SUBSISTENCIA & 5. Cobertura de las Necesidades de Subsistencia. \\
\hline PARTICIPACIÓN & 6. Cooperación social \\
\hline
\end{tabular}

Dado que los Servicios Sociales de Atención Primaria son competentes para la intervención territorial en dos niveles diferentes (individual/familiar y grupal/comunitario), creemos necesario reseñar que el presente trabajo se ocupa fundamentalmente del nivel individual y fa-

- Para situar adecuadamente la Intervención Primaria en el Sistema Público de Servicios Sociales, sirva como referencia el reciente "Catálogo de Prestaciones de Servicios Sociales de Atención Primaria", editado por el Ministerio de Trabajo y Asuntos Sociales. Madrid, 1998. 
miliar de la Intervención Primaria, y no del nivel grupal y comunitario de intervención, que entendemos que ha de ser objeto de una análisis diferente por cuanto aborda una realidad distinta a la individual y precisa un posicionamiento en origen también diferente. Por ello, las prestaciones y necesidades a las que nos referiremos en adelante excluirán el fomento de la solidaridad y de la participación social, más propios del nivel supraindividual.

\section{POLIVALENCIA, ESPECIALIZACIÓNE INTERVENCIÓN PRI- MARIA.}

En relación con el objetivo de este trabajo, nos interesan las acepciones de la polivalencia y la especialización que las definen como una modalidad de ejercicio profesional de los trabajadores sociales en los Servicios Sociales.

\subsection{La polivalencia y la especialización en la intervención primaria}

Como hemos podido observar, la intervención polivalente de los trabajadores sociales de los Servicios Sociales Generales consistiría en el desarrollo de:

- una prestación técnica dinámica,

- de carácter básico, primario y descentralizado,

- dirigida a un objeto múltiple: las necesidades sociales de la población general ("),

- en un territorio determinado.

Entendemos que la intervención polivalente en primera instancia es complementaria de una intervención específica que también se desarrolla desde los Servicios Sociales Generales, con la que comparte sus características principales, pero que se diferencia de la primera en:

- Su objeto de intervención, que es específico, limitado a determinadas necesidades sociales de sectores poblacionales en dificultad.

- Su carácter secundario, pues se activa tras la intervención del nivel más polivalente.

- Su contenido o prestaciones básicas que implica.

Este tipo de intervención conserva la capacidad de respuesta múltiple, característica del nivel de atención primaria, pero se hace compe-

10 Utilizamos aquí el concepto "necesidades sociales" en su sentido estricto, es decir, con referencia a las necesidades cuya cobertura es competencia del Sistema de Servicios Sociales. 
tente en dar respuesta a un grupo limitado de necesidades haciendo uso de un grupo también limitado de prestaciones. El resto de necesidades, no diagnosticadas como principales, son abordadas de forma complementaria con el resto de prestaciones de los Servicios Sociales Generales.

En consecuencia, en el continuo de la intervención social de los Servicios Sociales, distinguiríamos tres niveles profesionales interrelacionados para la intervención ${ }^{\prime \prime}$ :

\begin{tabular}{|l|l|}
\hline \multirow{2}{*}{ INTERVENCIÓN PRIMARIA } & Intervención polivalente \\
\cline { 2 - 2 } & Intervención específica \\
\hline INTERVENCIÓN SECUNDARIA & Intervención especializada \\
\hline
\end{tabular}

De este modo, los/as trabajadores/as sociales de los Servicios Sociales Generales no son, por ello, necesariamente polivalentes en su objeto. En su defecto, pueden y deben también desarrollar intervenciones específicas que exceden al nivel más polivalente.

Como ocurre en muchas otras disciplinas, la formación académica de los/as trabajadores/as sociales prepara profesionales polivalentes que, situados en los campos de trabajo, evolucionan hacia prácticas modeladas por el objeto de intervención, el ejercicio profesional, la organización y la formación continua.

El problema surge cuando, desde los profesionales o desde los servicios, tienden a mimetizarse la polivalencia de los servicios con la polivalencia de los profesionales. $\mathrm{O}$ a atribuir a un mismo profesional funciones polivalentes y funciones específicas. Son algunas de las falsas polivalencias.

\subsection{Las falsas polivalencias y sus "ventajas".}

a) La polivalencia "forzosa".

En muchos municipios u otras entidades locales, los Servicios Sociales Generales son responsabilidad de un único profesional: el/la trabajador/a social. De este modo, el trabajador necesariamente ha de desarrollar tanto las funciones polivalentes de información, orientación y asesoramiento, como las funciones dirigidas a cubrir necesidades específicas de sectores en dificultad. Ello implica grandes dosis de soledad del profesional, de aislamiento y de elevado desgaste.

"Como hemos visto con anterioridad, estos niveles de actuación profesional fueron ya identificados en 1988 por Maria Sitjà entre los términos utilizados por los/as trabajadores/as sociales, aunque no aclara en qué nivel se sitúa la intervención específica. 
Se traduce en la infradotación de muchos Servicios Sociales, en número y tipo de profesionales, en especial en el mundo rural. El trabajador se convierte en el/la "chico/a para todo". Un/a solo/a trabajador/a social realiza desde el trabajo puramente administrativo hasta el diseño y ejecución de proyectos de intervención comunitaria, pasando por la intervención directa con individuos y familias. Muy económico.

b) La polivalencia "multiprofesional".

Se produce en contacto con otras disciplinas. Ésta es una concepción de la polivalencia que enmascara una mal entendida multidisciplinariedad o interdisciplinariedad. Significa el "todos hacemos de todo" con independencia del perfil profesional; introduce y consolida el intrusismo profesional. Supone el desaprovechamiento de lo característico de cada disciplina y la dispersión de los esfuerzos.

Surge en gran medida como mecanismo de ocultación de la propia inseguridad frente a otras profesiones, por la escasa clarificación del objeto de nuestro trabajo, nuestros objetivos, nuestro sistema característico de abordaje de la realidad o metodología y/o nuestras técnicas e instrumentos específicos de trabajo ${ }^{12}$.

c) La polivalencia "rutinaria".

Es un ejercicio típico del activismo profesional: consiste en "hacer un poco de todo y con todos", incluso tareas que no son propias del Trabajo Social. Cuando coinciden distintas disciplinas en el mismo servicio, se puede transformar en una polivalencia "multiprofesional".

Traduce el miedo a acotar el trabajo y a profundizar en un área de la realidad social. Esconde también las carencias percibidas en la formación y en el ejercicio profesional, o simplemente la inercia de una práctica que no se revisa periódica y críticamente. En otras ocasiones, es un síntoma más del agotamiento profesional.

d) La polivalencia "dogmática":

Es la polivalencia desarrollada en mimesis con la polivalencia del servicio $^{\text {i3: }}$ El trabajador social de atención primaria es, como el ser-

12 Sirvan como ejemplo los ya habituales informes psicosociales, socineducativos, etc. realizados ¿conjuntamente? por trabajadores sociales y otros profesionales, cuya estructura básica es la del informe social. ¿En qué medida estas prácticas contribuyen a dotar de instrumentos estandarizados de trabajo a otras profesiones a costa de perder o desvirtuar los que nos son característicos?. O en su versión más grave, los informes sociales firmados por el/la trabajador/a social y otros profesionales.

13. L. Gaitán explica este ejercicio mimético trabajador social-servicio por el papel dominante 
vicio donde se ubica, polivalente. Se localiza con más facilidad en servicios recién creados y en profesionales sin experiencia.

\section{HACIA UN MODELO SALUDABLE DE INTERVENCIÓN: LA INTERVENCIÓN POR NIVELES.}

No pretendemos recoger aquí un modelo novedoso para la intervención y la organización de los Servicios Sociales Generales. Por un lado, desde las aportaciones teóricas, ya se han propuesto modelos de organización de los Centros de Servicios Sociales a los que se asemeja nuestra propuesta ${ }^{14}$. Por otro lado, muchas entidades locales funcionan desde hace tiempo con una distribución de funciones similar. Nuestra aportación consiste en realizar aquí una lectura sintética y actualizada de dicho sistema de intervención y organización de la Intervención Primaria.

\subsection{Bases para el encuadre del modelo.}

En nuestra propuesta, el modelo de trabajo se nuclea en torno a una idea central:

Una necesidad social ha de ser atendida desde el nivel profesional más próximo al ciudadano y desde el que implique la menor complejidad técnica posible, siempre que un diagnóstico profesional no indique lo contrario.

Ello supone que, en primer lugar, se ha de utilizar un criterio económico en la intervención, bien delegando aquellas funciones que puedan ser realizadas por otros profesionales (informadores/as, auxiliares administrativos, ordenanzas, etc.), bien asignando al nivel técnico más polivalente las intervenciones menos complejas en su contenido y menos intensas en el número de actuaciones necesarias. En segundo lugar, obliga a que la propuesta de derivación del nivel más polivalente al nivel específico se realice mediante un diagnóstico de los técnicos del primer nivel.

Pero avancemos un poco en la descripción de este modelo haciendo referencia a otras de sus características definitorias:

que el trabajo social tiene en los Servicios Sociales "ya que la filosofía de éstos está inspirada en gran parte por principios de bienestar social, estrechamente asociados a los de aquella disciplina". Vid. GAITÁN, L.: "El espacio profesional", en ZAMANILLO, T. y GAITÁN,

L.: Para comprender el trabajo social. Ed. Verbo Divino. Estella, 1997. P. 104.

14 Entre otras aportaciones, véase a modo de ejemplo a GARCÍA HERRERO, G., Centros de Servicios Sociales. Conceptualización y desarrollo operativo. Ed. Siglo XXI. Madrid, 1988. 
A) Objeto.

Sin dañar el principio de universalidad que prevalece en la Intervención Primaria de los Servicios Sociales, en ésta coexisten dos objetos de intervención:

- Múltiple: las necesidades sociales de la población general.

- Específico: las necesidades sociales de sectores de la población en dificultad

B) Polivalencia versus especificidad.

Los/as trabajadores/as sociales de Intervención Primaria son competentes para el desarrollo de funciones polivalentes, dirigidas al conjunto de la población, y de funciones específicas, dirigidas a sectores poblacionales en dificultad. Y dichas funciones diferenciadas deben ser asumidas por profesionales distintos.

Es preciso destacar que el nivel polivalente, al que denominaremos Primer Nivel de Intervención, asumiría la atención primaria a la demanda, desarrollando intervenciones directas con las necesidades que les son propias, que más adelante concretaremos, o diagnosticando y derivando al nivel específico, al que denominaremos Segundo Nivel, para que éste asuma la intervención directa en el ámbito de sus competencias (necesidades-prestaciones).

C) Capacidad versus conflicto.

La intervención polivalente se ha de orientar a estimular los aspectos de capacidad que sitúan a las familias en una situación de necesidad. Por el contrario, el nivel específico de la Intervención Primaria se ha de orientar hacia los aspectos de conflicto que bloquean o inhiben esas mismas capacidades de los individuos y las familias o que sitúan en posiciones vulnerables o de riesgo a algunos de sus miembros.

Los profesionales con experiencia saben que la intervención en situaciones graves de conflicto suele ser más intensa en actuaciones y que, por lo general, se ha de incidir prioritariamente sobre los aspectos emergentes del problema que producen bloqueo o riesgo, antes de pasar a actuar sobre las capacidades de los individuos/ familias que les permitan continuar una vida normalizada. En contraposición a este tipo de situaciones, también son habituales en los Servicios de Atención Primaria las situaciones en que no existe un conflicto o una crisis grave y donde la intervención se orienta a activar potencialidades y capacidades de individuos o familias que atraviesan una coyuntura desfavorable. Por lo general, estas otras situaciones no precisan el uso de recursos técnicos que impliquen un elevado número de actuaciones. 


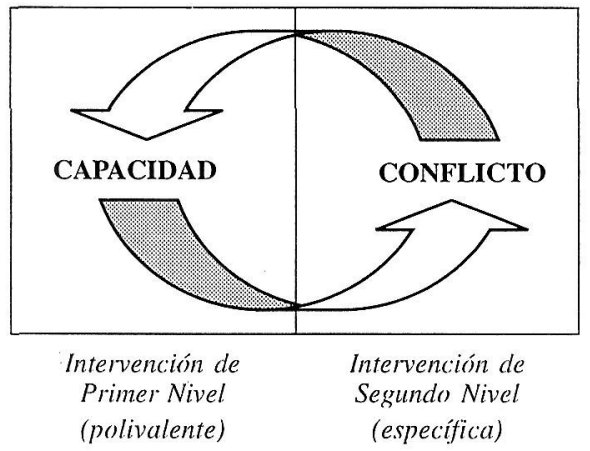

De cualquier modo, nuestra propuesta intenta no ser dogmática sino más bien flexible, y corresponderá al equipo de profesionales delimitar el grado de conflicto que puede o debe abordar el nivel más polivalente y señalar el momento en que se ha de producir una derivación interna hacia el nivel específico.

D) Intensidad.

La intensidad temporal de las intervenciones se define no tanto por la duración total de éstas como por el número de actuaciones que implica una intervención dada en un período de tiempo determinado. De este modo, el nivel polivalente desarrollará intervenciones de baja intensidad, mientras que al nivel específico le serán atribuidas las intervenciones de intensidad alta en el número de actuaciones necesarias.

E) Necesidades y prestaciones.

Como consecuencia de las características atribuidas hasta el momento a cada nivel profesional en la Intervención Primaria, se hace necesario delimitar el tipo de necesidades potenciales a que han de dar respuesta y las prestaciones cuya titularidad principal han de asumir ${ }^{15}$ :

- Nivel polivalente: Necesidades relacionadas con una adecuada información sobre el acceso a los recursos (1), con una adecuada integración social (3) y/o las relacionadas con la falta de medios de subsistencia (4). Suponen prestaciones de Información, Orientación, Valoración y Movilización de Recursos (1), de Inserción Social (4) y/o de Cobertura de las Necesidades de Subsistencia (5).

- Nivel específico: Necesidades relacionadas con una adecuada convivencia personal y familiar (2) y/o con una adecuada integración 
social (3). Supone prestaciones de Apoyo a la Unidad Convivencial y Ayuda a Domicilio (2), de Alojamiento alternativo (3) y/o de Inserción Social (4). Además, desde una perspectiva global de la intervención, utiliza el resto de prestaciones con carácter complementario.

3.2. Características del modelo: una combinatoria de factores.

\begin{tabular}{|l|l|l|}
\cline { 2 - 3 } \multicolumn{1}{c|}{} & $\begin{array}{l}\text { INTERVENCIÓN DE } \\
\text { PRIMER NIVEL }\end{array}$ & $\begin{array}{l}\text { INTERVENCIÓN DE } \\
\text { SEGUNDO NIVEL }\end{array}$ \\
\hline OB.IETO & $\begin{array}{l}\text { Múltiple (Necesidades de la } \\
\text { población en general) }\end{array}$ & $\begin{array}{l}\text { Específico (Necesidades de } \\
\text { sectores en dificultad) }\end{array}$ \\
\hline PRÁCTICA & Polivalente & Específica \\
\hline ORIENTACIÓN & Capacidad & Conflicto \\
\hline INTENSIDAD & Baja & Alta \\
\hline NECESIDADES & $1,3,4$ & 2,3 \\
\hline PRESTACIONES & 17 & $2,3,4$ \\
\hline
\end{tabular}

\begin{tabular}{|l|l|l|}
\hline EQUIPO & "Uniprofesional" & Muitiprofesional \\
\hline METODOLOGIA & Trabajo Social & $\begin{array}{l}\text { Multidisciplinar } \\
\text { Interdisciplinar }\end{array}$ \\
\hline ALCANCE & Alto & Limitado \\
\hline
\end{tabular}

Además de las características que ya señalamos, este modelo de división del trabajo en la atención primaria implica que:

- El nivel polivalente sea asumido por trabajadores/as sociales, junto a personal auxiliar, mientras que el nivel específico ha de tender a contar con profesionales de diferentes disciplinas (Trabajo Social, Psicología, Educación Social, etc.).

- La metodología de intervención en el nivel polivalente sea básicamente la propia del Trabajo Social, mientras que la metodología del segundo nivel ha de tender a la multidisciplinariedad, en un primer grado, y a la interdisciplinariedad, en un segundo grado.

- El número de situaciones abordables desde el primer nivel sea más elevado que en el caso del nivel específico, cuyo alcance es más limitado.

16. Remitimos al Manual de Cumplimentación de la Ficha Social editado por el Ministerio de Asuntos Sociales y las Comunidades Autónomas.

17 Remitimos al Manual de Cumplimentación de la Ficha Social editado por el Ministerio de Asuntos Sociales y las Comunidades Autónomas. 
Apostamos también en el modelo por que la intervención indirecta (la responsabilidad de la gestión y seguimiento de los programas de prestaciones básicas) sea competencia del director/a o coordinador/a del Centro de Servicios Sociales con el apoyo que proceda, mientras que la aplicación y seguimiento singular de las prestaciones corresponda a los profesionales de atención directa de cualquiera de los niveles. Ello en contraposición a la distribución de la responsabilidad sobre los programas entre profesionales de uno u otro nivel, tarea que entonces habrían de compatibilizar con la intervención directa. Entendemos que asumir parte de la gestión y seguimiento de los programas acaba limitando a los profesionales de uno y otro nivel al orientar su trabajo a los recursos disponibles y no ampliarlo a los recursos idóneos. A riesgo de caer en la perogrullada, corresponde al director/a promover los recursos suficientes y necesarios que los profesionales precisan para su trabajo. O dicho en otras palabras, los profesionales han de determinar las herramientas que necesitan y los/as directores/as han de intentar facilitárselas.

\subsection{Condiciones mínimas para la posibilidad del modelo.}

A) Concepción del trabajador social de Atención Primaria.

Adoptar un modelo de trabajo de estas características supone concebir al trabajador/a social en Intervención Primaria tal y como lo hemos definido a lo largo del artículo:

\begin{tabular}{|l|c|c|}
\cline { 2 - 3 } \multicolumn{1}{c|}{} & $\begin{array}{c}\text { INTERVENCIÓN DE } \\
\text { PRIMER NIVEL }\end{array}$ & $\begin{array}{c}\text { INTERVENCIÓNDE } \\
\text { SEGUNDO NIVEL }\end{array}$ \\
\hline FORMACIÓN Académica & \multicolumn{2}{|c|}{ Polivalente y multidisciplinar } \\
\hline FORMACIÓN Continua & Enfoque generalista adecuado al objeto/sujeto de intervención \\
\hline PRÁCTICA & Múltiple & Específico \\
\hline OBJETO & \multicolumn{2}{|c|}{} \\
\hline
\end{tabular}

B) Enfoque generalista.

Situarnos en este modelo de trabajo no significa abandonar el enfoque generalista en ninguno de los niveles de actuación señalados. Como recoge la National Asociation of Social Workers americana (N.A.S.W.) en su Enciclopedia de Trabajo Social's, "la prácti-

Is Acerca de la perspectiva generalista del Trabajo Social, la literatura profesional estadounidense ha producido un interesante artículo de B.D. SHEAFOR y P.S. LANDON "Generalist Perspective". en Encyclopedia of Social Work (18"t edition). National Asociation of Social Workers, Silver Spring, MD (U.S.A.), 1987. Pp. 660-669 (Volumen I). La cita es de la página 664 . 
ca generalista implica tanto la capacidad de tener una visión global de la situación concreta como las habilidades necesarias para intervenir en niveles múltiples y en una variedad de situaciones".

Entendemos, con L. Gaitán, que este enfoque, elemento característico y definitorio de los/as trabajadores/as sociales frente a otras profesiones, es especialmente útil en la atención social primaria "por partir de una premisa de globalización (no parcelación o compartimentación) de los problemas, por su capacidad discriminante acerca del tipo, modo, duración y lugar más adecuado para la atención de los problemas, a partir de la valoración (global) de la situación planteada, y por su flexibilidad y adaptabilidad a las características concretas de la/s persona/s, el entorno y el problema"'19.

C) Profesionales.

Como se puede deducir por lo expuesto hasta el momento, implica también contar con un número suficiente de trabajadores/as sociales (como mínimo, dos) a situar en cada nivel de intervención.

Además, supone contar con otros profesionales (psicólogos/as, educadores/as, trabajadores/as, familiares, etc.) que se integren en un equipo multiprofesional.

D) Trabajo en equipo.

Además no basta con que contemos con suficientes y variados profesionales, sino que éstos han de actuar como un verdadero equipo, sirviendo éste como instancia de consulta, estudio y supervisión del trabajo de cada nivel de intervención.

E) División del trabajo.

El modelo se traduce en una división del trabajo entre el nivel directivo y el nivel operativo y, dentro de este último, en una diferenciación funcional según el objeto de la intervención.

F) Formación.

Los profesionales han de estar formados adecuadamente para trabajar con el objeto/sujeto de su intervención. Y en este punto nos parece especialmente importante destacar que tan formados han de estar los profesionales del segundo nivel, cuyo objeto es más limitado, como los/as trabajadores/as sociales polivalentes, ya que estos últimos, entre otras funciones, son auténticos especialistas en intervenciones urgentes y breves ${ }^{20} \mathrm{y}$ en la realización a corto plazo

14 En cuanto al enfoque generalista de los/as trabajadores/as sociales de atención primaria en España, me parece especialmente relevante la lectura de GAITÁN, L. "El enfoque generalista del trabajo social", en Revista de Treball Social n ${ }^{\circ}$ 150. Col-legi Oficial de D.T.S. i AA.SS. de Catalunya. Barcelona, 1998. Pp. 6-42. La cita que incluimos es de la página 15.

20 Vid. DE ALFONSETI, N. "La figura del Trabajador Social en Servicios Generales del Sector 
de diagnósticos de paso al nivel específico de intervención.

G) Equipamientos.

Si hablamos de profesionales diferenciados funcionalmente, consecuentemente hemos de hacer referencia a la necesidad de que éstos cuenten también con espacios diferenciados dentro de los Centros de Servicios Sociales. Este aspecto no habría que mencionarlo si realmente existiera una red de Centros de Servicios Sociales adecuada y suficiente, con "auténticos" despachos para los profesionales, en lugar de sótanos y locales sin ventilación o pisos inaccesibles, por citar algunos penosos ejemplos. En nuestro planteamiento, el contexto físico donde el trabajo se lleva a cabo es fundamental para el buen ejercicio de los profesionales y para la digna atención que merece el ciudadano.

\subsection{Aspectos "saludables" del modelo.}

Para finalizar, cabe reseñar algunos de los elementos que al parecer del autor hacen "saludable" este modelo de organización de la atención primaria de los Servicios Sociales, tanto para los profesionales como para los destinatarios finales del mismo:

A) La división del trabajo.

El "todos hacemos de todo" se sustituye por el "cada uno hace una parte del todo", entendiendo por el "todo" el conjunto de áreas de necesidad en las que interviene el Centro de Servicios Sociales. No consiste en que una brigada de trabajadores sociales, especialistas cada uno en un área de necesidad, desembarque en la realidad individual o familiar para repararla, sino que un único/a trabajador/ a social asuma el papel aglutinador de la intervención y de los demás profesionales, y haga uso con ellos de todos los instrumentos y recursos disponibles y necesarios de los que dispone el Servicio.

B) La concreción del objeto de trabajo.

Se ha hablado de la dispersión de los esfuerzos de los profesionales de la Atención Primaria al tener que abordar una gran variedad de situaciones sociales. Este sistema permite a los profesionales acotar su objeto de trabajo a unas áreas de necesidad cuyo abordaje es competencia de los Servicios Sociales Municipales.

C) La asignación de casos.

Este sistema permite que las situaciones familiares más críticas, en las que actúa el Segundo Nivel, sean seguidas por el mismo tra-

Público", en DÍ. Aportes desde el Trabajo Social n 7/8. Colegio Oficial de D.T.S. y AA. SS. de Alicante. 1998. P. 16. 
bajador/a social, hasta que un diagnóstico profesional determine el cierre de la intervención o derive al Primer Nivel.

Compartimos con V. Coulshed ${ }^{21}$ que se trata de un método que no sólo afecta a la organización del tiempo, sino también a la calidad del servicio ofrecido al ciudadano al asignar la continuidad de la intervención en una situación problema a un único trabajador/a social y no a cualquier trabajador/a social del Servicio. Incide también en la productividad y en el volumen de casos tratados. Como método que deriva de la gestión por objetivos, se fundamenta en la valoración continua y en la revisión de la intervención.

Este sistema de organización interna de los servicios, se contrapone a lo que Vickery ${ }^{22}$ denominó «círculo de la práctica caótica» como definición de un trabajo no planificado y reactivo en el que los/as trabajadores/as sociales sólo responden a las crisis en lugar de desarrollar una intervención programada. De modo que la intervención se orienta a los «problemas visibles», con lo que se da una prioridad mínima a la valoración y a la revisión, favoreciendo que muchas situaciones se transformen en «crónicas».

D) La práctica específica.

Como consecuencia directa de la limitación del objeto de intervención, la práctica profesional se hace específica y más concreta en respuesta a unas necesidades limitadas.

E) La formación específica.

Un objeto y una práctica concretados en determinadas áreas de necesidad permiten orientar de manera más concreta la formación continua del trabajador/a, para dotarlo/a de habilidades y técnicas específicas de intervención adaptadas al objeto/sujeto de la actuación profesional.

F) La distribución de la carga de trabajo.

Aunque existen también otros mecanismos para equilibrar el volumen de trabajo de los diferentes trabajadores/as sociales, con este modelo de trabajo, el/la responsable del equipo de intervención, junto a los/as profesionales, puede situar con flexibilidad los límites y las áreas de necesidad en que actuarán uno u otro nivel en función de la carga de trabajo que representan para los profesionales.

21 COULSHED, V. La gestión del trabajo social. Paidós. Barcelona, 1998 (Edición original inglesa de 1990). P. 104.

22 VICKERY, A. Caseload Managenent. National Institut for Social Work. Londres, 1977. Citado por COULSHED, V. La gestión del trabajo social. Paidós. Barcelona, 1998 (Edición original inglesa de 1990). Pp. 105-107. 


\section{G) La rotación.}

Estamos convencidos que la intervención primaria provoca elevadas dosis de desgaste en los profesionales sometidos al mismo tipo de intervención y a actuar con las mismas necesidades y, muchas veces, con la misma población durante años. Además, la promoción interna de los/as trabajadores/as sociales en los Servicios Sociales Municipales está normalmente limitada al acceso a puestos de gestión de Programas o de Centros de Servicios Sociales, si un titulado superior no lo ha hecho ya.

Con este sistema de abordaje de la realidad local, los profesionales pueden establecer un sistema de rotación entre niveles, que les permita ampliar mínimamente sus posibilidades de alternancia y cambio en las tareas de atención directa.

De la experiencia vivida en la aplicación de este modelo, creemos que el período mínimo de permanencia en cada nivel ha de ser de 2 años. El intervalo concreto vendrá condicionado por la organización general del servicio, por los aspectos relacionados con la situación laboral de los trabajadores y por los ritmos de las familias, que aconsejen adelantar o retrasar la derivación de la intervención a otro profesional.

H) La formación y la perspectiva integrales.

La rotación permite el paso de los/as trabajadores sociales del Centro por los diferentes niveles de intervención, y en consecuencia se amplía el foco necesario para el diagnóstico global de las situaciones y se refuerza la perspectiva generalista. Además enriquece la formación integral del profesional. 



\section{ACOGIMIENTO FAMILIAR: ESTUDIO DE LAS INTERACCIONES ANTE LAS VISITAS FAMILIARES}

\section{JOSÉ RAMÓN BUENO ABAD}

Catedrático de Psicología Social. Universitat de València.

JOSÉ VICENTE PÉREZ COSÍN

Profesor Asociado de Trabajo Social E.U. Trabajo Social. Universitat de València.

\section{CLAVES CONCEPTUALES}

Desamparo, protección, tutela, acogimiento familiar, régimen de visitas, retorno, adopción.

Interacción padres e hijos, emociones, reacciones físicas, socialización, integración social.

\section{ABSTRACT}

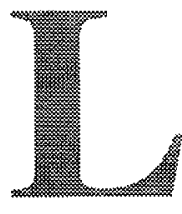

a ley orgánica 1/96 sobre Protección Jurídica del niño, establece una medida de protección denominada acogimiento familiar preadoptivo, en aquellos supuestos en donde se valora como irreversible el retorno a la familia de origen del niño, y en donde se dispone de una familia alternativa para la integración social de los niños.

La regulación del régimen de visitas compete, en primer lugar, a la administración responsable de la protección a la infancia y, en segundo lugar, a la Fiscalía de Menores, quien a través del Juzgado de Familia podrá regular judicialmente el régimen de visitas.

El desarrollo de estas visitas y su plasmación en actos concretos está mediatizado por la complejidad de la situación y por las circunstancias relacionadas con la estabilidad emocional del niño, consecuencia del desequilibrio producido por la desestructuración familiar anterior.

La no-justificación del régimen de visitas puede plantearse cuando existen problemas emocionales que hacen tambalear el equilibrio del acogimiento familiar y, sobre todo, en los casos en que está en juego la integración social del niño, a través de su familia acogedora. 


\section{INTRODUCCIÓN}

En los servicios de protección a la infancia, se desarrollan, entre otros, los programas de Acogimiento Familiar como medidas adecuadas para la integración social de los/as niños/as en situación de desamparo.

La ley orgánica 1/96 sobre Protección Jurídica del niño, establece una medida de protección, denominada acogimiento familiar preadoptivo, en aquellos supuestos en donde se valora como irreversible el retorno a la familia de origen del niño, y en donde se dispone de una familia alternativa para la integración social de los niños.

Además de las particularidades anteriores, este tipo de medida de protección tiene otras características reguladas por la legislación civil, que implican un proceso por medio del cual la familia de origen conoce la situación del niño, materializándose de hecho en un régimen de visitas.

La regulación del régimen de visitas compete, en primer lugar, a la administración responsable de la protección a la infancia, y en segundo lugar, a la Fiscalía de Menores quien a través del Juzgado de Familia podrá regular judicialmente el régimen de visitas.

El proceso de asignación de las visitas familiares se inicia a instancia de los progenitores o del niño o niña, si es menor de 12 años, como mencionamos en el párrafo anterior, bien en la entidad pública que ejerce la tutela del niño/a, o a través del juzgado de familia correspondiente, previo informe del fiscal de menores que es la figura institucional de superior vigilancia en la protección de los niños/as tutelados/as.

Recibida la petición, se estudia la idoneidad del régimen de visitas. Los profesionales que atienden al niño y los profesionales de los servicios sociales públicos que conocen a los progenitores la valoran conjuntamente, emitiendo informe positivo, pautando: temporalidad, frecuencia y número de personas autorizadas a realizar las visitas.

El interés fundamental, en este proceso, es el del niño, y la finalidad última es la integración social con las máximas garantías de bienestar.

En el caso de ser asignado un régimen de visitas por el Juzgado de Familia, corresponde al equipo psicosocial del mismo emitir informe favorable o desfavorable comunicándolo a la entidad pública responsable de la tutela del niño/a.

El desarrollo de estas visitas, y su plasmación en actos concretos, está mediatizado por la complejidad de la situación y por las circunstancias relacionadas con la estabilidad emocional del niño, consecuen- 
cia del desequilibrio producido por la desestructuración familiar anterior.

La no-justificación del régimen de visitas puede plantearse cuando existen problemas emocionales que hacen tambalear el equilibrio del acogimiento familiar y, sobre todo, en los casos en que está en juego la integración social del niño, a través de su familia acogedora.

Desde esta perspectiva, se plantea este estudio con la intención de contribuir a la mejora de la calidad de los servicios de protección a la infancia, y con la finalidad de mejorar la eficacia de una medida de protección como es el Acogimiento Familiar.

\section{MARCO TEÓRICO}

El trabajo que presentamos responde a la necesidad de profundizar en las distintas incidencias que se producen en el ámbito del acogimiento familiar. En este sentido, nos ha interesado profundizar en el conocimiento de las situaciones de interacción entre los niños en situación de acogimiento familiar y sus familias naturales.

Desde el punto de vista teórico, hemos de considerar este interés como una consecuencia de los mecanismos de creación del vínculo, tal y como históricamente fue recogido por Bowlby (1979): la Attachment Theory describe cómo los sujetos necesitados de protección necesitan disponer de un sistema de conducta relativamente estable que les facilite la posibilidad de vinculación. Estas conductas de vinculación son fundamentales para el desarrollo de los lazos afectivos y psicológicos de los niños en situación de crecimiento evolutivo. En este sentido, en las situaciones de desestructuración, abandono, malos tratos, dificultades, etc. , nos encontramos con una serie de rupturas en la creación del sistema vínculo, y para tratar de intervenir sobre estos mecanismos se plantean distintos instrumentos; entre ellos: el acogimiento familiar.

Como han recogido Ripol-Millet y Rubiol (1990), existen distintas perspectivas del acogimiento familiar para niños con problemas de adaptación, conducta, abandono, etc. Pero siempre este tipo de instrumentos pretenden ser una ayuda para que las familias que tienen dificultades temporales para hacerse cargo de alguno de sus miembros puedan beneficiarse eficazmente de la colaboración solidaria de otras personas o familias. Partiendo de estas características generales, y siendo coherentes con el sentido temporal de esta medida de acogimiento, hemos pretendido analizar las situaciones de interacción como una medida que se sitúa en la intervención psicoeducativa con el niño, tendente a mejorar y mantener sus relaciones de consolidación de los vínculos afectivos. 
El planteamiento de análisis de estas circunstancias surge de considerar estas medidas como parte de un mecanismo de apoyo social, tal como recogía históricamente Caplan (1974), como la creación de una serie de vínculos entre el niño y un grupo, en este caso la familia acogedora, para promover el dominio emocional, orientar en el comportamiento y aportar y estimular acerca de la propia identidad.

Desde esta perspectiva, hemos de destacar que los elementos de conformación de la identidad generan un desarrollo evolutivo, tal y como ha recogido L'Ecuyer (1990): la identidad evoluciona y varía según las distintas etapas, teniendo en consideración las primeras fases de emergencia del sí mismo ( 0 a 2 años), la confirmación del sî mismo (de 2 años a los 5 años) y la expansión de la identidad del sí mismo (de los 5 años a los 12 años), resultando decisivas las actuaciones e intervenciones psicosociales que se puedan plantear en dichas etapas.

Por último, hemos planteado este trabajo en el análisis de un proceso de interacción en un ámbito donde están presentes aspectos legales, sociales y psicológicos. Entendemos nuestro trabajo dentro de la definición de un espacio psicosocial. Para tratar de articular este proceso, consideramos que la intervención psicosocial tiene que tratar de enlazar los procesos de conexión entre lo psicológico y lo social, y en este sentido podemos plantear las posiciones de Doise (1982) para tratar de asentar la misma sobre cuatro niveles de explicación y de análisis.

- En primer lugar, el nivel de explicación intraindividual, por el cual el sujeto organiza sus percepciones y su experiencia del entorno social y los mecanismos cognitivos que llevan a esa percepción.

- Un segundo nivel reconocido como interindividual que pretende analizar lo que ocurre entre los individuos dentro de una situación, dada, qué dinámicas relacionales y organizacionales se desarrollan; se trata en este caso de un nivel de explicación intraindividual o intrasituacional.

- Un tercer nivel de explicación, el análisis posicional, esto es, las diferentes posiciones sociales entre los individuos y entre los grupos; se trata de precisar los efectos de estas diferencias, de status, de categorías, etc., sobre las interacciones que los individuos y los grupos mantienen entre ellos.

- Un cuarto tipo de trabajos que se fundamentan en una explicación ideológica, esto es, investigaciones que hacen intervenir las normas, las ideas, las creencias de un grupo social determinado y que buscan el análisis de las evidencias de sus funciones y efectos sobre las interacciones que se desarrollan entre los individuos y los grupos. 
Desde nuestra perspectiva, y para ser consecuentes con las propuestas psicosociales, tal como hemos recogido en Bueno Abad (1999), hemos optado por un análisis de la interacción desde el nivel interindividual. Esto es, la definición de la interacción desde una perspectiva ternaria generando una perspectiva tripolar: el niño, la familia natural y la familia acogedora.

Optamos por un análisis de las reacciones de los sujetos observados, en el que están en curso los procesos de identidad, las actitudes de las familias naturales, las expectativas de las familias acogedoras y las responsabilidades de la administración encargada de la intervención en el proceso. Los elementos de referencia de dicho proceso de interacción han sido dimensionados en función de variables emocionales medidas a través de las referencias a las teorías de activación-cognición-observación, siguiendo los planteamientos de Gergen (1982).

\section{METODOLOGÍA}

La metodología en un estudio de este tipo implica un proceso previo de conocimiento de las medidas de protección a la infancia en situación de desamparo, un proceso inicial de reflexión, para la determinación del problema que pretendemos investigar, y un proceso de elaboración, para plantear el objeto de observación, la formulación de la hipótesis causal que nos oriente en el planteamiento de las variables a observar en cada sesión, y que nos conduzca al diseño más idóneo, según el tipo de variables que debamos investigar.

\subsection{Determinación del problema}

En los procesos de Acogimiento familiar sin previsión de retorno se pueden producir cambios en la estabilidad emocional de los niños, manifestando conductas alteradas como consecuencia de los desequilibrios causados por las visitas a su familia de origen.

Cuando el pronóstico de la situación de los niños es de no retorno a su familia de origen, las conductas (reacciones emocionales) de los niños suelen dificultar el desarrollo material de los regímenes de visitas, además de producir situaciones tensas, en el lugar donde se producen las visitas. Generando, de hecho, una actividad contradictoria con las perspectivas y posibles alternativas de futuro.

De otro lado y para otro tipo de situaciones, las visitas familiares intentan mantener un clima de relación afectiva positiva entre el niño y su familia de origen; de manera que, tras la suspensión de la medida de protección, se pueda continuar con la convivencia familiar sin ocasio- 
nar problemas al niño al reintegrarlo a su familia de origen.

Parece que, en este sentido y para este tipo de situaciones, se muestra la coherencia e idoneidad de este tipo de medidas.

\subsection{Hipótesis}

La hipótesis que nos orienta en este estudio se podría resumir en: «Las visitas familiares de los niños en Acogimiento familiar provocan conductas (reacciones emocionales) en ellos, que suponen situaciones contradictorias y de falta de armonía, lo que podría justificar, para algunas situaciones y casos concretos, la suspensión de las visitas, en interés del niño, que es prevalente al de su familia».

\section{SUJETOS}

Los sujetos a observar son la totalidad de los niños que están en acogida familiar en la provincia de Valencia, durante el primer semestre del año 1995.

La referencia concreta de los niños es la siguiente: nos encontramos con un grupo de niños (ocho) comprendidos entre uno y seis años, que identificaremos por siglas (P.R. 3 años, R.L. 4 años, A.L. 4 años, V.A. 2 años, J.M.A. 2 años, C.L. 6 años, C.M. 2 años y A. G. 1 año), según muestra el gráfico 1.

GRÁFICO 1: Muestra por edades.

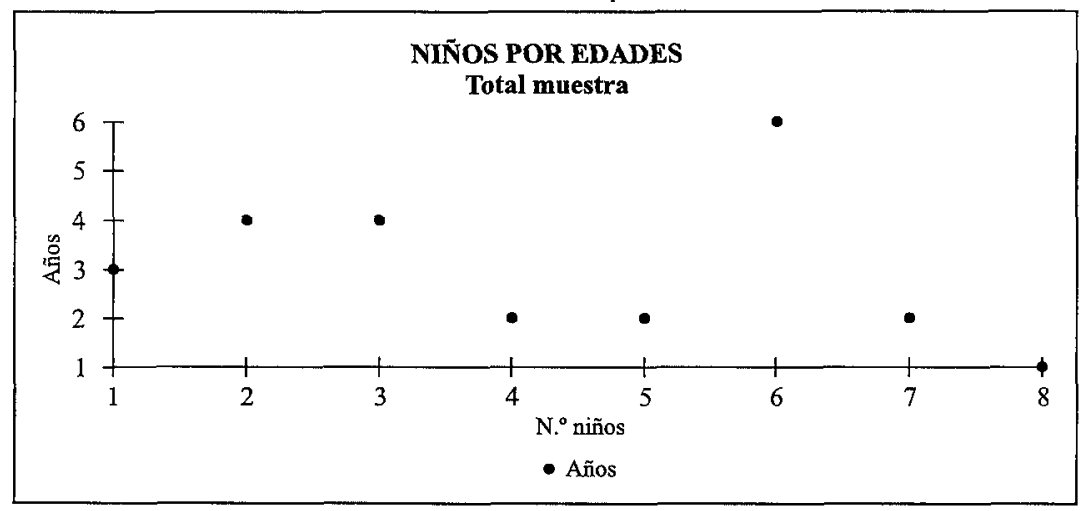

Elaboración propia. 


\section{VARIABLES}

Las conductas que presentan los niños se dimensionan en reacciones de base física y en reacciones emocionales consecuencia de la situación objeto de estudio (visitas), pudiéndose categorizar las variables para la observación (Anguera, 1992: 203-204) en:

a) Categorías de base física:

$1-$ llanto,

2 - rostro frío,

3 - sonrisa.

b) Categorías de conductas consecuencia de las visitas:

4- tristeza,

5- alegría,

6 - indiferencia.

En este sentido, la elección de las variables investigadas ha venido justificada por la presencia de una interacción interindividual, tal como recoge Doise (1982) cuando plantea el estudio de una situación dada ante las dinámicas relacionales que se plantean en las mismas. En este estudio, ambas categorías están relacionadas, de tal forma que la observación de una conducta (b), pueda ser validada por la medición de una reacción física (a). Desde esta perspectiva, existe una correspondencia directa entre ambas categorías, expresada en la tabla 1:

TABLA 1: Correspondencia entre categorías.

\begin{tabular}{|c|c|}
\hline \multicolumn{2}{|c|}{ CATEGORIAS } \\
\hline BASE FÍSICA & CONDUCTA \\
\hline LLANTO & TRISTEZA \\
\hline SONRISA & ALEGRÍA \\
\hline ROSTRO FRÍO & INDIFERENCIA \\
\hline
\end{tabular}

También es necesario indicar que las categorías son la expresión de los sentimientos de los niños ante el hecho (visitas de sus padres biológicos) objeto de estudio y que, por lo tanto, se entiende que expresan conductas favorables o positivas y conductas desfavorables o negativas, valorando que existe también una correspondencia entre las categorías y la conducta ante las visitas, según se presenta en la tabla 2 en la página siguiente. 
TABLA 2: Tipos conductas ante las visitas

\begin{tabular}{|c|c|}
\hline & TIPO DE CONDUCTA \\
\hline FAVORABLE (positiva) & DESFAVORABLE (negativa) \\
\hline Sonrisa & Llanto \\
\hline Alegría & Tristeza \\
\hline & Rostro Frío \\
\hline & Indiferencia \\
\hline
\end{tabular}

\section{DISEÑO}

En este apartado seguiremos a Anguera (1992: pp 33-69) y a Clemente (1992: pp 224-245). En primer lugar, una vez determinada la categorización de las conductas que deberemos observar, queda por definir cómo vamos a realizar el control de fiabilidad de la observación, por lo que optamos por realizar la determinación de fiabilidad interjueces y, posteriormente, calcular el índice de concordancia.

En segundo lugar, el nivel de descripción de las variables será molar, ya que las variables, aunque algunas de ellas son de base física, prevalece una descripción por las consecuencias que producen en los niños las visitas familiares.

Una vez determinadas las conductas que son útiles a nuestro problema hemos sistematizado las medidas que pretendemos obtener y la forma de registrar las categorías. La dimensión temporal es importante, ya que la forma que adopta la conducta de los niños es un estado duradero, en el que interesa apreciar el comienzo y el final de las conductas.

El tipo de medida que nos interesa observar es la duración de las conductas de los niños en las categorías definidas como unidades de conducta, aunque no debemos descartar tanto la frecuencia como la intensidad de determinadas unidades, ya que, dado el número de sesiones (24), pueden aportar algunas medidas significativas por frecuencia e intensidad.

Y en tercer lugar, la estrategia que utilizamos para la observación es la de un muestreo focal, delimitando los focos de observación a nivel individual, es decir, cada niño/a será un foco, y la estrategia de registro será un registro continuo de las conductas de todos los niños con especial interés en los periodos focales, que se definen en tres de cinco minutos de duración, apoyándonos en una estrategia tipo scan, para el grupo de niños en Acogimiento familiar, al inicio y al final de cada sesión. 


\section{PROCEDIMIENTO DE LA INVESTIGACIÓN}

Definir el procedimiento implica pautar el proceso de investigación observacional, partiendo de que es necesario contar en este caso con un conocimiento previo de lo que significa un régimen de visitas, qué regulación tiene a nivel judicial y qué repercusiones conductuales produce en las partes (padres e hijos).

\subsection{Lugar}

El lugar en donde se desarrollan las visitas es un centro residencial de protección, dependiente de la Dirección General de Servicios Sociales de la Generalidad Valenciana, ubicado en un municipio cercano a la capital de la provincia.

Este centro reúne unas condiciones especiales para el desarrollo de las sesiones: cuenta con puertas de entrada diferentes para las familias y para los niños que acuden acompañados por sus acogedores, además de contar con una sala especial para el desarrollo de la visita con un patio anexo para el juego, y en todo momento la relación niño/familia está supervisada por los educadores encargados de esta función.

\subsection{Sesiones}

Las sesiones se realizan semanalmente, en día sábado, en horario de 10 a 12 de la mañana, de forma que se realicen 4 sesiones al mes. Las sesiones se programan con antelación, y se comunican por escrito a las partes.

El total de sesiones de observación será de 24 , en cada una de las cuales cada niño ha sido observado como mínimo en 6 ocasiones, lo que nos permite contar con 144 registros de observación para cada niño observado.

\subsection{Desarrollo de la observación}

El momento de inicio de la sesión es cuando el niño es recibido por algún educador y se le acompaña a la sala de visita, teniendo el primer periodo focal de observación, para cada foco, puede ser secuenciado ya que los niños no acuden a la vez ni tienen por qué salir juntos; a continuación, se realizará un scan del grupo, una vez estén todo los niños en la sala. A la mitad de la visita, es decir, cuando ha transcurrido una hora, viene otro periodo focal, secuenciado de cinco minutos. Y, al final de la sesión, coincidiendo con el tercer periodo focal, se registra otro scan del grupo. 
Para poder realizar el control de fiabilidad, se precisará de dos observadores previamente entrenados en el registro de las variables y familiarizados con los instrumentos diseñados y que permanecen durante todas las sesiones.

\subsection{Registro de datos}

Para cada periodo focal, utilizamos una tabla por categorías y tiempos de duración de cada una de ellas. Cada tabla representa a un niño, según el modelo 1 que se representa en la tabla 3:

TABLA 3: Tiempo de reacción física (modelo 1)

\begin{tabular}{|l|c|c|}
\hline Niño/a: (siglas) & Sesión: (N.). & Periodo focal. (inicio/fin) \\
\hline \multicolumn{1}{|c|}{ Categoría } & (Min./seg.) & (Min./seg.) \\
\hline Llanto & (Min./seg.) & (Min./seg.) \\
\hline Sonrisa & (Min./seg.) & (Min./seg.) \\
\hline Rostro Frío & (Min./seg.) & (Min./seg.) \\
\hline
\end{tabular}

Para cada muestreo scan, utilizamos una tabla con indicación de las variables, y de los niños, según el modelo 2 , que se representa en la tabla 4:

TABLA 4: Resultados de la Interacción (modelo 2)

\begin{tabular}{|l|l|l|}
\hline Niño/a: (siglas): Sesión: (N-q) : & Scan: (inicio/fin) \\
\hline \multicolumn{1}{|c|}{ Categoría } & Existe & No existe \\
\hline Alegría & $(\mathrm{s} / \mathrm{n})$ & $(\mathrm{s} / \mathrm{n})$ \\
\hline Indiferencia & $(\mathrm{s} / \mathrm{n})$ & $(\mathrm{s} / \mathrm{n})$ \\
\hline Tristeza & $(\mathrm{s} / \mathrm{n})$ & $(\mathrm{s} / \mathrm{n})$ \\
\hline
\end{tabular}

Para el análisis de los resultados, se elaborará una tabla resumen por cada niño, con indicación de los tiempos de cada una de las reacciones físicas en cada una de las seis sesiones y los totales de cada categoría; además, se realizará una tabla resumen por cada niño con indicación de las actitudes al inicio y final de cada una de las seis sesiones.

Por último, se realizarán unas tablas (inicio y final), según los modelos 3 y 4 , que se representan en las tablas 5 y 6 , en que se indicará el tipo de conducta manifestada por todos los niños en el total de sesiones, a la vez que se registrará el total de conductas manifestadas por los niños según tipología. Y otras tablas que indiquen el tiempo total de las reacciones físicas (en las seis sesiones) que manifiesta cada niño en cada uno de los periodos focales, además de indicarnos el tiempo total de las reacciones físicas para todos los niños, según el modelo 6 , que se representa en la tabla 7. 
TABLA 5: Interacción (al inicio) (modelo 3)

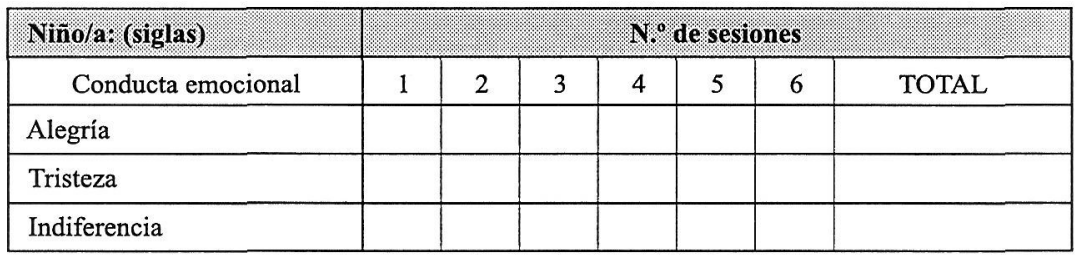

TABLA 6: Interacción (al final) (modelo 4)

\begin{tabular}{|c|c|c|c|c|c|c|c|}
\hline Niño/ar (siglas) & \multicolumn{7}{|c|}{ N. de sesiones } \\
\hline Conducta emocional & 1 & 2 & 3 & 4 & 5 & 6 & TOTAL \\
\hline Alegria & & & & & & & (N..$^{0}$ veces) \\
\hline Tristeza & & & & & & & (N..$^{0}$ veces) \\
\hline Indiferencia & & & & & & & (N..$^{\circ}$ veces) \\
\hline
\end{tabular}

TABLA 7: Duración de las reacciones físicas (modelo 5)

\begin{tabular}{|l|l|l|l|l|l|l|l|}
\hline Niñola: (siglas) & \multicolumn{7}{|c|}{} \\
\hline Conducta emocional & 1 & 2 & 3 & 4 & 5 & 6 & TOTAL \\
\hline Sonrisa & & & & & & & (Min.) \\
\hline Llanto & & & & & & & (Min.) \\
\hline Rostro Frío & & & & & & & (Min.) \\
\hline
\end{tabular}

\section{RESULTADOS}

Antes de iniciar el análisis de los resultados, es necesario indicar que éstos no han sido sometidos al análisis estadístico de concordancias, como en un principio nos planteamos, ya que la significación de las variables no ha resultado relevante a nivel cuantitativo.

Se ha realizado la validación de los instrumentos a través del sistema interjueces, ya que los dos observadores han obtenido resultados idénticos.

Una vez finalizado el trabajo de campo, pasaremos a indicar los resultados, según indicábamos anteriormente. Presentamos unas tablas resumen según el tipo de tendencia emocional manifestada por el total de niños, una para el inicio y otra para el final de las sesiones de observación (ver anexos).

Al inicio de las interacciones, la tendencia emocional más continua es la alegría, seguida de la tristeza y la indiferencia en igual medida. Y, en lo referente al final de las interacciones, la tendencia emocional 
más continua, con mucha diferencia, es la alegría, seguida de la indiferencia y la ausencia absoluta de la tristeza.

También presentamos una tabla resumen, indicando la duración en minutos de las reacciones físicas expresadas por cada uno de los niños $y$ en el total de sesiones (ver anexos).

En los resultados de las mediciones sobre las reacciones físicas han aparecido de forma más continua las reacciones físicas de rostro frío, después las sonrisas y finalmente el llanto.

Comenzamos el análisis de las actitudes mostradas por los niños en acogimiento familiar, expresadas en las sesiones de observación, y que se recogen en las tablas anexas, se resumen en las tablas 8 y 9 (ver anexos), y representadas gráficamente en los gráficos del 2 al 5 (ver anexos).

Lo referente a las reacciones físicas observadas en los niños en el total de sesiones, se registran en tablas y se resumen en la tabla 10 (ver anexos) y se expresan gráficamente en los gráficos 6 y 7 (ver anexos).

\section{CONCLUSIONES}

En la tabla 8, se resumen las tendencias emocionales de los niños mostradas al inicio. Las emociones de los niños no muestran ninguna significación global en las tres categorías observadas, ya que en 18 de las observaciones reflejan alegría, en 15 de las observaciones se refleja tristeza, y en otras 15 observaciones se refleja indiferencia.

Aunque deteniéndonos en este detalle, y si adicionamos las observaciones de estas dos últimas categorías (tristeza e indiferencia), nos encontramos con 30 observaciones con una representación emocional negativa en los niños; cuestión que nos hace inferir que la finalidad de las visitas familiares, el contacto físico entre niños y padres biológi$\cos$, no les gratifica en la mayoría de las observaciones, lo que permite acercarnos hacia la verificación de la hipótesis inicial.

Contrastando con otras investigaciones, se determina que los niños acogidos suelen perder las referencias afectivas de sus padres biológicos, reflejando con su actitud el ánimo con que los niños asumen este tipo de contactos.

Cuando nos detenemos en la observación de los niños individualmente, se hacen más significativas las diferencias. Así, los niños R.L. y A.L. muestran en todas las observaciones tristeza, ya que, prácticamente, no conocían a su madre a su padre; se les tuteló cuando contaban con meses de vida, y los únicos padres que reconocen son los acogedores. 
Por el contrario, los niños V.A. y J.M.A. muestran alegría en todas las observaciones, ya que el acogimiento pautado es de carácter temporal y la relación con los padres biológicos está facilitada por la familia acogedora, de manera que se potencia la reintegración familiar, y en el momento que se considere que las causas que motivaron la protección de los niños desaparezcan y los padres estén totalmente capacitados, podrán atender a sus hijos.

El resto de niños mostraron emociones cambiantes al iniciar las observaciones de las visitas, pasando de la «alegría» a la «indiferencia» en P.R., C.L. y A.G., y cambiante de la «tristeza» a la «indiferencia» en el niño C.M.

La observación sistemática nos permite comprobar que las emociones al inicio de las visitas se modifican en la mayoría de los niños, cuando el niño continúa con el régimen de visitas durante un proceso temporal prolongado.

Este cambio de respuesta podría deberse, entre otros, a los factores relacionados con, en primer lugar, la convivencia en las familias acogedoras y la pérdida de interés en su familia de origen y, en segundo lugar, a que los niños se acostumbran al contacto de las visitas, perdiendo afectividad como mecanismo de defensa ante la frustración.

En la tabla 9, se resumen las actitudes de los niños mostradas al final de las visitas en el total de sesiones. Así, en el gráfico 5, se observa la categoría alegría, ampliamente superior (se mostró en 36 de las observaciones realizadas al finalizar las visitas). En cuanto a las otras categorías, la indiferencia se observó en 12 ocasiones y la tristeza no se ha observado en ninguna ocasión.

La respuesta mayoritaria responde al reflejo emocional que manifiestan los niños ante la buena relación y atenciones que reciben en las familias acogedoras, en donde conviven durante el proceso de protección, y mientras se resuelven las causas que motivaron la separación de su familia biológica, si es el caso.

En otras ocasiones, se responde de manera afectivamente positiva ante la liberación de unas visitas terminadas, no muy agradables para el niño. Las emociones contrarias, de tristeza, al finalizar las visitas, reflejan una integración familiar suspendida, pero no rota, mantenida y apoyada por las familias acogedoras temporales.

Podemos inferir, pues, después de estos datos, que las visitas familiares repercuten escasamente en el mantenimiento de las relaciones paterno-filiales positivas entre los niños y sus familias biológicas.

Las reacciones físicas observadas en los niños en el total de sesiones se resumen en la tabla 10 y se representan en los gráficos 6 y 7 . 
De los resultados totales se desprende que la duración de las reacciones físicas en las observaciones se distribuye en un $51 \%$ para la categoría frialdad del rostro, seguida de la categoría sonrisa en un $32 \%$ y de la categoría llanto en un $17 \%$.

Con todos los resultados anteriores, se puede decir que posiblemente las emociones más dolorosas (tristeza) y la duración de sus reacciones físicas (llanto) más prolongadas para los niños estarán condicionadas por el tipo de relación y la duración de la convivencia entre niño y su familia de origen, por una parte, $y$, por otra parte, por las expectativas de adopción que tengan los acogedores.

De esta manera, cuanto menos tiempo ha durado la relación entre el niño y su familia de origen y más traumática sea esta relación, mayores posibilidades existirán de que el niño presente emociones de tristeza o indiferencia y mayor tiempo durarán las reacciones físicas de llanto, y viceversa.

Además, según la emoción manifestada por los niños al finalizar las visitas, tendrá una relación importante las expectativas de los acogedores con respecto a la adopción del niño, así, cuanto más tiempo permanezca el niño en la familia acogedora, más durarán las reacciones físicas de llanto de los niños al iniciar las visitas.

Completando el análisis de la interacción y de las categorías incluidas en la observación, nos centraremos en las correlaciones existentes con las reacciones físicas, sobre todo la frialdad de rostro manifestada en más de la mitad de las observaciones, determinando las emociones de indiferencia y tristeza que se observa en los niños.

Por otra parte, el llanto tiene poca significación, ya que la intervención de los educadores supervisores de las visitas familiares está especialmente volcada con los niños que presentan esta reacción física y suele remitir en poco tiempo ante su intervención.

Las sonrisas infantiles son mucho más significativas, ya que muestran la alegría del reencuentro con sus padres biológicos, y/o el retorno a los acogedores después de finalizada la visita en un ambiente no grato para el niño.

Así, podemos entender que los procesos de protección social a la infancia no son exclusivamente medidas legales o de procedimiento, llevan implícita una carga emocional importante, e influyen en los mecanismos individuales que los niños generan para poder afrontar situaciones de desintegración familiar, inadaptación social de los padres e incluso malos tratos hacia ellos o entre progenitores.

La observación sistemática de uno de estos procesos, como son las visitas familiares de los niños acogidos temporal o indefinidamente en familias seleccionadas con sus familias biológicas, nos permite preci- 
samente reconocer las incidencias que concurren en estas situaciones de interacción.

Las reacciones que manifiestan los niños revelan inferencias respecto de los vínculos parentales de las relaciones con las familias acogedoras y de la conveniencia o no de una reintegración familiar con garantías para el niño.

A modo de pronóstico, diremos que las visitas entre los niños acogidos judicialmente y sus familias de origen supondrán un riesgo para la integración familiar del niño, siempre que las emociones mostradas al inicio y al final de las visitas supongan un perjuicio para la emotividad del niño, y la duración de las reacciones físicas de llanto y frialdad en el rostro será mayor en función del tiempo de permanencia en acogida familiar judicial.

En este sentido, el derecho a la realización de estas visitas y su efectividad deberá ser analizado desde unas perspectivas relacionadas con las causas que crearon esta situación y las expectativas de los padres naturales ante las mismas.

Por lo tanto, la consideración legal de este régimen de visitas debe plantearse desde la influencia que en otros aspectos genere en los niños.

Aspectos psicológicos que están presentes en la interacción de los dos ámbitos, el natural y el de acogida, que se muestra como compleja y en ocasiones conflictiva, antes de resolver la demanda de visitas por parte de la familia biológica, deberán tenerse en cuenta las variables que consideramos en este estudio, además de las que apuntamos en esta conclusión final y, sobre todo, tener en cuenta que, por encima de los derechos y solicitudes de las familias de origen, están los derechos e intereses de los niños en situación de acogimiento familiar judicial, medida que, por cierto, ya lleva implícita, per se, un grave deterioro de la estructura familiar de origen.

Por último, quisiéramos llamar la atención hacia la reflexión del porqué de la reacción de un niño ante la inminente presencia de sus padres biológicos, porque es muy reveladora y útil para quienes han de tomar las decisiones pertinentes sobre la idoneidad de continuar promoviendo o suspendiendo este tipo de interacción. En ocasiones, las visitas pueden ser imperativos legales, pero deben proponerse teniendo en cuenta las posibles incidencias positivas o negativas en la situación emocional del niño. 


\section{BIBLIOGRAFIA}

ANGUERA, M ${ }^{\mathrm{a}} \mathrm{T}$.: Metodología de la observación en las ciencias humanas. Cátedra. Madrid, 1992.

BOWLBY, J.: El vínculo afectivo. Paidós. Buenos Aires, 1979.

BOWLBY, J.: La separación afectiva. Paidós. Buenos Aires, 1979.

BUENO ABAD, J.R.: "Retos y desafios para la intervención psicosocial". En Informació Psicológica, V época ${ }^{\circ} 69$. Col.legi Oticial de Psicólegs del País Valencià. Valencia, 1999. Pp: 42-49.

BUENO ABAD, J.R.: Representationes Sociales de l'inadaptation. Memoir de l'École des Hautes Études Sociales. París, 1998.

CAPLAN, G.: Support systems and community mental health. Basic Books. New York, 1974.

CLEMENTE, M.: Psicología Social. Métodos y técnicas de Investigación. Eudema Universidad. Madrid, 1992.

DELGADO, J.M. Y GUTIÉRREZ, J. (Coord.): Métodos y técnicas cualitativas de investigación en Ciencias Sociales. Síntesis Psicológica. Madrid, 1995.

GARCÍA FERRANDO, M., IBÁÑEZ, J., ALVIRA, F.: El análisis de la realidad social. Métodos y técnicas de investigación. Alianza Universidad. Madrid, 1993.

GERGEN, K.: Psychologie Sociale. Vigot. Quebec, 1992.

GUASCH, O.: Observación participante. CIS. Madrid, 1997.

L'ECUYER, R.: Méthode GPS et concept de soi. Presses de l'Université de Quebec. Quebec, 1990.

MAYNTZ, R., HOLM, K., HÜBNER, P.: Introducción a los métodos de sociología empírica. Alianza Universidad. Madrid, 1988.

PÉREZ COSÍN, J.V.: "Quiestions sobre adopció internacional". En Codi-46. I época $\mathrm{n}^{\circ}$ 2. Col.legi Oficial de Diplomats en Treball Social i Assistents Socials de València. Massamagrell (Valencia), 1993. Pp: 24-25.

RIPOL-MILLET, A. y RUBIOL, G.: L'acolliment familiar. Frontissa. BarceIona, 1988.

RIPOL-MILLET, A. y RUBIOL, G.: El acogimiento familiar. Ministerio de Asuntos Sociales. Madrid, 1990.

RUIZ OLABUÉNAGA, J.I.: Metodología de la investigación cualitativa. Universidad de Deusto. Bilbao, 1996.

SELLTIZ, C., WRIGHTSMAN, L., COOK, S.: Métodos de investigación en las relaciones sociales. Alianza. Madrid, 1980.

SIERRA, R.: Técnicas de investigación social. Teoría y ejercicios. Paraninfo. Madrid, 1987. 
TAYLOR, S.J. y BOGDAN, R.: Introducción a los métodos cualitativos de investigación. Paidós. Barcelona, 1998.

VALLÉS, M.: Técnicas cualitativas de investigación social. Reflexión metodológica y práctica profesional. Síntesis Sociológica. Madrid, 1997.

\section{ANEXOS}

TABLA 8: Resumen de las tendencias emocionales de los niños (al inicio)

\begin{tabular}{|l|c|c|c|}
\hline NINOS/AS (siglas) & AIEGR & IRISTEZA & INDIFERENCIA \\
\hline P.R. & 2 & 0 & 4 \\
\hline R.L. & 0 & 6 & 0 \\
\hline A.L. & 0 & 6 & 0 \\
\hline V.A. & 6 & 0 & 0 \\
\hline J.M.A. & 6 & 0 & 0 \\
\hline C.L. & 2 & 0 & 4 \\
\hline C.M. & 0 & 3 & 3 \\
\hline A.G. & 2 & 0 & 4 \\
\hline
\end{tabular}

Fuente y elaboración propias.

GRÁFICO 2

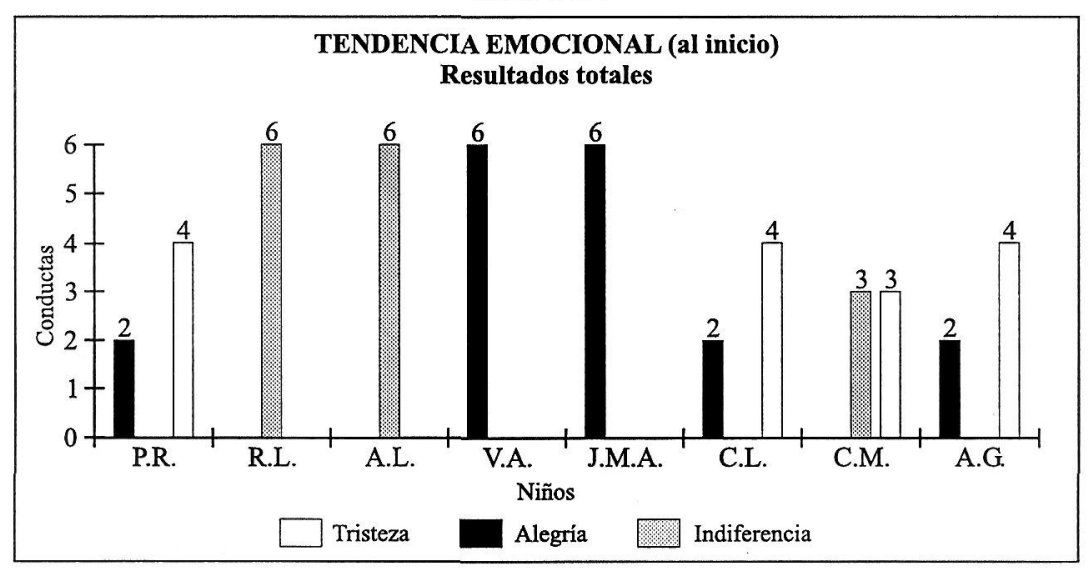

Elaboración propia. 


\section{GRÁFICO 3}

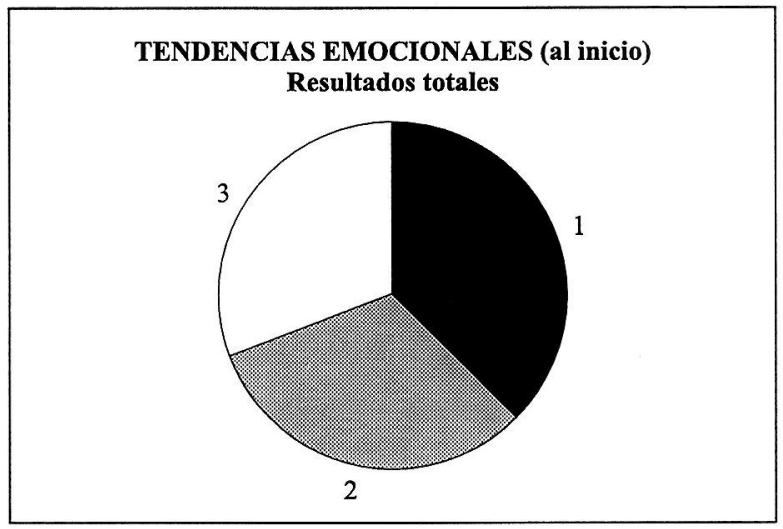

Elaboración propia.

TABLA 9: Resumen de las tendencias emocionales de los niños (al final)

\begin{tabular}{|c|c|c|c|}
\hline NINOS/AS (siglas) & ALEGRIA & TRISTEZA A & INDIFERENCIA \\
\hline P.R. & 6 & 0 & 0 \\
\hline R.L. & 0 & 0 & 6 \\
\hline A.L. & 0 & 0 & 6 \\
\hline V.A. & 6 & 0 & 0 \\
\hline J.M.A. & 6 & 0 & 0 \\
\hline C.L. & 6 & 0 & 0 \\
\hline C.M. & 6 & 0 & 0 \\
\hline A.G. & 6 & 0 & 0 \\
\hline TOTALES & 36 & 0 & 12 \\
\hline
\end{tabular}

Fuente y elaboración propias. 


\section{GRÁFICO 4}

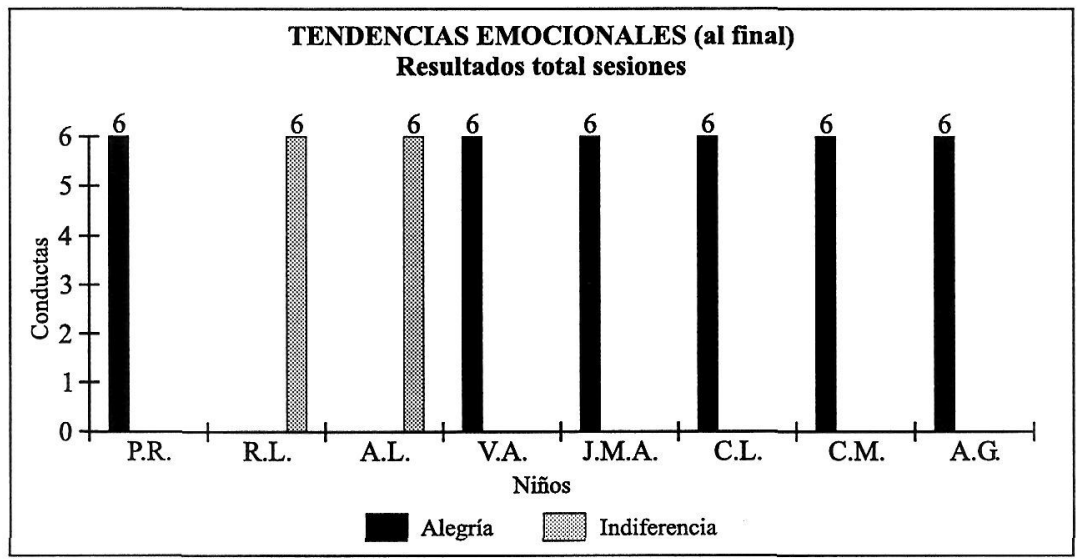

Elaboración propia.

GRÁFICO 5

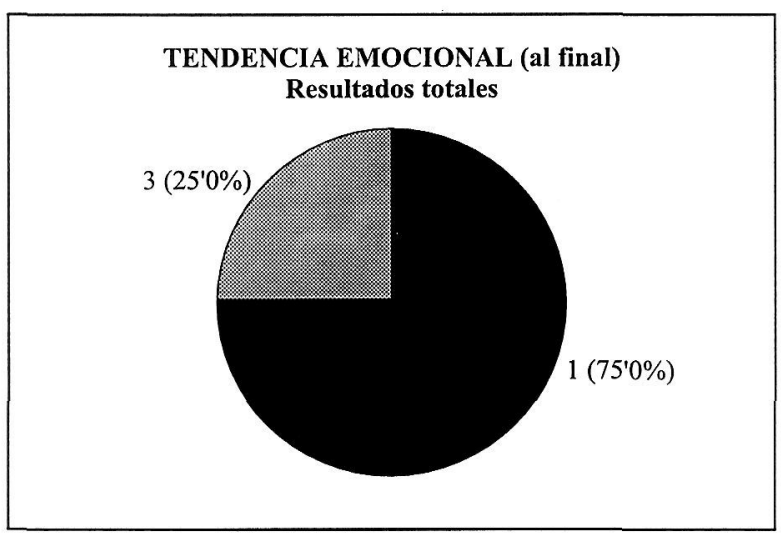

Elaboración propia. 
TABLA 10: Resumen de la duración de las reacciones físicas (Min.)

\begin{tabular}{|c|c|c|c|}
\hline NINOSS/AS (siglas) & SONRISA & I. A.NIO & ROSTRO FRIÓO \\
\hline P.R. & 47 & 0 & 43 \\
\hline R.L. & 0 & 48 & 42 \\
\hline A.L. & 0 & 42 & 48 \\
\hline V.A. & 72 & 0 & 18 \\
\hline J.M.A. & 47 & 11 & 32 \\
\hline C.L. & 25 & 0 & 65 \\
\hline C.M. & 0 & 22 & 67 \\
\hline A.G. & 42 & 0 & 48 \\
\hline TOTALES & 233 & 123 & 363 \\
\hline
\end{tabular}

Fuente y elaboración propias.

GRÁFICO 6

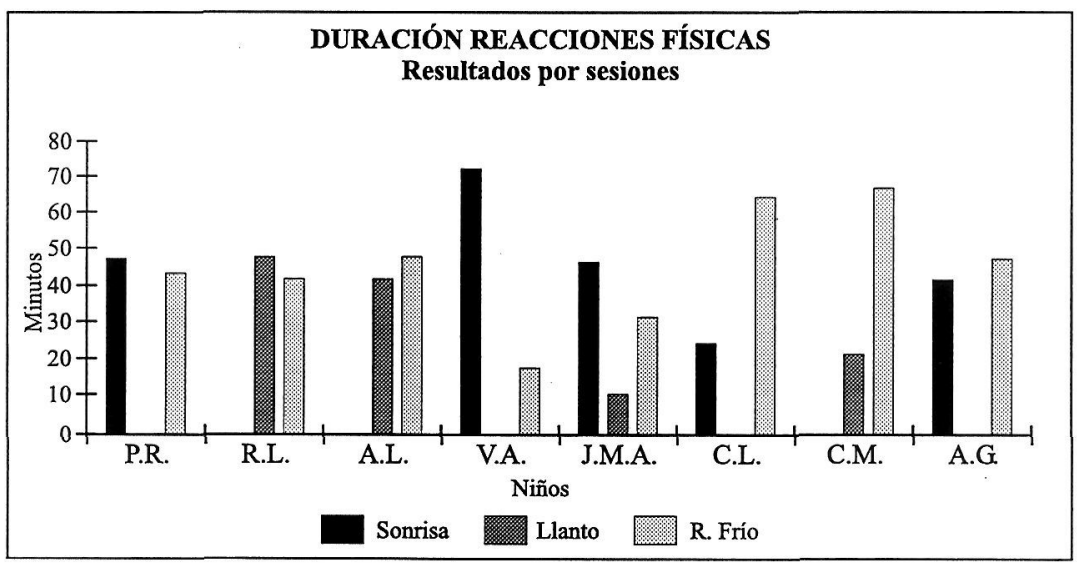

Elaboración propia. 
GRÁFICO 7

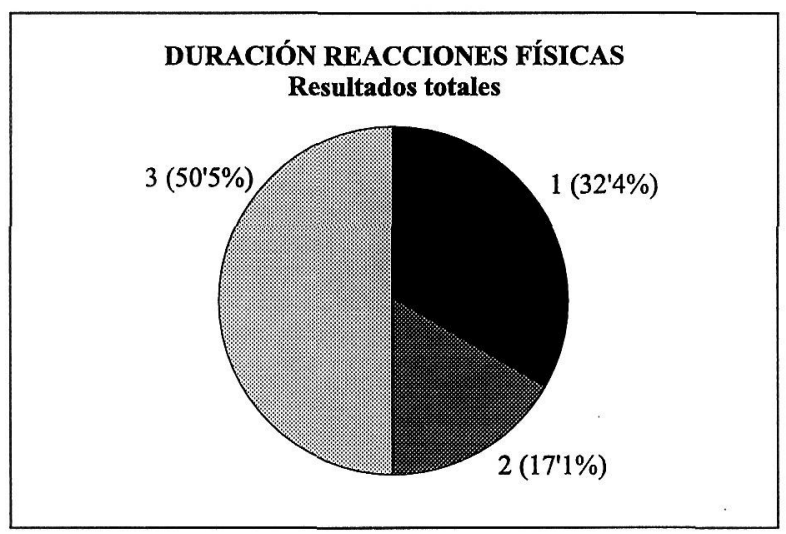

Elaboración propia. 

$\begin{array}{llllllllll}D & O & C & U & M & E & N & T & O & S\end{array}$ 



\section{Dictamen del Comité Económico y Social sobre la «Aplicación de las directrices para el empleo en 1999,}

(1999/C 209/14)

El 28 de encro de 1999 , de conformidad con cl apartado 3 del artículo 23 de su Reglamento Intemo, cl
Conité Económico y Social decidió elaborar un dictancon sobre la *Aplicación de las tirectrices para el empleo en 199\%.

La Sección de Eimpleo, Asuntos Sociales y Ciudadanía. encargada de preparar los trabajos en este asunto. aprobó su dictamen el 6 de mayo de 1999 (ponente: Sra. Engelen-kefer).

En su 364\% Pleno de los dias 26 y 27 de mayo de 1999 (sesión del 27 de mayo), el Comité Económico y Social lia aprobado por 105 votos a favor, 6 votos en contra y 11 abstenciones el presente Dictamen.

\section{Introducción}

1.1. La inclusión de un Título dedicado al enteleo en el Tratadio de Ansterdam y la cumbre sobre este tema, celebrada en Luxemburgo en noviembre de 1997, han supuesro el inicio de un proceso irteversible de coordinación a escala europea de las políticas de cmpleo con cl objetivo de reclucis de mancra palpable la elevada y persistente tasa de desempleo de Europa. los tistados miembros reconocen va el fomento del empleo conos un astunto de interés comin (articulo 126 del Tratado de Anasterdam). Las directrices para 1998 y la elaboración por los Estados miembros de los planes nacionales de acción han constituido la primera aplicación de los olvietivos $y$ procedimientos previstos en el Tírulo relativo al empleo én pro de una estrategia europea coordinada en este ánbito.

1.2. I.as cuatro líncas de acción principates en las que sc basan las directrices adoptadas en Luxemburgo (mejorar la conpicielad de inserción profesional, desarrollar el espiritu de empresa, fonentar la capacidad de adaptación de los trabajadores y de las empresas, y reforzar las políticas de igualdad de oportunidades) son cruciales para favorecer la reintegracion de los desempleados en la vida activa y crear nuevos puestos de trabajo. Todos los Estados niembros han presentado sus planes nacionales de acción con vistas a la aplicación de las directrices para 1998 con una celeridad que, ell sí, constituye ya un progreso. Ha resultado particularmente clicaz el que cstas directrices, en algunos ámbitos, previcran la obligación de resultados concretos y comprobables: por ejemplo. el número de desempleados que pueden acogerse a medidas activas capaces de facilitar su inserción profesional. $Y$ en la Resolución del Consejo se invita a los Fstados miembios a restablecer por su parte objetivos nacjonales que puedan cuantificarse siempre cue convenga.

1.3. El Convité, no obstante, considera necesario definir de común acucrdo el concepto de emedidas activas del mercado de trabajon. Asimismo, deberan garantizarse la comparabilidad de las estadisticas y objetivarse los correspondientes indicadores. El Comité sugicre además que se realicen también análisis cualitativos o se solicite a los Estados miembros su realización. con el fin de evaluar mejor el éxito de las medidas de fomento del empleo.
1.4. Las directrices para el empleo en 1999, aprobadas en la cumbre de Viena que se celcbró los días 11 y $12 \mathrm{de}$ diciembre de 1998, ponen de relicve que upara el éxito futuro del proceso de Luxemburgo, es primordial que todos los actores interesados, es decir el Consejo, la Comistón, el Parlamento Europeo, los interlocutores sociales, el Banco Central Europeo y el Banco Europeo de Inversiones, se asocien a un dialogo amplio e intersivon. A propuesta de la Presidencia alemana se añadio el nuevo considerando siguiente: "Lil Consejo Europeo de Viena encomondó al Consejo y a la Comisión que informasen al próxino Conscjo Europeo de Colonia sobre el desarrollo de un l'acto Europeo para el Empleo en d marco del proceso de Luxemburgow.

1.5. En el marco de esta misión. definida nor la cumbre de Viena, el Comité. como foro de la sociedad civil organizada de ha Unión Europea, manifjesta su deseo de contribuir de manera concreta a intensificar este diálogo sobre la estrategia curopea para el empleo. Esta contribución consistirá en lanzar un intercambio de experiencias de gran calado sobre ejemplos de buenas prácticas y participar así en la aplicación de las orientaciones para el empleo. El Comité está particulanncinte capacitado para ello, ya que representa no sólo a los interlocutores tradicionales del mercado laboral, sino también al otras importantes organizaciones económicas y sociales. In este contexto se celebró una audiencia sobre experieucias seleccionadas por su ejemplaridad. relativas a los cuatro pilares de la estrategia europea para el empleo. En su Informe conjunto sobre la politica europea de empleo, el Consejo de Economía y Hacienta y el Consejo de Trabajo y Asuntos Sociales definieron ejemplos de bucnas prácticas para cada uno de los cuatro pilares de las directrices para el empleo, que se han tomado en consideración en la audiencia.

\section{Evaluación y aplicación de las directrices para el empleo en 1999}

2.1. Con cl presente Dictamen de iniciativa, d CES se remite al apartado 2 del articulo 128 del Tratado de Anisterdaml. en virtud del cual el Consejo debera consultar al CES previamente a la aprobación antal de las orientaciones para el empleo.

2.2. El Comité acoge con satisfacción la posición de la Comisión Europea de atenerse fundamentalmentc, en sus directrices para 1999, a las cuatro lineas de acción principales. colocando así en un primer plano la consolidación y perennización del planteamiento adoptado en Luxemburgo. El Comite juzga razonables y apoya expresamente las medidas complementarias y las disposiciones de aplicación adoptadas en los siguientes ámbitos: 
- reforma de los sistemas fiscales y de gravámenes obligatorics:

- aprovechamiento del potencial de empleo que ofrece el sector de los servicios;

- intensificación de las medidas de formación permanente, en especial con vistas a la evolución de las tecnologias de la información:

- integración de las personas minusválicas y minorias etricas:

- mejores posibilidades de conciliar vida profesional y vida familiar.

2.3. La creación de nuevos pusestos de trabajo requicie nécesarianente invertir la tendencia actual en la Unión al aumento de los impuestos y gravámenes obligatolios sobre el trabajo(l). Por eso, d CES acoge favorablemente las propuestas concretas de las directrices para 1999, por las que se invita ad los Estados miembros a comprobar si sus sistemas fiscales y de prestaciones ofrecen $-y$ hasta qué punto- incentivos a los desernpleados para que busquen y accpten empleo, y a los enupresarios para que creen nuevos puestos de trabajo( $\left.{ }^{2}\right)$. No obstante, hay que cuidar de que, al misno tienpo, no empeoren las prestaciones sociales de los desempleados. En este contexto, el CES considera particularmente importante que se preste mayor atención a la lucha contra el rrabajo no declarado e ilcgal.

2.4. Una de las causas de los problemas del empleo en Europa reside en que, en comparación con la situación internacional, la partictipación del sector de los servicios es inferior a la media, incluidos los servicios sociales y los relacionzados con el medio ambiente y la industria. Por lo ranto, es lógico que en las directrices se invite a los Esrados miembros a desarrollar "un marco de condiciones para aprovechar plenamente el porencial de empleo que ofrece el sector de los servicios y los servicios relacionados con la industrian. Conto se destaca en las ditectrices, el pleno aprovechamiento del potencial de empleo de la sociedad de la información y del sector social y medioambiental reviste particular importancia para la creación de pucstos de trabajo mejores y más numerosos. Tampoco se puede ignorar la responsabilidad del sector público en materia de política social $y$ de empleo.

2.5. Paralelamente, es necesario proporcionar a los jóvenes, tri el marco de la formación general y profesional, cualificaciones en el ámbito de las tecnologías de la información que les faciliten el paso a la vida activa. Sin embargo, la répida crolución de estas tecnologias requiere tambiét la adaptación permanente de las cualificaciones de los trabajadores mediante el aprendizaje a lo largo de toda la vida, con el fu de mantener su apritud para el trabajo. El CES considera especialmente injportantes las medidas concretas propuestas a este respecto en las clirectrices.

2.6. De conformidad con la cousolidación del principio de nto discriminación previsto por al Tratado de Amsterdam, la Comisión Europea ha introducido en las directrices para 1999

(1) Yéise tambićn de Dictamen cid CES sobre d elnforine Econónico Anual de 1999 - la ccomomia de la UE a ta llegada del curo: estímulo del crecimicnto, cl empleo y la estabilidad.

(3) Vease también el Dictamen del CES sobrc la spropuesta de Directiva del Conscjo por la que se modifica la Directiva 77/388/CEE, por lo que se refiere a la posibilidad de aplicar, con caraster experimental, un tipo reducjdo del IVA sobre los servicios de gran intensid́al de mano de obrax. una nueva propuesta que prevé la creación de un mercido de trabajo abierto a todos, con especial atención a la integración de los grtupos desfavorecidos. EJ CES se congratula por este añadido. ya que precisamente las personas minusválidas, las minorías écricas y otros grupos especialmente desfavorecidos, como los parados de larga duración y las personas de edad avanzada, son los más amenazados por la exclusión social si no se les brindan oportunidades en el mercado laboral mediante medidas preventivas $y$ activas de integración. El Comité es partidario de que tanbién en este ámbito se adopte un enfoque de integración. El CES pide a la Comisión Europea que aplique las medidas anunciadas contra la discriminación mediante un plan de acción anual e, igualmente, a través de nedidas jutridicas apropiadas. Dicho plan deherá tener en cuenta que en estos grupos menos favorecidos existen muchas personas cuyas experiencias y competencias no se utilizan $y$ deberá proponer métodos que permital aprovechar esa riqueza de experiencia y conocimicntos en beneficio tanto de estas personas como de la sociedad en su conjunto.

2.7. En sus directrices para 1999, la Comisión Europea ha hecho especial hincapić en el fomento de la igualdad de oportunidades entre hombres y muteres. El CES apoya. en particular, el enfoque de xintegración adoptado en pro de la climinación, en los cuatro pilares de las directrices, de las discriminaciones por razones de sexo. En concreto, con vistas al objetivo de reducir el desempleo fememino (con tasa superior a la media), apoya la propusista destinada a que las mujeres se beneficien de las politicas activas del mercado de trabajo en proporción a su tasa de desempleo. El aumento de la tasa de actividad de las mujeres es necesario para la mejora global de la tasa de empleo en Europa. Conviene crear a cal fin las condiciones marco adecuadas, eliminando los incentivos disuasivos de tipo fiscal y de prestaciones. Además, ell requiere que se prevean suficientes servicios de cuidado a los niños y se facilite la flexibilización de las normativas sobre permisos $y$ horarios de trabajo pare mujeres $y$ hombres, a fin de conciliar mejor vida profesional y familiar. El CES considera especialmente eficaces las medidas complementarias propuestas en este capitulo por las directrices para 1999, ya que a las medidas directamente orientadas hacia la inserción en el mercado de trabajo se añade también la nodificación del marco socioeconómico aún hoy contrario a una mayor participación de las mujeres en la vida activa.

2.8. Asimisno, como ya indicaba en su Dictamen sobre la Comunicación de la Conisión relativa a la «Propuesta de directrices para las politicas de empleo de los Estados micmbros en 1999 , (3), el Comité considera que deberá desarrollarse un planteamiento global, que abarque tanto la política econónica eu general, como también otros campos de acción que incidan en el empleo. A tal efecto, considera recesario armonizar las directrices para el empleo y las orientaciones generales para. las politicas econónicas (que, conforme al aparrado 2 del articulo 99 del Tratado de Amsterdam, deberán elaborarse anualmente). Ello exige una mayor coordinación de la política económica, financiera y monetaria, así como reformas estructurales en la cconomía.

2.9. El CES se muestra satisfecho de que el Consejo Europeo de Viena haya destacado la necesidad de dicho planteamiento

(3) DOC 19 de 21.1.1998 
global y haya alegado que "será necesario tanro intensificar como reforzar la coordinatión de la política econónica (...) para garantizar el éxito de la UEM y para apoyar un crecimiento sostenible creador de empleow. Esto significa, a juicio del Consejo, quse xtanto en los Estados miembros como a escala de la Union, son necesarias respuestas adecuadas y coordinadas a los retos económicos, en las que se integren politicas presupuestarias y monetarias junto con politicas estructurales y se tome en consideración la evolución salarialis.

2.10. El CES se declara también plenamente de acuerdo con la declaración del Consejo relativa a la necesidad de fortalecer los instrumentos existentes ay darles la forma de una estrategia colserente en pro del crecimiento, el empleo, la estabilidad y la reforma económica que evolucione hacia un Pacto Europer para el Enzplco dentro del narco del proceso de Luxemburgo.

2.11. H Comité se declara convencido de que solamente una estrategia global de este tipo, que abarque todos los ambitos políticos que inciden en el empleo y haga extensible a los agentes interesados la responsabilidad comun en el marco de un Pacto Europeo para el Enppleo, podrá tener éxito.

2.12. Por bo que se refiere al proceso de Luxenburgo, el Comité considera que el mecanismo de evaluación comparaciva de los resultados (abenchmarkingy) y la definición de buenas prícticas son invortantes instrumentos que pueden comtribuir a una competencia productiva en tomo a medidas eficaces en materia de cmpleo. No obstante, en opinión del Comité, es necesario que los criterios de definición de las bucnas prácticas scan transparentes y controlables y sc tengan en cuenta las distintas situaciones de partida de los Estado miembros en cuanto a las políticas acrivas de empleo. Una evaluación cualitativa debería ir más allà del estrecho marco del control de los efectos a corto plazo. En este contexto, d CES desea recordar la importancia que el proceso de Luxemburgo concede a la participación de los interlocutores sociales. En la cumbre de Luxemburgo se indicó que los interlocutores sociales de todos los niveles deberán participar en la elaboración de las medidas y en la aplicación de las directrices. El Comité considera que csto implica, por cjenplo, que las partes puedan participar en la claboración y presentar su evaluación de los planes nacionales de acción antes de que se clabore ol Infome conjunto sobre dempleo.

2.13. El Comité suscribe básicamente la intención del Consejo de refozzar este proceso de comparación positiva y constructiva de los resultados. Por eso, apoya expresamente al Conscjo Europeo en cuanto a la necesidad de wijarse nuevos objetivos y plazos verificables, tanto a nivel europeo como a nivel nacional, indicadores de los resultados y políticas comunes y una base estadistica untiforne a modo de clementos clave en el camino bacia un pacto europeo de empleos.

2.14. El CES considera que para el ulterior desarrollo de la estrategia turopea en nateria de empleo conviene que la in portancia equivalente. según el Tratado de Antsterdam, do las políticas de estabilidad, crecimiento $y$ empleo se haga efectiva. Deberá garantizarse, mediante una política economica y estructural equilibrada, que la inportancia que sc atribuya la consecución del objetivo de un alto nivel de empleo sca equivalente a la de las políticas de consolidación de los presupuestos públicos y de lucha contra la inflación. Sin por ello cuestionar la independencia del Banco Central Europeo, la política monetaria reviste en uste contexto particular importancia('). A juicio del CES, conviene garantizar una coordinación reforzada de las políticas econimica, financiera y monetaria a nivel europeo, asi como la introducción de reformas económicas en el marco de un diálogo estructurado entre los gobiernos. la Comisión Europea, el BCE y los interlocutores sociales.

2.15. El CES confia en que de Consejo Europeo de Colonia dé la serial para un pacto europeo en favor del enipleo (cir el sentido de un proceso) y que este pacto será tomado en consideración en las directrices para el enpleo del año 2000.

\section{Evaluación de las buenas prácticas}

3.1. Con el Informe conjunto sobre el empleo de los Consejos de Trabajo y Asuntos Sociales y de Economia y Hacienda, la Comisión Europea sometió por primera vez, en 1998 la aplicación de las directrices para el empleo on los Estados miembros a una cvaluación comparativa, por medio de indicadores cuantitativos seleccionados. El método clegido para deterninar, con ayuda de estos indicadores, la posición relativa de cada Estado miembro con relación a la media de los tres Estados que mejores resultados hayan obtenido es más positivo que los anteriores informes. Puede dar Jugar entre los Estados miembros a una emulación constructiva en la lucha contra el desempleo. Por otro lado, la Comisión Europea debería valorar - también desde un punto de vista cualitativo-m las medidas adoptadas por los Estados niembros para mejorar la situación del emploo y someterlas a un análisis comparativo. La Comision ha realizado a cste respecto un importante trabajo previo, presentando informes por paises. como parte del Iniorme conjunio sobre el cmplco. Sin embargo, este trabajo deberá asentarse sobre una base sólida, aceptada por todos los Estados miembros, mediante un acuerdo sobre indicadores de resultados e indicadores politicos comunes. Convenelria, por otra parte, profundizar en los intercambios de experiencias entre Estados miembros sobre medidas que hayan demostrado su eficacia en materia de empleo, teniendo en cuenta la estrategia global seguida por cada Estado miembro en este ámbito.

3.2. Existen comparaciones internacionales que ponen de manifiesto que los éxitos cosechados en a mercado laboral dependen de muiltiples factores, y, sobre todo, de un enfoque macroeconómico orientado hacia un crecimiento y emples sostenibles acompañado de medidas financieras, monetarias y fiscales.

3.3. En el análisis realizado por el $\mathrm{IAB}\left({ }^{2}\right)$ de las experiencias de tres Estados miembros europeos - Reino Unido, Países Bajos y Dinamarca- en comparación con los Estados Unidos. los resultados de los estudios por pais han pernitido definir, por cjemplo, los elementos siguienres, que pueden contribuir al éxito de la politica de empleo (el CES los expone sin entrar en la cuestion de su valoración:

(1) Véase también el Dictamen del CES sobre el anforme Econónico Anual de 1999 - La economía de lia UE a la legadia del euro: estímulo def crecimiento, el empleo y la estabilidads.

(2) Inscicue für Arbeitsmarkt -utdd Berulsforschung IAB, Instituto de investigación del mercado laboral y profcsional), $102,1998$. 
- enfoque macroeconomico global, orientado hacia el crecininiento sostenible y el empleo;

- creación de un maco general favorable a las inversiones y al forlalecimiento de fa demanda interior, por medio de unedidas financieras, monetarias y fiscales;

- aumentos salariales moderados y sistemas salariales diferenciados con mantenimiento de la función reguladora de convenios colectivos para el mercado laboral:

.... reducción de los costes del factor trabajo mediante la reducción de las cargas sociales legales;

-... medidas activas a faror del conpleo combinadas con incentivos institucionales para la búsqueda de un empleo. como en Dinantarca y los Países Bajos;

- reformas estructurales de la coconomía a fin de aumentar la comperitividad.

3.4. En general, el análisis del $I A B$ pone de manifiesto qua para luchar eficazmente contra el desempleo no hay que actuar en distintos aspectos tomados aisladamente, sino tratar et conjunto de los sectores de las políticas económica, financicra, nonetaria y laboral. Sólo una politica global colnerente, orientada a largo plazo, pernitirá obtener resultados. En opinión del CES, esco confirma el planteamiento global adoprado ya en el Libro Blanco de la Comisión *Crecintento, competitividad y Empleom de 1993.

3.5. En la audiencja celcorada por el grupo de estudio el $15 \mathrm{de}$ abril de 1999 , en la Oficina federal del trabajo de Nuremiterg, se presentó una selección de ejemplos relativos a las política de cmplco y de mercado laboral. Se hizo hincapic en los aspectos siquicnies de las direcerices: fonento de la capacidad de empleo y desarrollo del espiritu de empresa: asinismo, la prornoción de la igualdad de oportunidades con un enloque de integración se tomó en consideración a la hora de elegir los ejemplos concretos y presentur los temas véase Anexo 2).

3.6. Los ejemplos citados llevan al CES a formular las siguientes conclusiones:

- las medidas de mercado de trabajo son más eficaces cuando se consigue que los interlocutores sociales y los organismos interesados a escala nacional participen en su desarrollo y aplicacion

-- la realización de los proyectos a nivel local, en cooperación con las autoridades publicas responsables del empleo, es especialmente prometedora. A memudo, las iniciativas de proyectos parten del nivel local y regional y sólo posteriormente son adoptadas por las instituciones estatales:
- la participación de los grupos interesados - por ejemplo. en proyectos del tìpo edesempleados ayudan a desenpleadosn- abren nuevas posibilidades de aumentar la eficacia de las medidas de inserción de la política de empleo;

- la responsabilización de los propios interkoutores sociales. por medio de acuerdos sobre nuedidas en al ambito de lis política de empleo y de organización des tienspo de trabajo. y la concesión de ayudas econónicas en relación también con fondos públicos restita particularmente cjomplar;

- las medidas de formación profesional deberian combinar una amplia base de fomacion profesional y periodos $y$ elementos de formacion orimtados hacia la príctica $y$ las necesidades de la empresa. A este respecto, resulta especialmente importante la cooperación entre los principales agentes de la formación profesional, es decir. los medios econónicos, los sindicatos y el Estado;

- la promoción de las jóvenes empresas cosechará éxicos si se brinda asesoramiento específico y ayruda financiera para la creación de actividades independientes. Es igualnente necesaria la reducción de las trabas administrativas que obstaculizan la creación de empresas.

\section{Perspectivas para una contribución duradera a la estracegia europea para el empleo}

4.1. El CES manifiesta su deseo de que la organización de la audiencia sobre buenas prácticas en materia de politica de enpleo se concibiera como un primer paso hacia la intensificación del debate sobre una estrategia europea para el empleo, al que siguieran otros actus. Es indispensable, a este respecto, evirar trabajos por duplicado en la Comisión Europea y cin los distintos comitis que existen a nivel curopeo. y que el CES se concentre en su cometido especifico cono foro de la sociedacl civil organizada. El objetivo del CES consiste en dar a conocer su posición sobre la estrategia curopea para el enjpleo. de conformidad con el apartado 2 del artículo 128 del Tratado de Amsterdarn, conciliando los intereses de los distintos sectores sociocconomicos representados en ê.

4.2. El papel particular que, gracias a su composición, el CES podría desempeñar en el desarrollo de la estrategia europea para el empleo radica en su orientación práctica. Por tanto, podría aportar una contribución específica sometiendo las experiencias que hayan demostrado su eticacia en el ámbito de el emplen a un análisis regular, asi como organizando un intercambio de experiencias sobre las buenas prácticas.

4.3. A fin de que el Comité pueda realizar estils tarcas, deberían crearse las condiciones adecuadas. Por ejemplo, debería garantizarse que los trabajos realizados en las distintas secciones relativos a la politica curopea de enpleo estavieran cootdinados, a fin de que el Clis pueda seguir constantemente dicha politica y aportar su propia contribución.

Bratelas, el 27 de mayo de 1999

Lo Presiderta

del Comité Fconómico y Social

Beatrice RANGONI MACHIAVELI 
ANEXO

\section{al Dictamen del Comité Económico y Socią]}

La propuesta de enniendi siguicnte, que obturo más de wn ctarto de los volos enitidos, fac rechazada en el iranscurso de los debates.

\section{Punto 4.3}

Suprimase.

Resultudo de la votarión

Volos a favor: 38 , wotos en contra: 74 , abstenciones: 5 .

ANEXO I

al Dictamen del Comité Económico y Social

Resumen de las experiencias ejemplares en el ámbito de la política de empleo y nercido de truhajo presentados en la audiencia de la Sección de Enploo. Asuntos Sociales y Ciudadanía, celebrada el 15 de alril de 1999 en Nuremberg.

\section{Países Brjos: inserción de desempleados de larga duración}

En los Paises Majos, la organización + Bray-en instroomprojekten. (proyecros de colocación e inserción), fundacla en 1987 y respaldada por los dos principales sindicatos neerlandeses, FNV (federación de sindicatos neerlandeses) y CNV (sindicato macional cristiano). Fomenta medidas activas de reintegración de desenypleados de larga duración on CNV (sindicato macional cristiano). Fomenta medidas activas de reintegración de desenpleados de larga duración en busca de ennplco y la cooperación con los servicios públicos. En 1998 consiguió empleo para 903 áesennpleados de larga duración de dificil inserción, ya que en parte licvaban más de tres años desempleados o cran inayotes de 40 añes o de orinen extraniero. il trabajo de los proyectos se basa en gran parte en convenios colectivos entre los interfocutores sociales de los distintos sectores o de uns determinada cmpresa.

Desde hace cuatro anos la organización esta encargada de la aplicación de un convenio colectivo para la integración de desenpleados de harga duración en el sector de la hostelef́il y la restatración. En nueve proyectos regionales se estabiecieron contacios, en colaboración con las oficinas de empleo. entre empresas dispuestas a contratar personal estabiecieron contacios, cn colaboración con las oficinas de empleo, entre empresas dispuestas a contratar personal
$y$ desempleados de larga duración. Los costes de la reatización de los proyectos son surragados a partes iguales por $y$ desempleados de larga daración. Los costes de la realización de los proyectos son sufragados a partes igutales por
las oficinas de empleo y el secior de la hosteletia y la restauración. De esta nantra, la ayuda oficial se combinal con jas contribuciones económicas de los empleadores conforme a los convetios colectivos, lo cual constituye un requisito esencial para cl ćxilo de los proyectos. Sólo en 1998. 227 desempleados de larga duración obtuvicron um ompleo en este scotor, de un total de 800 en los últintos cuatro anos.

Desde hace algunos años, el convenio colectivo del sector bancario prevc la asiennción del 0.2 \% de la masa salarial para ayuda a las medidas a favor del enpleo tuera de su sector. El proyecto de colocación desarrollado en la provincia de Flevoland se centra en la reintegración en el mercado de trabajo de personas con problemas psiquicos. La atención a los grupos de personas interesadas se realiza de modo individual y va dirigida a su estabilidad psiquica y a sutperar los obstáculos del cntomo cn el que viven que les impiden empezat a rrabajar. Sólo cnionces se procede a la colocación de facto. Hasta 1998 se ha podido das trabajo a 165 participantes, la mayoria de los cuales llevaban dos colocación de facto. Hasta 1998 se ha podido dar trabajo a 165 participantes, la mayoria de los cuales levaban dos
o tres ańos sin trabajo. Desde abril de 1999 . el proyecto está dirigido por el instituto oficial de empleo, a fin de conferirle un carícter permanente. Los requisitos del exito de este proyecto son: la ayuda cconómica por parte de los servicios públicos $y$ de los empleadores, el procediniento experimental y el trato individual de los desempleados de larga duración, que incluye todo su contexio vital.

\section{Sttecia: inserción de jóvenes desempleados}

En Suecia existen centros especiales cle trabajo pari jóvenes desernpleados. dorde pueden optat por un puesto de Irabajo o un programe de inserción o de cualifieación. Se han lanzado a tal fin distintos progratras oficialcs de ayuda. Fia centres informíticos se proporeiona cualificación en el sector de las ternologias de fa información, así como 
ayula a la colocación. Un porcentaje significativo - el $20 \%$ - de los jovenes ha encontrato enpleo res mest despucis de concluir el programa de fornación. Un programa especial a nivel local de ayuda a los jóvenes menorts de 20 años está dirigito a clesarrollar, a la modida de cada participante, posibilidades de trabajo o de períodos de prácricas en el sector público o privado, así cono ofertas de formación. La oficina municipal, que recibe para cllo una contribución oficial, es responsable del joven durante un feríodo máximo de doce meses, durante el cual el joven debe aceptar también ofertas procedentes de la oficina de empleo. En 1998 se pudo facilitar un empleo al $40 \%$ de los particiunces en dicho progrnn de fomento y un $22 \%$ se benefició de ot a toedida de ayuda al cnipleo. Desde de enero de 1998 existe el programa garantia de desarrollow para jovenes de entre 20 y 24 ahtos de edad. gracias al cua la oficina de emplco ofrece modidas de apoyo individuales. Si en el intervalo de 100 días no se encucntra una ofert adecaiada el joven seguirá recibiendo atención en el anibito del progrima municipal de apoyo. Durante este periodo, los jóvencs recitien un subsidio de descropleo estatal o una isignación especial para ayuda a la formacion o un subsidio social.

España: inserción de las personas minusválidas

Un conjitc conjunte, constituido en octubre de 1997 formado pur representantes del Mivisterio de Trabajo $y$ de Conité Español de Representantes de Minusválidos (CERMT), ha celebrado un acucrdo sobre Promoción del Enjplen de las Personas con Discapacidad. Las nedides acordadas se refieren a la mejora de la participación insilucional de los minusválidos, ofertas de enpleo y asesoraniento, perfeccionaniento y medidas especificas para la inserción. El objetivo de estas medidas es mejorar las capacidades de las personas ninusválidas, particularmente de los jóvenes o de las mujeres, y ofrecerles nuevas posibilidades de empleo adectadas a su condición. Los esfuerzos de integración han dado como resultado sólo en 1998, 15000 contratos de trabajo para ninusválidos; los empleadores reciben del Estado hasta el $90 \%$ de las cotizncioncs correspondientes a la seguridad social. En cl matco de dicho actierdo del plan nacional de acción para la aplicacion de las directrices para el empleo en 1998, la Fundación ONCE ha lanzado una inicjativa privada de fomento del cmplco de minusválidos, el ePlan 5000 . La Fundación ONCE pretende crear en un período de cuatro años (1997-2000) 5000 puestos de tabajo y 10000 plazas de fotmación pari minusválides. En th cortes plazo de clus años se ban creado gracias a esta inicintiva 5089 puestos de trabajo par: minusválides. Las medictas de promoción del cmpleo debcrán prestas particular atención a las ofertas para los ninusválidos, de nodo que tengan la nosibilidad de integrarse en un mercado de trabajo sujeto a rípidos cambjos.

\section{ltalia: fóvenes empresarios}

La *Socictà per linurenditorialità giovanilex (IC: sociedad para las jóvenes iniciativas empresariales) fuc fundada en 1994 para sustituir el programa estatal de ayuda a los jóvenes empresarios creado en 1986, cuyo oljjetivo era fomentar la actividad económica en reyiones desfavorecidas de Italia. La sociedad, que trabaja por encargo público. contribuye por medio de asesoramiento, ofertas de instrucción, ayudas materiales y económicas, al proceso de recstructuración en las cmpresas y de creación de nuevas empresas. La sociedad trabaja en 40 centres locales de asesoramicrto, en coopcración con las cánaras de comertio y las oficints publicas.

Las actividades desarrolladas cn los úitimos doce años se han centrado en:

- el fomento de las iniciativas cmpresariales, especialmente para ol sur dic ltaliai

...- La valoracion de 6000 proyectos cmpresariales:

- la realización de 1500 proyectos cmpresariales, con un volumen global de inversiones de 2000 millones do euros $y$ la creación de 25000 nuevos puestos de trabaio

- la funariación de 970 nuevas enpresas - el 81 \% de las cuales sigue existicndo actualmente.

La cresción de asociaciones de empresis y la asistencia al empresneio en la fase de consolidación, por tun turor experimentado en materia de gestión o asesoramiento de empresas, son deterninantes para el éxito de las áctividades.

Desde 1986 IG participa igualinente en el foncneo y apoyo wconóninco de los descinpleados que desean cjercer una actividad independiente. Asimismo, ofrece asesoraniento sobre la aplicación de proyectos cmpresariales proporciona cursos especialcs de formacion y perfecciomamicnto para la preparación a la actividad por cuenta propia y la gestión de empresa, La teficacii del programa IG de creación de comprexas viene subrayada por el hecho de que el gobicrno italiano lo haya selecionndo como cjemplo.

\section{Francia: servicios nuevos y empleos nuevos}

El programa francés aservicios uueves/cmupleos nuevos ve dirigido a los jóvenes desempleados menores de 30 años y prevé la creaciói de nuevos puescos de trabajo de utilidad social en los servicios públicos. así como una subvención del Estado, durante un periodo de cinco años, hasta un total del $80 \%$ del salerio mínimo garantizado, para cada pucsto de trabajo ocupado por un joven. El objetivo de crear 150000 empleos hasta finales de 1998, o sea algo más de un año desce la aplicación del programa, ha sido superado. Sc han creado 85000 puestos en entes y asuciacionts, 65000 en centros locales de enserianza y 8250 en servicios locales de polića. Se ban creado nuevos servicios en diferentes ambitos: ayuda familiar, sanidud sectur social mocio ambicnte cultura, do principalmente de tareas de coordinación y organización, actividades de atruda y cutidado de personas depcndicntes 
como los ancianos y minusvilidas, o tareas de acompañamiznto en las escuthas. Dado gue el prograna extá dirigito en primer lugar a la creación de puestos de trabajo a nivel local y regional, la participación de los agentes localcs erla el mercado laboral tiene una importancia decisiva. Los acuerdos marco celebrados entre las organizaciones nacionales y las autoridades públicas a nivel nacional se aplican a nivel local. Tajes acuerdos existen por ejemplo en los servicios de corrcos, asociaciones para la formación de adultos, los secrores social y de sanidad y los servicios de construcciótr de viviendas sociales. El programa tiene por objetivo consolidar las actividades iniciadas y garantizar a los jóvenes u empleo duradero en los centros oportunos y, más tarde, en el mercado de trabajo regular.

\section{Suecia: servicios de los interlocutores sociales para el empleo}

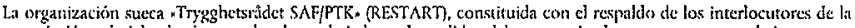
negociación salarial colcciva, ayıda a los trabajadores despedidos del sector privado a encontrar un trabajo nuevo o a crar una empresï. Sus actividades se basan en un canvenio colectivo frmado en 1974 por SAF y PTK. RESTART propone a las cmpresas afiliadus y a los cmpleados amenazados con el desemploo asesoraniento profesional y ayuda para buscar trabajo o iniciar una actividad independiente. La organización está financiada por las cotizaciones de las 30000 cmpresas miembros, que actualmente asignan el 0,3\% de su masa salarial a dicho fin. Los servicios ofrecidos abarcan el plan de carrera personalizado. distintos programas de formación y reciclaje adaptados a las necesidades individuales la ayuda a la búsqueda de un ernpleo o la creación de una empresa, e incluso el apoyo econóntico de los desempleados de mis edad bajo determinadas condiciones. La combinación del subsidio de desempleo y la los desempleados de miss edad bajo determinadas condiciones. La combinacion del subsiclio de desenpleo y la hasta cl $75 \%$ del antiguo salario durante an periodio de un año $y$ medio $y$ hasta dos afios y nactio. La dave de RESTART es una red de 100 asesores, distribuidos en unas 30 oficinas lochles y regionales. Entre las 143000 personas que han recurrido a los servicios de Restart en los años noventa, 85000 han encontrado un muevo cripleo, 12000 conkerzaron una actividad por cuenta propia y 16000 siguen buscando trabajo. La creación de empresas. que representa alrededor del $10 \%$ de los tasos. se da sobre todo en el sector comertial y de vesias, donde d porcentaje de mujeres ha aumenkado en 1998 , y el $80 \%$ de las empresas aún siguen existiendo hoy. El planteamiento de RESTART de asesoramiento personalizado se basa en el principio segín el cuil todo cambio de empleo puede también ser la ocasión de comenzar una nueva carrera si va acon!jañado de medidas de apoyo adecuadas.

\section{Finlandia: períodos de prácticas en empresas en el marco de la formación inicial}

Fin 1995, cl Gobicrno finlandés decidió que a partir del año 2000, la primera formación profesional debcría incluir seis meses de prácticas en una empresa a fin de proporcionar experiencia profesional. Simultáneamente. la duración de la formación profesional inicial se alargó a tres años. Esta reforna tiene por objeto brindar a los jóvenes lit

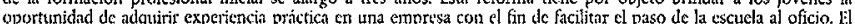
Gohierno y los interlocutores seciales celebram an acuerdo en encro de $1998 \mathrm{com}$ el tin de aplicar los objetivos de estos periodos de prácticas en empresa. Estc acuerdo incluye las siguientes medictas:

-... creación de posibilidades de periodos de prácticas en empresas mediante la cooperaction entre centros de fornación, interiocutores sociales $y$ empresas;

- creación de las concticiones gencrales adccuadas para la formtación en el lugar de aprendizaje, es decir. ha empresi.

Los interlocutores seciales coincidjeron en que esta fornación en empresa no es contparable a la actividad profesionul regular $y_{1}$ por lo tanto. pidicron al Cobieno que modificara en consecuencia la legislación laboral. Asinismo, pusieron de relicve que las práctices realizadas en empresas en el marco de la formación profesional no debían pusicron de relicve que las prácticas tealizadas en empresas on el marco de lat formación profesional no debian sustituir a los ptestos de trabajo regulares. Lste nuevo sistema de formation comenzará oficialmente en agosto de
1999 en tres sectores: la metalurgia, la agrimensurn y las instalaciones técnicas de edificios. Los proyectos piloto concluyeron son éxito, en particular gractas a la buena conperación entre el Gobietno y los interlocutores sociales.

\section{Alemania: acuerdo sobre formación en Renania del Norte-Westfalia}

Fi Fistado federado, los muaicipios, las orgarizaciones empresariales, los sindicatos y la oficina de empleo alemanes son los interlocutores del acuerdo sobre formación en Renania del Norte-Westfalia. Se están chabondo proyectos conjuntos en diecisceis centros regionalés de coordinación con las cámaras de comercio c industria. El objetivo consiste en proponer un paesto de aprendizaje de calidad a took persona que desec formarse en Reiania del Norte-Westfalia. A lal efecto, sc incita a las cmpresns a crear más plazas de aprendizaje y se convence a cumpresas nuevas a participar en la fonnación de jóvenes, con el fin de explotar plenantente la totalidad de los puestos de. aprendizaje disponibles. Además se reslizan proyectos pilon para la reforma del sistena dual de formación. Los interlocutores de estos proyectos se centran sobre todo en los siguientes elementos:

- experimentación de modelos de formación especifica para grepos concretos, en el marco de profusiones existentes; hen dado comienzo ya cuatro proycctos piloto:

-- creación de nuevas profesiones. en paticular en los sectores en pleno crecimiento como las relecomunicaciones a los medios de comunicaciorr: 
- desarrollo de modelos ofganizarivos para una organización más flexible de la cliserianza col las escuchas de formación profesional, con el fin de mejorar los periodos de formación en empresa:

-.- desntrollo del porencial te plazas de aprendizaje disponibles mediante una intormación completa a las olicinas de emploo y una amplia difusión a través de los nucvos medios de comunicación como Internet, payà que cl mercado de piazas de aprendizaje sea lo más transparente posible.

Las acciones realizadas en el marco del acuerdo sobre formación en Renania del Noriz-Westfalia se refuren tamibién a una intensiticaciôn de la iıformación y asesommienco a las cmpresas para que creen puestos de aprendizaje. A este respecto, los grupos clave son sobre todo las empresas extranjeras, así como los creadores de empresas en fase de consolidación en el mercido. Además la formación con cualificaciones adicionales mejor adaptadas a las necesidades deberí crear un vinculo idónco entre la formación y la formación permanente, con el fin de mejoras las oportunidades de cjerer una actividad profesionel enalifteacla, Por otra parte, se intensifica cl ascsoramicnto e información de les de cyerer una ectividad profesional eualifteacla, Por otra parte, se intensifica cl ascsoramiento e información de los profesional, explotar mejor la oferta de períodos de précticas $\mathrm{c}$ informal solore nuevas profesiones y sectures cn creciniento. Sólo en 1998 , estas acciones han permitido crear más de 2900 plazas de apreodizaje suplententarias. Ea tolat, en 1 DDS se limiaron I 22000 nucros contratos frente a los 112000 del ano antertor 


\section{Disposición transitoria primera.}

Lo dispuesto en esta Ley, salvo en materia de expropiación forzosa en que se estará a to establecido en la disposición transitoria segunda, será de aplicación a las obras de nueva construcción y a obras en los edificios existentes, para cuyos proyectos se solicite la correspondiente licencia de edificación, a partir de su entrada en vigor.

\section{Disposición transitoria segunda}

Lo establecido en la dispesición adicional quinta no será de aplicación a aquellos bienes y derechos sobre los que, a la entrada en vigor de la ley, se hubiera presentado la solicitud de reversión.

\section{Disposición derogatoria primera.}

Quedan derogadas todas las disposiciones de igual o inferior rango que se opongan a lo dispuesto en esta Ley.

\section{Disposición derogatoria segunda}

Los articulos 64 a 70 del Reglamento de la Ley de Expropiación Forzosa, aprobado por Decreto de 26 de abril de 1957, seguirán vigentes en cuanto no se opongan o resulten compatibles con lo establecido en la disposición adicional quinta.

Disposición final primera. Fundamento constitucional.

Esta Ley se dicta al amparo de la competencia que corresponde al Estado de conformidad con los artículos de la Constitución siguientes:

a) El articulo $149.1 .60^{\circ}, 8^{\circ}$ y $300^{\circ}$ en relación con las materias civiles y mercantiles de los capítulos y ll y con las obligaciones de los agentes de la edificación $y$ atribuciones derivadas del ejercicio de las profesiones establecidas en el capitulo III, sin perjuicio de los dere chos civiles, forales o especiales existentes en determi nadas Comunidades Autónomas

b) El artículo 149.1.16.",21.", 23." y $25^{\circ}$ para el articulo 3

c) El articulo 149.1.6." 8. ${ }^{\mathrm{A}}$ y $11 .^{\mathrm{A}}$ para el capitulo IV

d) El artículo 149.1.18." para la disposición adicional quinta.

Lo dispuesto en esta Ley será de aplicación sin perjuicio de las competencias legislativas y de ejecución que tengan asumidas las Comunidades Autónomas en este ámbito.

Disposición final segunda. Autorización al Gobierno para la aprobación de un Código Técnico de la Edificación.

Se autoriza al Gobierno para que, mediante Real Decreto y en el plazo de dos años a contar desde entrada en vigor de esta Ley, apruebe un Código Tecnico de la Edificación que establezca las exigencias que deben cumplir los edificios en relación con los requisitos básicos establecidos en el artículo 3, apartados 1.b) y 1.c).

Hasta su aprobación, para satisfacer estos requisitos básicos se aplicarán las normas básicas de la edificación-NBE que regulan las exigencias técnicas de los edificios y que se enumeran a continuación.

NBE CT-79 Condiciones térmicas en los edificios.

NBE CA-88 Condiciones acústicas en los edificios.
NBE AE-88 Acciones en la edificación

NBE FL-90 Muros resistentes de fábrica de ladrillo.

NBE OB-90 Cubiertas con materiales bituminosos.

NBE EA-95 Estructuras de acero en edificación.

NBE CPI-96 Condiciones de protección contra in cendios en los edificios.

Asimismo, se aplicará el resto de la reglamentación técnica de obligado cumplimiento que regule alguno de los requisitos básicos establecidos en el artículo 3 .

Disposición final tercera. Adaptación del Reglamento de la Lev de Expropiación Forzosa.

El Gobierno, en un plazo de seis meses, adaptará la sección 4." del capitulo IV del Título II del Reglamento de la Ley de Expropiación Forzosa a lo dispuesto en esta Loy.

\section{Disposición final cuarta. Entrada en vigor.}

Esta Ley entrará en vigor a los seis meses de su publicación en el abletin oficial del Estadow salvo sus disposiciones adicional quinta, transitoria segunda, derogatoria primera por lo que se refiere a la legislación en materia de expropiación forzosa, derogatoria segunda, y final tercera que entrarán en vigor $\theta$ día siguiente al de dicha publicación.

\section{Por tanto,}

Mando a todos los españoles, particulares y autoridades, que guarden y hagan guardar esta Ley.

Madrid, 5 de noviembre de 1999

\section{JUAN CARLOS R}

El Presidente del Gohiarno.

JOSÉ MARIA AZNNAR LÓPEZ

21568 LEY 39/1999, de 5 de noviembre, para promover la conciliación de la vida familiar y laboral de las personas trabajadoras.

\section{IUAN CARLOS 1 \\ REY DE ESPAÑA}

A todos los que la presente vieren y entendieren, Sabed: Que las Cortes Generales han aprobado y Yo vengo en sancionar la siguiente ley.

\section{EXPOSICIÓN DE MOTIVOS}

La Constitución Española recoge en su articulo 14 el derecho a la igualdad ante la ley $y$ el principio de no discriminación por razón de nacimiento raza, sexo, religión $u$ opinión o cualquier otra condición. En el articulo 39.1 , el texto constitucional establece el deber de los poderes públicos de asegurar la protección social, económica y jurídica de la familia $y$, en el artículo 9.2, atribuye a los poderes públicos el deber de promover igualdad del individuo $y$ de los grupos en que se integran sean reales y efectivas; y remover los obstáculos que impidan o dificulten su plenitud facilitando la participación de todos los ciudadanos en la vida política, económica, cultural y social.

La incorporación de la mujer al trabajo ha motivado uno de los cambios sociales más profundos de este siglo. Este hecho hace necesario configurar un sistema que contemple las nuevas relaciones sociales surgidas y un nuevo modo de cooperación y compromiso entre muje- 
res $y$ hombres que permita un reparto equilibrado de responsabilidades en la vida profesional y en la privada.

La necesidad de conciliación del trabajo y la familia ha sido ya planteada a nivel internacional y comunitario como una condición vinculada de forma inequívoca a la nueva realidad social. Ello plantea una compleja y difícil problemática que debe abordarse, no sólo con importantes reformas legislativas, como la presente, sino con la necesidad de promover adicionalmente servicios de atención a las personas, en un marco más amplio de politica de familia.

En este sentido, en la IV Conferencia mundial sobre las mujeres, celebrada en Pekín en septiembre de 1995 se consideró como objetivo estratégico fomentar una armonización de responsabilidades laborales $y$ familiare entre hombres y mujeres y en la Declaración aprobada por los 189 Estados alli reunidos, se reafirmó este com promiso.

Por su parte, en el ámbito comunitario, la maternidad y la paternidad, en su más amplio sentido, se han reco gido en las Directivas del Consejo $92 / 85 / C E E$ de 19 de octubre, y $96 / 34 / C E$, del Consejo, de 3 de junio La primera de ellas contempla la maternidad desde punto de vista de la salud y seguridad en el trabajo de la trabajadora embarazada que haya dado a luz en periodo de lactancia. La segunda, relativa al Acuerdo marco sobre el permiso parental, celebrado por la UNICE, el CEEP y la CES, prevé el permiso parental y la ausencia del trabajo por motivos de fuerza mavor como medio importante para conciliar la vida profesional y familia importante para conciliar la vida profesional y familiar y promover la iguald
hombres y mujeres.

Mediante la presente Ley se completa la transposición a la legislación española de las directrices marcadas por la normativa internacional y comunitaria superando los niveles minimos de protección previstos en las mismas.

La Ley introduce cambios legislativos en el ámbito laboral para que los trabajadores puedan participar de la vida familiar, dando un nuevo paso on el camino de la igualdad de oportunidades entre mujeres y hombres. Trata además de guardar un equilibrio para favorecer los permisos por maternidad y paternidad sin que ello afecte negativamente a las posibilidades de acceso al empleo, a las condiciones del trabajo y al acceso a pues tos de especial responsabilidad de las mujeres. Al mismo tiempo se facilita que los hombres puedan ser coparticipes del cuidado de sus hijos desde el mismo momento del nacimiento o de su incorporación a la familia.

El primer capitulo introduce madificaciones en el Estatuto de los Trabajadores en lo relativo a permisos y excedencias relacionadas con la maternidad, paternidad y el cuidado de la farmilia. Estas modificaciones mejoran el contenido de la normativa comunitaria y ajustan los permisos a la realidad social

Asi, se hacen concordar los permisos o ausencias retribuidas con la Directiva $96 / 34 / \mathrm{CE}$, previendo la ausencia del trabajador en los supuestos de accidente $\checkmark$ de hospitalización, al mismo tiempo que se flexibiliza el derecho al permiso de lactancia.

Iguaimente se amplia el derecho a la reducción de jornada y excedencia a los trabajadores que tengan que ocuparse de personas mayores y enfermas, en línea con los cambios demográficos $y$ el envejecimiento de la población.

Como novedad importante, cabe destacar que la Ley facilita a los hombres el acceso al cuidado del hijo desde el momento de su nacimiento o de su incorporación a la familia, al conceder a la mujer la opción de que sea el padre el que disfrute hasta un maximo de diez semanas de las dieciséis correspondientes al permiso por maternidad, permitiendo además que lo disfrute simultáneamente con la madre y se amplía el permiso de maternidad en dos semanas más por cada hijo en el caso de parto múltiple.

Asimismo, se introducen importantes modificaciones en la regulación de los permisos por adopción $y$ acogimiento permanente y preadoptivo. Frente a la legislación actual en la que la duración del permiso depende de la edad del menor, concediéndose distintos períodos de tiempo, según el niño o niña sea menor de nueve meses o de cinco años, ta Ley no hace distinción en la edad de los menores que generan este derecho, siempre que se trate de menores de seis años.

Por último, se establece la aplicación de la reducción de la jornada o excedencia para atender al cuidado de familiares que por razón de edad, accidente o enfermedad no puedan valerse por si mismos y no desempeñen actividad retribuida, configurándose este derecho como individual de los trabajadores.

El último artículo del capitulo I prevé las modificaciones que han de realizarse en el Estatuto de los Tra bajadores relativas a la extinción del contrato de trabajo. Para ello, se declara expresamente nula la decisión extintiva o el despido motivado, entre otros. por el embarazo. tiva o el despido motivado, entre otros. por el embarazo, paternidad o cuidado de familiares o el despido de los trabajadores con contrato de trabajo suspendido, salvo que se demuestre su procedencia por causa ajena a la discriminación.

Como novedad se amplian los supuestos que no pueden computarse como faltas de asistencia a efectos de extinción del contrato de trabajo por absentismo labora. Entre ellos se incluyen el riesgo durante el embarazo. las enfermedades causadas por el mismo, el parto y la lactancia.

El capitulo II introduce modificaciones al Real Decreto legislativo 2/1995, de 7 de abril, por el que se aprueba el texto refundido de la Ley de Procedimiento Laboral, para garantizar el ejercicio libre de estos derechos su resolución en caso de discrepancia mediante procedimiento urgente y de tramitación preferente.

El capitulo III modifica la Ley 31/1995, de 8 de noviembre, de Prevención de Riesgos Laborales, y cubre una laguna actualmente existente, previendo que en los supuestos de maternidad en los que, por motivos de salud de la madre o del feto, se hace necesario un cambio de puesto de trabajo o función $y$ este cambio no sea posible, se declare a la interesada en situación de riesgo durante el embarazo con protección de la Seguridad Social.

El capitulo IV introduce modificaciones en el Real Decreto legislativo 1/1994, de 20 de junio, por el que se aprueba el texto refundido de la Ley General de la Seguridad Social. La novedad más importante reside en la creación de una nueva prestación dentro de la acción protectora de la Seguridad Social, la de riesgo durante el embarazo, con la finalidad de proteger la salud de la mujer trabajadora embarazada.

Con la finalidad de que no recaigan sobre los empresarios las costes sociales de estos permisos, lo que podria acarrear consecuencias negativas en el acceso al empleo, especialmente de la población femenina, y como medida de fomento del empleo, el capitulo $V$ prevé reducciones en las cotizaciones empresariales a la Seguridad Social por contingencias comunes, siempre que se contrate interinamente a desempleados para sustituir al trabajador o trabajadora durante los períados de descanso por maternidad, adopción o acogimiento.

Los capitulos VI, VII y VIII introducen las correspondientes modificaciones en las leyes reguladoras de la Función Pública, con el objeto de adaptar el contenido de la Ley a los colectivos comprendidos en su ámbito de aplicación. 


\section{CAPITULO 1}

Modificaciones que se introducen en el texto refundido de la Ley del Estatuto de los Trabajadores, aprobado por el Real Decreto legislativo 1/7995, de 24 de marzo

Articulo primero. Permisos retribuidos.

La letra b) del apartado 3 del artículo 37 queda redactada de la siguiente forma:

«b) Dos dias por el nacimiento de hijo o por el fallecimiento, accidente o enfermedad graves u hospitalización de parientes hasta el segundo grado de consanguinidad o afinidad. Cuando con tal motivo el trabajador necesite hacer un desplazamiento al efecto, el plazo será de cuatro días."

Artfculo segundo. Reducción de la jornada por motivos familiares.

1. El apartado 4 del articulo 37 queda redactado de la siguiente forma:

"4. Las trabajadoras, por lactancia de un hijo menor de nueve meses, tendrán derecho a una hora de ausencia del trabajo, que podrán dividir en dos fracciones. La mujer, por su voluntad, podrá sustituir este derecho por una reducción de su jornada en media hora con la misma finalidad. Este permiso podrá ser disfrutado indistintamente por la madre o el padre en caso de que ambos trabajen."

2. El apartado 5 del artículo 37 queda redactado de la siguiente forma:

45. Quien por razones de guarda legal tenga a su cuidado directo algún menor de seis años o un minusválido físico, psiquico o sensorial, que no desempeñe una actividad retribuida, tendrá derecho a una reducción de la jornada de trabajo, con la disminución proporcional del salario entre, a menos, un tercio y un máximo de la mitad de la duración de aquélla.

Tendrả el mismo derecho quien precise encargarse del cuidado directo de un familiar, hasta el segundo grado de consanguinidad o afinidad, que por razones de edad, accidente o enfermedad no pueda valerse por sí mismo, y que no desempeñe actividad retribuida.

La reducción de jornada contemplada en el presente apartado constituye un derecho individual de los trabajadores, hombres o mujeres. No obstante. si dos o más trabajadores de la misma empresa generasen este derecho por el mismo sujeto causante, el empresario podrá limitar su ejercicio simultáneo por razones justificadas de funcionamiento de la empresa."

3. Se añade un nuevo apartado al artículo 37 del Estatuto de los Trabajadores:

"6. La concreción horaria y la determinación del periodo de disfrute del permiso de lactancia y de la reducciön de jornada, previstos en los apartados 4 y 5 de este articulo, corresponderá al trabajador dentro de su jornada ordinaria. El traba. jedor debera preavisar al empresario con quince días de antelación la fecha en que se reincorporará a su jornada ordinaria.

Las discrepancias surgiclas entre empresario y trabajador sobre la concreción horaria y la determinación de los períodos de disfrute previstos en los apartados 4 y 5 de este artículo serán resueltas por la jurisdicción competente a través del proce- dimiento establecido en el articulo 138 bis de la Ley de Procedimiento Laboral."

Artículo tercero. Suspensión del contrato por maternidad, riesgo durante el embarazo, adopción o acogimiento.

El apartado 1.d) del articulo 45 queda redactado de la siguiente forma:

«d) Maternidad, riesgo durante el embarazo de la mujer trabajadora y adopción o acogimiento. preadoptivo o permanente, de menores de seis años."

Artículo cuarto. Excedencia por cuidado de familiares.

El apartado 3 del articulo 46 queda redactado de la forma siguiente:

«3. Los trabajadores tendrán derecho 3 un periodo de excedencia de duración no superior a tres años para atender al cuidado de cada hijo. tanto cuando lo sea por naturaleza, como por adoptanto cuando lo sea por naturaleza, como por adop-
ción, o en los supuestos de acogimiento, tanto permanente como preadoptivo, a contar desde la fecha de nacimiento o, en su caso. de la resolución judicial o administrativa.

También tendrán derecho a un periodo de excedencia, de duración no superior a un año, salvo que se establezca una duración mayor por negociación colectiva, los trabajadores para atender al cuidado de un familiar, basta el segundo grado de consanguinidad o afinidad, que por razones de edad accidente o enfermedad no pueda valerse por si mismo, $y$ no dese

La excedencia contemplada en el presente apartado constituye un derecho individual de los trabajadores, hombres o mujeres. No obstante, si dos - más trabajadores de la misma empresa generasen este derecho por el mismo sujeto causante, el empresario podrá limitar su ejercicio simultáneo por razones justificadas de funcionamiento de la

por razone

Cuando un nuevo sujeto causante diera derecho a un nuevo periodo de excedencia, el ínicio de la misma dará fin al que, en su caso, se viniera disfrutando.

El período en que el trabajador permanezca en situación de excedencia conforme a lo establecido en este artículo será computable a efectos de antigüedad y el trabajador tendrá derecho a la asistencia a cursos de formación profesional a cuya participación deberá ser convocado por el empresario, especialmente con ocasión de su reincorporación. Durante el primer año tendrá derecho a la reserva de su puesto de trabajo. Transcurrido dicho plazo, la reserva quedará referida a un puesto de trabajo del mismo grupo profesional o categoria equivalente. $n$

Artículo quinto. Suspensión con reserva de puesto de trabajo.

El apartado 4 del articulo 48 queda modificado de la siguiente manera:

44. En el supuesto de parto, la suspensión tendrá una duración de dieciséis semanas, que se disfrutarán de forma ininterrumpida, ampliables en el supuesto de parto múltiple en dos semanas más por cada hijo a partir del segundo. El periodo de suspensión se clistribuirá a opción de la interesada seis semanas sean inmediatamente posteriores al parto. En caso de fallecimiento de 
la madre, el padre podrá hacer uso de la totalidad o, en su caso, de la parte que reste del periodo de suspensión.

No obstante 10 anterior, y sin perjuicio de las seis semanas inmediatas posteriores al parto de descanso obtigatorio para la madre, en el caso de que el padre y la madre trabajen, ésta, al iniciarse el periodo de descanso por maternidad, podrá optar por que el padre disfrute de una parte determinada e ininterrumpida del periodo de descanso posterior al parto bien de forma simultánea o sucesiva con el de la madre, salvo que en el momento de su efectividad la incorporación al trabajo de la madre suponga un riesgo para su salud.

En los supuestos de adopción y acogimiento. tanto preadoptivo como permanente, de menores de hasta seis años, la suspensión tendrá una duración de dieciséis semanas ininterrumpidas, ampliable en el supuesto de adopción o acogimiento múlble en el supuesto de adopción o acogimiento mú-
tiple en dos semanas más por cada hijo a partir del segundo, contadas a la elección del trabajador. bien a partir de la decisión administrativa o judicial de acogimiento, bien a partir de la resolución judicial por la que se constituye la adopción. La duración de la suspensión será, asimismo, de dieciséis semanas en los supuestos de adopción o acogimiento de menores mayores de seis años de edad cuando se trate de menores discapacitados o minusválidos o que por sus circunstancias y experiencias personales o que por provenir del extranjero, tengan especiales dificultades de inserción social y familiar debidamente acreditadas por los servicios sociales competentes. En caso de que la madre y el padre trabajen, el periodo de suspensión se distribuirá a opción de los interesados, que podrán disfrutarla de forma simultánea o sucesiva, siempre con periodos ininterrumpidos y con los limites señalados.

En los casos de disfrute simultáneo de periodos de descanso. la suma de los mismos no podrá exceder de las dieciséis semanas previstas en los apartados anteriores o de las que correspondan en caso de parto múltiple.

Los periodos a los que se refiere el presente artículo podrán disfrutarse en régimen de jornada completa o a tiempo parcial, previo acuerdo entre los empresarios y los trabajadores afectados, en los términos que reglamentariamente se determinen.

En los supuestos de adopción internacional, cuando sea necesario el desplazamiento previo de los padres al pais de origen del adoptado, el período de suspensión, previsto para cada caso on el pre sente articulo, podrá iniciarse hasta cuatro semanas antes de la resolución por la que se constituye la adopción."

Artículo sexto. Suspensión con reserva de pusesto de trabajo en el supuesto de riesgo durante el embarazo.

Se introduce un nuevo apartado 5 en el artículo 48 de la Ley del Estatuto de los Trabajadores, en los siguientes términos:

«5. En el supuesto de riesgo durante el embarazo, en los términos previstos en el articulo 26 , apartados 2 y 3 , de la Ley $31 / 1995$, de 8 dé noviembre de Prevención de Riesgos Laborales, la suspensión del contrato finalizará el dia en qué se inicie la suspensión del contrato por maternidad biológica o desaparezca la imposibilidad de la trabajadora de reincorporarse a su puesto anterior o a otro compatible con su estado,"

Artículo séptimo, Extinción del contrato de trabajo.

Uno. La letra d) del articula 52 queda modificada de la siguiente manera:

ad) Por faltas de asistencia al trabajo, aun justificadas pero intermitentes, que alcancen el 20 por 100 de las jornadas hábiles en dos meses consecutivos, 0 el 25 por 100 en cuatro meses discontinuos dentro de un período de doce meses, siempre que el indice de absentismo total de la plantilla del centro de trabajo supere el $\mathbf{5}$ por $\mathbf{1 0 0}$ en los mismos períodos de tiempo.

No se computarán como faltas de asistencia, a los efectos del párrafo anterior las ausencias debidas a huelga legal por el tiempo de duración de la misma, el ejercicio de actividades de representación legal de los trabajadores, accidente de trabajo, maternidad, riesgo durante ol embarazo, enfermedades causadas por embarazo, parto o lactancia, licencias y vacaciones, ni enfermedad o accidente no laboral, cuando la baja haya sido acordacla por los servicios sanitarios oficiales y tenga una duración de más de veinte días consecutivos."

Dos. El apartado 4 del artículo 53 queda modificado de la siguiente manera:

44. Cuando el empresario no cumpliese los requisitos establecidos en el apartado 1 de este artículo o la decisión extintiva del empresario tuviera como móvil algunas de las causas de discriminación prohibidas en la Constitución o en la ley o bien se htubiera producido con violación de dereo bien se htubiera producido con violación de dere-
chos fundamentales y libertades públicas del trabajador, la decisión extintiva será nula, debiendo la autoridad judicial hacer tal declaración de oficio. La no concesión del preaviso no anulará la extinción si bien el empresario, con independencia de los demás efectos que procedan, estará obligado a abonar los salarios correspondientes a dicho periodo. La posterior observancia por el empresario de los requisitos incumplidos no constituirá, en ningún caso, subsanación del primitivo acto extintivo, sino un nuevo acuerdo de extinción con efectos desde su fecha.

Será también nula la decisión extintiva en los siguientes supuestos:

a) La de los trabajadores durante el período de suspensión del contrato de trabajo por maternidad, riesgo durante el embarazo, adopción o acogimiento al que se refiere la letra d) del apartado 1 del artículo 45 de esta Ley, o la notificada en una fecha tal que el plazo de preaviso finalice dentro de dicho período.

b) La de las trabajadoras embarazadas, desde la fecha de inicio del embarazo hasta la del comienzo del periodo de suspensión a que se refiere la letra a) y la de los trabajadores que hayan solicitado uno de los permisos a los que se refieren los apartados 4 y 5 del articulo 37 de esta Ley, o estén disfrutando de ellos, o hayan solicitado la excedencia prevista en el apartado 3 del articulo 46 de la misma. 
Lo establecido en las letras anteriores será de aplicación salvo que, en ambos casos, $s e$ declare la procedencia de la decisión extintiva por motivos no relacionados con el embarazo o con el ejercicio del derecho a los permisos y excedencia señalados."

Tres. El apartado 5 del articulo 55 queda redactado en la siguiente forma

"5. Será nulo el despido que tenga por móvil algunas de las causas de discriminación prohibidas en la Constitución o en la Ley, o bien se produzca con violación de derechos fundamentales y libertades públicas del trabajador.

Será también nulo el despido en los siguientes supuestos:

a) El de los trabajadores durante el período de suspensión del contrato de trabajo por maternidad, riesgo durante el embarazo, adopción o acogimiento al que se refiere la letra d) del apartado 1 del articulo 45 de esta Ley, o el notificado en una fecha tal que el plazo de preaviso finalice dentro de dicho periodo.

b) El de las trabajadoras embarazadas, desde la fecha de inicio del embarazo hasta la del comienzo del periodo de suspensión a que se refiere la letra a), y la de los trabajadores que hayan solicitado uno de los permisos a los que se refieren los apartados 4 y 5 del articulo 37 de esta Ley, o estén disfrutando de ellos, o hayan solicitado la excedencia prevista en el apartado 3 del artículo 46 de la misma.

Lo establecido en las letras anteriores será de aplicación, salvo que, en ambos casos, se declare la procedencia del despido por motivos no relacionados con el embarazo o con el ejercicio del derecho a los permisos y excedencia señalados."

\section{CAPITULO ॥}

Modificaciones que se introducen en el texto refundido de la Ley de Procedimiento Laboral, aprobado por el Real Decreto legislativo 2/1995, de 7 de abril

Artículo octavo. Extinción del cantrato de trabajo.

Uno. El apartado 2 del articulo 108 queda redactado de la siguiente forma:

12. Será nulo el despida que tenga como móvil alguna de las causas de discriminación previstas en la Constitución y en la ley, o se produzca con violación de derechos fundamentales y libertades públicas del trabajador.

Será también nulo el despido en los siguientes supuestos:

a) El de los trabajadores durante el periodo de suspensión del contrato de trabajo por maternidad, riesgo durante el embarazo, adopción o acogimiento al que se refiere la letra d) del apartado $1 \mathrm{del}$ articulo 45 del texto refundido de la Ley del Estatuto de los Trabajadores, o el notificado en una fecha tal que el plazo de preaviso concedido finalice dentro de dicho periodo.

b) El de las trabajadoras embarazadas, desde la fecha de inicio del embarazo hasta el comienzo del periodo de suspensión a que se refiere la letra a). $y$ el de los trabajadores que hayan solicitado uno de los permisos a los que se refieren los apartados 4 y 5 del articulo 37 del Estatuto de los Trabajadores, o estén disfrutando de ellos, o hayan soli- citado la excedencia prevista en el apartado 3 del articulo 46 del Estatuto de los Trabajadores.

Lo establecido en las letras anteriores será de aplicación, salvo que, en ambos casos, se declare la procedencia del despido por motivos no relacionados con el embarazo o con el ejercicio del derecho a los permisos y excedencia señalados."

Dos. El apartado 2 del articulo 122 queda redactado de la siguiente forma:

42. La decisión extintiva será nula cuando:

a) No se hubieren cumplido las formalidades legales de la comunicación escrita, con mención de causa.

b) No se hubiese puesto a disposiciōn del trabajador la indemnización correspondiente, salvo en aquellos supuestos en los que tal requisito no viniera legalmente exigido.

c) Resulte discriminatoria o contraria a los derechos fundamentales $y$ libertades públicas del trabajador.

d) Se haya efectuado en fraude de ley eludiendo las normas establecidas por los despidos colectivos, en los casos a que se refiere el último párrafo del artículo 51.1 del texto refundido de la Ley del Estatuto de los Trabajadores.

Será también nula la decișión extintiva en los siguientes supuestos:

a) La de los trabajadores durante el periodo de suspensión del contrato de trabajo por maternidad, riesgo durante el embarazo, adopción o acogimiento al que se refiere la letra d) del apartado 1 del artículo 45 del Estatuto de los Trabajadores, - la notificada en una fecha tal que el plazo de preaviso finalice dentro de dicho período.

b) La de las trabajadoras embarazadas, desde la fecha de inicio del embarazo hasta la del comienzo del período de suspensión a que se refiere la letra a), y de los trabajadores que hayan solicitado uno de los permisos a que se refieren los apartados 4 y 5 del articulo 37 del Estatuto de los Trabajadores, o estén disfrutando de ellos, o hayan solicitado la excedencia prevista en el apartado 3 del artícula $\mathbf{4 6}$ del Estatuto de los Trabajadores.

Lo establecido en las letras anteriores será de aplicación, salvo que en ambos casos, se declare la procedencia de la decisión extintiva por motivos no relacionados con el embarazo o con el ejercicio del derecho a los permisos y excedencia señala. dos."

Artículo noveno. Modalidad procesal en materia de permisos de lactancia y reducciones de jornada por motivos familiares.

1. Se modifica la rúbrica del capítulo $\mathrm{V}$ del Título II del Libro Il, que queda denominado:

"Vacaciones, materia electoral, clasificaciones profesionales, movilidad geográfica, modificaciones substanciales de condiciones de trabajo permisos por lactancia y reducción de jornada por motivos familiares.

2. Se incluye una nueva sección en el capitulo $V$ del Titulo II del Libro II, del siguiente tenor literal:

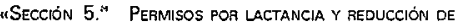
JORNADA POR MOTVOS FAMILIARES

Articulo 138 bis.

El procedimiento para la concreción horaria y la determinación del periodo de disfrute en los per- 
misos por lactancia y por reducción de jornada por motivos familiares se regirán por las siguientes reglas:

a) El trabajador dispondrá de un plazo de veinte dias a partir de que el empresario le comunique su disconformidad con la concreción horaria y el períado de disfrute propuesto por aquél, para presentar demanda ante el Juzgado de lo Social.

b) El procedimiento será urgente y se le dará tranitación preferente. El acto de la vista habrá de señalarse dentro de los cinco dias siguientes al de la admisión de la demanda. La sentencia. que será firme, deberá ser dictada en el plazo de tres dias."

3. El primer párrafo del apartado 1 del artículo 189 queda redactado en la forma siguiente:

"1. Las sentencias que dicten los Juzgados de lo Social en los procesos que ante ellos se tramiten. cualquiera que sea la naturaleza del asunto, salvo las que recaigan en los procesos relativos a la fecha de disfrute de las vacaciones, concreción horaria y determinación del periodo de disfrute en permisos por lactancia y reducción de la jornada por motivos familiares en los de materia electoral en los de clasificación profesional, en los de impugnación de sanción por falta que no sea muy grave, así como por falta muy grave no confirmada judicialmente. y las dictadas en reclamaciones cuya cuantia litigiosa no exceda de 300.000 pesetas ( 1.803 euros). Procederá en todo caso la suplicación."

\section{CAPITULO III}

Modificaciones que se introducen en la Ley $31 / 1995$ de 8 de noviembre, de Prevención de Riesgos Laborales

\section{Artículo décimo. Protección de la maternidad.}

El articulo 26 queda redactado de la siguiente forma:

“1. La evaluación de los riesgos a que se refiere el articulo 16 de la presente Ley deberá comprender la determinación de la naturaleza, el grado y la duración de la exposición de las trabajadoras en situación de embarazo o parto reciente a agentes, procedimientos o condiciones de trabajo que puedan influir negativamente en la salud de las trabajadoras o del feto en cualquier actividad susceptible de presentar un riesgo especifico. Si los resultados de la evaluación revelasen un riesgo para la seguridad y la salud o una posible repercusión sobre el embarazo o la lactancia de las citadas trabajadoras, el empresario adoptará las medidas necesarias para evitar la exposiciön a dicho riesgo, a través de una adaptación de las conciciones o del tiempo de trabajo de la trabajadora afectada. Dichas medidas incluirán, cuando resulte necesario, la no realización de trabajo nocturno o de trabajo a turnos.

2. Cuando la adaptación de las condiciones o del tiempo de trabajo no resultase posibleo, a pesar de tal adaptación, las condiciones de un puesto de trabajo pudieran influir negativamente en la salud de la trabajadora embarazada o del feto. y asi lo certifiquen los Servicios Médicos del Instituto Nacional de la Seguridad Social o de las Mutuas, con el informe del médico del Servicio Nacional de la Salud que asista facultativamente a la trabajadora, ésta deberá desempeñar un puesto de trabajo o función diferente y compatible con su estado. El empresario deberá determinar, previa consulta con los representantes de los trabajadores, la relación de los puestos de trabajo exentos de riesgos a estos efectos.

El cambio de puesto o función se llevará a cabo de conformidad con las reglas y criterios que se apliquen en los supuestos de movilidad funcional y tendrá efectos hasta el momento en que el estado de salud de la trabajadora permita su reincorporación al anterior puesto.

En el supuesto de que, aun aplicando las reglas señaladas en el párrafo anterior, no existiese puesto de trabajo o función compatible, la trabajadora podrá ser destinada a un puesto no correspondiente a su grupo o categoría equivalente, si bien conservará el derecho al conjunto de retribuciones de su puesto de origen.

3. Si dicho cambia de puesto no resultara técnica u objetivamente posible, o no pueda razonablemente exigirse por motivos justificados, podrá declararse el paso de la trabajadora afectada a la situación de suspensión del contrato por riesgo lo 45.1.d) del Estatuto de los Trabajadores, durante el periodo necesario para la protección de su seguridad o de su salud y mientras persista la imposibilidad de reincorporarse a su puesto anterior o a otro puesto compatible con su estado.

4. Lo dispuesto en los números 1 y 2 de este articulo será también de aplicación durante el periodo de lactancia, si las condiciones de trabajo pudieran influir negativamente en la salud de la mujer o del hijo y así la cerrificase el médico que en e| régimen de Seguridad Social aplicable, asista facultativamente a la trabajadora.

5. Las trabajadoras embarazadas tendrán derecho a ausentarse del trabajo, con derecho a remuneración, para la realización de exámenes prenatales y tecnicas de preparación al parto, previo aviso al empresario y justificación de la necesidad de su realización dentro de la jornada de trabajo."

\section{CAPITULO IV}

Modificaciones que se introducen en el texto refundido de la Ley General de la Seguridad Social, aprobado por el Real Decreto legislativo 1/1994, de 20 de junio

Artículo undécimo. Acción protectora del sistema de la Seguridad Social.

Se modifica el primer párrafo del articulo 38.1.c) de la Ley General de la Seguridad Social, en los siguientes términos:

uc) Prestaciones económicas en las situaciones de incapacidad temporal; maternidad; riesgo durante el embarazo; invalidez, en sus modalidades contributiva y no contributiva; jubilación, en sus modalidades contributiva y no contributiva; desempleo. en sus niveles contributivo y asistericial; muerte y supervivencia; asi como las que se otorguen en las contingencias y situaciones especiales que reglamentariamente se determinen por Real Decreto, a propuesta del Ministro de Trabajo y Asuntos Sociales."

Articulo duodécimo. Duración de la obligación de cotizar.

Se modifica el apartado 4 del artículo 106 de la Ley General de la Seguridad Social, que queda redactado en los siguientes términos: 
44. La obligación de cotizar continuará en las situaciones de incapacidad temporal, cualquiera que sea su causa, en la de riesgo durante el embarazo y en la de maternidad, asi como en las demás situaciones previstas en el artículo 125 en que asi se establezca reglamentariamente."

\section{Articulo decimotercero. Situaciones protegidas.}

Se modifica el artículo 133 bis de la Ley General de la Seguridad Social. que queda redactado en los términos siguientes:

"Articulo 133 bis. Situaciones protegidas.

A efectos de la prestación por maternidad, se consideran situaciones protegidas la maternidad la adopción $\mathrm{y}$ el acogimiento, tanto preadoptivo como permanente, durante los períodos de descanso que por tales situaciones se disfruten, de acuerdo con lo previsto en el número 4 del artículo 48 del texto refundido del Estatuto de las Trabajadores, aprobado por Real Decreto legislativo $1 / 1995$, de 24 de marzo, y en el número 3 del articulo 30 de la Ley $30 / 1984$, de 2 de agosto, de Medidas para la Reforma de la Función Pública,s

Artículo decimocuarto. Prestación económica de la Seguridad Social por riesgo durante el embarazo.

Se incluye, en el Título II de la Ley General de la Seguridad Social, un nuevo capitulo IV ter, con la siguiente redacción:

\section{"CAPITULO IV TER}

\section{Riesgo durante el embarazo}

Articulo 134, Situación protegida.

A los efectos de la prestación económica por riesgo durante el embarazo, se considera situación protegida el periodo de suspensión del contrato de trabajo en los supuestos en que, debiendo la mujer trabajadora cambiar de puesto de trabajo por otro compatible con su estado, en los términos previstos en el articulo 26, apartado 3 , de la Ley $31 / 1995$ de 8 de noviembre de Prevención de Riesgos Laborales, dicho cambio de puesto no resulte técnica u objetivamente posible, o no pueda razonablemente exigirse por motivos justificados. Articulo 135. Prestación económica.

1. La prestación económica por riesgo durante el embarazo se concederá a la mujer trabajadora en los términos $y$ condiciones previstos en esta Ley para la prestación económica de incapacidad temporal derivada de enfermedad común, sin más particularidades que las previstas en los siguientes apartados.

2. La prestación económica, cuyo pago corres ponderá a la Entidad Gestora, nacerá el dia en que so inicie la suspensión del contrato de trabajo $y$ finalizará el día anterior a aquél en que se inicie la suspensión del contrato de trabajo por maternidad o el de reincorporación de la mujer trabajadora a su puesto de trabajo anterior o a otro compatible con su estado.

3. La prestación económica consistirá en subsidio equivalente al 75 por 100 de la base reguladora correspondiente. A tales efectos, la base reguladora será equivalente a la que esté estable cida para la prestación de incapacidad temporal derivada de contingencias comunes.

4. La prestación económica por riesgo durante el embarazo se gestionará directamente por el Ins- tituto Nacional de la Seguridad Social siguiendo el procedimiento que reglamentariamente se establezca.n

Artículo decimoquinto. Adaptaciones on la Ley General de la Seguridad Social.

Se introducen las siguientes adaptaciones en el capitulo V "Invalidez" del Título II de la Ley General de la Seguridad Social:

a) El actual articulo 134 pasa a quedar numerado como articulo 136 formando el contenido de la sección $1{ }^{a}$ del capituio $V$ del Título II de la Ley General de la Seguridad Social.

b) Las secciones $3 .^{\circ}, 4^{\circ}$ y $5^{\circ}$ pasan a numerarse, respectivamente, secciones $2 .^{a}, 3 .{ }^{a} \mathrm{Y} 4^{a}$ con idéntico contenido.

Artículo decimosexto. Normas de desarrollo y aplicación a Regímenes Especiales.

Se modifica el apartado 3 de la disposición adicional actava de la Ley General de la Seguridad Social, en los siguientes términos:

«3. Lo previsto en los articulos 134, 135 y 166 será aplicable, en su caso, a los trabajadores por cuenta ajena de los Regímenes Especiales. Asimismo resultará de aplicación a los trabajadores por cuenta propia incluidos en el Régimen Especial del Mar Régimen Especial Agrario y Régimen Especial de Trabajadores Autónomos, en los términos y condiciones que se establezcan reglamentariamente..

\section{CAPÍTULOV}

Modificaciones que se introducen en la disposición adicional decimocuarta del Real Decreto legislativo $1 / 1995$, de 24 de marzo, por el que se aprueba el texto refundido de la Ley del Estatuto de los Trabajadores, y en el Real Decreto-ley 11/1998, de 4 de septiembre, por el que se regulan las bonificaciones de cuotas a la Seguridad Social de los contratos de interinidad que se celebren con las personas deseminterinidad que se celebren con las personas desem-
pleadas para sustituir a trabajadores durante los períodos de descanso por maternidad, adopción y acogimiento

Articulo decimoséptimo. Modificación del encabezamiento de la disposición adicional decimocuarta del texto refundido del Estatuto de los Trabajadores.

El encabezamiento de la disposición adicional decimocuarta queda redactado en los siguientes términos:

"Decimocuarta. Sustitución de trabajadores excedentes por cuidado de familiares."

Articulo decimoctavo. Modificaciones que se introducen al Real Decreto-tey $11 / 1998$, de 4 de septiembre por el que se regulan las bonificaciones de cuotas a la Seguridad Social de los contratos de interinidad que se celebren con personas desempleadas para sustituir a trabajadores durante los periodos do descanso por maternidad, adopción y acogimiento.

Se modifica el artícula 1 del Real Decreto-ley $11 / 1998$, de 4 de septiembre, que quedara redactado de la siguiente forma:

"Darán derecho a una bonificación del 100 por 100 en las cuotas empresariales de la Seguridad Social, incluidas las de accidentes de trabajo y enfermedades profesionales, $y$ en las aportaciones 
empresariales de las cuotas de recaudación conjunta:

a) Los contratos de interinidad que se celebren con personas desempleadas para sustituir a trabajadoras que tengan suspendido su contrato de trabajo por riesgo durante el embarazo y hasta tanto se inicie la correspondiente suspensión del contrato por maternidad biológica o desaparezca la imposibilidad de la trabajadora de reincorporarse a su puesto anterior o a otro compatible con su estado.

b) Los contratos de interinidad que se celebren con personas desempleadas para sustituir a trabajadores y trabajadoras que tengan suspendido su contrato de trabajo durante los periodos de descanso por maternidad, adopción y acogimiento preadoptivo o permanente, en los términos establecidos en el número 4 del artículo 48 del Estatuto de los Trabajadores.

La duración máxima de las bonificaciones previstas en este a partado b) coincidira con la del periodo de descanso a que se refiere el número 4 del articulo 48 del Estatuto de los Trabajadores.

En el caso de que el trabajador no agote el periodo de descanso a que tuviese derecho, los beneficios se extinguirán en el momento de su incorporación a la empresa.

c) Los contratos de interinidad que se celebren con personas desempleadas para sustituir a trabajadores autónomos, socios trabajadores o socios de trabajo de las sociedades cooperativas, en los supuestos de riesgo durante el embarazo, períodos de descanso por maternidad, adopción y acogimiento preadoptivo o permanente en los términos establecidos en los párrafos anteriores."

\section{CAPITULOVI}

Modificaciones que se introducen en la Ley 30/1984, de 2 de agosto de Medidas para la Reforma de la Función Pública

Artículo decimonoveno. Excedencia por cuidado de familiares.

El apartado 4 del artículo 29 queda redactado de la forma siguiente:

"4. Los funcionarios tendrán derecho a un periodo de excedencia de duración no superior a tres años para atender al cuidado de cada hijo. tanto cuando lo sea por naturaleza como por adop ción o acogimiento permanente o preadoptivo, a contar desde la fecha de nacimiento o, en su caso. de la resolución judicial o administrativa.

También tendrán derecho a un periodo de excedencia, de duración no superior a un año, los funcionarios para atender al cuidado de un familiar que se encuentre a su cargo, hasta el segundo grado inclusive de consanguinidad o afinidad, que por razones de edad, accidente o enfermedad, no pueda valerse por sí mismo, y no desempeñe actividad retribuida.

El periodo de excedencia será único por cada sujeto causante. Cuando un nuevo sujeto causante diera origen a una nueva excedencia, el inicio de periodo de la misma pondrá fin al que se viniera disfrutando.

Esta excedencia constituye un derecho individual de los funcionarios. En caso de que dos funcionarios generasen el derecho a disfrutarlo po el mismo sujeto causante, la Administración podra limitar su ejercicio simultáneo por razones justifi- cadas relacionadas con el funcionamiento de los servicios.

El período de permanencia en esta situación será computable a efectos de trienios, consolidación de grado personal y derechos pasivos. Durante el primer año, los funcionarios tendrán derecho a la reserva del puesto de trabajo que desempeñaban. Transcurrido este período, dicha reserva lo será al puesto en la misma localidad y de igual nivel $y$ retribución.

Artículo vigésimo. Permiso por maternidad y paternidad.

El apartado 3 del artículo 30 queda redactado de la forma siguiente:

«3. En el supuesto de parto, la duración del permiso será de dieciséis semanas ininterrumpidas. ampliables en el caso de parto múltiple en dos semanas más por cada hijo a partir del segundo. El permiso se distribuirá a opción de la funcionaria siempre que seis semanas sean inmediatamente posteriores al parto. En caso de fallecimiento de la madre, el padre podra hacer uso de la totalidad o, en su caso, de la parte que reste del permiso.

No obstante lo anterior, y sin perjuicio de las seis semanas inmediatas posteriores al parto de descanso obligatorio para la madre, en el caso de que la madre y el padre trabajen, ésta, al iniciarse el periodo de descanso por maternidad, podrá optar por que el padre disfrute de una parte determinada e ininterrumpida del periodo de descanso posterior al parto, bien de forma simultánea o sucesiva con el de la madre, salvo que en el momento de su efectividad la incorporación al trabajo de la madre suponga un riesgo para su salud.

En los supuestos de adopción o acogimiento, tanto preadoptivo como permanente, de menores de hasta seis años, el permiso tendrá una duración de dieciséis semanas ininterrumpidas, ampliables en el supuesto de adopción o acogimiento múltiple en dos semanas más por cada hijo a partir del segundo, contadas a la elección del funcionario, bien a partir de la decisión administrativa o judicial de acogimiento, bien a partir de la resolución judicial por la que se constituya la adopción. La duración del permiso será, asimismo, de dieciséis semanas en los supuestos de adopción a acogimiento de menores, mayores de seis años de edad, cuando se trate de menores discapacitados o minusválidos - que por sus circunstancias y experiencias personales o que, por provenir del extranjero, tengan especiales díficultades de inserción social y familiar. debidamente acreditadas por los servicios sociales competentes. En caso de que la madre y el padre trabajen, el permiso se distribuirá a opción de los interesados, que podrán disfrutarlo de forma simultánea o sucesiva, siempre con periodos ininterrum pidos.

En los casos de disfrute simultáneo de periodos de descanso, la suma de los mismos no podrá exceder de las dieciseis semanas previstas en los apartados anteriores o de las que correspondan en caso de parto múltiple.

En los supuestos de adopciön internacional. cuando sea necesario el desplazamiento previo de los padres al país de origen del adoptado, el permiso previsto para cada caso en el presente articulo, podrá iniciarse hasta cuatro semanas antes de la resolución por la que se constituye la adopción.»" 
CAPITULO VII

Modificaciones que se introducen en la Ley de Funcionarios Civiles del Estado, texto articulado aprobado por Decreto 315/1964. de 7 de febrero

Artículo vigésimo primero. Licencia por riesgo durante el embarazo.

Se introduce un nuevo número 3 en el artículo 69 con la siguiente redacción:

"3. Cuando la circunstancia a que se refiere el número 3 del artículo 26 de la Ley $31 / 1995$. de 8 de noviembre, de Prevención de Riesgos Laborales, afectase a una funcionaria incluida en el ámbito de aplicación del mutualismo administrativo podrá concederse licencia por riesgo durante el embarazo en los mismos términos y condiciones que las previstas en los números anteriores."

\section{CAPÍTULO VII}

Modificaciones que se introducen en la Ley 28/1975 de 27 de junio, sobre Seguridad Social de las Fuerzas Armadas, y en la Ley $29 / 1975$, de 27 de junio, de Seguridad Social de los Funcionarios Civiles del Estado

Articulo vigésimo segundo. Situación de riesgo durante el embarazo en el mutualismo administrativo.

Se introduce un nuevo párrafo, después del tercero actual, en el artículo 21 de la Ley $28 / 1975 \mathrm{y}$ en $\theta$ articulo 20 de la Ley $29 / 1975$, con la siguiente redacción:

"Tendrả la misma consideración y efectos que la situación de incapacidad temporal la situación de la mujer funcionaria que haya obtenido licencia por riesgo durante el embarazo en los términos previstos en el artículo 69 , apartado 3 , de la Loy de Funcionarios Civiles del Estado."

\section{Disposición adicional primera.}

Podrán acogerse a los beneficios establecidos en esta Ley los socios trabajadores o socios de trabajo de las sociedades cooperativas y trabajadores de las sociedades laborales, durante los periodos de descanso por maternidad, riesgo durante el embarazo, adopeión y acogimiento, con independencia del régimen de afiliación de la Seguridad Social, en el que estuvieren incluidos, con las peculiaridades propias de la relación societaria.

\section{Disposición adicional segunda.}

La legislación de la Seguridad Social en materia de convenios especiales se adaptará a las modificaciones previstas en la presente Ley, en el plazo de un año contado a partir de su entrada en vigor.

\section{Disposición adicional tercera.}

Se modifica la redacción del apartado 1 .el del artículo 141 de la Ley $17 / 1999$, de 18 de mayo, de Régimen del Personal de las Fuerzas Armadas, que quedará de la siguiente forma:

we) Lo soliciten para atender al cuidado de los hijos, por naturaleza o adopción o acogimiento per- manente o preadoptivo. En este supuesto, tendran derecho a un periodo de excedencia voluntaria no superior a tres años para atender al cuidado de cada hijo, a contar desde la fecha de nacimiento de éste o, en su caso. de la resolución judicial o administrativa Los sucesivos hijos darán derecho a un nuevo periodo de excedencia que, en su caso. pondrá fin al que vinieran disfrutando.

También tendrán derecho a un periodo de excedencia de duración no superior a un año los que lo soliciten para encargarse del cuidado directo de un familiar, hasta el segundo grado de consanguinidad o afinidad que, por razones de edad, accidente $o$ de enfermedad, no pueda valerse por si mismo, y que no desempeñe actividad retribuida.

Estos derechos no podrán ser ejercidos por dos personas por el mismo sujeto causante.n

\section{Disposición adicional cuarta.}

El Gobierno, en el marco de sus competencias, y de acuerdo con los agentes sociales, impulsará campañas de sensibilización pública al objeto de conseguir que los hombres asuman una parte igual de las responsabilidades familiares, y de manera especial se acojan, en mayor medida, a las nuevas posibilidades que esta Ley ofrece para compartir el permiso parental.

Disposición adicional quinta.

A los efectos de lo establecido en esta Ley, se considerarán juridicamente equiparables a la adopción y acogimiento preadoptivo o permanente, aquellas instituciones juridicas declaradas por resoluciones judiciales o administrativas extranjeras, cuya finalidad y efectos jurídicos sean los previstos para la adopción y acogimiento preadoptivo o permanente, cualquiera que sea su denominación.

Disposición derogatoria única. Alcance de la derogación nomativa.

Quedan derogadas cuantas disposiciones se opongan a lo establecido en esta Ley.

Disposición final primera. Facultades de aplicación $y$ desarrollo.

Se autoriza al Gobierno para dictar cuantas disposiciones fueran necesarias para el desarrollo y ejecución de la presente Ley.

Disposición final segunda. Entrada en vigor.

Esta Ley entrará en vigor el día siguiente al de su publicación en el "Boletín Oficial del Estado".

Por tanto.

Mando a todos los españoles, particulares y autoridades, que guarden y hagan guardar esta Ley

Madrid, 5 de noviembre de 1999

El Vicepresidenta Primero dal Gohierno y Ministro de la Presidencia. FRANCISCO ALVAREZ-CASCOS FERNANDEZ 



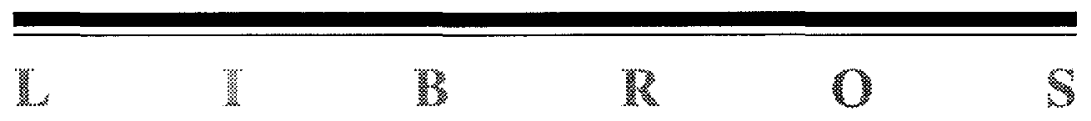



Título: Hacia una economía plural. Un trabajo, una actividad, una renta para todos.

Autores: Aznar, G., Caillé, A., Laville, J.L., Robin, J. y Sue, R.

Edita: Miraguano-Promocions. Madrid, 1999. Edición original: Vers une... économie plurelle. Un travail, une activité, un revenu pour tous. Éditions La Découverte-Syros. París, 1997.

Título: Trabajar para Vivir. Una propuesta innovadora de inserción sociolaboral.

Autores: Frago, E., Jover, D. López, V.M, Márquez, F. y Mora, G. Edita: Miraguano-Promocions. Madrid, 1999.

Estos dos libros se centran en el tema de la inserción sociolaboral de las personas que, por diferentes circunstancias, se encuentran con obstáculos para acceder a un empleo y a participar plenamente en la vida social.

El primero, «Hacia una economía plural. Un trabajo, una actividad, una renta para todos» reúne las reflexiones de una serie de autores muy conocidos por quienes trabajan en el tema de la inserción sociolaboral. Analizan, a través de un debate, el aumento de la pobreza y la precariedad que tiene lugar como consecuencia del actual modelo económico y social. El debate hay que enmarcarlo en el contexto de la realidad socioeconómica francesa, no muy diferente a la nuestra, pero con una mayor sensibilidad social ante esta situación, habiendo dado lugar a movilizaciones de la población a favor de los más desfavorecidos consiguiendo importantes medidas políticas.

Las reflexiones, fruto de muchos años de experiencia, se estructuran en torno a una serie de temas considerados clave, de cuyo análisis se 
derivan las alternativas que se proponen. Estos temas son los límites de las políticas de crecimiento, la reducción de la jornada de trabajo como fin y como medio, una nueva renta mínima de inserción, el papel de la economía asociativa, así como la necesaria complementariedad entre ellos, dada su estrecha interrelación.

En relación a todo ello los autores exponen sus diferentes puntos de vista y, más allá de las divergencias, comparten la idea de que la situación puede y debe modificarse puesto que no es irreversible, por lo que están convencidos de que con voluntad política es posible lograr lo que consideran un objetivo común: la reorientación hacía un modelo de sociedad menos desigual, menos excluyente. Así, tras analizar las causas y consecuencias de la situación actual, describen su propuesta de una economía y una ciudadanía plurales. Esto se conseguiría, en su opinión, aplicando lo que consideran criterios básicos («certezas»), que se corresponderían con tres tipos de medidas políticas que han de implantarse conjuntamente:

a) La necesidad de una reducción del tiempo de trabajo importante y rápida, como otra forma de vivir la economía y de vivir en sociedad.

b) La utilidad de valorar y desarrollar actividades organizadas según una lógica que no prescinda ni del mercado ni del Estado, una economía asociativa (no residual) que contribuya a la vez al reforzamiento del vínculo social y a la creación de riqueza.

c) La legitimidad a corto plazo de un salario mínimo más generoso que la actual RMI, basado en dos derechos: derecho al salario y derecho a la inserción. Estas propuestas están siendo defendidas por cada vez mayor número de personas, quedando recogidas en el Manifiesto Europeo por una Ciudadanía y Economía plurales, con el que finaliza el libro.

En definitiva, se trata de un libro que puede resultar muy útil para las personas interesadas en estos temas y puede ser un buen instrumento al servicio de los docentes de las ciencias sociales en general y de las Escuelas de Trabajo Social en particular, con múltiples sugerencias para suscitar el debate de estos temas entre los alumnos.

En cuanto al libro «Trabajar para Vivir. Una propuesta innovadora de inserción sociolaboral», se trata de una obra de sistematización de la práctica en proyectos de inserción socio-laboral tanto en el ámbito de la docencia, formación de formadores, como de la experiencia directa con administraciones públicas y con entidades sociales.

Los autores, que comparten la filosofía del Manifiesto Europeo por una Ciudadanía y Economía plurales, conciben los programas de inserción sociolaboral como medios para «facilitar puentes entre el tra- 
bajo y la vida» subrayando que los aspectos relacionales, la voluntad, la comunicación y la capacidad de pensar y de organizarse son tan importantes para la cualificación social y personal como la propia cualificación profesional y, a la vez, son factores decisivos para la creación y obtención de empleo.

Dividen la obra en dos partes. En la primera parte, se presenta el marco para un Programa de Inserción socio-laboral a partir de una experiencia práctica, el proyecto «Labora Vita» (enmarcado en la Iniciativa Comunitaria de Empleo Integra). Este proyecto se basa en una metodología y estrategias para la inserción sociolaboral con un abordaje integral en los ámbitos de empleo, salud, vivienda y problemas socio-familiares, con un enfoque sociosanitario y comunitario, enmarcado en un territorio y promoviendo la corresponsabilidad de todos los agentes sociales.

En la segunda parte, con el título «Materiales e instrumentos de trabajo», se presenta una serie de materiales diversos utilizados en el proyecto. La segunda parte contiene tanto una guía para la evaluación de indicadores, modelos de expedientes y protocolo para la derivación de usuarios como otras propuestas generales a modo de criterios a tener en cuenta en la fase de acogida, en la entrevistas o el perfil profesional del Técnico en Inserción sociolaboral.

El libro es muy práctico y didáctico, es evidente que se basa en la experiencia directa de los autores y la metodología propuesta está en la línea de las actuales orientaciones de la Unión Europea en materia de lucha contra la pobreza y la exclusión social. Las personas interesadas en la inserción sociolaboral de personas con dificultades encontrarán muchas pistas para su trabajo.

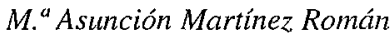

Catedrática de Trabajo Social y Servicios Sociales Universidad de Alicante 
Título: Trabajo Social. Orientaciones y prácticas formativas.

Autores: Gómez Moya, J. Julve Negro, M. y Pérez Cosín, J.V. Pró-
logo de Cristina de Robertis.

Edita: Editorial Gules. Valencia, 1999.

Esta obra es fruto de los años de experiencia de los autores como trabajadores sociales y, además, docentes en la Escuela U. de Trabajo Social de la Universidad de Valencia, que nos exponen sus ricas reflexiones sobre la difícil, pero muy necesaria, articulación teoría-práctica, argumentando que esto resulta fundamental para los docentes, para los alumnos y, en mayor medida, para los personas con las que se va a intervenir.

Los autores consideran que existe la necesidad de recuperar y consolidar la importancia de las prácticas pre-profesionales en la Diplomatura de Trabajo Social, «ya que, sin ellas, perdemos: la opinión, las percepciones, las situaciones de los usuarios en su ámbito propio y, a la vez, con ellas nos nutrimos de los argumentos metodológicos y técnicos necesarios para diseñar nuestra intervención». Por ello, se conciben las prácticas como «una acción sistemática, para la reflexión y teorización sobre los fenómenos sociales que observamos cotidianamente». Como primer paso proponen la ubicación de las prácticas en modelos teóricos de referencia y a ello dedican el capítulo 2.

El núcleo del libro es el capítulo 3 en el que, tras definir el Trabajo Social como actividad profesional en constante relación dialéctica con la realidad social, advierten acerca de las limitaciones que la propia realidad impone a la hora de diseñar programas de prácticas externas a la Universidad y proponen reflexiones y propuestas en relación a la elaboración de un plan general de formación práctica con tres fases (de acuerdo con el proceso metodológico del Trabajo Social) diferenciadas pero interdependientes y relacionadas con la adquisición de los conocimientos teóricos. 
Las fases pueden organizarse de modo diverso (proponiéndose cuatro modelos diferentes) y de cada una de ellas se exponen objetivos, contenidos, documentación y evaluación. No se olvidan otros elementos esenciales del proceso de aprendizaje, como son la supervisión (elementos, objetivos, modalidades) y el contrato de prácticas (institución, profesionales y alumnos), finalizando con unas consideraciones en relación a los escenarios de las prácticas relativos a cada una de las etapas del proceso de formación práctica.

En conjunto, puede decirse que se trata de una valiosa aportación en la que se percibe claramente la coherencia entre las orientaciones propuestas y la metodología de elaboración de la obra. La propuesta docente de interrelación entre los contenidos teóricos y la formación práctica de los futuros Diplomados en Trabajo Social se basa en la sistematización de la práctica docente de Trabajadores Sociales-docentes. Sin duda, será de gran utilidad para docentes y alumnos de las Escuelas de Trabajo Social y, también, para los Trabajadores Sociales en ejercicio profesional que tienen responsabilidades de tutela de los alumnos en los campos de prácticas.

En cuanto a los obstáculos actuales que impiden un proceso de aprendizaje personalizado, cabría deducir que los autores se resignan a la situación, aunque manifiesten su desacuerdo al compararlo con la formación que se impartía antes de la integración en la Universidad o con el modelo francés actual. La alusión a las limitaciones resulta muy realista y hay que decir muy explícitamente que la formación práctica de los Diplomados en Trabajo Social difícilmente se puede conseguir mientras se asigne el nivel uno del factor de experimentalidad. En este sentido, la apuesta por una formación práctica rigurosa y de calidad que se realiza a lo largo del libro, no se puede llevar a la práctica sin los medios necesarios.

M. ${ }^{a}$ Asunción Martínez Román

Catedrática de Trabajo Social y Servicios Sociales Universidad de Alicante 
Título: Los inmigrantes irregulares en España. La vida por un sueño.

\section{Autores: Ruiz Olabuénaga, J.L., Ruiz Vieytez, E.J. y Vicente To- rrado, T.L.}

Edita: Universidad de Deusto-Serie Derechos Humanos, vol. 4. Bilbao, 1999.

Es un informe de la situación española que forma parte de un Proyecto de Investigación realizado en Reino Unido, Alemania y España con el fin de estudiar las condiciones de vida de los inmigrantes que han llegado a Europa y se encuentran en situación de irregularidad jurídica, quedando abocados a graves problemas sociales, legales y políticos que marcan su existencia y sus expectativas.

El interés de los autores, profesores de la Universidad de Deusto, se ha centrado en conocer cómo viven estas personas, por lo que se han basado en una metodología cualitativa, entrevistando a un centenar de personas procedentes de cinco entornos socioculturales diferentes: magrebíes, latinoamericanos, subsaharianos, chinos y europeos del Este, en cinco comunidades autónomas.

A través de las experiencias vitales de estas personas se ponen de manifiesto una serie de constantes que o bien se desconocen o bien se están ignorando por parte de la Administración, por lo que el informe resulta de suma utilidad para hacer visibles a la sociedad española otras caras del fenómeno migratorio que suelen resultar ocultas. Un ejemplo es la constatación de que el proceso migratorio no es homogéneo ni unidireccional, es decir, no sólo vienen pobres no-cualificados desde los países pobres a los países ricos y el desconocimiento de esta realidad está llevando al despilfarro de recursos humanos.

Este desconocimiento puede deberse, tal como se destaca entre las conclusiones, a la falta de estudios sobre miles de personas en situación irregular, que no existen oficialmente para la Administración, pero 
existen realmente en la sociedad española. La síntesis de la situación (brutal, pero real) es la calificación de «muerte civil».

Tras el análisis de la situación se proponen alternativas de actuación tanto en los propios países de origen como una vez atravesada la frontera española. Por todo ello, será de gran utilidad para todas las personas que tienen que tomar decisiones en este creciente campo de las políticas sociales y para quienes, desde diversos ámbitos, estén interesados en mejorar las condiciones de vida de estas personas.

M. ${ }^{a}$ Asunción Martínez Román

Catedrática de Trabajo Social y Servicios Sociales

Universidad de Alicante 
Título: Crítica y futuro del Estado del Bienestar. Reflexiones desde
la izquierda.

Coord.: Fernández, T. y Garcés, J.

Edita: Tirant lo Blanch. Valencia, 1999.

El libro «Crítica y futuro del Estado del Bienestar. Reflexiones desde la izquierda» hace un recorrido a lo largo de trece capítulos sobre el debate del Estado del Bienestar. Los diferentes autores -procedentes de diversos ámbitos laborales y de formación- analizan con un sentido crítico y, por tanto, transformador el Estado del Bienestar. El carácter enriquecedor del libro que nos ocupa reside tanto en la pluralidad de los enfoques planteados como en la procedencia de los análisis. Así, el Estado del Bienestar se analiza desde diferentes prismas, entre los que se incluyen: los derechos sociales, el territorial, el sindical, el Tercer Sector, el laboral, el familiar, la inmigración, las pensiones y la sanidad, entre otros. Otro de los valores del libro que merece ser destacado se refiere al carácter absolutamente actual de los diferentes estudios realizados, en los que se aportan todo tipo de indicadores más recientes. Por otra parte, las continuas referencias históricas, tanto sobre la concepción como la gestación del Estado del Bienestar, constituyen un valor añadido que permiten al lector contextualizar a la perfección el debate actual en este ámbito.

En el presente libro se hace especial hincapié en la reformulación del sistema de protección social y la despolitización de los derechos sociales que la reorientación ideológica gestada en los años 80 -tanto del sentido como de la extensión de los derechos sociales- ha provocado. Así, en primer lugar, esta reorientación ideológica obliga a replantear el grado de reversibilidad de los niveles de protección social y el principio de la suficiencia de las prestaciones. En segundo lugar, se critica el proceso de despolitización experimentado por los derechos sociales, el cual supone que los ciudadanos dejan de ser aquéllos 'que 
tienen derecho a una prestación social' -y, en ese sentido, son exigibles de acuerdo a ley-para pasar a ser 'usuarios de un servicio', sobre el que tiene interés en que sea prestado en las mejores condiciones. En tercer lugar, aunque el planteamiento neoliberal sobre la protección social no se ha traducido en unas reformas legales significativas sí que se constatan dos tendencias: una asistencialización y una territorialización de la protección básica, por un lado, y una mercantilización de la protección no esencial, por otro.

Los principales argumentos aducidos por las corrientes neoliberales prevalecientes en la actualidad que cuestionan la posibilidad de que el Estado del Bienestar persista como un derecho social en las sociedades avanzadas de Europa son los siguientes: impide el funcionamiento de las leyes del mercado, no existen suficientes ingresos para asumir el gasto social, la competitividad que exigen la competencia internacional y la globalización de la economía hacen necesario un abaratamiento de los costes o la irrelevancia de la cobertura de servicios públicos para las clases medias - que son las mayoritarias- relegando el Estado del Bienestar a un sistema meramente asistencialista de menor magnitud. No obstante, en contra de las opiniones neoliberales, las fuerzas progresistas consideran que las tendencias actuales de la economía refuerzan la desigualdad de la riqueza y la polarización de la misma, de forma que es más urgente que nunca defender el Estado del Bienestar. En este sentido se cuestiona el papel que pueden jugar las diferentes fuerzas políticas de izquierda y los sindicatos en el desarrollo y la defensa del Estado del bienestar.

En este libro se destacan los cambios experimentados en el modelo de bienestar social español en los últimos años, proponiendo un reforzamiento y una mejora de la protección social, adaptándola a las nuevas necesidades y problemas de la sociedad actual. Así, entre los cambios más destacables que se han producido en la sociedad española, los cuales exigen un replanteamiento del Estado del Bienestar destacan, en primer lugar, la crisis del empleo considerando tanto la falta de empleo -que se traduce en un aumento del paro- como desde la pérdida de la calidad del mismo. En segundo lugar, se abordan los desafíos que plantea para el Estado del Bienestar el ejercicio de la autonomía política, tanto en cuanto a los problemas territoriales como a la descentralización del gasto público, de tal manera que este último se desarrolle manteniendo sus exigencias de igualdad y solidaridad. En tercer lugar, la transformación que se ha producido en la estructura familiar en los últimos años, que se plasma en una multivariedad de las formas familiares, si bien no cuestiona los objetivos de cohesión, socialización e integración que continúan siendo atributos de la familia, sí que obliga a replantearse las políticas de bienestar social. En este 
sentido, se reivindica el fomento de la democratización de la vida familiar y de la equidad entre sexos, así como la garantía de una cobertura adecuada de las demandas sociales, especialmente en coyunturas económicas desfavorables, para evitar el retroceso socioeconómico de los colectivos sociales más vulnerables. Por último, en cuarto lugar, el desafío que supone la cuestión de la inmigración para el Estado del Bienestar exige una reivindicación de la dimensión territorial y personal del Estado del Bienestar, especialmente en un contexto de globalización económica como el actual.

Ante la transformación que está sufriendo el Estado del Bienestar se recuerda que no es prudente defender la paulatina desaparición de la intervención estatal en materia de bienestar, dejando que sea el ámbito privado sin ánimo de lucro y el mercado quienes se responsabilicen mayoritariamente de las cuestiones sociales. En definitiva, se pone en evidencia el riesgo de sentar las bases para pasar desde el Estado del Bienestar hacia la 'sociedad del bienestar', esto es, de la transferencia de la responsabilidad del bienestar del ámbito público al privado.

No obstante, la tendencia actual hacia la privatización del Bienestar a través de la provisión privada de servicios públicos -mediante fórmulas como la del concierto- nos indican que es precisamente el propio Estado quien explora nuevas fórmulas de intervención y, consecuentemente, el replanteamiento de sus funciones tratando de compartir responsabilidades con el mercado y la sociedad civil. De manera que algunos autores reivindican la mayor participación de la sociedad civil en la asunción de las responsabilidades concernientes a la esfera social a través del Tercer Sector, si bien no como un mecanismo alternativo frente al bienestar aportado por el Estado y el mercado sino complementario.

Finalmente, entre las principales reivindicaciones que se destacan en el libro y que exigen un replanteamiento del Estado del Bienestar se encuentran, por un lado, la necesidad de lograr una convergencia real que no se limite a la reducción de los diferenciales de renta per capita sino en la mejora del grado de equidad -a través de la homogeneización de las tasas de desempleo y los stocks de capital humano, tecnológico y físico-. Por otro lado, la necesidad de crear organismos de decisión que contrarresten a los grandes grupos de presión que se están configurando en la economía mundial y una reforma del Estado del Bienestar que garantice la supervivencia del mismo. 


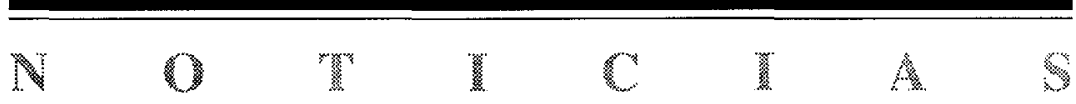



II Curso de Especialista en Dificultad y Conflicto Social: Técnicas de Intervención.

Universidad P. de Comillas. Fundación Universidad-Empresa. Madrid, enero-diciembre 2000. 300 horas lectivas ( 30 créditos).

Curso dirigido a licenciados o diplomados universitarios en titulaciones relacionadas con las Ciencias Sociales o Jurídicas. El objetivo es formar de manera integral en las técnicas de evaluación e intervención dentro del campo de menores en situación de riesgo o de conflicto social. Para ello, obtendrán conocimientos sobre sistemas de protección social a la infancia, teorías de la delincuencia, relaciones drogadelincuencia, técnicas de habilidades sociales aplicadas a menores y jóvenes, etc. La metodología es mixta y contempla aspectos a distancia y otros presenciales (sábado-domingo, una vez al mes).

Plazo de inscripción: hasta el 29 de octubre de 1999.

Información: Fundación Universidad-Empresa

Teléfonos: 915489881 - 915489879

Fax: 915417294

E-mail: pilar.fue@hardlogic.es 
Federación Internacional de Trabajadores Sociales (IFSW). Conferencias de Trabajo Social 2000-2001.

- Conferencia Promoting Equitable Societies in the Global Economy: Social Work in the 21st Century. Montreal (Canadá). Del 29 de julio al 2 de agosto del año 2000.

Secretaría de la conferencia: World Conference of IFSW/IASSW 2000, Events International Meeting Planners Inc., 759 Victoria Square, Suite 300. Montréal, Québec, Canada H2Y $2 J 7$.

Teléfono: (1) 5142860855

Fax: (1) 5142866066

E-Mail: info@eventsintl.com

- IFSW European Seminar «The Danube Conference». Managing conflicts in Social Work: Dealing with contradictions. Viena (Austria) y Bratislava (Eslovaquia). 7-30 de agosto 2001.

Secretaría de la conferencia: Austrian Association of Social Workers, Mariahilferstrasse 81/1/14, A-1060 Vienna, Austria.

Teléfono: (43) 15874656

Fax: (43) 1587465610

E-Mail: oebds@ins.at 


\section{Conclusiones del Congreso Internacional «Una Sociedad para To- das las Edades». Alicante, 5-7 de mayo, 1999.}

El Congreso Internacional «Una sociedad para todas las edades» ha sido una iniciativa de la Agrupación de Jubilados y Pensionistas de las Cajas de Ahorro Europeas, contando con el patrocinio de la UNESCO, la colaboración de la Obra Social de la Caja de Ahorros del Mediterráneo y la Universidad de Alicante.

Han participado más de cuatrocientos congresistas de España, Reino Unido, Francia, Bélgica, Alemania, Holanda, e Italia, representando a diferentes generaciones, lo que ha sido especialmente valorado por los participantes por haber contribuido a enriquecer el debate y el mutuo conocimiento.

En este «Año Internacional de las Personas Mayores», el Congreso ha querido ser un foro para reflexionar sobre su situación, siguiendo el objetivo de Naciones Unidas de avanzar hacia «Una sociedad para todas las edades» y partiendo del reconocimiento de que constituyen un numeroso colectivo cuyas características difieren de aquéllas a las que tradicionalmente se les ha asociado. Por lo tanto, el Congreso se ha dedicado tanto a las personas en activo, pero cercanas a la jubilación, como a personas jubiladas que pueden llevar una vida activa y autónoma, sin olvidar a las personas muy mayores o enfermas, con disminución de su autonomía.

Estamos hablando de un grupo social muy heterogéneo, con diferentes necesidades específicas que suponen un nuevo desafío a nuestra sociedad. Como señala la Comisión de las Comunidades Europeas, el envejecimiento repercute en diferentes ámbitos: mayor disponibilidad de tiempo libre, organización del mercado de trabajo, gastos de protección social, situación económica y social de los pensionistas y rol social de las personas mayores. Por lo tanto, desde la perspectiva de las 
políticas atañe, entre otras, a las políticas de empleo, seguridad social, salud, cultura y ocio, exclusión social, igualdad de oportunidades, urbanismo y vivienda y transportes.

Hablar de «una sociedad para todas las edades» significa en la práctica que una parte de las personas mayores, tiene dificultades para participar en la vida social, como ocurre a otros grupos sociales. La Cumbre Mundial sobre Desarrollo Social de Naciones Unidas (1995) adoptó, entre otros, el compromiso de promover la integración social, fomentando sociedades estables, seguras y justas y basadas en la promoción y protección de todos los derechos humanos, con la participación plena de todas las personas: que cada persona, con sus propios derechos y responsabilidades, tenga una función activa que desempeñar:

"Reconoceremos y respetaremos la contribución de personas de todas las edades como igual y decisivamente importantes para la construcción de una sociedad armoniosa y fomentaremos el diálogo entre las distintas generaciones en todos los sectores de la sociedad》

La iniciativa de Naciones Unidas para este año, pretende promover cinco grupos de principios en favor de las personas mayores aprobados por su Asamblea General: independencia, participación, cuidados, autorrealización y dignidad, cuyo cumplimiento asegura el bienestar de las personas mayores, su desarrollo humano. De acuerdo con estas directrices, en el Congreso se han tenido en cuenta las cuatro dimensiones recomendadas por el Comité Español de este Año Internacional de las Personas Mayores: su situación, desarrollo permanente de las personas, relaciones intergeneracionales y desarrollo y envejecimiento. Estas dimensiones se han abordado en una doble vertiente, académica y práctica. En el primer caso, se han presentado cinco ponencias a cargo de expertos que han versado sobre: políticas para las personas mayores y políticas laborales, estructuras de solidaridad familiar en España, las personas mayores y la Economía, el concepto de la jubilación en una sociedad en cambio y el papel de la cultura en el desarrollo de las relaciones intergeneracionales.

En la vertiente práctica, como complemento a las ponencias, tres paneles han permitido la difusión de «buenas prácticas» que promueven la participación social de las personas mayores y la solidaridad intergeneracional, destacando la presencia de los protagonistas de estas «buenas prácticas» que nos han expuesto experiencias de ayuda mutua y promoción del bienestar social de las personas mayores; la perspectiva de género en las relaciones intergeneracionales y modos de revertir la experiencia profesional y social de las personas prejubiladas y mayores en otras generaciones, así como la necesidad de una preparación a la jubilación. Todas las experiencias han demostrado 
que es posible hacer muchas cosas para promover la integración social de las personas mayores y la solidaridad intergeneracional, y que están al alcance de todos.

Además, con el fin de asegurar la continuidad de los objetivos señalados en este Año Internacional de las Personas Mayores, como colofón del Congreso, se ha presentado la Fundación Cultural Europea «Intergeneraciones», iniciativa pionera en la puesta en práctica de las orientaciones de Naciones Unidas y que cuenta con el apoyo de la UNESCO, aprobándose una Declaración de Principios que se ha entregado a la Comisión Española de la UNESCO con el fin de que la haga llegar a la sede de la UNESCO en París.

En síntesis, las conclusiones del Congreso Internacional «Una Sociedad para todas las Edades» son las siguientes:

1. La ciudadanía no tiene jubilación, por lo que se rechaza cualquier tipo de discriminación por razón de la edad. Las personas mayores quieren ser CIUDADANOS (con mayúsculas), con plenos derechos y deberes, con un rol social activo a desempeñar y valorado socialmente.

2. Las personas mayores constituyen un grupo social muy heterogéneo, con diferentes necesidades específicas que suponen un nuevo desafío a nuestra sociedad. Las actitudes discriminatorias a causa de la edad ignoran esta diversidad.

3. Las personas mayores, que no quieren ser calificadas como «tercera edad», piden a las Administraciones Públicas y a la sociedad que se promueva un cambio cultural que revierta la situación actual de infravaloración, recobrando la tradicional consideración y prestigio asociados a la madurez.

4. Hay que modificar la actual política de jubilación, promoviendo una transición gradual, con planteamientos más flexibles y una preparación para la jubilación. La percepción de una pensión de jubilación no debe impedir la realización de algún tipo de actividad remunerada a tiempo parcial o esporádica.

5. El asociacionismo es un medio con grandes potencialidades para promover la integración social de las personas mayores. «Hay que salir de casa» y hay que actuar porque «quien calla, otorga». Tendremos el modelo de sociedad que todos queramos.

6. Las actitudes discriminatorias a causa de la edad se acumulan en el caso de las mujeres mayores. Hay que tener en cuenta la perspectiva de género en relación a la jubilación y a la edad avanzada.

7. Hay personas mayores con insuficientes ingresos, por lo que se pide el incremento de las pensiones, especialmente las de viudedad. 
8. Ante el aumento de las necesidades sociosanitarias por razón de la edad, se considera prioritario un aumento del gasto social para garantizar Servicios Sociales y Sanitarios que presten una atención integral, al alcance de todos y de calidad.

9. Las personas mayores quieren defender los intereses de los jóvenes y desean vivamente la solidaridad intergeneracional.

10.Las personas mayores quieren unir sus esfuerzos y luchar para conseguir una sociedad para TODOS, una sociedad INTEGRADA e INTEGRADORA. 
NUMEROS PUBLICADOS 



\section{NUMERO 1 (1992)}

Jesús Daza Martínez, director.

Presentación

María José Escartín Caparrós. Profesora de Trabajo Social. E.U.T.S. Alicante Consideraciones preliminares

\section{Estudios sobre la familia}

Isabel Ramírez de Mingo. Titular de Trabajo Social. Universidad Complutense. Madrid.

El Trabajo Social con familias

María Asunción Martínez Román, María Teresa Mira-Perceval Pastor, Hortensia Redero Bellido. E.U.T.S. de Alicante.

Función especifica de la Familia en la atención social comunitaria: su valor como recurso para la sociedad

María José Escartín Caparrós. Profesora E.U.T.S. Alicante.

El Sistema familiar y el Trabajo Social

Dr. D. Agustín Bueno Bueno. Profesor del Departamento de Psicología de la Salud. Universidad de Alicante.

Estilos de vida familiar y riesgo social infantil

María Asunción Martínez Román. Profesora de Servicios Sociales. E.U.T.S. Alicante.

Participación de la Familia en el proceso de rehabilitación de los enfermos crónicos: Los Insuficientes Respiratorios Crónicoss Graves (I.R.C.G.) y el Bienestar Social

Josefa Lorenzo García, Manuela Palomar Villena, Esperanza Suárez Soto. Trabajadoras sociales. Profesoras de la E.U.T.S. Alicante.

Mujer y Familia. Reflexiones críticas desde nuestra experiencia profesional.

Dr. Don Francisco Ortega Beviá. Director Master Terapia Familiar y Profesor Terapia Familiar, Curso Superior Psicosociológico. Da Elisa Pérez de Ayala Morenos Santa María. Profesora de Trabajo Social Familiar. Universidad de Sevilla.

La ilusión de las alternativas: vivir en pareja

Antonio Bellido Alonso, Esther Villegas Castrillo. Profesores del Area de Trabajo Social y Servicios Sociales. E.U.T.S., Alicante.

Influencia de la Familia en el desarrollo de pautas inadecuadas de conducta

Josep-Lluís Orts Molines. Profesor de Valencià a l'E.U.T.S. Universitat d'Alacant.

Idees sobre la familia a la tardor medieval a través de Lo Libre de les dones de Francesc Eiximenis (1327-1490)

M. ${ }^{a}$ Dolores Vargas Llovera. Profesora del Area de Antropología. Universidad de Alicante.

La función familiar en el actual pluralismo religioso: El caso de los Testigos de Jehová

Jesús Daza Martínez. Catedrático de Derecho Romano.

La ley de Divorcio de 1932. Presupuestos ideologicos y significación politica 
II. Tribuna Libre

Manuel Moix Martínez. Catedrático de Trabajo Social y Servicios Sociales. Problematismo del Bienestar Social

Esther Villegas Castrillo, Antonio Bellido Alonso. Profesores de Trabajo Social. E.U.T.S. Alicante.

La Teoría Sistémica en Trabajo Social. Criterios de apli-cación y observaciones criticas

Ana M." Herthogue. Trabajadora Social jubilada de la «Family Welfare Association» de Londres.

Relevancia de algunos conceptos y arquetipos de C. Jung para la labor profesional de los trabajadores sociales

Jorge Garcés Ferrer, M." José Lahoz Campos, Fco. José Ródenas Riga, Estrella Durá Ferrandis. Profesores de SS.SS. en la Escuela de Trabajo Social. U. de Valencia.

Vulowes y características de personalidad en estudiantes de Trabajo Social de la Comunidad Valenciana

III. Actualidad bibliográfica

María Asunción Martínez Román, María Teresa Mira-Perceval, Hortensia Redero Bellido. E.U.T.S. de Alicante. Jorge Garcés Ferrer. Escola Universitària de Treball Social. Universitat de València.

La familiat

IV. Apéndice documental

Decreto 23/1988 de 8 de febrero, del Consell de la Generalitat Valenciana, de medidas de protección de menores en situación de desamparo en la Comunidad Valenciana

Orden de 20 de marzo de 1986, de la Conselleria de Trabajo y Seguridad Social, por la que se establece el recurso de familias Educadoras en la Comuniclad Valenciana

Ley $21 / 1987$, de 11 de noviembre, por la que se modifican determinados artículos del Código Civil y de la Ley de Enjuiciamiento Civil en materia de adopción

Decret 23/1988, de 8 de febrer, del Consell de la Generalitat Valenciana, de mesures de protecció de menors en situació de desamparament a la Comunitat Valenciana

Ordre de 20 de març de 1986, de la Conselleria de Treball i Seguretat Social, per la qual s'estableix el recurs de Famílies Educadores de la Comunitat Valenciana 


\section{NUMERO 2 (1993)}

Jesús Daza Martínez.

Presentación

\section{Algunas claves del Estado social contemporáneo}

Jorge Hurtado Jordá. Profesor del Departamento de Ciencias Sociales y de la Educación. Universidad de Alicante.

Sociedad, Estado, tal vez, mercado

Fermín Aliaga Aliaga. Profesor del Departamento de Economía Aplicada y Política Económica. Universidad de Alicante.

Política económica y calidad de vida

Ramón Martín Mateo. Catedrático de Derecho Administrativo.

La cultura del ocio

\section{Cuestiones teórico-prácticas sobre el Trabajo Social}

M." José Escartín Caparrós. Profesora titular de Trabajo Social de la EUTSA de Alicante

Influencia de las diferencias culturales en la relación de ayuda

Esperanza Suárez Soto, Manuela Palomar Villena. Profesoras titulares de Trabajo Social en la EUTSA de Alicante.

El cliente en Trabajo social. Cuestiones conceptuales y análisis tipológico.....

Esther Villegas Castrillo. Profesora titular de Trabajo Social en la EUTSA de Alicante.

El Trabajador Social en el trabajo de grupo

Antonio José Bellido Alonso. Profesor titular de Trabajo Social en la EUTSA de Alicante.

La primera entrevista en la relación de ayuda del Trabajo Social Individualizado

Josefa Lorenzo García. Profesora Titular de Trabajo Social en la EUTSA de Alicante.

La intervención profesional con familias multiproblema desde los Servicios Sociales Municipales

Manuela Palomar Villena y Esperanza Suárez Soto. Profesoras Titulares de Trabajo Social en la EUTSA de Alicante.

El modelo sistémico en el Trabajo Social familiar. Claves teóricas e intervención práctica

\section{Problemas y perspectivas de los servicios sociales}

Manuel Moix Martínez. Catedrático de Trabajo Social y Servicios Sociales. «Universalidad» versus «Selectividad» en los Servicios Sociales. La «discriminación positivas

María del Carmen Alemán Bracho. Catedrática de Servicios Sociales de la EUTS de la Universidad de Granada.

Una perspectiva de los Servicios Sociales en España

M. Asunción Martínez Román, M. ${ }^{a}$ Teresa Mira-Perceval Pastor y Hortensia Redero Bellido. Profesoras titulares de SS.SS. de la EUTS de Alicante. ¿Viejos o nuevos? Orientaciones actuales de los Servicios Sociales en España 
Rafael Barranco Vela. Profesor de Derecho Administrativo de la EUTS de la Universidad de Granada.

El principio de participación en las Leyes de Servicios Sociales

\section{Miscelánea}

Manuel Oliver Narbona y $\mathbf{M}^{\text {a }}$ Dolores Vargas Llovera. Profesores del Departamento de Humanidades Contemporáneas. Y M. ${ }^{a}$ José Escartín Caparrós, Josefa Lorenzo García, Antonio Bellido Alonso, Roberto Mohedano Menéndez, Manuela Palomar Villena, Esperanza Suárez Soto y Esther Villegas Castrillo. Profesores de la EUTS de Alicante.

Inmigración y cultura: Reflexiones críticas sobre las diferencias sociales y culturales que produce el hecho migratorio

Carmen Gimeno Escrig, Médica Experta Universitaria en Drogodependencias; $\mathrm{M}^{\mathrm{a}}$ Angeles Amérigo Martínez, Trabajadora Social y Experta Universitaria en Drogodependencias; $M^{a}$ José Martí García, Psicóloga Experta Universitaria en Drogodependencias.

Perfil de los drogodependientes y familias atendidos en el Servicio Municipal de Drogodependencias de la Vila Joiosa

Francisco Martínez Carrasco y M. Dolores Vargas Llovera. División de Antropología. EUTS de Alicante.

Cultura y salud mental. Influencia del medio institucional en los enfermos profiundos adultos

Agustín Bueno Bueno. Departamento de Psicología de la Salud. Universidad de Alicante

Autoconcepto adolescente y clase social

\section{Actualidad bibliográfica}

M. Asunción Martínez Román, $\mathrm{M}^{\mathrm{a}}$ Teresa Mira-Perceval Pastor y Hortensia Redero Bellido. Profesoras titulares de SS.SS. de la EUTS de Alicante.

Bienestar Social y Política Social

\section{NUMERO 3 (1995)}

M." Teresa Mira-Perceval Pastor. Directora E.U. Trabajo Social. Universidad de Alicante.

Presentación

M. José Escartín Caparrós, Esperanza Suárez Soto.

Editorial

\section{Trabajos sobre la mujer}

Jose Manuel Díez Fuentes. Universidad de Alicante.

República y Primer Franquismo: La mujer española entre el esplendor y la miseria, 1930-1950

M. José Frau Llinares. Departamento Ciencias Sociales y de la Educación. Universidad de Alicante.

La tipificación sexual del trabajo mercantil. El caso valenciano

M. Dolores Díez García y Sergio Quesada Rettschlag. Catedráticos Matemáticas E.U. Trabajo Social. Departamento de Economía Aplicada. Universidad de Alicante. Silvia M. ${ }^{a}$ Quesada Díz. ICADE. Madrid.

Una empresaria de los 90. Análisis y valoración de un caso 
María José Escartín Caparrós. Profesora titular de Trabajo Social. Universidad de Alicante.

Violencia y Mujer. La intervención de crisis con mujeres maltratadas y sus hijos

Trinidad Pablo Cervera, Ruth Pérez Segovia y M. ${ }^{a}$ Dolores Vargas Llovera. Area de Antropología. Escuela Universitaria de Trabajo Social. Universidad de Alicante.

Mujer, Familia y mundo rural. Dos modelos para un cambio social

Yolanda Domenech López. Profesora ayudante del Area de Trabajo Social y Servicios Sociales. Universidad de Alicante.

La situación de la mujer en Honduras

\section{Tribuna Libre}

Carmen Gimeno Escrig. Médica Servicio Municipal de Alcoholismo y Drogodependencia. Villajoyosa. Angeles Amérigo Martínez. Trabajadora Social, Servicio Municipal de Alcoholismo y Drogodependencia. Villajoyosa. Programa de intervención en familias. Evaluación con el cuestionario de salud general de Goldberg

Agustín Bueno Bueno. Profesor titular de Psicología Social de la Escuela Universitaria de Trabajo Social. Universidad de Alicante. $\mathrm{M}^{\mathrm{a}}$ Teresa Mira-Perceval Pastor. Profesora titular de Servicios Sociales de la Escuela Universitaria de Trabajo Social. Universidad de Alicante.

Reflexiones ante la Ley de la Infancia de la Comunidad Valenciana

Antonio Gutiérrez Resa. Profesor titular de Servicios Sociales. Universidad de Zaragoza.

Las ONGs y su papel en el futuro de la sociedad

María José Gallego Ayllón. Trabajadora Social. Estrella Gualda Caballero. Socióloga. Octavio Vázquez Aguado. Trabajador Social. Departamento de Filosofía, Sociología y Trabajo Social. Universidad de Huelva.

Las ideas previas de los alumnos de $1^{\circ}$ de Trabajo Social de Huelva respecto a la profesión

Yolanda Domenech López. Profesora ayudante del Area de Trabajo Social y Servicios Sociales. Universidad de Alicante. Juan Carlos Gómez Díaz. Licenciado en Ciencias Económicas y Empresariales. Universidad de Alicante.

Una alternativa al trabajo social institucionalizado: El trabajo social en la empresa privada

\section{Apéndice documental}

Ley 7/1994, de 5 de diciembre, de la Generalitat Valenciana, de la Infancia. DOGV $n .{ }^{\circ} 2$

La Declaración de Pekín. Conclusiones de la IV Conferencia Mundial sobre las Mujeres. Beijing. Septiembre 1995

\section{Libros}

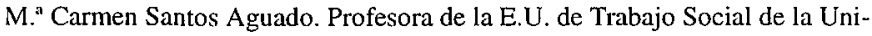
versidad Complutense de Madrid.

Título: "Las enseñanzas de Trabajo Social en España: 1932-1983. Estudio socio-educativo». Autora: M. ${ }^{a}$ Victoria Molina Sánchez. 


\section{NUMERO 4 (1996)}

Esperanza Suárez Soto. Directora técnica del consejo editorial de la revista «Alternativas. Cuadernos de Trabajo Social».

Presentación

\section{Trabajos sobre migración}

Abel Albet-Mas. Departamento de Geografia. Universidad Autónoma de Barcelona. Maria Dolors Garcia-Ramon. Universidad Autónoma de Barcelona. Joan Nogué-Font. Departamento de Geografía. Universidad de Gerona. Lluis Ruidor-Gorgas. Facultad de Humanidades. Universidad Pompeu Fabra. Barcelona.

Gengrafia, ordenación del territorio y colonialismo español en Marruecos.

Mikel de Epalza. Catedrático de Estudios Arabes e Islámicos. Universidad de Alicante

Estructuras de acogida de los moriscos emigrantes de España en el Magreb (siglos XIII a XVIII).

Joan Lacomba. Departamento de Trabajo Social y Servicios Sociales. Escuela Universitaria de Trabajo Social. Universidad de Valencia.

Identidad y religión en innigración. A propósito de las estrategias de inserción de los musulmanes senegaleses.

M. ${ }^{a}$ Dolores Vargas Llovera. Area de Antropología. Universidad de Alicante. Inmigración, etnicidad y pluralismo cultural.

José Cabanes Hernández. Sociólogo. Luz Vera García. Trabajadora social. Asociación P.G. Arakerando. Alicante. María Isabel Bertomeu Martínez. Trabajadora social. Asociación P.G. Arakerando. Alicante.

Gitanos: historia de una migración.

D. Ribera, A. Reig, M. Carrillo, J.L. Talavera, A. Caruana, C. Ferrera, A. Majos, R. Climent, C. Clavijo, M. Verdú. Escuela Universitaria de Enfermería. Universidad de Alicante. Hospital General de Alicante. Facultad de Medicina. Universidad de Alicante. Ayuntamiento de Alfaz del Pi (Alicante).

Hábitos y necesidades de cuidados en el colectivo de extranjeros de 80 y más años residentes en la costa mediterránea.

Mercedes González. Octavio Vázq̨uez. Departamento de Filosofía, Sociología y Trabajo Social. Universidad de Huelva.

Trabajo social e inmigrantes. Las intervenciones del trabajo social

Carmen Santos Aguado. Escuela Universitaria de Trabajo Social. Universidad Complutense de Madrid.

Trabajo social en el campo de actuación de inmigración y refugio.

Socorro Escobar Rubio. Trabajadora social. IRCOSAN. Madrid. Nieves Gascón Navarro. Trabajadora social. Mancomunidad Intermunicipal de La Encina. Madrid.

Metodología del trabajo social con inmigrantes y refugiados.

Ana M." Ortiz Duque. Trabajadora social. Ayutamiento de Majadahonda. Madrid.

Fases de la intervención social con inmigrantes.

M. Jesús Vega Pascual. Trabajadora social. Alto Comisariado de las Naciones Unidas para los Refugiados (ACNUR). Secretaria de la sección legal.

Fases de la intervención social con refugiados. 


\section{Tribuna libre}

Nieves Lillo Herranz. Trabajadora social. Area de bienestar social del Excmo. Ayuntamiento de Elche (Alicante).

El educador gitano, profesional clave para una intervención integral con el pueblo gitano.

Sonia Ródenas Picardat. Trabajadora social. Asociación ciudadana contra el SIDA de la provincia de Alicante.

Grupos de ayuda mutua: una respuesta alternativa en la práctica del trabajo social.

Alfredo Hidalgo Lavié. E.U. Relaciones Laborales - Trabajo Social. Jerez. Universidad de Cádiz.

El marco jurídico-administrativo de los Servicios Sociales de la Comunidad Autónoma Andaluza.

Jorge Hurtado Jordá. Departamento de Ciencias Sociales. Universidad de Alicante.

Lecciones de la informalidad.

Idris M. Iwaki. Hector O. Beaton. Ernesto A. López. Departamento de Sociología. Universidad de Oriente-Santiago. Cuba. Javier M. Ferrer. Departamento de Trabajo Social. Universidad de Alicante.

Turismo y cambio social en Santiago de Cuba.

\section{Actualidad bibliográfica}

Carmen Santos Aguado. M. Jesús Vega Pascual. Socorro Escobar Rubio. Ana M. ${ }^{a}$ Ortiz Duque.

Actualidad bibliogrática sobre inmigración y refugio.

IV. Libros

Gonzalo Musitu. Coordinador del Area de Psicología Social. Universidad de Valencia.

Título: "Estudio longitudinal de la presencia de la mujer en los medios de comunicación de prensa escita». Cuadernos de Investigación de Psicología Comunitaria. Universidad de Valencia. Nau Llibres. Valencia, 1996. Autor: José Ramón Bueno Abad.

\section{NUMERO 5 (1997)}

Esperanza Suárez Soto. Directora técnica del consejo editorial de la revista "Alternativas. Cuadernos de Trabajo Social».

Presentación

\section{Trabajos sobre violencia}

M. Asunción Martínez Román. Departamento de Trabajo Social y Servicios Sociales. Universidad de Alicante.

"Pobreza y exclusión social como formas de violencia estructural". La lucha contra la pobreza y la exclusión social es la lucha por la paz.

Gonzalo Musitu Ochoa. Profesor y director del Area de Psicología Social. Facultad de Psicología. Universidad de Valencia.

Violencia y terrorismo: Un análisis desde la perspectiva ecológica. 
E. Bosch-Fiol, M. Gili-Planas y V.A. Ferrer-Pérez. Departamento de Psicología. Universidad de las Islas Baleares.

La violencia doméstica como una forma de expresión deactitudes misóginas.

Dra. M. ${ }^{2}$ Dolores Díez García. Profesora de la E.U. de Trabajo Social. Universidad de Alicante. Dr. Sergio Quesada Rettschlag. Profesor de la E.U. de Trabajo Social. Universidad de Alicante. M." Dolores Sala Bonmatí. Trabajadora social.

El maltrato a menores en la provincia de Alicante en el periodo 1980-1997...

Agustín Bueno Bueno. Profesor de Psicología Social. Universidad de Alicante.

El maltrato psicológicofemocional como expresión de violencia hacia la infancia.

Javier Domínguez, José R. Brocal, José J. Cases, Virginia Tovar y Agustín Bueno.

Análisis del programa de seguimiento de medidas judiciales de régimen abierto en la ciudad de Alicante durante 1996.

José Conrado Moya Mira. Psicólogo. Jefe de la Sección de Familia, Infancia y Juventud de la Dirección Territorial de Bienestar Social de Alicante Organización de los Servicios de Protección a la Infancia en la Comunidad Valenciana. Análisis normativo y funcional.

M. ${ }^{a}$ José Escartín Caparrós. Profesora Titular de Trabajo Social. Departamento de Trabajo Social y Servicios Sociales. Universidad de Alicante.

Los niños maltratados y sus familias. Algunas indicaciones para la intervención del trabajador social.

\section{Tribuna libre}

Salvador Amigó Borrás. Profesor asociado de la Facultad de Psicología. Universidad de Valencia.

El "problema de la droga" y la prevención del consumo de drogas: mitos y alternativas, con una especial referencia al consumo de cannabis.

M. José Salvador Pedraza, Eva Domínguez Sánchez, Raquel Carracedo Manzanera. Técnicos de la Consejería de Sanidad y Bienestar Social de la Junta de Castilla y León.

Marco operativo de las intervenciones de inserción asociadas a la percepción de rentas minimas.

Jesús Moragón Nava. Trabajador Social. Centro de Salud de Atención Primaria. INSALUD. Albacete.

La realidad rural: situación en una región. La organización de equipamientos.

Trinidad Banda Gallego. Profesora titular de la Escuela Universitaria de Trabajo Social. Universidad de Huelva.

El debate sobre la provisión pluralista de los Servicios Sociales.

Víctor M. Giménez Bertomeu. Trabajador Social. Coordinador del Centro Social n. ${ }^{\circ}$ 4. Servicios Municipales del Ayuntamiento de Alicante.

El trabajador social en la dirección de un Centro de Servicios Sociales.

Enrique di Carlo. Equipo E.I.E.M. Universidad Nacional de Mar del Plata. Argentina.

El paradigma humanista como sustancia del Trabajo Social. El Trabajo Social y el paradigma humanista dialéctico. Alternativa de reorganización teorética y metodología del trabajo social profesional 


\section{Libros}

M. ${ }^{a}$ José Escartín Caparrós. Profesora Titular del Departamento de Trabajo Social y Servicios Sociales. Universidad de Alicante.

Título: «Violencia. Memoria amarga». Siglo XXI de España Editores, S.A. Madrid, 1997, 303 páginas. Autor: Javier Urra Portillo. Defensor del Menor en la Comunidad de Madrid.

M. ${ }^{a}$ Asunción Martínez Román. Departamento de Trabajo Social y Servicios Sociales. Universidad de Alicante.

Titulo: "Los Modelos en Trabajo Social. Intervención con personas y familias». Siglo XXI de España Editores, S.A. Madrid, 1996, 405 páginas. Autora: Mathilde du Ranquet.

M. ${ }^{\mathrm{a}}$ Victoria Molina Sánchez. Catedrática de Trabajo Social. Universidad Complutense de Madrid.

Titulo: "Introducción al Trabajo Social II. Trabajo Social con individuos y familias». Editorial Aguaclara. Alicante, 1997, 287 páginas. Autoras: Escartín Caparrós, M.J., Palomar Villena, M., Suárez. Soto, E.

\section{NÚMERO 6 (1998)}

M. ${ }^{a}$ Asunción Martínez Román y Hortensia Redero Bellido. Directora técnica y Secretaria rèspectivamente del Consejo Editorial de la Revista «Alternativas. Cuadernoside Trabajo Social».

Presentación.

I. El marco actual de la acción social: ¿Servicios Sociales públicos o privados?

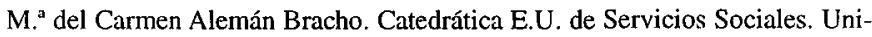
versidad de Granada. Mercedes García Serrano. Universidad de Granada.

Tercer sector: buscando el equilibrio entre solidaridad y eficiencia.

Michael Barratt Brown. Universidad de Sheffield (Reino Unido).

Defending the Welfare State.

Antonio Gutiérrez Resa. Catedrático E.U. de Trabajo Social y Servicios Sociales. Universidad de Zaragoza.

Público-privado. Un modo de intervenir en la sociedad global-local.

Manuel Enrique Medina Tornero. Profesor titular de Servicios Sociales. E.U. de Trabajo Social. Universidad de Murcia.

El debate de lo público y lo privado en Servicios Sociales.

\section{Tribuna libre}

Agustín Bueno Bueno y Conrado Moya Mira. Area de Psicología Social. Universidad de Alicante.

La delincuencia juvenil como síntoma: perspectivas de intervención psicosocial.

José Cabanes Hernández. Sociólogo. Servicios Sociales Municipales de Villena (Alicante). Monitor de minorías étnicas.

La escolarización de los niños gitanos en el País Valenciano. 
Yolanda Domenech López. Profesora titular de Trabajo Social de la E.U.T.S. Universidad de Alicante.

Los grupos de autoayuda como estrategia de intervención en el apoyo social.

Alfredo Hidalgo Lavié. Profesor de Servicios Sociales y Política Social. E.U. de Trabajo Social de Jerez de la Frontera. Universidad de Cádiz.

Ciencia Política y Servicios Sociales. Den entendimiento al «concubinage».

Silvia Quesada Díez. Universidad Pontificia de Comillas, ICADE.

La acción social en la Unión Europea: evolución histórica.

Elena Roselló Nadal. Profesora ayudante del Depto. de Trabajo Social y Servicios Sociales. Universidad de Alicante.

Reflexiones sobre la intervención del trabajador social en el contexto educativo.

Ana Rosser Limiñana. Psicóloga de la Unidad de Adopción de la Conselleria de Bienestar Social. Alicante.

Maro legislativo del acogimiento familiar:

Octavio Vázquez Aguado. Profesor titular de E.U. Depto de Sociología y Trabajo Social. Universidad de Huelva.

Pensar la epistemología del Trabajo Social.

III. Libros

José María Tortosa. Catedrático de Sociología. Universidad de Alicante

Título: «Trabajo Social Experimental». Tirant lo Blanch. Valencia, 1998. Autora: Rosario Conde Megías. 


PAUTAS GENERALES PARA LA
PRESENTACION DE ARTICULOS



1. La Revista «Alternativas. Cuadernos de Trabajo Social» está abierta a aportaciones, investigaciones, trabajos teóricos y metodológicos, de carácter profesional o académico, tanto del trabajo social, política social y servicios sociales, como de otras disciplinas y profesiones que desde un punto de vista multi e interdisciplinar enriquecen y complementan la acción profesional.

2. Contenido de los artículos.

El Consejo Editorial solicitará el asesoramiento de expertos independientes quienes, valorando la calidad técnica y científica de los artículos, realizarán la correspondiente selección. Los autores de los artículos publicados recibirán un ejemplar de la Revista.

3. Los artículos publicados quedan en propiedad de la Revista, siendo necesaria la autorización del Consejo Editorial para su reproducción total o parcial.

4. Los artículos que no sean inéditos se publicarán bajo la valoración del Consejo editorial y en función de:

- Que su difusión haya sido en algún medio de difícil acceso a la profesión y disciplina del trabajo social.

- Que haya sido publicado en otro idioma.

- Que se consideren de particular relevancia e interés científico profesional.

5. Normas de presentación

- Los artículos deberán ser remitidos a la Redacción de la Revista «Alternativas. Cuadernos de Trabajo Social». Escuela Universitaria de Trabajo Social. Universidad de Alicante. 03690 San Vicente del Raspeig. Alicante.

- Tres copias escritas y diskette (Microsoft Word y Word Perfect para Windows). Mecanografiados en papel tamaño DIN-A4, a doble espacio (escritura en $12 \mathrm{CPI}$ ), por una sola cara.

- La extensión deberá ajustarse a un mínimo de 10-12 páginas y un máximo de 40.

- De cada uno de los artículos los autores presentarán las claves conceptuales y un «abstract» de 12/15 líneas al comienzo del trabajo.

- Todos los artículos deberán ir acompañados en folio aparte de los datos personales del autor/res: nombre y apellidos, D.N.I., dirección, teléfono, profesión, actividad, cargo, teléfono de con- 
tacto, indicando claramente el título del artículo y si ha sido publicado en algún otro medio.

- Las anotaciones a pie de página se numerarán por orden de aparición en el texto y se mecanografiarán en hoja aparte.

- Las referencias bibliográficas se presentarán al final del texto y por orden alfabético de autores, en la forma siguiente:

- Para los libros: apellidos e inicial del nombre del autor/a/ o autores/as, título de la obra (cursiva), editorial, ciudad, año y número de las páginas a que se hace referencia.

- Para las revistas: Apellidos e inicial del nombre del autor/a o autores/as, título del artículo (entre comillas), nombre de la revista (en cursiva), nombre de la entidad editora, ciudad, año, número de la revista y el de las páginas a que se hace referencia.

- Las tablas y figuras deberán presentarse en hoja aparte numerándose correlativamente e indicando el lugar de colocación en el artículo.

- Los apartados y subapartados se confeccionarán de manera homogénea utilizando la numeración I, II, III; 1.1.,1.2; etc. 
Próxima sección monográfica:

\section{LA ATENCIÓN SOCIAL DE MENORES EN LOS SERVICIOS SOCIALES EUROPEOS}

Plazo para presentación de artículos: 30 de mayo del 2000 



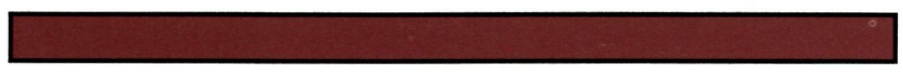

